\title{
DIALÉLICO PARCIAL CIRCULANTE INTERPOPULACIONAL EM MILHO (Zea mays L.) COM DOIS NÍVEIS DE ENDOGAMIA DOS PARENTAIS
}

\author{
JOÃO ANTONIO DA COSTA ANDRADE \\ Engenheiro Agrônomo
}

Orientador: Prof. Dr. JOSÉ BRANCO DE MIRANDA FILHO

Tese apresentada à Escola Superior de Agricultura "Luiz de Queiroz", da Universidade de São Paulo, para obtenção do título de Doutor em Agronomia, Área de Concentração: Genética e Melhoramento de Plantas.

PIRACICABA

Estado de São Paulo - Brasil

Janeiro - 1995 
Andrade, João Antonio da Costa

M672d Dialélico parcial circulante interpopulacional em milho (Zea mays

L.) com dois níveis de endogamia dos parentais. Piracicaba, 1995. $134 \mathrm{p}$.

Tese - ESALQ

Bibliografia.

1. Endogamia em milho 2. Milho - Cruzamento dialélico 3. Milho Melhoramento I. Escola Superior de Agricultura Luiz de Queiroz, Piracicaba. 


\section{DIALÉLICO PARCIAL CIRCULANTE \\ INTERPOPULACIONAL EM MILHO (Zea mays L.) COM DOIS NIIVEIS DE ENDOGAMIA DOS PARENTAIS}

João Antonio da Costa Andrade

Aprovado em: 20/03/1995

Comissão Julgadora:

Prof. Dr. José Branco De Miranda Filho

ESALQ/USP

Dr. Paulo De Souza Gonçalves EMBRAPA/AC

Prof. Dr. Lázaro José Chaves

EA/UFGO

Prof. Dr. Décio Barbin

ESALQ/USP

Prof. Dr. Ernesto Patemiani

ESALQ/USP

$\frac{\text { Mhlui a a d alichol }}{\text { Prof. Dr. José Branco de Miranda Filho }}$

Orientador 
Aos meus pais Luiz e Margarida,

à minha sogra Pierina.

OFEREÇO.

À minha esposa Vera Lúcia,

aos meus filhos Felipe

e Gabriel.

DEDICO. 


\section{AGRADECIMENTOS}

O autor expressa seus agradecimentos a DEUS, que permitiu a realização de mais este passo em sua vida, e a todos que direta ou indiretamente participaram deste trabalho, em especial:

- Ao Prof. Dr. José Branco de Miranda Filho pela segura orientação e pelos ensinamentos proporcionados ao longo de 15 anos de conhecimento.

- Aos funcionários do Instituto de Genética, Srs. Antonio Miotto e Marcos Cella, pela colaboração prestada nos serviços de campo e pela sincera amizade.

- Aos funcionários da Fazenda de Ensino e Pesquisa da Faculdade de Engenharia de Ilha Solteira (UNESP), representados pêlos Srs. Cícero Orjeda, Jair José dos Santos e ao Chefe da Seção de Produção Vegetal, Cláudio Lopes de Souza, pela colaboração na condução dos experimentos finais deste trabalho.

- À CAPES-PICD pela bolsa concedida.

- À CIBA SEMENTES, unidade de Uberlândia, pelo auxilio na multiplicação de sementes.

- Aos colegas Mário Luiz Teixeira de Moraes e Marli de Fátima Stradioto pelo constante incentivo, auxílio e amizade.

- Ao colega Walter Veriano Valério pelo auxílio nas análises de interpretações estatísticas.

- Ao Polo Computacional de Ilha Solteira, nas pessoas do Sr. Antonio César Garcia Torres e Sra. Maria do Carmo Gomes da Silveira, pelo desenvolvimento do programa de predição de híbridos.

- À FEIS/UNESP e ESALQ/USP pela oportunidade da realização do curso de pós-graduação.

- A todos os colegas do Departamento de Biologia da FEIS/UNESP pelo incentivo e amizade. 


\section{SUMÁRIO}

Página

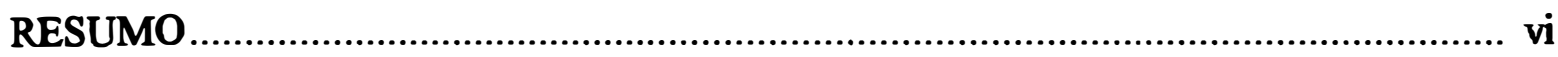

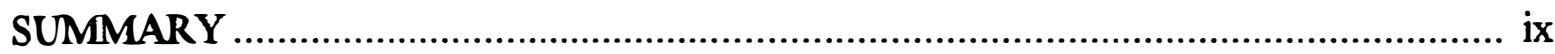

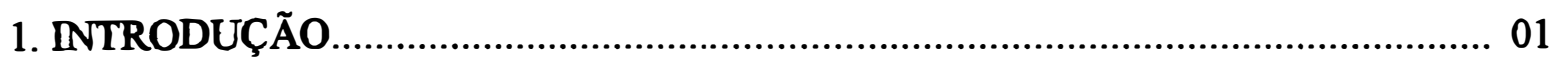

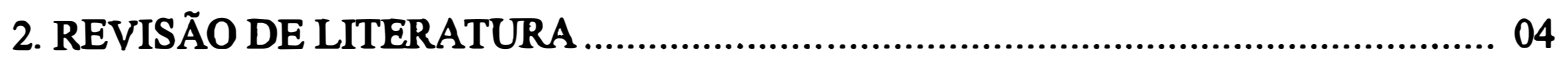

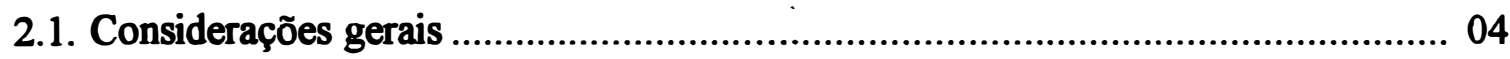

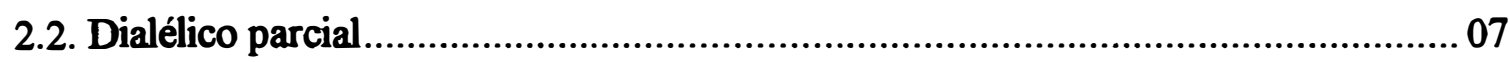

2.3. Híbridos intervarietais e intermediários :..................................................... 12

2.4. Predição de médias de híbridos .......................................................... 13

3. MATERIAL E MÉTODOS .................................................................... 18

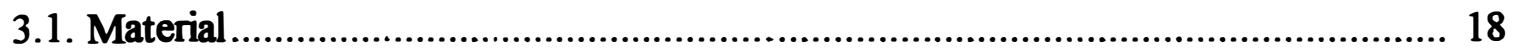

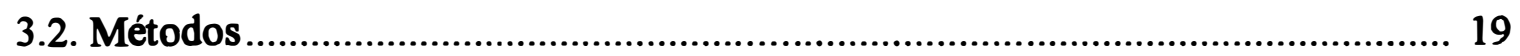

3.2.1. Obtenção dos híbridos intermediários ..................................................... 19

3.2.2. Avaliação dos híbridos intermediários................................................. 20

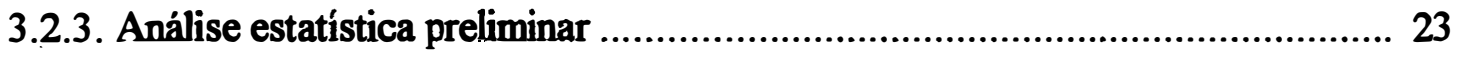

3.2.4. Estimativas dos parâmetros genéticos..................................................... 26

3.2.5. Comparação dos sistemas de multiplicação das progênies........................... 29

3.2.6. Análise das tabelas dialélicas e estimativas dos componentes de médias ......... 30

3.2.7. Predição de médias de híbridos........................................................... 32

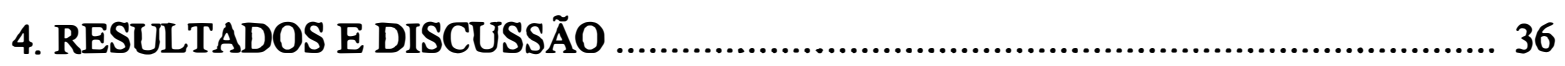

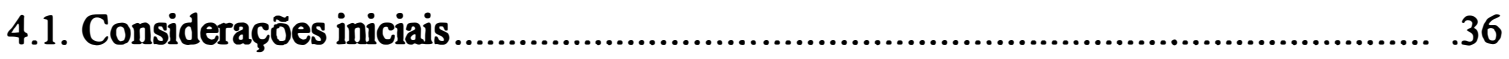

4.2. Análise de variância preliminar............................................................... 37

4.3. Estimativas dos parâmetros genéticos ...................................................... 41

4.3.1. Com base na análise de variância preliminar......................................... 41

4.3.2. Com base na análise das diagonais do dialélico ...................................... 45

4.4. Comparação dos sistemas de multiplicação das progênies .............................. 47 
4.5. Análise da capacidade de combinação ............................................................. 51

4.5.1. Análise da variância para capacidade de combinação ................................... 51

4.5.2. Efeitos da capacidade geral de combinação ……...................................... 53

4.5.3. Efeitos da capacidade específica de combinação ......................................... 56

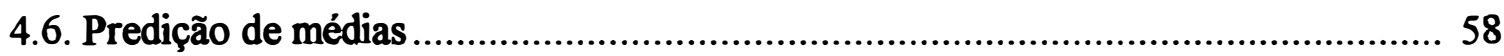

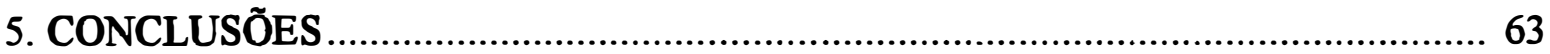

5.1. Predição e comportamento dos híbridos intermediários ..........................................63

5.2. Parâmetros genéticos e sistemas de multiplicação dos parentais .............................. 64

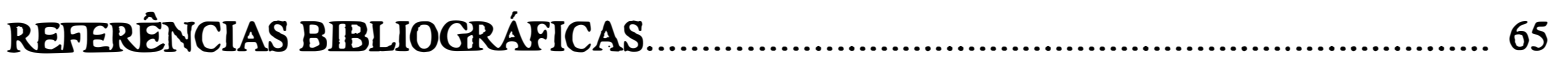

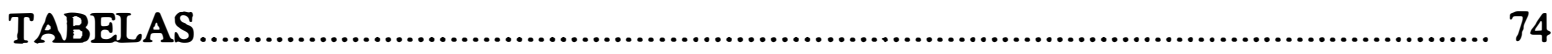

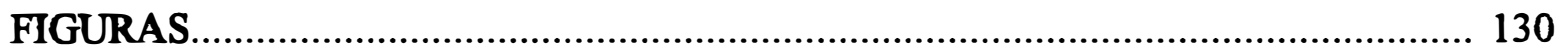




\title{
DIALÉLICO PARCIAL CIRCULANTE INTERPOPULACIONAL EM MILHO (Zea mays L.) COM DOIS NIVEIS DE ENDOGAMIA DOS PARENTAIS
}

\author{
Autor: JOÃO ANTONIO DA COSTA ANDRADE \\ Orientador: Prof. Dr. JOSÉ BRANCO DE MIRANDA FILHO
}

\section{RESUMO}

Progênies de irmãos germanos das populações SUWAN e ESALQ-PB 1 de milho (Zea mays L.), multiplicadas manualmente por autofecundação e cruzamentos fratemais, foram cruzadas em um esquema dialélico parcial circulante interpopulacional com três cruzamentos por parental $(s=3)$. Foram utilizadas 100 progênies de cada população e os 600 híbridos resultantes (300 para cada nivel de endogamia), mais uma testemunha comercial, foram avaliados em 19 experimentos em blocos ao acaso, com três repetições.

Análises de variância individuais e conjunta foram realizadas para as variáveis tempo de florescimento feminino, altura de plantas, altura de espigas, peso de espigas e peso de grãos, com o objetivo de estudar a eficiência do sistema dialélico parcial circulante na avaliação de combinações híbridas, verificar a variabilidade e potencialidade dos híbridos intermediários interpopulacionais e comparar os dois níveis de endogamia dos parentais na obtenção de híbridos intermediários. Para produção de grãos também foi aplicado um modelo fatorial de análise das diagonais do dialélico parcial circulante (MIRANDA FILHO \& VENCOVSKY, 1995), para fins de estimação de parâmetros genéticos interpopulacionais.

As estimativas dos componentes de médias foram obtidas através do método dos quadrados mínimos com base no modelo aleatório reduzido $Y_{i j}=m+g_{i}+g_{j}$ $+d_{i j}$, onde $Y_{i j}$ é a média do híbrido, $g_{i}$ a capacidade geral de combinação (cgc) da 
progênie $\mathbf{i}$ (população SUWAN), $\mathrm{g}_{\mathrm{j}}$ a cgc da progênie $\mathbf{j}$ (população ESALQ- PB1) e $\mathrm{d}_{\mathrm{ij}}$ um desvio composto pela capacidade específica de combinação (cec) mais o erro experimental médio. Em seguida os mesmos componentes foram estimados através das fórmulas $k_{i}=\bar{Y}_{i .}-\bar{Y}_{. .}$e $k_{j}=\bar{Y}_{. j}-\bar{Y}_{. .}$Os dois tipos de estimativas foram obtidos para cada experimento, em cada nível de endogamia dos parentais.

Com base nas estimativas dos g's foram preditas as produtividades médias de todos os híbridos simples, triplos e duplos possiveis pelas fórmulas $\mathrm{HS}_{\mathrm{ij}}=\mathbf{m}+\mathrm{g}_{\mathrm{i}}+\mathrm{g}_{\mathrm{j}}$;

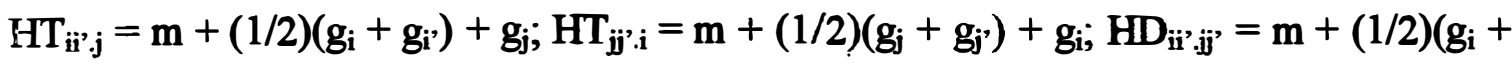
$\left.g_{i}+g_{j}+g_{j}\right)$. As mesmas predições foram feitas utilizando-se os k's em substituição aos g's.

A variabilidade entre os híbridos intermediários, mostrou significância para todas as variáveis estudadas, e uma grande potencialidade dos mesmos para utilização comercial.

Em média, os dois níveis de endogamia não mostraram diferenças nos resultados, mas a sua interação com experimentos e com híbridos foi significativa, indicando que a amostragem das progênies nos momentos de multiplicação e cruzamento não foi perfeita, acarretando problemas de deriva genética.

A variância aditiva interpopulacional para produção de grãos foi de $40,85 \pm 18,04$ e $72,27 \pm 17,03(\mathrm{~g} / \mathrm{pl})^{2}$, respectivamente para os sistemas de autofecundação e cruzamentos fraternais; a variância dominante foi de $96,00 \pm 29,55$ e $69,30 \pm 23,27$ $(\mathrm{g} / \mathrm{pl})^{2}$, respectivamente. Esses valores mostraram-se inferiores em relação às estimativas de mesma natureza, obtidas através de outra metodologia, para as mesmas populações.

Em ambos os níveis de endogamia houve alta correlação entre os híbridos simples observados e os previstos pelo modelo reduzido. 0 mesmo ocorreu entre os híbridos triplos e duplos previstos pelo método B de JENKINS (1934) e aqueles previstos pelo modelo reduzido. 
Os dois tipos de estimativas da capacidade geral de combinação (g's e k's) foram altamente correlacionados, assim como os híbridos previstos com base nos mesmos. Isto mostra que os k's podem ser utilizados em substituição aos g's na seleção de progênies promissoras, desde que os efeitos da cec sejam menos importantes que os efeitos da cgc, como ocorreu no presente trabalho. 


\title{
INTERPOPULATION CIRCULANT DIALLEL CROSSES UNDER TWO \\ LEVELS OF INBREEDING IN THE PARENTS
}

\author{
Author: JOÃO ANTONIO DA COSTA ANDRADE \\ Adviser: Prof. Dr. JOSÉ BRANCO DE MIRANDA FILHO
}

\section{SUMMARY}

Full-sib progenies of the maize populations, SUWAN and ESALQ-PB1, were increased by selfing and sib-cross and crossed under the partial circulant diallel scheme where each parent from each population were crossed with three $(s=3)$ parents of the opposite population. One hundred progenies were taken from each population and the 600 hybrid cross ( 300 for each level of inbreeding) and the hybrid check were evaluated in 20 experiments in completely randomized block design with three replications.

The analysis of variance were performed for the traits: female flowering, plant height, ear height, ear weight and grain weight. The purpose of this project was to study the efficiency of interpopulation partial circulant diallel scheme for the evaluation of hybrid crosses; to estimate the variability and potential of the interpopulation intermediate hybrids; and to make comparisons between the two levels of inbreeding for obtention of intermediate hybrids. For grain yield the factorial model was also used for the analysis of the diagonals of the diallel table (MIRANDA FILHO \& VENCOVSKY, 1995).

The components of means were estimated through the least square procedure based on the random model: $Y_{i j}=m+g_{i}+g_{j}+d_{i j}$, where $Y_{i j}$ is the hybrid mean; $g_{i}$ and $g_{j}$ are the general combining ability for progenies $\mathbf{i}$ (SUWAN) and $\mathbf{j}$ (ESALQ-PB1); and $d_{i j}$ is the deviation from the model and includes the specific 
combining ability and the error term. Estimates of general combining ability were also obtained from $k_{i}=\bar{Y}_{i .}-\bar{Y}_{. .}$and $k_{j}=\bar{Y}_{. j}-\bar{Y}_{. .}$.

All possible single, three way and double cross hybrid means were predicted by: $\mathrm{HS}_{\mathrm{ij}}=\mathrm{m}+\mathrm{g}_{\mathrm{i}}+\mathrm{g}_{\mathrm{j}}, \mathrm{HT}_{\mathrm{ii} \cdot \mathrm{j}}=\mathrm{m}+(1 / 2)\left(\mathrm{g}_{\mathrm{i}}+\mathrm{g}_{\mathrm{i}}{ }^{\prime}\right)+\mathrm{g}_{\mathrm{j}}, \mathrm{HT}_{\mathrm{ji}} \mathrm{j}^{\mathrm{i}}=\mathrm{m}+(1 / 2)\left(\mathrm{g}_{\mathrm{j}}\right.$ $\left.+g_{j}\right)+g_{i}$ and $H D_{i i^{\prime} \cdot j^{\prime}}=m+(1 / 2)\left(g_{i}+g_{i j}+g_{j}+g_{j}\right)$. The same predictions were made by replacing $\mathrm{g}$ 's by k's estimates.

On average, the levels of inbreeding did not show differences in the results; however they showed significant interaction with experiments and with hybrid combinations, indicating that sampling during the multiplication of the parental progenies may led to genetic drift.

The interpopulation additive variances for grain yield were $40.85 \pm 18,04$ and $72.27 \pm 17.03(\mathrm{~g} / \mathrm{pl})^{2}$, respectively for selfing and sib-cross as systems for progeny multiplication; the estimates of dominant variances were $96.00 \pm 29.55$ and $69.30 \pm 23.27$, respectively.

For both levels of inbreeding a high correlation between observed and predicted single cross means was detected. A high correlation also was observed between triple and double cross means predicted by JENKINS's (1934) method B and those predicted by the reduced model.

The two estimates for general combining ability (g's and k's) were highly correlated, as well as the hybrid means predicted by g's and k's. The overall results indicated that g's can be replaced by k's for selection of outstanding parents, provided that the specific combining ability is a less important source of variation, as observed in the present study. 


\section{INTRODUÇÃO}

Sem dúvida uma das maiores descobertas para a agricultura foi o vigor híbrido e a cultura do milho teve o privilégio de servir como suporte para esse estudo tanto no aspecto básico (SHULL, 1908 e 1909; EAST, 1909) como aplicado (JONES, 1918 e 1922). $O$ grande avanço em termos de produtividade do milho foi possível graças à utilização dessa descoberta através do milho híbrido, introduzido comercialmente por JONES (1922).

Um dos problemas enfrentados pelos melhoristas que trabalham com hibridos de linhagens, desde a introdução da técnica, foi e continua sendo a avaliação das linhagens parentais. Até o final da década de 20 costumava-se testar todos os hibridos possíveis com um grupo de $\mathbf{n}$ linhagens. Entretanto, para altos valores de $\mathbf{n}$, esse método toma-se impraticável, pois o número de híbridos duplos possíveis $[(1 / 8)(n-1)(n-2)(n-3)]$ é muito grande.

Em seguida o método que passou a ser utilizado foi o "top cross" (JENKINS \& BRUNSON, 1932), que consistia na avaliação dos cruzamentos de um grande número de linhagens com um testador comum. Na década de 40, com a introdução do conceito de capacidade geral de combinação e capacidade específica de combinação, verificou-se que o "top cross" fornecia informação apenas da capacidade de combinação das linhagens com o testador e nenhuma informação sobre a capacidade específica de combinação com outras linhagens.

Os esquemas de cruzamentos dialélicos começaram a ser estudados também com base nos conceitos de capacidade geral e específica de combinação (GRIFFING, 1956a e b), embora outros métodos de análise também tenham sido propostos sem levar tais conceitos em consideração (JINKS \& HAYMAN, 1953; 
HAYMAN, 1954a e b). No entanto o problema do grande número de genótipos a serem avaliados persistia e a proposta seguinte foi a avaliação de apenas uma amostra dos cruzamentos possíveis. Essa proposta, feita por KEMPTHORNE \& CURNOW (1961), introduz um esquema de dialélico parcial chamado de circulante. Neste esquema cada membro de um grupo de $n$ linhagens de origem comum (mesma população) é cruzado com $s$ outras linhagens do mesmo grupo.

O fato do esquema de KEMPTHORNE \& CURNOW (1961) basear-se em amostragem aleatória de linhagens de uma mesma população, não permitiu a sua aplicação no melhoramento moderno do milho híbrido, onde é comum o cruzamento de linhagens de origens diferentes (HALLAUER \& MIRANDA FILHO, 1988). Buscando uma solução para esse problema, o setor de Genética Quantitativa do Instituto de Genética/ESALQ/USP vem desenvolvendo estudos no sentido de adaptar esse esquema para um dialélico parcial circulante interpopulacional onde são utilizados dois grupos de linhagens ou progênies, cada um oriundo de uma população diferente (GONÇALVES, 1987; DANTAS, 1988; SAMPAIO, 1989; DANTAS, 1992; MIRANDA FILHO \& VENCOVSKY, 1995). Desta maneira o esquema continua sendo aleatório e apenas "ns" cruzamentos precisam ser avaliados, sendo possivel prever os hibridos simples não avaliados e os hibridos triplos e duplos, com base nas estimativas da capacidade geral de combinação.

A utilização de progênies com endogamia parcial, vem ao encontro de um outro tema, também recente no campo da exploração de híbridos de milho no Brasil, que é a produção de híbridos intermediários. Esse tipo de híbrido, cujos parentais possuem um nivel de endogamia menos severo que as linhagens (MIRANDA FILHO, 1985), apresentam uma base genética mais ampla, tendo um menor risco de cultivo, principalmente nas áreas marginais, além de permitir a seleção recorrente constante nas progênies parentais. Suas variáveis contribuem decisivamente para amenizar o problema da vulnerabilidade genética que preocupa grande parte dos melhoristas de milho.

Em continuidade às linhas de pesquisa acima citadas, este trabalho consistiu na aplicação do esquema dialélico parcial circulante para avaliação e predição de híbridos intermediários entre progênies de irmãos germanos das populações SUWAN 
e ESALQ-PB1 de milho. Foram estudados os sistemas de multiplicação das progênies parentais por autofecundação e cruzamentos fratemais.

Pelo fato do trabalho envolver duas linhas de pesquisa recentes e ser um tipo de complemento a outros trabalhos já realizados, os seguintes objetivos específicos foram propostos:

1 - Avaliar a eficiência do sistema dialélico parcial circulante na avaliação de combinações híbridas;

2 - Avaliar a eficiência do processo de predição de combinações híbridas, utilizando as estimativas da capacidade geral de combinação obtidas segundo o modelo proposto;

3 - Verificar a possibilidade do uso do dialélico parcial circulante para obter estimativas de parâmetros genéticos interpopulacionais;

4 - Comparar os sistemas de multiplicação das progênies parentais (autofecundação e cruzamentos fratemais) na obtenção de híbridos intermediários. 


\section{REVISÃO DE LITERATURA}

\subsection{Considerações gerais}

O surgimento e estabelecimento, com potencialidade comercial, do milho híbrido (JONES, 1922) exigiu o delineamento de métodos para testar linhagens. Embora desconhecido o conceito de capacidade geral e específica de combinação, Davis (1927), citado por HALLAUER \& MIRANDA FILHO (1988), foi o responsável pela sugestão do uso de "top cross" para avaliação de linhagens endogâmicas em um programa de melhoramento de milho hibrido.

O "top cross" até hoje ainda é utilizado com a finalidade de avaliar linhagens. Além disso pode ser utilizado na obtenção de estimativas de parâmetros genéticos intra e interpopulacionais, dentro de um programa de seleção reconrente recíproca. MIRANDA FILHO \& PATERNIANI, (1983) utilizaram progênies de meios irmãos intrapopulacionais (própria população como testador) e interpopulacionais (população recíproca como testador) para obter tais estimativas.

Com o passar do tempo houve uma evolução nos métodos de avaliação de linhagens. JENKINS \& BRUNSON (1932) já relataram que muitos melhoristas de milho dessa época costumavam testar suas linhagens utilizando uma combinação sistemática de cruzamentos comparáveis. $O$ descarte ou seleção de uma linhagem era feito com base na média de todos os seus cruzamentos, o que tomava necessário realizar e testar um grande número de cruzamentos.

O termo dialélico foi primeiramente utilizado em 1919 por Schmidt (citado por FYFE \& GILBERT, 1963) para identificar os cruzamentos possíveis entre um grupo de animais, fềmeas e machos. Segundo FEDERER (1967), Schmidt considerou o 
cruzamento teste como uma forma de cruzamento dialélico, embora parcial. Outros pesquisadores, também citados por FYFE \& GILBERT (1963), se envolveram com cruzamentos dialélicos nas décadas de 1930 e 1940. Kudrjawzew (1934) utilizou um tipo de dialélico parcial, enquanto Yates (1947) mostrou como analisar um grupo incompleto de cruzamentos entre plantas individuais. Lerner (1945) e Hazel \& Lamoreux (1947) foram citados por VENCOVSKY (1970) como tendo empregado o termo cruzamentos dialélicos, especificamente para designar o processo em que " $n$ " fềmeas são acasaladas com um grupo de "m" machos, formando-se "mn" progênies de irmãos germanos, neste caso, de animais. Nesta época o embasamento teórico da análise de cruzamentos de linhagens já havia sido estabelecido por SPRAGUE \& TATUM (1942). Estes autores definiram capacidade geral de combinação como o comportamento médio de uma linhagem em combinações híbridas. Capacidade específica de combinação foi definida como sendo aquele comportamento que leva certas combinações a se mostrarem superiores ou inferiores ao esperado, em relação ao comportamento médio das linhagens envolvidas.

A conceituação estabelecida por SPRAGUE \& TATUM (1942) não foi considerada em alguns trabalhos subsequentes como JINKS \& HAYMAN (1953) e HAYMAN (1954a e b). Estes autores introduziram uma metodologia de análise estatística aplicável a um conjunto fixo de linhagens endogâmicas que posteriormente foi estendida para uma amostra aleatória. GRIFFING (1956a e b) considerou os conceitos de capacidade geral e específica de combinação em seus diferentes modelos de análise de dialélicos. JINKS \& HAYMAN (1953), HAYMAN (1954a e b) e GRIFFING (1956a e b) consideraram cruzamento dialélico como o conjunto de " ${ }^{2}$ " genótipos obtidos a partir de " $n$ " linhagens puras. A tabela dialélica surgiu como decorrência, constituindo-se no conjunto de $" \mathrm{n}^{2 n}$ médias obtidas dos cruzamentos. Mais tarde o termo cruzamento dialélico foi estendido para o interctuzamento de linhagens com qualquer grau de endogamia ou mesmo variedades (VENCOVSKY, 1970), pois os métodos anteriores foram desenvolvidos especificamente para linhagens puras, sendo utilizado largamente em espécies autógamas. 
GRIFFING (1956 a e b) considerou quatro tipos de tabelas dialélicas. A tabela completa incluiu os tipos parentais, seus híbridos e recíprocos e as outras três derivaram-se desta pela supressão de alguns de seus elementos como por exemplo os parentais ou os recíprocos. Foi definida uma metodologia de análise para cada uma das diversas situações, buscando extrair as informações sobre capacidade de combinação dos parentais envolvidos.

Com o grande interesse pelas variedades de polinização livre e híbridos intervarietais, novos modelos genéticos, bastante flexiveis, foram propostos para a análise das médias das tabelas dialélicas de um gnupo fixo de variedades parentais (de acasalamento ao acaso), seus cruzamentos dialélicos e outras populações relacionadas (GARDNER, 1965; GARDNER \& EBERHART, 1966; EBERHART \& GARDNER, 1966). A flexibilidade desses métodos prende-se ao fato de que também são adequados para linhagens puras, linhagens autofecundadas com qualquer grau de endogamia ou variedades sintéticas.

GARDNER \& EBERHART (1966) mostraram a possibilidade de se obterem informações sobre o potencial heterótico dos cruzamentos de um dialélico através dos componentes heterose média, heterose de variedades e heterose especifica. Fórmulas simplificadas para a estimação dos componentes de médias e para a análise da variância de um modelo completo foram apresentadas por GARDNER (1967), enquanto MIRANDA FILHO (1974) forneceu as fórmulas obtidas pelo método dos quadrados mínimos para modelos reduzidos. Um amplo estudo sobre os modelos de GARDNER \& EBERHART (1966) também foi feito por VENCOVSKY (1970), mostrando aspectos importantes de sua utilização, análise e interpretação. Neste trabalho o autor define procedimentos para uso do dialélico com outras finalidades além daquelas referentes apenas aos híbridos. Uma expressão simples e geral foi desenvolvida para estimar a média de uma variável em compostos de variedades possíveis de serem formados com os parentais envolvidos no dialélico. Inclusive a média do cruzamento entre possíveis compostos pode ser predita com tal expressão.

A predição de compostos e seus cruzamentos se torna interessante para os melhoristas que utilizam seleção recorrente, uma vez que norteia a escolha de 
germoplasmas para início de programas de melhoramento. Se o dialélico envolver linhagens puras, além da predição do comportamento de qualquer tipo de híbrido, também o comportamento de possiveis variedades sintéticas e seus cruzamentos pode ser predito.

A ampla utilização dos esquemas de análise, principalmente pelos melhoristas de milho, gerou discussões teóricas e resultados práticos interessantes. Além dos trabalhos já referidos, revisões abrangentes sobre o assunto dialélicos foram feitas por FEDERER (1967) e SOUZA JÚNIOR $(1981,1983)$. Desta maneira muitos detalhes sobre o uso de esquemas dialélicos foram determinados.

\subsection{Dialélico parcial}

$\mathrm{Na}$ prática os dialélicos completos limitam o número de germoplasmas parentais a serem utilizados. Em milho além do grande número de polinizações manuais necessárias, as dificuldades nas operações de campo podem afetar a precisão desejada. Com isso apareceram estudos propondo a análise de apenas uma amostra dos cruzamentos possiveis entre os parentais, surgindo então os esquemas de dialélicos parciais. Entre as vantagens desses esquemas, enumerados por KEMPTHORNE \& CURNOW (1961), estariam as seguintes: 1) um grande número de parentais pode ser avaliado para capacidade geral de combinação e a perda em precisão é compensada pelo maior ganho genético na seleção mais intensa que pode ser aplicada aos parentais; 2) a seleção pode ser feita entre os cruzamentos de uma amplitude maior de parentais; 3) a variância devida à capacidade geral de combinação, da população origem dos parentais, pode ser estimada com maior precisão.

Segundo KEMPTHORNE \& CURNOW (1961) e CURNOW (1963), os estudos iniciais sobre a idealização dos métodos de amostragem de cruzamentos, através do esquema "circulante", são creditados a G. W. Brown (1948). Inspirados nesse trabalho os citados autores desenvolveram a sua metodologia a respeito dos dialélicos parciais, baseando-se em ns/2 cruzamentos, onde $\mathrm{n}$ representa o número de parentais e $\mathrm{s}$ o número de vezes que cada parental participa dos cruzamentos. Nesse esquema, 
denominado de "circulante", para haver o fechamento dos ns $/ 2$ cruzamentos, n e s não podem ser ímpares ou pares simultaneamente e s tem que ser inteiro e maior ou igual a 2 . O esquema de KEMPTHORNE \& CURNOW (1961) baseia-se em amostragem essencialmente aleatória de linhagens obtidas de uma única população. Assim, embora o método seja interessante para estudar a estrutura genética de populações, ele é pouco recomendável no que diz respeito à avaliação de linhagens em programas de melhoramento de híbridos.

Com base no fato do delineamento circulante de KEMPTHORNE \& CURNOW (1961) não ser balanceado, FYFE \& GILBERT (1963) propuseram esquemas triangulares e fatoriais, com número ímpar de parentais, argumentando que eram melhor balanceados, proporcionando maiores informações sobre a capacidade geral de combinação dos parentais além de serem mais facilmente analisados. Comparações entre os dois sistemas indicaram que o esquema por eles proposto resultaria em informações com o mesmo nível de precisão, porém com menor número de repetições. Outro esquema circulante foi apresentado por FEDERER (1967), envolvendo todos os casos, exceto quando $\mathrm{n}$ e s eram ímpares simultaneamente.

Comparações teóricas dos dialélicos com outros delineamentos utilizados para estimação de componentes de variância foram feitas por KEMPTHORNE \& CURNOW (1961). Embora existam muitos fatores complicando o processo de comparação, foi verificado que o dialélico parcial pode ser superior aos delineamentos I $\mathrm{e}$ II de COMSTOCK \& ROBINSON (1948) e inferior ao delineamento III de ROBINSON et alii (1949).

Em relação ao dialélico parcial circulante, uma das questões é a determinação do tamanho ideal de $\mathrm{s}$, no sentido de que as informações tenham uma precisão aceitável.

Com o objetivo de estudar o assunto MURTY et alii (1967) e ANAND \& MURTY (1969) compararam as precisões das estimativas da capacidade geral de combinação, quando ocorria o decréscimo no tamanho do dialélico parcial em relação ao completo, utilizando dez cultivares altamente endogâmicas de linho. Neste sistema fixo foram feitas análises com $s=9,7,5$ e 3 e as comparações permitiram concluir que não 
era conveniente reduzir o número de cruzamentos por parental para valores menores que $\mathrm{n} / 2$. Com $\mathrm{s}$ menor que $\mathrm{n} / 2$ observaram uma superestimação na capacidade geral de combinação e um aumento expressivo no erro padrão médio dos contrastes $\mathrm{g}_{\mathrm{i}}$-gj. No entanto, salientam que em casos de $n$ muito grande os valores de $\mathbf{s}$ poderão ser diminuídos além do limite $\mathrm{n} / 2$. Também é preciso salientar que, pelo fato do modelo ser fixo, tais conclusões pouco contribuem para os estudos dos sistemas de cruzamentos aleatórios.

BRAY (1971) trabalhando com alfafa, também comparou os diferentes tipos de dialélicos parciais $(s=3,5,7$ e 9$)$ com o dialélico completo $(s=n-1=11)$. Uma de suas observações foi de que aqueles caracteres para os quais os parentais exibem capacidade específica de combinação, estão mais propensos a interpretações errôneas quando s diminui. Também observou que entre oito e dez cruzamentos por parental foi suficiente para se obter estimativas confiáveis de componentes de variância, herdabilidade e capacidade geral de combinação.

DHILLON \& SINGH (1978) compararam dialélicos parciais com $\mathrm{s}=3,5$, 7, 11 e 15 com o dialélico completo $(s=n-1=19)$ em milho. Concluíram que estimativas com uma razoável precisão podem ser obtidas com $s=7$. Também salientaram que a redução de s, sem risco para a confiabilidade dos resultados, está ligada à necessidade dos germoplasmas em avaliação terem uma alta variabilidade genotípica total, da qual uma proporção expressiva seja devida à ação gênica aditiva.

Uma consideração a ser feita neste ponto é que MURTY et alii (1967), ANAND \& MURTY (1969), BRAY (1971) e DHIILLON \& SINGH (1978), utilizaram parentais que se enquadram em sistemas fixos. Nos dois primeiros casos são variodades de diferentes origens. No caso seguinte foram utilizados clones de alfafa da mesma população, mas previamente selecionados para produtividade, e no terceiro, embora não fique muito claro no trabalho, os parentais também são de origem diversa. Esse fato pode tornar de pouca utilidade as possíveis comparações com sistemas aleatórios como ocorre no presente trabalho.

Uma comparação entre os esquemas de dialélicos parciais, dados por KEMPTHORNE \& CURNOW (1961), FYFE \& GILBERT (1963) e FEDERER (1967), 
com o dialélico completo de GRIFFING (1956 b), foi feita por SINGH et alii (1984). Os quadrados médios para capacidade geral de combinação mostraram-se significativos em todos os esquemas, enquanto os resultados para capacidade específica de combinação apresentaram-se discrepantes nos diferentes esquemas avaliados.

Nos programas de melhoramento de híbridos o habitual é realizar cruzamentos entre populações representativas de germoplasmas geneticamente divergentes, buscando a maximização da heterose. Portanto os cruzamentos dentro de populações são de menor interesse. Este fato, juntamente com as limitações já expostas dos dialélicos completos, tornaram necessária a adaptação dos esquemas propostos de dialélico parcial para abranger a análise de cruzamentos interpopulacionais.

VENCOVSKY (1978) sugeriu a avaliação da capacidade geral e específica de combinação de dois conjuntos de variedades segundo um modelo análogo ao método 4 de GRIFFING (1956 b), onde são avaliados somente os hibridos intervarietais. Da mesma maneira, MIRANDA FILHO \& GERALDI (1984) propuseram um modelo para análise de dialélicos parciais entre grupos distintos de variedades representando uma adaptação da análise do dialélico completo de GARDNER \& EBERHART (1966). O modelo é especialmente útil para avaliação de materiais onde o interesse principal é a obtenção de híbridos intervarietais. Essa metodologia foi aplicada por MIRANDA FILHO (1986) mostrando-se eficiente.

Uma adaptação do método 2 do modelo de GRIFFING (1956 b), onde se avaliam as médias das variedades e dos híbridos intergrupos, foi feita por GERALDI \& MIRANDA FILHO (1988). Os autores fornecem expressões para estimação dos componentes de médias e também para o cálculo das somas de quadrados, comparando a metodologia proposta com aquelas apresentadas por GRIFFING (1956 b), GARDNER \& EBERHART (1966) e MIRANDA FILHO \& GERALDI (1984). É importante ressaltar que os métodos de análise de GARDNER \& EBERHART (1966), VENCOVSKY (1978), MIRANDA FILHO \& GERALDI (1984) e GERALDI \& MIRANDA FILHO (1988) referem-se a conjuntos fixos de variedades, cujas análises se prestam para estimação dos componentes de médias e para testes de hipóteses sobre a 
nulidade dos efeitos. Portanto não são apropriados para estimar componentes da variância genética.

MARTINS (1986) avaliou linhagens "flint" e "dent" tomadas aleatoriamente de duas populações e subdivididas em $n$ conjuntos de tamanho $k$, obtendo-se $\mathrm{nk}^{2}$ híbridos simples em um esquema semelhante ao proposto no delineamento II de COMSTOCK \& ROBINSON (1948). A metodologia foi considerada altamente eficiente tanto do ponto de vista prático como teórico, pois permite avaliar a capacidade de combinação das linhagens, detectar combinações específicas superiores possíveis de serem utilizadas na obtenção de híbridos duplos, estimar componentes de médias e de variância e prever médias de híbridos simples com base nos efeitos de capacidade geral de combinação.

O método de cruzamento dialélico parcial circulante de KEMPTHORNE \& CURNOW (1961) foi adaptado por MIRANDA FILHO (1993) para avaliação de híbridos ao nível interpopulacional, ou seja, $\mathrm{n}$ linhagens de cada população são cruzadas com $\mathbf{s}$ linhagens da população contrastante, resultando ns híbridos que são avaliados experimentalmente. Detalhes sobre a metodologia de análise e estimação de parâmetros ainda não foram publicados (MIRANDA FILHO \& VENCOVSKY, 1995).

A primeira avaliação sobre a aplicabilidade do referido método foi realizada por GONÇALVES (1987), estudando linhagens de duas populações de milho (ESALQ PB-2 e ESALQ PB-3). Cada linhagem da população ESALQ PB-2 foi cruzada com três linhagens da população ESALQ PB-3 $(s=3)$. O autor salienta que a metodologia utilizada pode ser altamente eficiente do ponto de vista prático, mostrando a possibilidade de se prever a média de um híbrido com base na capacidade geral de combinação das linhagens. Estudo semelhante foi feito por DANTAS (1988), com o objetivo principal de prever médias de híbridos simples, duplos e triplos, com base na capacidade geral de combinação das linhagens das populações ESALQ PB-1 e SUWAN. SAMPAIO (1989) também utilizou um dialélico parcial circulante com $\mathrm{s}=3$ para avaliar o potencial genético de progênies de meios irmãos na obtenção de híbridos intermediários. Em ambos os casos a metodologia foi efetiva na identificação de híbridos intermediários superiores. DANTAS (1992), após aplicar a mesma metodologia, 
utilizando progênies de irmãos germanos, selecionou as dez melhores progênies de cada população, com base nos melhores híbridos observados. Em seguida essas progênies foram submetidas a cruzamentos em um esquema dialélico parcial tipo fatorial completo $10 \times 10$ interpopulacional. A análise pelo método de MIRANDA FILHO \& GERALDI (1984) identificou progênies com alto potencial heterótico.

\subsection{Híbridos intervarietais e intermediários}

Os híbridos intervarietais já eram conhecidos pelos melhoristas e biólogos na época de Darwin, ao redor do ano de 1880. As causas que determinaram o sucesso relativamente pequeno desses híbridos foram-a dificuldade em se manter o padrão das variedades parentais sem alterações, a produtividade não muito superior às populações parentais e o melhor desempenho dos híbridos de linhagens, especialmente na década de 20 (TRIFUNOVIC, 1978). Para HALLAUER \& MIRANDA FILHO (1988), além dessas causas, a diferença fenotípica pouco marcante entre o híbrido e suas variedades parentais e a heterose geralmente menos expressiva, contribuíram para a não aceitação dos híbridos intervarietais na grande lavoura. Entretanto bons valores de heterose são encontrados na literatura. Estes mesmos autores mostram uma tabela onde são comuns valores de heterose acima de $10 \%$ do pai superior, chegando a um máximo de $43 \%$.

BARRIGA \& VENCOVSKY (1973) relatam que os cruzamentos intervarietais podem ser utilizados diretamente na utilização do vigor híbrido dos melhores cruzamentos, ou na síntese de compostos de variedades com elevada freqüência de alelos favoráveis. Estes cruzamentos e os compostos indicam ou tomam-se boas fontes de obtenção de linhagens para produção de híbridos superiores.

Entre os híbridos intervarietais e os de linhagens tem-se hoje o que se convencionou chamar de híbridos intermediários. Segundo MIRANDA FILHO (1985) este tipo de híbrido é obtido pelo cruzamento de parentais com um nível de endogamia menos severo que aqueles das linhagens puras.

Segundo VASAL (1986) os híbridos de progênies têm sido objeto de estudos em alguns países, porém poucas informações foram publicadas. $\mathbf{O}$ autor 
enumerou as seguintes vantagens que este tipo de híbrido apresentaria para países em desenvolvimento: 1) Manutenção mais simples e mais produtivos na obtenção de sementes devido ao maior vigor dos parentais em relação às linhagens; 2) Facilidade na identificação dos híbridos através de um programa de melhoramento intra e interpopulacional; 3) Uniformidade, desde que uma cuidadosa seleção seja exercida sobre as progênies; 4) Possibilidade do melhoramento de progênies durante a fase de produção de sementes; 5) Menor suscetibilidade das progênies às variações ambientais; e 6) Possibilidade da utilização das melhores progênies para obtenção de linhagens. No entanto tais vantagens são questionadas, uma vez que a manutenção e melhoramento dos pais exige maiores conhecimentos técnicos para se evitar contaminação e principalmente deriva genética, que podem descaracterizar os-mesmos. Nos países em desenvolvimento, a escassez de mão de obra especializada pode tomar-se um fator limitante para o uso adequado dos híbridos intermediários. O trabalho de despendoamento também fica oneroso e complicado, uma vez que o período de florescimento dos parentais de endogamia intermediária é maior que das linhagens, por apresentarem maior variabilidade. Por este ponto de vista a maior utilidade dos híbridos intermediários seria a identificação de boas fontes para extração de linhagens.

No Brasil, alguns estudos de avaliação de híbridos intermediários foram realizados com diversos tipos de progênies: meios irmãos (MOTA, 1984; SAMPAIO, 1989), irmãos germanos (DANTAS, 1992) e $S_{2}$ (MIRANDA FILHO, 1993).

\subsection{Predição de médias de híbridos}

O tema predição de médias é uma das maiores contribuições da Genética Quantitativa para o melhoramento. Tudo começou com os estudos de Wright (1922), citado por SPRAGUE (1955). Esses estudos originaram posteriormente a chamada "fórmula de Wright" para predição de médias de variedades sintéticas: $F_{2}=F_{1}-(1 / n)\left(F_{1}\right.$ - P) onde, $F_{2}$ é a média da população resultante do intercruzamento das linhagens parentais; $F_{1}$ é a média de todos os híbridos simples possíveis entre as $n$ linhagens parentais; P é a média das linhagens parentais. 
A predição de médias de variedades sintéticas e compostos foi discutida por diversos autores tanto sob o ponto de vista teórico como prático (VENCOVSKY, 1970; MIRANDA FILHO, 1974; CARVALHO, 1980; SOUZA JÚNIOR, 1981; HALLAUER \& MIRANDA FILHO, 1988).

No presente estudo é de maior interesse a predição de médias de cruzamentos controlados. A preocupação com este assunto surgiu juntamente com a viabilização da exploração comercial da heterose em híbridos de milho, através dos híbridos duplos (JONES, 1922). Na mesma época foi mostrada a impraticabilidade de se obter e avaliar todos os híbridos duplos possíveis, a partir de um grupo relativamente grande de linhagens endogâmicas.

JENKINS (1934) propôs uma metodologia para predição do comportamento de híbridos duplos com base nos dados dos híbridos simples entre as linhagens envolvidas. Como o número de híbridos simples entre $\mathbf{n}$ linhagens é bem menor do que o número de híbridos duplos, a metodologia tomou-se viável e tem sido empregada até hoje nos programas de milho híbrido. Quatro alternativas para predição dos híbridos duplos (HD) foram sugeridas:

Método A: HD estimado pela média dos seis híbridos simples possíveis entre as quatro linhagens envolvidas;

Método B: HD estimado pela média dos quatro híbridos simples não parentais;

Método C: HD estimado pela média de um grupo de quatro linhagens em uma série de híbridos simples;

Método D: HD estimado pela média do grupo de quatro linhagens parentais avaliadas em "top crosses".

Os métodos A, C e D pressupõem apenas ação gênica aditiva, enquanto o método B considera também os efeitos não aditivos. Os coeficientes de correlação, estimados por JENKINS (1934), entre produções médias preditas e observadas foram de 0,75 para o método A, 0,76 para o método $B, 0,73$ para o método $C$ e 0,61 para o método D. Portanto, embora o método B leve em conta os efeitos não aditivos, 
praticamente não difere dos primeiros. Mesmo o método $\mathrm{D}$ mostra-se eficiente e, como salientado pelo próprio autor, leva a vantagem de envolver avaliação de apenas um cruzamento por parental. Com exceção dos poucos casos de predominância dos efeitos não aditivos entre os genes que controlam a produtividade em milho, qualquer dos métodos têm uma boa eficiência. Entretanto, $\mathrm{O}$ método $\mathrm{B}$ foi melhor aceito pelos melhoristas de milho pelo fato de ser mais coerente com as teorias da Genética Quantitativa. Sua eficiência foi verificada por diversos autores (DOXTATOR \& JOHNSON, 1936; ANDERSON, 1938; HAYES et alii, 1943; HAYES et alii, 1946) logo após a divulgação do trabalho de JENKINS'(1934).

EBERHART (1964) apresentou um modelo que permite uma análise das médias de todos os hibridos simples, triplos $\theta$ duplos derivados de um grupo de quatro linhagens homozigóticas. Este modelo leva em consideração os efeitos gênicos aditivos, dominantes e epistáticos, além de considerar os princípios da herança diplóide e a ausência de alelos múltiplos, ligação e efeitos recíprocos. $\mathrm{O}$ autor apresenta cinco fórmulas normalmente utilizadas pelos melhoristas de milho na predição de híbridos duplos:

$$
\begin{gathered}
D_{i j . k l}^{1}=(1 / 6)\left(S_{i j}+S_{i k}+S_{i l}+S_{j k}+S_{j l}+S_{k l}\right) \\
D_{i j . k l}^{2}=(1 / 4)\left(S_{i k}+S_{i l}+S_{j k}+S_{j l}\right) ; \\
D_{i j . k l}^{3}=(1 / 2)\left(T_{k l . j}+T_{k l . j}\right) ; \\
D_{i j . k l}^{4}=(1 / 2)\left(T_{i j . k}+T_{i j . l}\right) ; \\
D_{i j . k l}^{5}=(1 / 2)\left(D_{i j . k l}^{3}+D_{i j . k l}^{4}\right) ;
\end{gathered}
$$

$\mathrm{S}_{\mathrm{ij}}=$ média do híbrido simples entre as linhagens $\mathrm{i}$ e $\mathrm{j}$, e assim para os demais híbridos simples;

$\mathrm{T}_{\mathrm{ij} . \mathrm{k}}=$ média do hibrido triplo entre o híbrido simples $\mathrm{S}_{\mathrm{ij}}$ e a linhagem $\mathrm{k}$;

$D_{i j \mathbf{l d}}=$ média do híbrido duplo entre os hibridos simples $S_{i j}$ e $S_{k d}$.

Como se nota as duas primeiras fórmulas correspondem aos métodos $\mathrm{A} \mathrm{e}$ B de JENKINS (1934), sendo mais empregada a segunda. As demais baseiam-se no 
comportamento de híbridos triplos e são normalmente empregadas na seleção das linhagens $\mathrm{k}$ e 1 para formar, juntamente com o híbrido simples $S_{\mathrm{ij}}$, o híbrido duplo $\mathrm{D}_{\mathrm{ij} . \mathrm{kl}}$. O autor sugere ainda uma expressão para predição de híbridos duplos quando houver epistase:

$$
\begin{gathered}
D_{i j . k l}^{6}=D_{i j \cdot k l}^{5-2}=2 D_{i j . k l}^{5}-D_{i j . k l}^{2} \\
D_{i j . k l}^{6}=(1 / 2)\left(T_{i j . k}+T_{i j . l}+T_{k l . i}+T_{k l . j}\right)-(1 / 4)\left(S_{i k}+S_{i l}+S_{j k}+S_{j l}\right) ;
\end{gathered}
$$

O autor considera que, não havendo epistase ou quando o efeito desta for pequeno, a intensidade de seleção entre híbridos duplos preditos pelos híbridos simples não parentais pode ser mais intensa, resultando em menor número de híbridos duplos a serem testados.

COCKERHAM (1967) também propôs um preditor ótimo com mínima variância do erro, a partir de informações obtidas em cruzamentos dialélicos, verificando sua eficiência somente quando a variância aditiva, dominante e devida ao erro experimental contribuem para a magnitude da variância fenotípica. As expressões para os conceitos de preditor ótimo foram apresentadas por OTSUKA et alii (1972), baseandose em funções lineares de efeitos em vários ambientes. As fórmulas referentes a predições de híbridos simples, triplos e duplos foram apresentadas como:

$$
\begin{aligned}
& \mathrm{Y}_{\mathrm{kk}}=\mathrm{g}_{\mathrm{k}}+\mathrm{g}_{\mathrm{k}},+\mathrm{KS}_{\mathrm{kk}} \text {; }
\end{aligned}
$$

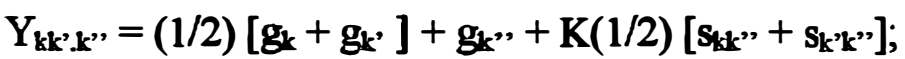

$$
\begin{aligned}
& Y_{k k^{\prime} \cdot k^{\prime \prime} k^{\prime \prime}}=(1 / 2)\left[g_{k}+g_{k^{\prime}}+g_{k^{\prime}}+g_{\left.k^{\prime \prime},\right]}+K(1 / 4)\left[s_{k k^{\prime}}+s_{k k^{\prime},}+s_{k^{\prime} k^{\prime}}+s_{\left.k^{\prime} k^{\prime \prime}\right]}\right]\right.
\end{aligned}
$$

sendo que o coeficiente $K$, para os efeitos específicos é variável entre 0 e 1 . Com a aplicação dessas expressões verificou-se, através das magnitudes dos coeficientes de correlação linear entre médias observadas, que os efeitos da interação genótipo $\mathrm{x}$ ambiente reduziram a eficiência dos métodos de predição.

Informações provenientes do dialélico parcial circulante intrapopulacional foram utilizados por KEMPTHORNE \& CURNOW (1961) para predição de médias de cruzamentos, através dos efeitos de capacidade geral de combinação (g's) das linhagens envolvidas. A validade da utilização de tais parâmetros na predição de combinações híbridas foi evidenciada pela avaliação da eficiência do modelo $Y_{i j}=\mathbf{u}+\mathbf{g}_{\mathrm{i}}+\mathbf{g}_{\mathrm{j}}$, através 
da comparação dos erros envolvidos nas estimativas. $\mathbf{O}$ modelo reduzido $Y_{i j}=\mathbf{u}+\mathbf{g}_{\mathrm{i}}+\mathrm{g}_{\mathrm{j}}$ também foi utilizado por MARTINS (1986) que encontrou coeficientes de determinação $\left(r^{2}\right)$ variando de 70 a $90 \%$ entre as médias observadas e estimadas, em um esquema de cruzamento segundo o modelo fatorial.

Trabalhando com um dialélico parcial circulante interpopulacional, GONÇALVES (1987) utilizou um modelo reduzido, onde foram ignorados os efeitos específicos, para estimar os efeitos de capacidade geral de combinação das linhagens. Com tais estimativas fez a estimação das médias dos híbridos simples interpopulacionais utilizando a fórmula de KEMPTHORNE \& CURNOW (1961). A análise dos coeficientes de determinação entre médias observadas e estimadas demonstrou a validade do modelo.

Estudo semelhante foi feito por DANTAS (1988), com o objetivo principal de prever médias de hibridos simples, triplos e duplos, com base na capacidade geral de combinação das linhagens. A eficiência do processo de predição com base nos parâmetros estimados pelo dialélico parcial circulante foi comprovada de duas maneiras: a) alta correlação entre médias observadas e estimadas dos híbridos simples; e b) alta correlação entre médias estimadas dos hibridos triplos e duplos pelo método em questão e pelo método B de JENKINS (1934).

Em milho, as estimativas da capacidade geral de combinação obtidas com os dialélicos parciais circulantes é uma das altemativas que o Instituto de Genética da ESALQ/USP vem estudando no sentido de facilitar a identificação de futuros bons híbridos, sejam de linhagens ou intermediários. 


\section{MATERIAL E MÉTODOS}

\subsection{Material}

O dialélico parcial circulante utilizado no presente estudo foi esquematizado à partir de progênies de irmãos germanos das populações de milho SUWAN e ESALQ-PB1.

A população ESALQ-PB1 foi obtida no Instituto de Genética da ESALQ/USP, a partir do interctuzamento de sete variedades de porte baixo como característica poligênica (MIRANDA FILHO, 1974). Durante a fase de recombinação foi praticada seleção branda para características agronômicas e em seguida iniciou-se um programa de melhoramento visando a obtenção de uma variedade produtiva e com porte de planta reduzido (MIRANDA FILHO, 1977). Os grãos variam de flint a dente e das cores laranja claro a laranja escuro, com alguma segregação para branco. $\mathbf{O}$ ciclo pode ser considerado precoce.

A população SUWAN é um composto formado com germoplasma do Caribe, obtido na Tailândia pela recombinação de 16 progênies $S_{1}$ selecionadas para resistência ao "downy mildew" (Peronosclerospora sorghi (West. \& Uppal) C.G. Shaw). Apresenta plantas de porte baixo, ciclo intermediário e grãos semi-duros de coloração amarelo-alaranjada. Segundo MÔRO et alii (1981) este composto foi introduzido no Brasil em 1976 pelo CNPMS-EMBRAPA, com a denominação de CMS 05. 


\subsection{Métodos}

\subsubsection{Obtenção dos híbridos intermediários}

No ano agrícola 1988/89, dentro das populações SUWAN e ESALQ-PB1, foram realizados cruzamentos planta a planta, obtendo-se 100 progênies de irmãos germanos (PIG), tomadas ao acaso, de cada uma. No ano agrícola seguinte as progênies foram semeadas em linhas individualizadas, contendo 25 plantas, nas cidades de Uberlândia (ESALQ-PB1) e Piracicaba (SUWAN). Em cada progênie da população ESALQ-PB1 foram autofecundadas, em média, quatro plantas, enquanto que na população SUWAN foram feitos em tomo de quatro cnuzamentos fraternais (CF) por progênie. As mesmas progênies iniciais foram semeadas em Piracicaba, no ano agrícola 1990/91, e houve a inversão dos sistemas de multiplicação. Autofecundações foram realizadas nas progênies da população SUWAN e CF nas progênies de ESALQ-PB1. Em todos os casos as sementes das plantas polinizadas foram misturadas para representar cada uma das progênies.

As 100 progênies de cada população, multiplicadas pelo mesmo sistema, foram divididas em grupos de 10. Cada dois grupos, de populações diferentes, foram submetidos a um esquema de cruzamento dialélico parcial circulante, formando uma cadeia, conforme representado na Tabela 1. Portanto, foram necessárias 10 cadeias para cobrir as 100 progênies de cada população, em cada sistema de multiplicação das progênies.

Através de polinizações manuais cada progênie foi então cruzada com três progênies da outra população, resultando 30 híbridos em cada cadeia, num total de 300 híbridos em cada sistema de multiplicação das progênies.

Os cruzamentos foram realizados no campo experimental do Instituto de Genética/ESALQ/USP, onde os pares de progênies pré-determinados foram semeados em linhas de quatro metros espaçadas entre si de um metro, com cinco plantas por $\mathrm{m}$, espaçadas de 0,20 m entre covas. $O$ número médio de cruzamentos efetuados em cada par de parentais (progênies) foi de 6,39 e 6,83, respectivamente para os sistemas de 
autofecundação e cruzamentos fratemais. No entanto, o intervalo de variação foi de um a 11, havendo dificuldades em alguns cruzamentos devido à falta de sincronismo no florescimento. Por isso, não foram efetuados um cruzamento na primeira cadeia e quatro na décima cadeia do sistema de autofecundação, além de um cruzamento na primeira cadeia do sistema de cruzamentos fraternais. Para efeito de avaliação dos híbridos intermediários os cruzamentos recíprocos, dentro de cada par de parentais, foram misturados.

Tabela 1 - Esquema dos cruzamentos em cadeia referentes às 10 primeiras progênies de cada população.

\begin{tabular}{|c|c|c|c|c|c|c|c|c|c|c|c|}
\hline & \multicolumn{10}{|c|}{ E S A L Q P B - 1} \\
\hline & & $1^{\prime}$ & $2^{\prime}$ & $3^{\prime}$ & $4^{\prime}$ & $5^{\prime}$ & $6^{\prime}$ & 7 & 8 & $9^{\prime}$ & $10^{\prime}$ \\
\hline & 1 & $1.1^{\prime}$ & $1.2^{\prime}$ & $1.3^{\prime}$ & & & & & & & \\
\hline & 2 & & $2.2^{\prime}$ & $2.3^{\prime}$ & $2.4^{\prime}$ & & & & & & \\
\hline $\mathbf{S}$ & 3 & & & $3.3^{\prime}$ & $3.4^{\prime}$ & $3.5^{\prime}$ & & & & & \\
\hline $\mathrm{U}$ & 4 & & & & $4.4^{\prime}$ & $4.5^{\prime}$ & $4.6^{\prime}$ & & & & \\
\hline W & 5 & & & & & $5.5^{\prime}$ & $5.6^{\prime}$ & $5.7^{\prime}$ & & & \\
\hline A & 6 & & & & & & $6.6^{\prime}$ & $6.7^{\prime}$ & $6.8^{\prime}$ & & \\
\hline $\mathbf{N}$ & 7 & & & & & & & 7.7' & 7.8' & 7.9' & \\
\hline & 8 & & & & & & & & $8.8^{\prime}$ & $8.9^{\prime}$ & $8.10^{\prime}$ \\
\hline & 9 & $9.1^{\prime}$ & & & & & & & & $9.9^{\prime}$ & $9.10^{\prime}$ \\
\hline & 10 & $10.1^{\prime}$ & $10.2^{\prime}$ & & & & & & & & $10.10^{\prime}$ \\
\hline
\end{tabular}

\subsubsection{Avaliação dos híbridos intermediários}

De cada cruzamento foram retirados três amostras de 20 sementes. Estas representaram as três repetições de cada cruzamento que foi avaliado em um delineamento experimental em blocos ao acaso. 
Cada cadeia de cruzamentos ( 30 híbridos) foi colocada em um experimento juntamente com o híbrido comercial FT 9043, totalizando 31 parcelas por repetição. Portanto, foram instalados 20 experimentos, sendo 10 de cada sistema de multiplicação das progênies. Nas parcelas correspondentes àqueles híbridos que não foram obtidos, foi colocada a testemunha. A parcela experimental utilizada foi uma linha de quatro metros, o espaçamento entre parcelas foi de $0,90 \mathrm{~m}$ e o espaçamento entre plantas foi de $0,20 \mathrm{~m}$.

Para uma visão global das operações realizadas é interessante observar o fluxograma apresentado na Figura 1.

Os experimentos foram instalados nos dias 05 e 06/01/93, na Fazenda de Ensino e Pesquisa da Faculdade de Engenharia de Tha Solteira (FEIS/UNESP), em um solo tipo latossol vermelho escuro cuja análise química é mostrada na Tabela 2. Foi aplicada uma dose de $250 \mathrm{~kg} / \mathrm{ha}$ do adubo formulado 4-30-10 no sulco de semeadura e $250 \mathrm{~kg} /$ ha de sulfato de amônio em cobertura, 40 dias após a semeadura. Utilizou-se também de uma dose de $20 \mathrm{~kg} /$ ha de Furadan $\mathrm{G}$ no sulco, para controle de pragas do solo e 4,0 l/ha de herbicida Primextra. Também foi realizado um cultivo, com cultivador de tração animal, aos $\mathbf{4 0}$ dias após semeadura.

Tabela 2 - Análise química do solo nas áreas onde foram instalados os experimentos dos dois sistemas de multiplicação das progênies.

\begin{tabular}{|c|c|c|c|c|c|c|c|c|}
\hline & \multirow{2}{*}{$\begin{array}{l}\text { P-resina } \\
\mu \mathrm{g} / \mathrm{cm}^{3}\end{array}$} & \multirow{2}{*}{$\begin{array}{l}\text { M.O. } \\
(\%)\end{array}$} & \multirow{2}{*}{$\begin{array}{l}\mathrm{pH} \mathrm{em} \\
\mathrm{CaCl}_{2}\end{array}$} & $\mathrm{~K}^{+}$ & $\mathrm{Ca}^{++}$ & $\mathbf{M g}^{+}$ & $\left(\mathrm{H}^{+}+\mathrm{Al}^{++}\right)$ & \multirow{2}{*}{$\frac{V}{(\%)}$} \\
\hline Sistema & & & & \multicolumn{4}{|c|}{$\mathrm{meq} / \mathrm{cm}$} & \\
\hline Autofec. & 42 & 2,72 & 5,3 & 0,24 & 2,85 & 1,15 & 2,8 & 60 \\
\hline Cruzam. frat. & 18 & 2,55 & 5,1 & 0,21 & 2,04 & 0,74 & 3,1 & 49 \\
\hline
\end{tabular}

As variáveis observadas nos experimentos foram as seguintes:

FF - Florescimento feminino: número de dias necessários para que $50 \%$ das plantas da parcela apresentassem estigmas soltos (cerca de três centímetros de comprimento), a contar da emergência das plântulas; 


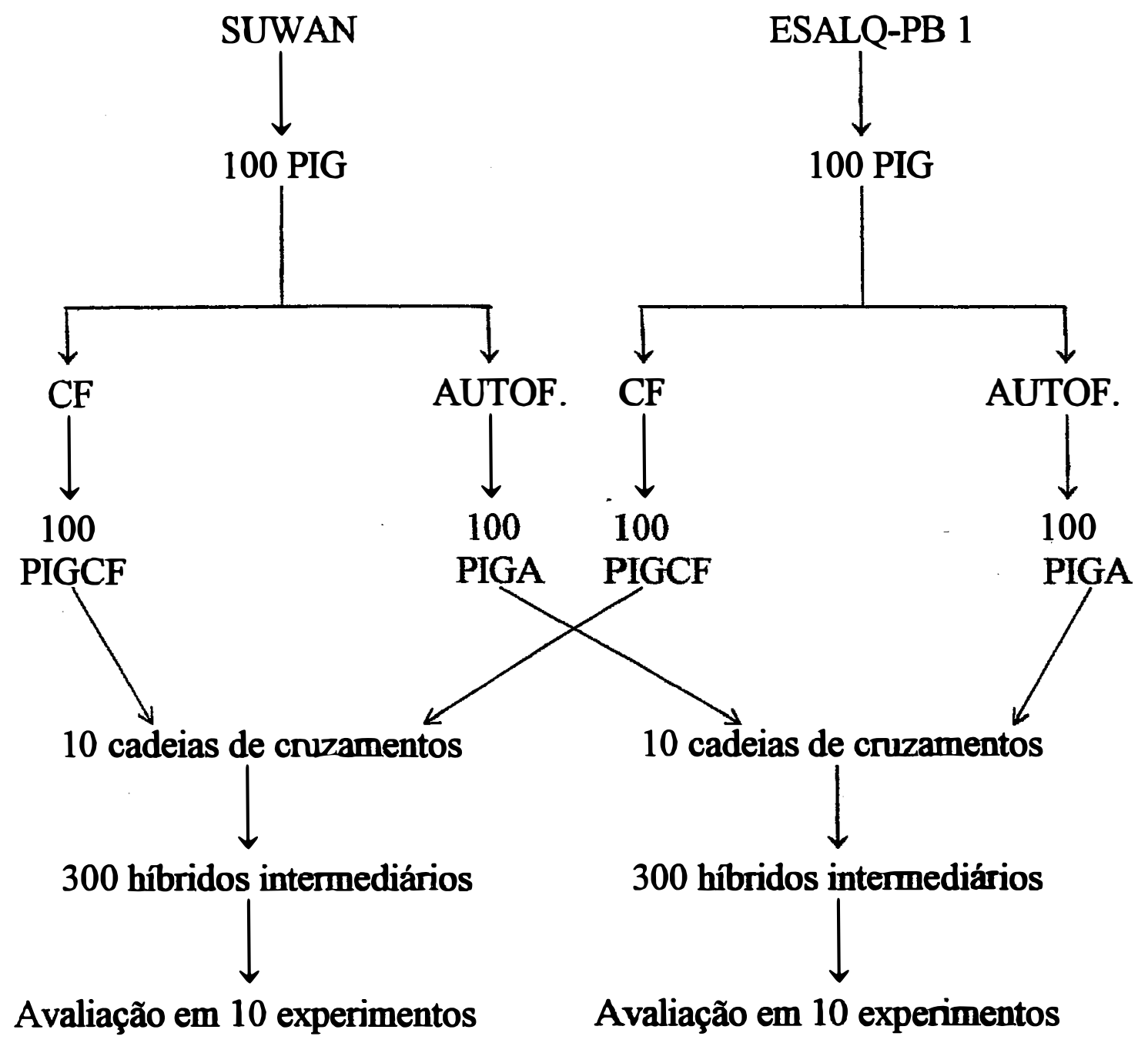

Figura 1 - Esquema de obtenção e avaliação dos híbridos intermediários entre progênies de irmãos germanos (PIG) de duas populações de milho. CF, AUTOF., PIGCF e PIGA, simbolizam, respectivamente, cruzamentos fratemais, autofecundação, progênies de irmãos germanos multiplicadas por cruzamentos fraternais e progênies de innãos germanos multiplicadas por autofecundação. 
AP - Altura de plantas: medida em metros desde o nível do solo até a inserção do limbo da folha bandeira, de cinco plantas competitivas da parcela. Esta operação foi realizada logo após o encerramento da polinização;

AE - Altura de espigas: medida em metros do nível do solo até o nó de inserção da espiga principal (superior), das mesmas cinco plantas medidas para AP;

E - Estande: número de plantas existente na parcela no momento da colheita;

PE - Peso de espigas: peso em $\mathrm{kg}$ do total de espigas, despalhadas, da parcela, tomado com auxílio de balança eletrônica;

PG - Peso de grãos: peso em kg dos grãos resultantes da debulha do total de espigas da parcela, tomado com auxílio de balança eletrônica;

U - Umidade dos grãos: medida em porcentagem de uma amostra dos grãos de cada parcela, imediatamente após a pesagem, com auxilio de aparelho eletrônico.

O PE e PG foram corrigidos para umidade constante de $13 \%$ pela fórmula $\mathrm{PCU}=\mathrm{PC}(1-\mathrm{U}) / 0,87$ onde $\mathrm{PCU}$ é o peso de campo corrigido para umidade, $\mathrm{PC}$ é o peso de campo observado (PE ou PG) e U é a umidade observada.

Na seqüência os pesos corrigidos para umidade foram ajustados, em cada parcela, para as variações de estande, através do método da covariância (STEEL \& TORRIE, 1960). O ajuste foi feito para estande ideal de 20 plantas por parcela, utilizando-se a fórmula PCC=PCU-b(E-20), conforme sugestão de Miranda Filho (citado por VENCOVSKY \& BARRIGA, 1992), onde PCC é o peso corrigido para umidade e estande ideal, PCU é o peso corrigido para umidade, b é o coeficiente de regressão de PCU em relação às variações de estande. A correção foi feita parcela por parcela.

Para cálculo do coeficiente $b$ foram feitas análises de variância e covariância para estande e produção (PE ou PG), em blocos casualizados. $O$ valor foi encontrado pelo quociente entre a soma de produtos residual da análise de covariância (SP $\mathrm{EP}_{\mathrm{E}}$ e a soma de quadrados residual da análise de variância para estande $\left(\mathrm{SQ}_{\mathrm{E}}\right)$.

\subsubsection{Análise estatística preliminar}

Para cada uma das cinco variáveis foi realizada uma análise de variância segundo o modelo aleatório $Y_{i j}=\mu+t_{i}+b_{j}+e_{i j}$, onde: 
$\mathrm{Y}_{\mathrm{ij}}=$ observação da variável $\mathrm{Y}$ do tratamento i na repetição $\mathrm{j}$;

$\mu=$ média geral da variável, $\mathrm{E}(\mu)=\mu, \mathrm{E}\left(\mu^{2}\right)=\mu^{2}$;

$t_{i}=$ efeito de tratamento sendo $i=1,2, \ldots 30$ para híbridos (aleatório) e $i^{\prime}=31$ para

a testemunha (fixo). Em relação a híbridos $\mathrm{E}\left(t_{i}\right)=0 \mathrm{e} \mathrm{E}\left(t_{i}^{2}\right)=\sigma_{h}^{2}$;

$b_{j}=$ efeito de repetição, $\mathrm{j}=1,2,3, \mathrm{E}\left(b_{j}\right)=0$ e $\mathrm{E}\left(b_{j}^{2}\right)=\sigma_{b}^{2}$;

No sistema de cruzamentos fraternais a mesma análise foi realizada para os dados ajustados através da multiplicação por um índice obtido pelo quociente entre a média da testemunha no sistema de autofecundação e no sistema de cruzamentos fraternais (Tabela 19). Isso foi feito para cada par de experimentos correspondentes, por que as médias da testemunha, para as variáveis PE e PG no sistema de cruzamentos fraternais, foram bem inferiores em relação àquelas dos experimentos correspondentes no outro sistema, evidenciando um problema ambiental e não genético. Esse procedimento foi necessário para efeitos de comparação dos sistemas de multiplicação das progênies (item 3.2.5.). Como o índice multiplicativo altera as variâncias, optou-se também pela apresentação dos resultados obtidos com os dados ajustados.

Os graus de liberdade de tratamentos foram desdobrados nas fontes HÍBRIDOS e HIIBRIDOS vs. TESTEMUNHA Os graus de liberdade de híbridos também foram desdobrados nas fontes dentro de cada diagonal e entre diagonais. As diagonais são grupos de $\mathbf{n}$ híbridos onde cada progênie aparece apenas uma vez. Assim a primeira diagonal é formada pelos híbridos $\mathrm{i} \times \mathrm{j}$, a segunda pelos híbridos $\mathrm{i} \times \mathrm{j}+1$ e a terceira pelos híbridos $\mathrm{i} x \mathrm{j}+2, \operatorname{com} \mathrm{i}=\mathrm{j}=1,2,3, \ldots \mathrm{n}$. No caso de $\mathrm{j}+1$ e $\mathrm{j}+2$ maiores do que " $n$ ", há necessidade da subtração de n para encontrar a segunda progênie do híbrido. Como pode ser verificado na Tabela 3, a E(QM) das fontes híbridos e dentro de diagonais contêm a variância de híbridos, permitindo assim diversas estimativas dessa variância. No entanto, na fonte de variação híbridos, a amostragem não é totalmente aleatória, pois engloba híbridos com parentais comuns, obedecendo uma certa regra pré-detemininada.

Após as análises individuais optou-se por eliminar o décimo experimento do sistema de autofecundação de multiplicação das progênies, por este ter mostrado um 
coeficiente de variação muito alto em relação aos demais. Então nove experimentos foram agrupados para o sistema de autofecundação e 10 para o sistema de cruzamentos fraternais. Os quadrados médios agrupados foram obtidos através da ponderação dos quadrados médios de cada experimento pelos respectivos graus de liberdade. Na Tabela 3 encontram-se esquematizadas as análises de variância individuais e agrupadas.

Tabela 3 - Quadro da análise de variância segundo o delineamento em blocos ao acaso, com as esperanças dos quadrados médios ao nível de totais de parcelas, em um dialélico parcial circulante com' $n$ progênies de cada população, $\mathbf{S}$ cruzamentos por progênie e uma testemunha comercial.

\begin{tabular}{lcrrrlll}
\hline Fontes de Variação & $\mathrm{GL}^{\mathrm{A}}$ & $\mathrm{GL}^{\mathrm{B}}$ & $\mathrm{GL}^{\mathrm{C}}$ & $\mathrm{GL}^{\mathrm{C}}$ & $\mathrm{QM}$ & $\mathrm{E}(\mathrm{QM})$ & $\mathrm{F}$ \\
\hline Blocos & $(\mathrm{r}-1)$ & 2 & 18 & 20 & $\mathrm{Q}_{1}$ & - & \\
Tratamentos & $\mathrm{ns}$ & 30 & 269 & 299 & $\mathrm{Q}_{2}$ & - & \\
$\quad$ Hibridos & $(\mathrm{ns}-1)$ & 29 & 260 & 289 & $\mathrm{Q}_{3}$ & $\sigma^{2}+\mathrm{r} \sigma_{h}^{2}$ & $\mathrm{Q}_{3} / \mathrm{Q}_{9}$ \\
$\quad$ Diagonal 1 & $(\mathrm{n}-1)$ & 9 & 81 & 90 & $\mathrm{Q}_{4}$ & $\sigma^{2}+\mathrm{r} \sigma_{h}^{2}$ & $\mathrm{Q}_{4} / \mathrm{Q}_{9}$ \\
$\quad$ Diagonal 2 & $(\mathrm{n}-1)$ & 9 & 80 & 90 & $\mathrm{Q}_{5}$ & $\sigma^{2}+\mathrm{r} \sigma_{h}^{2}$ & $\mathrm{Q}_{5} / \mathrm{Q}_{9}$ \\
$\quad$ Diagonal 3 & $(\mathrm{n}-1)$ & 9 & 81 & 89 & $\mathrm{Q}_{6}$ & $\sigma^{2}+\mathrm{r} \sigma_{h}^{2}$ & $\mathrm{Q}_{6} / \mathrm{Q}_{9}$ \\
$\quad$ E. Diagonais & $(\mathrm{s}-1)$ & 2 & 18 & 20 & $\mathrm{Q}_{7}$ & $\sigma^{2}+\mathrm{r} \mathrm{V}_{\mathrm{D}}$ & $\mathrm{Q}_{7} / \mathrm{Q}_{9}$ \\
H vs. Testemunha & 1 & 1 & 9 & 10 & $\mathrm{Q}_{8}$ & $\sigma^{2}+\mathrm{rV}_{\mathrm{g}}$ & $\mathrm{Q}_{8} / \mathrm{Q}_{9}$ \\
Erro & $\mathrm{ns}(\mathrm{r}-1)$ & 60 & 541 & 601 & $\mathrm{Q}_{9}$ & $\sigma^{2}$ & \\
\hline TOTAL & $\mathrm{r}(\mathrm{ns}+1)-$ & 92 & 828 & 920 & & &
\end{tabular}

\footnotetext{
${ }^{A}, B$ : referem-se aos graus de liberdade genérico e específico das análises individuais $(n=10, s=3$,

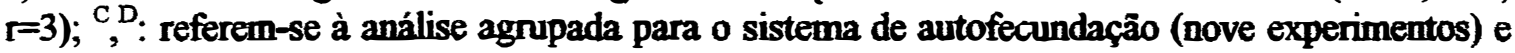
cruzamentos fraternais (10 experimentos); $r$ : número de repetições; $V_{\mathrm{g}}$ e $V_{\mathrm{D}}$ : componentes quadráticos da variação entre grupos; Para todas as variáveis $\mathrm{n}-\mathbf{1}=\mathbf{8}$ na diagonal 2 (autofecundaçäo-exp. 1) e diagonal 3 (CF-exp. 1). Para PE e PG (ajustados por covariância), GL do erro $=$ ns(r-1)-1 e GL do erro médio $=532$ e 591, respectivamente para o sistema de autofecundação e cruzamentos fratemais.
} 


\subsubsection{Estimativas dos parâmetros genéticos}

Com base nos quadrados médios da análise agrupada, e na esperança dos mesmos, foram obtidas estimativas dos componentes de variância $\hat{\sigma}_{h}^{2}$ (variância genética entre híbridos), $\hat{\sigma}_{h^{*}}^{2}$ (variância genética entre híbridos considerando apenas as fontes dentro de diagonais) e $\hat{\sigma}^{2}$ (variância do erro experimental), para cada variável, através das seguintes expressões:

$$
\begin{aligned}
& \hat{\sigma}_{h}^{2}=\left(Q_{3}-Q_{9}\right) / 3, \text { para ambos os sistemas; } \\
& \hat{\sigma}_{h^{*}}^{2}=(1 / 3)\left[(1 / 242)\left(81 Q_{4}+80 Q_{5}+81 Q_{6}\right)-Q_{9}\right] \text {, para autofecundação; } \\
& \hat{\sigma}_{h^{*}}^{2}=(1 / 3)\left[(1 / 269)\left(90 Q_{4}+90 Q_{5}+89 Q_{6}\right)-Q_{9}\right] \text {, para cruzamentos fraternais; } \\
& \hat{\sigma}^{2}=Q_{9} \text {, para ambos os sistemas. }
\end{aligned}
$$

Estimativas da variância fenotípica ao nível de médias de híbridos $\left(\hat{\sigma}_{F}^{2} \mathrm{e}\right.$ $\left.\widehat{\sigma}_{F^{*}}^{2}\right)$, da herdabilidade no sentido amplo ao nível de média de híbridos $\left(\widehat{h}_{H}^{2}\right.$ e $\left.\widehat{h}_{H^{*}}^{2}\right)$, do coeficiente de variação genética $\left(\mathrm{CV}_{\mathrm{g}}\right.$ e $\left.\mathrm{CV}_{\mathrm{g}^{*}}\right)$ e do índice de variação genética $\left(\theta\right.$ e $\left.\theta^{*}\right)$ foram obtidas pelas seguintes expressões:

$$
\begin{gathered}
\hat{\sigma}_{F}^{2}=\hat{\sigma}_{h}^{2}+\hat{\sigma}^{2} / \mathrm{r} ; \quad \hat{\sigma}_{F^{*}}^{2}=\hat{\sigma}_{h^{*}}^{2}+\hat{\sigma}^{2} / \mathrm{r} ; \quad \hat{h}_{H}^{2}=\hat{\sigma}_{h}^{2} / \hat{\sigma}_{F}^{2} ; \quad \hat{h}_{H^{*}}^{2}=\hat{\sigma}_{h^{*}}^{2} / \hat{\sigma}_{F^{*}}^{2} ; \\
\mathrm{CV}_{\mathrm{g}}(\%)=100 \hat{\sigma}_{h} / \hat{\mu} ; \quad \mathrm{CV}_{\mathrm{g}^{*}}(\%)=100 \hat{\sigma}_{h^{*}} / \hat{\mu} ; \quad \theta=\mathrm{CV}_{\mathrm{g}} / \mathrm{CV}_{\mathrm{e}}=\hat{\sigma}_{h} / \hat{\sigma} ; \\
\theta^{*}=\mathrm{CV}_{\mathrm{g}^{*}} / \mathrm{CV}_{\mathrm{e}}=\hat{\sigma}_{h^{*}} / \hat{\sigma} ;
\end{gathered}
$$

Nas expressões, o asterisco simboliza estimativas obtidas em função da variância genética entre híbridos dentro de diagonais.

Com as diagonais do esquema dialélico parcial circulante, foram obtidos dois grupos, conforme mostrado na Tabela 4. De acordo com a metodologia apresentada por MIRANDA FILHO \& VENCOVSKY (1995), os dois grupos de diagonais foram analisados como tabelas de dupla entrada, apenas para a variável PG, segundo o modelo fatorial:

$$
\mathrm{Y}_{\mathrm{ik}}=\mu+\alpha_{\mathrm{i}}+\delta_{\mathrm{k}}+(\alpha \delta)_{\mathrm{ik}}+\bar{e}_{j k}, \text { para o grupo I; }
$$




$$
\mathrm{Y}_{\mathrm{jk}}=\mu+\alpha_{\mathrm{j}}+\delta_{\mathrm{k}}+(\alpha \delta)_{\mathrm{jk}}+\bar{e}_{j k} \text {, para o grupo II; }
$$

onde, $\mu$ é a média geral, comum para os dois grupos; $\alpha_{i}$ e $\alpha_{j}$ são efeitos constantes (capacidade geral de combinação) das progênies parentais, $\mathbf{E}\left(\alpha_{i}^{2}\right)=\sigma_{P I}^{2}=\sigma_{g I}^{2}$ e $\mathbf{E}\left(\alpha_{j}^{2}\right)=$ $\sigma_{P I}^{2}=\sigma_{g I}^{2} ; \delta_{\mathrm{k}}$ é o efeito de diferenças entre diagonais, $\mathbf{E}\left(\delta_{k}^{2}\right)=\sigma^{2}+\sigma_{s}^{2} ;(\alpha \delta)_{\mathrm{ik}} \mathbf{e}(\alpha \delta)_{\mathrm{jk}}$ são efeitos da interação de progênies com diagonais dentro do respectivo grupo, $\mathbf{E}(\alpha \delta)_{i k}^{2}=\mathbf{E}(\alpha \delta)_{j k}^{2}=\sigma_{P D}^{2} ; \bar{e}_{j k}$ e $\bar{e}_{j k}$ são efeitos do erro médio experimental.

Dentro de cada grupo as diagonais são representadas por cruzamentos envolvendo as mesmas progênies, de maneira que as suas médias diferem apenas devido ao erro médio e uma pequena quantidade representada pela média de uma amostra aleatória dos efeitos da capacidade específica de combinação $\left[1 / \mathrm{n}\left(\sum_{i j} s_{i j}\right)\right]$. Por isso, em termos de esperança temos $\mathbf{E}\left(\delta_{k}^{2}\right)=\hat{\sigma}^{2}+\sigma_{s}^{2}$, como colocado acima.

A análise de variância das tabelas de dupla entrada, para o grupo I de diagonais, é mostrada na Tabela 5. A estrutura de análise é similar para o grupo dois.

Em termos de esperança, a covariância entre duas diagonais é:

$$
\begin{aligned}
& \operatorname{COV}_{\mathrm{I}}=\mathbf{E}\left[\left(\mathrm{Y}_{\mathrm{ij}}-\mu\right)\left(\mathrm{Y}_{\mathrm{ij}}-\mu\right)\right]=\sigma_{g l}^{2}, \text { para o grupo I; } \\
& \operatorname{COV}_{\mathrm{II}}=\mathbf{E}\left[\left(\mathrm{Y}_{\mathrm{ij}}-\mu\right)\left(\mathrm{Y}_{\mathrm{ij}}-\mu\right)\right]=\sigma_{g I}^{2}, \text { para o grupo II. }
\end{aligned}
$$

Tomando todas as covariâncias entre diagonais haverá $\mathrm{s}(\mathrm{s}-1) / 2$ estimativas de $\sigma_{g}^{2}$ para cada população e a estimativa média das covariâncias corresponde à estimativa média da variância devida aos efeitos da capacidade geral de combinação.

As estimativas dos componentes de variância foram obtidas com base nas seguintes fórmulas:

$$
\begin{gathered}
\mathrm{c} \hat{O} \mathrm{~V}_{\mathrm{gI}}=\hat{\sigma}_{g I}^{2}=\left(\mathrm{Q}_{\mathrm{P}}-\mathrm{Q}_{\mathrm{PD}}\right) / \mathrm{s}, \text { para o grupo I; } \\
\mathrm{c} \hat{O} \mathrm{~V}_{\mathrm{gII}}=\hat{\sigma}_{g I}^{2}=\left(\mathrm{Q}_{\mathrm{P}}-\mathrm{Q}_{\mathrm{PD}}\right) / \mathrm{s}, \text { para o grupo II; } \\
\hat{\sigma}_{H}^{2}=(\mathrm{s}-1) \mathrm{Q}_{\mathrm{PD}} / \mathrm{s}+\mathrm{Q}_{\mathrm{p}} / \mathrm{s}-\mathrm{Q}_{\mathrm{E}} \\
\hat{\sigma}^{2}=\mathrm{Q}_{\mathrm{E}} ;
\end{gathered}
$$


Tabela 4 - Dois grupos possíveis para as três diagonais do esquema dialélico parcial circulante.

\begin{tabular}{|c|c|c|c|c|c|}
\hline \multicolumn{3}{|c|}{ Grupo I } & \multicolumn{3}{|c|}{ Grupo II } \\
\hline $\mathrm{D}_{1}$ & $\overline{D_{2}}$ & $\mathrm{D}_{3}$ & $\mathrm{D}_{1}$ & $\mathrm{D}_{2}$ & $\mathrm{D}_{3}$ \\
\hline $1.1^{\prime}$ & $1.2^{\prime}$ & $1.3^{\prime}$ & $1.1^{\prime}$ & $10.1^{\prime}$ & $9.1^{\prime}$ \\
\hline $2.2^{\prime}$ & $2.3^{\prime}$ & $2.4^{\prime}$ & $2.2^{\prime}$ & $1.2^{\prime}$ & $10.2^{\prime}$ \\
\hline $3.3^{\prime}$ & $3.4^{\prime}$ & $3.5^{\prime}$ & $3.3^{\prime}$ & $2.3^{\prime}$ & $1.3^{\prime}$ \\
\hline $4.4^{\prime}$ & $4.5^{\prime}$ & $4.6^{\prime}$ & $4.4^{\prime}$ & $3.4^{\prime}$ & $2.4^{\prime}$ \\
\hline $5.5^{\prime}$ & $5.6^{\prime}$ & $5.7^{\prime}$ & $5.5^{\prime}$ & $4.5^{\prime}$ & $3.5^{\prime}$ \\
\hline $6.6^{\prime}$ & $6.7^{\prime}$ & $6.8^{\prime}$ & $6.6^{\prime}$ & $5.6^{\prime}$ & $4.6^{\prime}$ \\
\hline $7.7^{\prime}$ & $7.8^{\prime}$ & $7.9^{\prime}$ & $7.7^{\prime}$ & $6.7^{\prime}$ & $5.7^{\prime}$ \\
\hline $8.8^{\prime}$ & $8.9^{\prime}$ & $8.10^{\prime}$ & $8.8^{\prime}$ & $7.8^{\prime}$ & $6.8^{\prime}$ \\
\hline $9.9^{\prime}$ & $9.10^{\prime}$ & $9.1^{\prime}$ & $9.9^{\prime}$ & $8.9^{\prime}$ & $7.9^{\prime}$ \\
\hline $10.10^{\prime}$ & $10.1^{\prime}$ & $10.2^{\prime}$ & $10.10^{\prime}$ & $9.10^{\prime}$ & $8.10^{\prime}$ \\
\hline
\end{tabular}

Tabela 5 - Esquema de análise de variância das tabelas de dupla entrada, representando as diagonais, para a estimação de parâmetros genéticos. Representação para o grupo I de diagonais (MIRANDA FILHO \& VENCOVSKY, 1995).

\begin{tabular}{lrllll}
\hline & & & \multicolumn{1}{c}{$\mathrm{E}(\mathrm{QM})^{7}$} \\
\cline { 4 - 5 } \multicolumn{1}{c}{ F. V. } & $\mathrm{GL}$ & $\mathrm{QM}$ & Geral & Grupo I \\
\hline Diagonais (D) & $\mathrm{s}-1$ & $\mathrm{Q}_{\mathrm{D}}$ & $\sigma^{2}+\sigma_{s}^{2}$ & $\sigma^{2}+\sigma_{s}^{2}$ \\
Linhas (L) & $\mathrm{n}-1$ & $\mathrm{Q}_{\mathrm{P}}$ & $\sigma^{2}+\sigma_{P D}^{2}+s \sigma_{P}^{2}$ & $\sigma^{2}+\left(\sigma_{H}^{2}-C O V_{g I}\right)+s C O V_{g I}$ \\
L x D & $(\mathrm{n}-1)(\mathrm{s}-1)$ & $\mathrm{Q}_{\mathrm{PD}}$ & $\sigma^{2}+\sigma_{P D}^{2}$ & $\sigma^{2}+\left(\sigma_{H}^{2}-C O V_{g I}\right)$ \\
Erro & $(\mathrm{r}-1)(\mathrm{ns}-1)$ & $\mathrm{Q}_{\mathrm{E}}$ & $\sigma^{2}$ & $\sigma^{2}$ \\
\hline Híbridos/D & $\mathrm{s}(\mathrm{n}-1)$ & $\mathrm{Q}_{\mathrm{H} / \mathrm{D}}$ & $\sigma^{2}+\sigma_{H}^{2}$ & \\
\hline
\end{tabular}

$" \bar{l}-\sigma_{H}^{2}$ é a média das $\mathrm{s}$ variâncias dentro de diagonais; $\sigma_{P D}^{2}$ é a variância da interaçāo linhas $\mathrm{x}$ diagonais; $\sigma_{P}^{2}$ é a variância entre progênies (linhas); $\sigma_{s}^{2}$ é a variância devido aos efeitos da capacidade especifica de combinação; $\operatorname{COV}_{\mathrm{gI}}$ é a média das $\mathrm{s}(\mathrm{s}-1) / 2$ covariâncias entre diagunais do grupo I. 


$$
\begin{gathered}
\hat{\sigma}_{H}^{2}=\hat{\sigma}_{g I}^{2}+\hat{\sigma}_{g I}^{2}+\hat{\sigma}_{s}^{2} \\
\hat{\sigma}_{s}^{2}=\hat{\sigma}_{H}^{2}-\hat{\sigma}_{g I}^{2}-\hat{\sigma}_{g I}^{2}
\end{gathered}
$$

De acordo com HALLAUER \& MIRANDA FILHO (1988):

$\sigma_{g I}^{2}=(1+\mathrm{F}) \sigma_{A(12)}^{2} / 4 ; \sigma_{g I I}^{2}=(1+\mathrm{F}) \sigma_{A(21)}^{2} / 4$ e $\sigma_{s}^{2}=[(1+\mathrm{F}) / 2]^{2} \sigma_{D(12)}^{2}$; onde $\mathrm{F}$ é o coeficiente de endogamia das progênies parentais, $\sigma_{g I}^{2}$ e $\sigma_{g I I}^{2}$ são as variâncias da capacidade geral de combinação dos grupo I e II, $\sigma_{A(12)}^{2}$ e $\sigma_{A(21)}^{2}$ são os homólogos da variância aditiva interpopulacional e $\sigma_{D(12)}^{2}$ é a variância dominante interpopulacional. Então os componentes da variância genética foram estimados por:

$$
\left.\hat{\sigma}_{A(12)}^{2}=[2 /(1+\mathrm{F})]\left[\hat{\sigma}_{g I}^{2}+\hat{\sigma}_{g I}^{2}\right)\right] ; \quad \hat{\sigma}_{D(12)}^{2}=[2 /(1+\mathrm{F})]^{2} \hat{\sigma}_{s}^{2}
$$

\subsubsection{Comparação dos sistemas de multiplicação das progênies}

De acordo com o esquema realizado, cada híbrido intermediário teve duas versões, uma com os pais multiplicados por autofecundação e outra com os pais multiplicados por cruzamentos fratemais. Para comparar esses dois sistemas de multiplicação das progênies parentais, foi necessário fazer uma análise estatística envolvendo 18 experimentos, sendo nove do sistema de autofecundação e os nove correspondentes do sistema de cruzamentos fraternais. Como colocado anteriormente, o experimento 10 do sistema de autofecundação, foi eliminado e por isso, neste tipo de análise, o seu correspondente no sistema de cruzamentos fratemais não pôde ser considerado. Uma outra providência tomada foi o ajuste das parcelas dos experimentos do sistema de cruzamentos fraternais como descrito no item 3.2.3.

O modelo utilizado para esta análise foi o seguinte:

$$
\mathrm{Y}_{\mathrm{ijkl} l}=\mu+\mathrm{S}_{l}+\mathrm{E}_{\mathrm{k}}+\mathrm{h}_{\mathrm{ijk})}+\mathrm{SE}_{(\mathrm{kk})}+\mathrm{Sh}_{\overline{z j}(\mathrm{k})}+\bar{e}_{i j k l} \text {, onde, }
$$

$\mathrm{Y}_{\mathrm{ijk} /}=$ valor do híbrido ij no experimento $\mathrm{k}$, sistema $l$;

$\mu=$ média geral, $E(\mu)=\mu, E\left(\mu^{2}\right)=\mu^{2}$; 
$\mathbf{S}_{l}=$ efeito de sistemas (fixo), $l=1,2, \mathbf{E}\left(\mathbf{S}_{l}\right)=\mathbf{S}, \mathbf{E}\left(S_{l}^{2}\right)=S_{l}^{2}$;

$\mathrm{E}_{\mathrm{k}}=$ efeito de experimentos (fixo), $\mathrm{k}=1,2, \ldots 9, \mathbf{E}\left(\mathrm{E}_{\mathrm{k}}\right)=\mathrm{E}, \mathbf{E}\left(E_{k}^{2}\right)=E_{k}^{2}$;

$h_{i j(k)}=$ efeito de híbridos dentro de experimentos (aleatório), $i=1,2, \ldots 10, j=$ $1,2, \ldots 10, \mathbf{E}\left(\mathrm{h}_{\mathrm{ij}(\mathrm{k})}\right)=0, \mathbf{E}\left(h_{i j(k)}^{2}\right)=\sigma_{h}^{2}$;

$\mathrm{SE}_{\mathbf{k k}}=$ efeito da interação de sistemas com experimentos (fixo);

$\mathrm{Sh}_{\mathrm{rj}(\mathrm{k})}=$ efeito da interação sistemas com híbridos dentro de experimentos (aleatório);

$\bar{e}_{i j k l}=$ erro médio experimentais $\mathbf{E}\left(\bar{e}_{i j k l}\right)=0, \mathbf{E}\left(\bar{e}_{i j k l}^{2}\right)=\sigma^{2}$

$O$ esquema da análise de variância englobando os dois sistemas de multiplicação das progênies para 18 experimentos ficou como mostrado na Tabela 6 .

Tabela 6 - Esquema da análise de variância englobando os dois sistemas de multiplicação das progênies (18 experimentos).

\begin{tabular}{lrcc}
\hline Fontes de Variação & \multicolumn{1}{c}{$\mathrm{GL}$} & $\mathrm{QM}$ & $\mathrm{F}$ \\
\hline Blocos/E/S & $\mathbf{k} l(\mathrm{r}-1)$ & $\mathrm{Q}_{1}$ & - \\
Experimentos & $(\mathrm{k}-1)$ & $\mathrm{Q}_{2}$ & - \\
Hibridos/E & $\mathbf{k}(\mathrm{ns}-1)$ & $\mathrm{Q}_{3}$ & $\mathrm{Q}_{3} / \mathrm{Q}_{7}$ \\
Sistemas & $(l-1)$ & $\mathrm{Q}_{4}$ & $\mathrm{Q}_{4} / \mathrm{Q}_{5}$ \\
S x E & $(l-1)(\mathrm{k}-1)$ & $\mathrm{Q}_{5}$ & $\mathrm{Q}_{5} / \mathrm{Q}_{6}$ \\
S x H/E & $\mathbf{k}(l-1)(\mathrm{ns}-1)$ & $\mathrm{Q}_{6}$ & $\mathrm{Q}_{6} / \mathrm{Q}_{7}$ \\
Erro médio & $\mathrm{k} l(\mathrm{~ns}-1)(\mathrm{r}-1)$ & $\mathrm{Q}_{7}$ & \\
\hline
\end{tabular}

\subsubsection{Análise das tabelas dialélicas e estimativas dos componentes de médias}

O modelo matemárico básico, utilizado como referência para as análises das capacidades geral e específica de combinação, para cada experimento, foi o seguinte: 


$$
\mathrm{Y}_{\mathrm{ij}}=\boldsymbol{\mu}+\mathrm{g}_{\mathrm{i}}+\mathrm{g}_{\mathrm{j}}+\mathrm{s}_{\mathrm{ij}}+\bar{e}_{i j} \text {, sendo, }
$$

$\mathrm{Y}_{\mathrm{ij}}=$ média das três repetições do híbrido entre a progênie $\mathrm{i}$ da população ESALQ-PB1 e a progênie j da população SUWAN;

$\mu=$ média geral do experimento, $E(\mu)=m, E\left(\mu^{2}\right)=\mu^{2}$;

$\mathrm{g}_{\mathrm{i}}=$ efeito da capacidade geral de combinação das progênies da população ESALQ-PB $1, \mathrm{i}=1,2, \ldots 10, \mathbf{E}\left(\mathrm{g}_{\mathrm{i}}\right)=0, \mathbf{E}\left(g_{i}^{2}\right)=\sigma_{g I}^{2}$;

$\mathrm{g}_{\mathrm{j}}=$ efeito da capacidade geral de combinação das progênies da população SUWAN, $\mathrm{j}=1,2, \ldots 10, \mathbf{E}\left(\mathrm{g}_{\mathrm{j}}\right)=0, \mathbf{E}\left(g_{j}^{2}\right)=\hat{\sigma}_{g I}^{2}$;

$\mathrm{s}_{\mathrm{ij}}=$ efeito da capacidade específica de combinação para o cruzamento entre as progênies i ej, $\mathbf{E}\left(s_{i j}\right)=0, E\left(s_{i j}^{2}\right)=\sigma_{s}^{2}$;

$\bar{e}_{i j}=$ erro associado às médias dos híbridos, $\mathbf{E}\left(\bar{e}_{i j}\right)=0, \mathbf{E}\left(\bar{e}_{i j}^{2}\right)=\sigma^{2}$.

A análise em questão é proposta para modelos aleatórios. No presente caso os híbridos formam uma amostra ao acaso de todos os possíveis hibridos interpopulacionais, sendo perfeitamente coerente a aplicação de tal modelo.

O modelo matemático em questão foi substituído pela equação matricial Y $=\mathrm{X} \beta+\varepsilon$ onde $\mathrm{Y}$ foi $\mathrm{o}$ vetor dos dados (médias), $\mathrm{X}$ a matriz dos coeficientes (quantidades fixas expressas em termos de 0 e 1 , de acordo com a representação matricial do modelo), $\beta$ o vetor de parâmetros e $\varepsilon$ o vetor correspondente aos erros.

Através do método dos quadrados mínimos, conforme utilizado por GONÇALVES (1987), DANTAS (1988), SAMPAIO (1989) e DANTAS (1992), as equações normais resultantes foram $X^{\prime} X \widehat{\beta}=X^{\prime} Y$ onde $X^{\prime}$ representa a transposta da matriz X. Como a matriz X'X é singular, a estimativa dos parâmetros só foi possível admitindo-se as restrições $\sum_{i} \hat{g}_{i}=\sum_{j} \hat{g}_{j}=0$.

No presente trabalho foi utilizado o modelo reduzido $Y_{i j}=\mu+g_{i}+g_{j}+d_{i j}$ , onde $d_{i j}$ refere-se ao desvio do modelo, incluindo $s_{i j}$. Isto foi feito em função do maior 
interesse nas capacidades gerais de combinação e em função do grande número de parâmetros a serem estimados. Neste caso as estimativas das capacidades específicas de combinação foram obtidas por diferença $\left(s_{i j}=Y_{i j}-\mu-g_{i}-g_{j}\right)$.

Para um melhor entendimento da metodologia utilizada, encontra-se na Tabela 7 a matriz $Y=X \beta+\varepsilon$ em forma genérica.

Paralelamente às estimativas dos $g_{i}$ 's, $g_{j}$ 's e $s_{i j}$ 's foi obtida a análise de variância para cada experimento, de acordo com o esquema mostrado na Tabela 8. As somas de quadrados para capacidade geral de combinação, assim como as estimativas dos parâmetros, foram obtidas com a aplicação do programa SISMUL (Sistema para Estatística Multivariada), desenvolvido e gentilmente cedido pelo Prof. Dr. Cássio Roberto de Melo Godoy, do Departamento de Matemática e Estatística da ESALQ/USP.

As análises individuais foram agrupadas para cada sistema de multiplicação das progênies, conforme esquematizado na Tabela 8.

Outro tipo de parâmetro $\left(k_{i}\right.$ e $\left.k_{j}\right)$ foi estimado para as progênies, em cada experimento, pela diferença entre a média dos cruzamentos de cada progênie e a média geral de todos os cruzamentos, através das expressões $k_{i}=(1 / s) \sum_{j} Y_{v}-(1 / n s) \sum_{i j} Y_{v} \mathrm{e}$ $k_{j}=(1 / s) \sum_{i} Y_{i}-(1 / n s) \sum_{j} Y_{i}$, sendo s o número de cruzamentos por progênie (s=3) e n o número de progênies de cada população $(n=10)$.

\subsubsection{Predição de médias de híbridos}

A partir das estimativas dos $\mathrm{g}_{\mathrm{i}} \mathbf{s}, \mathrm{g}_{\mathrm{j}}$ 's, $\mathbf{k}_{\mathrm{i}}$ 's e $\mathrm{k}_{\mathrm{j}}$ 's foram previstas as médias dos hibridos simples (HS), triplos (HT) e duplos (HD) interpopulacionais, separadamente para cada tipo de parâmetro, através das seguintes fórmulas:

$$
\begin{aligned}
& \mathrm{HS}_{\mathrm{ij}}=\mathbf{m}+\mathrm{g}_{\mathrm{i}}+\mathrm{g}_{\mathrm{j}} ; \\
& H T_{i i}, j=m+(1 / 2)\left(g_{i}+g_{i}\right)+g_{j} \text {; } \\
& \mathrm{HT}_{\mathrm{ij} \cdot \mathrm{i}}=\mathrm{m}+(1 / 2)\left(\mathrm{g}_{\mathrm{j}}+\mathrm{g}_{\mathrm{j}}{ }^{\prime}\right)+\mathrm{g}_{\mathrm{i}} ; \\
& H D_{i i^{\prime} ; j^{\prime}}=m+(1 / 2)\left(g_{i}+g_{i}+g_{j}+g_{j}\right)
\end{aligned}
$$


Tabela 7 - Representação genérica da equação matricial $Y=X \beta+\varepsilon$, utilizada para análise das capacidades geral e específica de combinação, segundo o modelo proposto: $Y_{i j}=\mu+g_{i}+g_{j}+d_{i j}$

\begin{tabular}{|c|c|c|c|c|c|c|c|c|c|c|c|c|c|c|}
\hline \multirow{2}{*}{\multicolumn{2}{|c|}{$\mathbf{Y}=$}} & \multicolumn{10}{|c|}{$\mathrm{X}$} & & \multicolumn{2}{|c|}{$\beta+\varepsilon$} \\
\hline & $=\frac{}{\mu}$ & $\mathrm{g}_{1}$ & $\mathrm{~g}_{2}$ & $\mathbf{g}_{3}$ & $\cdots$ & $\mathrm{g}_{\mathrm{i}}$ & $\mathbf{g}_{\mathbf{1}^{\prime}}$ & $\mathbf{g}_{2}$ & $\mathrm{~g}_{3}$ & $\ldots$ & $\mathrm{g}_{j^{\prime}}$ & & & \\
\hline$\left[Y_{11},\right]$ & {$[1$} & 1 & 0 & 0 & $\ldots$ & 0 & 1 & 0 & 0 & $\ldots$ & 0 & & {$[\mu$} & \\
\hline$Y_{12}$ & 1 & 1 & 0 & 0 & $\ldots$ & 0 & 0 & 1 & 0 & $\ldots$ & 0 & & $g_{1}$ & \\
\hline$Y_{13}$ & 1 & 1 & 0 & 0 & $\ldots$ & 0 & 0 & 0 & 1 & $\ldots$ & 0 & & $\mathrm{~g}_{2}$ & \\
\hline$Y_{22}$ & 1 & 0 & 1 & 0 & $\ldots$ & 0 & 0 & 1 & 0 & $\ldots$ & 0 & & $g_{3}$ & \\
\hline • & . & . & . & . & $\cdots$ & . & . & . & . & $\ldots$ & . & & . & \\
\hline & . & . & $\cdot$ & - & $\cdots$ & . & $\cdot$ & . & . & $\cdots$ & . & & & \\
\hline . & $=$ & . & . & . & $\cdots$ & . & . & . & . & $\ldots$ & . & . & . & $+\varepsilon$ \\
\hline . & . & $\cdot$ & $\cdot$ & . & $\cdots$ & $\cdot$ & . & . & . & $\cdots$ & . & & $g_{i}$ & \\
\hline - & . & $\cdot$ & $\cdot$ & $\cdot$ & $\cdots$ & $\cdot$ & $\cdot$ & . & $\cdot$ & $\cdots$ & $\cdot$ & & $\mathrm{g}_{1^{\prime}}$ & \\
\hline - & . & $\cdot$ & $\cdot$ & $\cdot$ & $\cdots$ & $\cdot$ & . & . & . & $\cdots$ & $\cdot$ & & $\mathrm{g}_{2}$ & \\
\hline${ }^{\circ}$ & . & . & . & $\cdot$ & $\ldots$ & . & . & . & . & $\ldots$ & $\cdot$ & & $g_{3}$, & \\
\hline$Y_{i j}$ & 1 & 0 & 0 & 0 & $\ldots$ & 1 & 0 & 0 & 0 & $\ldots$ & 1 & & & \\
\hline$Y_{i 1}$ & 1 & 0 & 0 & 0 & $\ldots$ & 1 & 1 & 0 & 0 & $\ldots$ & 0 & & & \\
\hline$Y_{\mathrm{i} 2}$ & 1 & 0 & 0 & 0 & $\ldots$ & 1 & 0 & 1 & 0 & $\cdots$ & 0 & & $g_{j}$ & \\
\hline
\end{tabular}


Tabela 8. Esquema da análise individual e agrupada de variância para capacidade de combinação do cruzamento em dialélico parcial circulante.

\begin{tabular}{|c|c|c|c|c|c|c|}
\hline \multirow[b]{2}{*}{ F. V. ${ }^{A}$} & \multicolumn{4}{|c|}{ Graus de Liberdade } & \multirow[b]{2}{*}{$\mathrm{QM}$} & \multirow[b]{2}{*}{ F } \\
\hline & Geral $^{8}$ & Individual & Agnupada auto ${ }^{c^{-}}$ & Agrupada $\mathrm{CF}^{\mathrm{C}}$ & & \\
\hline Híbridos & (ns-1) & 29 & 260 & 289 & $\mathrm{Q}_{1}$ & $\overline{Q_{1} / Q_{6}}$ \\
\hline CGC/Grupos & $(2 n-2)$ & 18 & 162 & 180 & $\mathrm{Q}_{2}$ & $\mathrm{Q}_{2} / \mathrm{Q}_{6}$ \\
\hline $\mathrm{CGC}_{1}$ & n-1 & 9 & 81 & 90 & $\mathrm{Q}_{3}$ & $\mathrm{Q}_{3} / \mathrm{Q}_{6}$ \\
\hline $\mathrm{CGC}_{2}$ & n-1 & 9 & 81 & 90 & $\mathrm{Q}_{4}$ & $\mathrm{Q}_{4} / \mathrm{Q}_{6}$ \\
\hline CEC & $n(s-2)+1$ & 11 & 98 & 109 & $Q_{5}$ & $\mathrm{Q}_{5} / \mathrm{Q}_{6}$ \\
\hline Erro & $\mathrm{ns}(\mathrm{r}-1)$ & 60 & 541 & 601 & $Q_{6}$ & \\
\hline
\end{tabular}

A - CGC/Grupos = capacidade de combinaçäo dentro de grupos; CGC $_{1}=$ capacidade geral de combinação do grupo 1 de progênies (população ESALQ-PB1); CGC $_{2}=$ capacidade geral de combinação do grupo 2 de progênies (população SUWAN); CEC = capacidade específica de combinação; ${ }^{\mathrm{B}}-\mathrm{n}=$ múmero de progênies de cada população por experimento $(\mathrm{n}=10)$; $\mathrm{s}=$ rúmero de cruzamentos por progênie $(\mathrm{s}=3) ; \mathrm{r}=$ número de repetiç̄es $(\mathrm{r}=3){ }^{\mathrm{C}}$ - nove experimentos para autofecundaçăo, 10 experimentos para cruzamentos fraternais, um hibrido perdido em cada sistema, 532 e 591 GL para PE e PG respectivamemte nos sistema de autofecundafäo e cruzamentos fratemais.

$$
\begin{aligned}
& \mathrm{HS}_{\mathrm{ij}}=\mathbf{m}+\mathbf{k}_{\mathbf{i}}+\mathbf{k}_{\mathbf{j}} ; \\
& H T_{i i}, j=m+(1 / 2)\left(k_{i}+k_{i}\right)+k_{j} ; \\
& H T{ }^{\prime}, i=m+(1 / 2)\left(k_{j}+k_{j}\right)+k_{i} ; \\
& \mathrm{HD}_{\mathrm{i} \mathbf{i}^{\prime}, \mathrm{j}^{\prime}}=\mathrm{m}+(1 / 2)\left(\mathrm{k}_{\mathrm{i}}+\mathrm{k}_{\mathrm{i}},+\mathrm{k}_{\mathrm{j}}+\mathrm{k}_{\mathrm{j}^{\prime}}\right)
\end{aligned}
$$

Exceto para HS as demais fórmulas foram adaptadas do método $B$ de JENKINS (1934), considerado como padrão para predição de híbridos.

A validade das predições foi testada através do coeficiente de correlação (r) entre os três tipos de médias, ou seja, médias observadas (híbridos simples) ou estimadas pelo método B de JENKINS (1934) (híbridos triplos e duplos) e médias estimadas pelo processo proposto, com base nos g's e k's. Foi utilizada a seguinte fórmula, apresentada por STEEL \& TORRIE (1960): $\mathrm{r}=\operatorname{COV}_{\mathrm{XY}} / \sigma_{X} \sigma_{Y}$ onde, $\operatorname{COV}_{\mathrm{XY}}=$ 
covariância entre dois tipos quaisquer de médias, $\sigma_{\mathrm{X}}=$ desvio padrão para o primeiro tipo de médias considerado e $\sigma_{\mathrm{Y}}=$ desvio padrão para o outro tipo de média considerada.

Utilizando-se de um programa de predição de híbridos desenvolvido pelo Polo Computacional de Tha Solteira, especialmente para este trabalho, foi feita a predição, com base nos g's e k's, da PG de todos os híbridos intermediários simples, triplos e duplos possíveis com 90 progênies de cada população, nos dois sistemas de multiplicação das progênies. Neste processo foi feito um ajuste dos g's e k's do sistema de cruzamentos fraternais como aquele feito para as médias, comentado no início do item 3.2.5. Os valores foram colocados em uma gráfico de distribuição de frequêencia, pois a sua apresentação completa é praticamente impossível. Com as 90 progênies de cada população foi possível prever um total de 8.100 híbridos simples, 720.900 híbridos triplos e 16.040.025 híbridos duplos para cada parâmetro considerado (g's e k's) nos dois sistemas de multiplicação dos parentais. 


\section{RESULTADOS E DISCUSSÃO}

\subsection{Considerações iniciais}

Praticamente todas as progênies de irmãos germanos foram multiplicadas por autofecundação de cinco plantas no primeiro sistema e por cruzamentos fraternais de cinco plantas no segundo. Isso permitiu a obtenção de um número suficiente de sementes para a realização dos cruzamentos e para manutenção como sementes remanescentes, caso haja interesse na seleção dos parentais mais promissores.

Em termos de tamanho efetivo, a multiplicação por cruzamentos fraternais representou melhor as progênies do que o sistema de autofecundação. De acordo com FALCONER (1987), o tamanho efetivo da progênie multiplicada por cinco autofecundações de $\mathrm{N}=5$ plantas é $\mathrm{Ne}=\mathrm{N}=5$, e da progênie multiplicada por cruzamentos fraternais é $\mathrm{Ne}=2 \mathrm{~N}=10$. $O$ coeficiente de endogamia $(\mathrm{F})$ dos parentais dos híbridos intermediários também é diferente, sendo $1 / 2$ para o sistema de autofencundação e 1/4 para o sistema de cruzamentos fratemais. Esses valores são obtidos através da fórmula $\mathrm{F}=1 /(2 \mathrm{Ne})+[1-1 /(2 \mathrm{Ne})] \mathrm{F}^{\prime}(\mathrm{LI}, 1976)$, onde $\mathrm{Ne}$ é o tamanho efetivo e $\mathrm{F}^{\prime}$ o coeficiente de endogamia da geração anterior. Em ambos os sistemas $F^{\prime}=0$, pois partiuse de progênies de irmãos germanos de primeira geração e realizou-se uma geração a mais para multiplicação. Não há motivo para considerar mais um aumento devido ao tamanho reduzido da população pois não houve uma segunda geração de multiplicação das progênies. $O$ que houve foi uma amostragem dos gametas dessas progênies multiplicadas, para a realização dos cruzamentos. Nesse ponto pode ter havido uma influência do tamanho efetivo provocando uma possível deriva genética, mas não um aumento em F. 
O número de cruzamentos realizados em cada par de progênie variou de um a 11, com média de 6,39 e 6,83, respectivamente para autofecundação e cruzamentos fraternais, e a correlação desses números entre os dois sistemas foi baixíssima $(0,06)$. 0 número pequeno de cruzamentos pode não representar corretamente um híbrido intermediário. Nesse ponto entra novamente o problema do tamanho efetivo reduzido, afetando a representatividade dos híbridos intermediários que, além de pequena em alguns casos, varia de maneira diferente para cada híbrido quando se muda o sistema de multiplicação das progênies parentais.

Quanto aos híbridos perdidos na primeira cadeia de cruzamentos, nos dois sistemas de multiplicação das progênies, não houve grandes problemas, pois bastou eliminar a linha correspondente aos mesmos no sistema matricial para estimativa e análise de variância dos g's. Isso foi possível pelo fato de se ter $s=3$ no dialélico parcial circulante e portanto as progênies participantes desses cruzamentos ainda foram avaliadas em dois outros cruzamentos. Neste caso as estimativas dos g's envolvidos em tais cruzamentos possuem um erro experimental diferente dos demais, pois apareceram apenas duas vezes no sistema, enquanto que os outros apareceram três.

\subsection{Análise de variância preliminar}

Nas Tabelas 9 a 13 encontram-se as médias observadas, das cinco variáveis consideradas, dos híbridos avaliados no sistema de autofecundação de multiplicação dos parentais. Os mesmos tipos de dados, para o sistema de cruzamentos fraternais, encontram-se nas Tabelas 14 a 18 . Com relação às médias dos híbridos e, principalmente às médias da testemunha, nota-se que os dois sistemas de multiplicação foram equivalentes para as variáveis FF, AP e AE. No entanto, para PE e PG, as médias do sistema cruzamentos fraternais foi consistentemente inferior ao sistema autofecundação. Embora o tipo de solo, em que os experimentos representativos dos dois sistemas foram instalados, fosse o mesmo, as áreas foram diferentes em sua fertilidade, como mostrado na Tabela 2. Neste caso as variáveis de produção foram mais afetadas. 
A comparação das médias dos híbridos com as médias da testemunha permite verificar que a maioria dos híbridos apresentou FF equivalente ou superior. Pelas Tabelas 10, 11, 15 e 16 verifica-se que a maioria dos híbridos mostraram média de AP e AE superior à testemunha. Quanto à produtividade, vários híbridos intermediários se equipararam ao híbrido comercial FT 9043 e outros o superaram. Estes resultados podem ser visualizados nas Tabelas 12, 13, 17 e 18 e na Figura 3. No sistema de autofecundação apareceram híbridos intermediários com produtividade superior à testemunha em $13 \%$, $18 \%$ e até $34 \%$. No sistema de cruzamentos fraternais essa superioridade foi ainda mais acentuada com o aparecimento de um maior número de híbridos com superioridade em torno de $30 \%$ em relação à testemunha.

A testemunha FT 9043 é um híbrido triplo, semi-precoce, de porte baixo e grãos semi-duros de cor laranja escuro. Portanto os resultados referentes a FF, AP e AE estão dentro do esperado, considerando que os híbridos intermediários originaram-se de populações variáveis geneticamente. Embora essas populações sejam caracterizadas como de porte baixo, elas não estão na mesma faixa de altura da testemunha. Quanto ao FF, ambas as populações não são caracterizadas como precoce ou semi-precoce. Em relação à produtividade, os resultados são promissores, mesmo considerando que a semeadura dos experimentos tenha sido feita tardiamente (janeiro), o que deve ter afetado um pouco a média da testemunha.

Resultados semelhantes a estes foram obtidos por DANTAS (1992), que estudou duas outras populações e os mesmos tipos de progênies. Em seu trabalho foram identificados híbridos intermediários com $12,5 \%, 25 \%, 41 \%$ e até $48 \%$ de superioridade em relação à testemunha. DANTAS (1988) estudou as mesmas populações envolvidas no presente trabalho, porém utilizando linhagens $(F=1)$. 0 melhor híbrido superou a testemunha em 9,7\%. Resultados parecidos foram encontrados por GONÇALVES (1987) que utilizou linhagens de duas outras populações. Essas comparações mostram a potencialidade dos hibridos intermediários e as diferenças de um trabalho para outro deve-se ao material básico utilizado ou às diferentes testemunhas utilizadas em cada caso.

Pela Figura 3 nota-se que a amplitude de variação das médias no sistema de cruzamentos fraternais foi ligeiramente superior. É preciso considerar que, nesta 
figura, as médias referentes aos cruzamentos fratemais estão ajustadas pelo índice multiplicativo descrito no item 3.2.3. Este índice pode não ter sido tão preciso no ajuste das médias, provocando essa diferença de amplitude.

Após a análise individual dos experimentos notou-se que os quadrados médios do resíduo, para todas as variáveis, eram homogêneos, exceto para o experimento 10 do sistema de autofecundação. Os coeficientes de variação experimental para as variáveis PE e PG foram 24,06\% e 24,95\%, totalmente discrepantes dos demais e fora dos padrões normais de experimentação com milho. Como não se conseguiu detectar nenhum problema que pudesse ser corrigido, optou-se pela sua eliminação. Além do problema de precisão, esse experimento apresentava-se muito desbalanceado pois, na cadeia de cruzamentos que ele comportou, não foram conseguidas sementes para quatro híbridos intermediários.

O agrupamento das análises individuais foi feito, para cada sistema de multiplicação das progênies, e os resultados estão colocados na Tabelas 20 e 21 . Os coeficientes de variação experimental indicam uma boa precisão . Os maiores valores encontrados foram para PE e PG no sistema de cruzamentos fratemais $(14,19 \%$ e $14,93 \%$ respectivamente), estando dentro do limite de variação normal em experimentação agronômica com milho, embora um pouco superiores aos valores obtidos por DANTAS (1992) e SAMPAIO (1989).

Uma primeira indicação de que existe variação genética entre híbridos foi a significância do teste $\mathrm{F}$, ao nível de $1 \%$ de probabilidade, na respectiva fonte de variação, para todas as variáveis nos dois sistemas em estudo. $\mathrm{O}$ teste $\mathrm{F}$ do contraste HíBRIDO vs. TESTEMUNHA mostrou-se significativo apenas para AP e AE nos dois sistemas e FF no sistema de cruzamentos fraternais. $\mathbf{O}$ nível de significância desta fonte de variação não fornece muita informação, pois não serve para comparar cada híbrido intermediário com a testemunha. Para esse tipo de comparação torna-se mais informativa a observação das médias de cada híbrido intermediário em comparação com a testemunha, em cada experimento. Esse tipo de discussão foi feito no início deste item.

$\mathrm{O}$ desdobramento dos quadrados médios de híbridos segundo as fontes "entre diagonais" e "dentro de diagonais" (diagonal 1, diagonal 2 e diagonal 3 da Tabelas 
20 e 21) foi realizado visando evitar uma possível tendenciosidade na estimativa da variância de híbridos, ao se considerar todos os híbridos intermediários de uma cadeia como uma amostra. Uma cadeia completa torna-se uma amostra não totalmente aleatória, pois o mesmo progenitor participa de três híbridos na mesma amostra. Ao se considerar cada diagonal como uma amostra, a aleatoriedade completa é restabelecida. Neste caso cada diagonal forneceu uma estimativa da variância de híbridos. Além disso, o quadrado médio dentro de diagonais foi utilizado para o cálculo das variâncias aditiva e dominante interpopulacionais, como será discutido em item posterior.

A alta significância dos quadrados médios dentro de diagonais, mostrada para todas as variáveis, nos dois sistemas, comporta o mesmo tipo de discussão apresentado para a variação entre híbridos. Na-verdade, cada diagonal é uma amostra dos híbridos potenciais entre as duas populações, apenas com um tamanho menor que a cadeia completa, embora todas as 10 progênies de cada população participem de cada diagonal.

Com relação ao quadrado médio entre diagonais, houve significância ao nível de $1 \%$ de probabilidade para AP e AE no sistema de autofecundação e PE no sistema de cruzamentos fraternais. Para FF, AE e PG, no sistema de cruzamentos fratemais, houve significância ao nível de $5 \%$ de probabilidade. As variáveis FF, PE e PG no sistema de autofecundação e AP no sistema de cruzamentos fratemais não mostraram significância. A significância entre diagonais demonstra que a média dos efeitos da capacidade específica de combinação difere de uma diagonal para outra. Isso se justifica pelo fato das progênies de cada população formarem diferentes combinações híbridas em cada diagonal, portanto com diferenças na capacidade específica de combinação. Devido a isso a melhor estimativa da variância de híbridos é a média das variâncias entre diagonais, ponderada pelos graus de liberdade. 


\subsection{Estimativas dos parâmetros genéticos}

\subsubsection{Com base na análise de variância preliminar}

Na Tabela 22 encontram-se as estimativas para variância entre hibridos $\left(\hat{\sigma}_{h}^{2}\right.$ e $\left.\hat{\sigma}_{h^{*}}^{2}\right)$, variância fenotípica ao nível de médias $\left(\hat{\sigma}_{F}^{2}\right.$ e $\left.\hat{\sigma}_{F^{*}}^{2}\right)$, herdabilidade no sentido amplo ao nível de médias de híbridos $\left(\hat{h}_{H}^{2}\right.$ e $\left.\hat{h}_{H^{*}}^{2}\right)$, coeficiente de variação genética $\left(\mathrm{CV}_{\mathrm{g}} \mathrm{e}\right.$ $\mathrm{CV}_{\mathrm{g}^{*}}$ ), e índice de variação $(\theta$ e $\theta *$ ), para as cinco variáveis, respectivamente para o sistema de autofecundação e de cruzamentos fraternais. Cada estimativa possui duas versões, sendo a primeira baseada na fonte de variação híbridos e a segunda (marcada com asterisco) baseada na fonte de variação dentro de diagonais. Para as variâncias, no sistema de cruzamentos fraternais, dentro de cada versão tem-se ainda as estimativas obtidas com os dados ajustados pelo índice multiplicativo. As duas versões foram semelhantes entre si para todas as variáveis, nos dois sistemas, indicando que a falta de completa aleatoriedade não causa tendenciosidade expressiva nas estimativas. Portanto é desnecessário o desdobramento do quadrado médio de híbridos, se o objetivo for apenas as estimativas acima citadas, não se justificando a preocupação colocada e discutida no item anterior.

Uma primeira comparação a ser feita é aquela entre os parâmetros dos dois sistemas de multiplicação das progênies. Para a variável FF a estimativa de $\sigma_{h}^{2}=$ 1,98 (dias) $^{2}$, no sistema de cruzamentos fratemais, foi 3,9 vezes maior que a estimativa

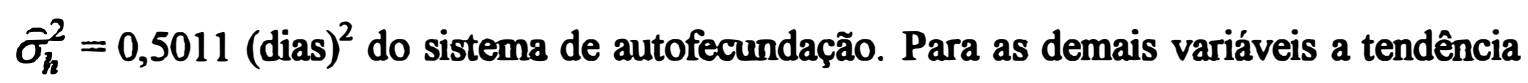
de superioridade das estimativas foi invertida. As variâncias, expressas em (cm/planta) ${ }^{2}$ para AP e AE e em (g/planta) $)^{2}$ para PE e PG, foram respectivamente de 68,83, 64,64, 99,82 e 76,34 no sistema de autofecundação, e 62,77, 50,43, 89,16 e 69,06 no sistema de cruzamentos fraternais. $O$ ajuste do sistema de cruzamentos fratemais pelo índice multiplicativo, multiplicou as variâncias pelo quadrado do índice considerado. Para as variáveis FF, AP e AE as modificações não foram significativas. Porém, para PE e PG as 
tendências foram invertidas, considerando a comparação com os resultados não ajustados. Para efeito de discussão neste item serão considerados principalmente os resultados não ajustados pelo índice multiplicativo.

De acordo com a teoria genético-estatística é esperado que a variância entre híbridos, seja maior no cruzamento entre parentais com maior grau de endogamia. Isto se deve ao fato de que os indivíduos dentro de tais parentais possuem uma maior covariância (DANTAS, 1992). A variância de híbridos é composta pelas variâncias aditiva e dominante interpopulacionais. Uma maior ou menor participação destes componentes no referido parâmetro depende do'valor do coeficiente de endogamia dos parentais. Um maior valor de $\mathrm{F}$ provoca uma maior participação das variâncias aditiva $\mathrm{e}$ dominante interpopulacionais na variância de hibridos. No sistema de autofecundação (F $=1 / 2$ ) a variância de híbridos contém $3 / 4$ da variância aditiva e 9/16 da variância dominante, contra 5/8 e 25/64, respectivamente, no sistema de cruzamentos fraternais (F $=1 / 4)$. Para a variável PG as estimativas obtidas no presente trabalho, em $(\mathrm{g} / \mathrm{pl})^{2}$, foram de 76,34 e 69,06, respectivamente para os sistemas de autofecundação e cruzamentos fraternais. Estas estimativas pouco diferem daquela obtida por DANTAS (1989) para as mesmas populações $(94,50)$, porém com a utilização de linhagens $(F=1)$. GONÇALVES (1987), também utilizando linhagens, encontrou um valor de 84,75. DANTAS (1992), utilizando progênies de irmãos germanos multiplicadas por cruzamentos fraternais, em duas outras populações, encontrou valores de 157,75, 103,50, 120,00, 83,00 e 2,278, respectivamente para PE, PG, AP, AE e FF.

A baixa magnitude da variância de híbridos do sistema de autofecundação em relação ao sistema de cruzamentos fratemais, para a variável FF não é esperado, a princípio, do ponto de vista teórico. Como foi colocado acima, o maior coeficiente $\mathrm{F}$ dos progenitores resulta em maior variância de híbridos. Revisão feita por HALLAUER \& MIRANDA FLHO (1988) mostra que na maioria dos germoplasmas de milho essa variável não sofre depressão por endogamia, mas sim um aumento no tempo de florescimento quando $\mathrm{F}$ é maior. Devido a isso os parentais endogâmicos são mais tardios que os seus híbridos. Mesmo assim, teoricamente, a variância deveria ser maior com o aumento de F. Apenas interações não alélicas podem causar uma diminuição na 
estimativa da variância quando se aumenta o coeficiente de endogamia. No presente estudo os efeitos de interações não alélicas para a variável em questão foram significativos apenas no sistema de cruzamentos fraternais (CEC na Tabela 27), e mesmo assim a magnitude do quadrado médio da capacidade específica de combinação foi bem inferior ao da capacidade geral de combinação. No entanto esta fonte de variação também contém efeitos de dominância, que não acarretam mudança na variância com o aumento de $\mathrm{F}$. $\mathrm{O}$ problema de deriva genética no momento da multiplicação das progênies parentais e do cruzamento entre progênies pode ser o responsável por este tipo de resultado, como será discutido mais profundamente no item 4.4.

As estimativas de herdabilidade foram diferentes entre os dois sistemas apenas para FF, uma vez que a variância de hibridos do sistema de cruzamentos fratemais foi muito superior. Mesmo a variancia fenotípica sendo superior neste sistema, a herdabilidade foi de $72,43 \%$ contra $48,70 \%$ no sistema de autofecundação. Para as demais variáveis os valores foram parecidos quando se comparou os dois sistemas. A maior diferença ocorreu para AP, obtendo-se $\hat{h}_{H}^{2}=68,62 \%$ no sistema de cruzamentos fraternais contra $\hat{h}_{H}^{2}=61,64 \%$ no sistema de autofecundação. Essa diferença de aproximadamente $7 \%$ se explica pelo menor valor da variância fenotípica no sistema de cruzamentos fraternais. A variável PE mostrou herdabilidade de 52,38\% e 53,65\% para autofecundação e cruzamentos fraternais, enquanto que para PG as estimativas foram de $53,65 \%$ e $56,07 \%$ respectivamente. Em comparação com valores obtidos em outros trabalhos parecidos, deve ser salientado que DANTAS (1988) obteve $\widehat{h}_{H}^{2}=49,40 \%$ para PG quando realizou um dialélico parcial circulante entre linhagens das mesmas populações aqui estudadas. DANTAS (1992) encontrou valores de 52,94\% para PE, 51,54\% para PG, $76,43 \%$ para AP, 77,88\% para AE e 62,78\% para FF. Para a variável PG, os valores obtidos no presente estudo foram superiores ainda a outros obtidos ao nível de média de híbridos de linhagens (GONÇALVES, 1987), ao nível de médias de híbridos entre progênies de meios irmãos (MOTA, 1984; SAMPAIO, 1989) e ao nível de médias de progênies no sentido restrito (HALLAUER \& MIRANDA FILHO, 1988; LORDÊLO, 1982; SOARES FILHO, 1987). 
Os valores de herdabilidade dependem do tamanho da parcela, densidade de plantio e número de repetições (ROBINSON, 1963), como também da unidade em que são baseados (HALLAUER \& MIRANDA FILHO, 1988). Caso todos esses fatores fossem comuns, as estimativas referentes aos híbridos de linhagens seriam superiores às demais pois a variação entre híbridos, nesse caso, é composta por toda a variância aditiva e dominante. No caso de híbridos intermediários $(\mathrm{F}<1)$ a participação desses componentes diminui de acordo com a diminuição de F. Essas considerações tomam as comparações pouco informativas, sendo mais interessante a discussão em torno dos valores em si, dentro de cada caso. No presente estudo esses valores mostram que é perfeitamente possivel um trabalho de seleção com alta eficiência, como aqueles que utilizam testes de progênies de irmãos germanos, uma vez que é comprovada a existência de variabilidade genética entre os híbridos.

Outra maneira de se confirmar a existência de variabilidade genética entre os híbridos é a observação dos coeficientes de variação genética (CVg) e dos índices de variação $(\theta)$. Para FF o valor de $\mathrm{CVg}=1,32 \%$ para o sistema de autofecundação e $\mathrm{CVg}$ $=2,61 \%$ para o sistema de cruzamentos fraternais, foram os menores encontrados. Porém o valor de $\theta$ no sistema de cruzamentos fraternais foi o maior entre as variáveis estudadas. Isto indica possibilidades não muito boas para seleção, de acordo com o critério de VENCOVSKY (1978), que considera valores de $\theta>1$ como indicadores de situação mais favorável à seleção. Para $\mathrm{AP}$ os valores do $\mathrm{CVg}$ aqui encontrados $(3,53 \% \mathrm{e}$ $3,42 \%$ ) foram semelhantes ao valor de 5,38\%, encontrado por DANTAS (1992). A estimativa de $\mathrm{CVg}=8,46 \%$, para $\mathrm{AE}$, obtida por DANTAS (1992) foi superior às estimativas de $\mathrm{CVg}=5,92 \%$ e $5,28 \%$ nos dois sistemas em estudo no presente trabalho. Os valores de $\mathrm{CVg}=7,70 \%$ e $9,14 \%$ para $\mathrm{PE}$ e $\mathrm{CVg}=8,15 \%$ e $9,73 \%$ para $\mathrm{PG}$, respectivamente no sistema de autofecundação e cruzamentos fraternais, foram superiores aos valores encontrados DANTAS (1988) e DANTAS (1992). Quando se considera o índice de variação os valores do presente estudo foram menores que os de DANTAS (1992) para as variáveis AP e AE e equivalentes para PE e PG. Os valores do índice de variação também precisam ser comparados com cautela pois uma diferença no 
erro experimental pode comprometer as comparações. Na presente discussão vale ressaltar que o erro experimental deste trabalho foi maior que os demais citados.

\subsubsection{Com base na análise das diagonais do dialélico}

Os quadrados médios resultantes da análise estatística (Tabela 5) dos dois grupos de diagonais (Tabela 4), segundo o modelo fatorial proposto por MIRANDA FILHO \& VENCOVSKY (1995), e da covariância entre as diagonais dentro de cada grupo, estão apresentados na Tabelas 23 e 24. Esta análise foi feita individualmente por experimento para os dois sistemas de multiplicação dos parentais. Com base nestes quadrados médios foi possível a obtenção das-estimativas dos seguintes parâmetros, para cada sistema de multiplicação das progênies, apenas para variável PG:

$\hat{\sigma}_{g I}^{2} \quad$ - variância da capacidade geral de combinação da população SUWAN;

$\hat{\sigma}_{g I}^{2} \quad$ - variância da capacidade geral de combinação da população ESALQ-PB1;

$\tilde{\sigma}_{s}^{2} \quad$ - variância da capacidade específica de combinação;

$\widehat{\sigma}_{A(12)}^{2}$ - variância aditiva interpopulacional;

$\hat{\sigma}_{D(12)}^{2}$ - variância dominante interpopulacional.

A estimativa da variância de híbridos $\left(\widehat{\sigma}_{H}^{2}\right)$ aqui obtida, considerando a média de todos os experimentos, corresponde à $\widehat{\sigma}_{h^{*}}^{2}$ da Tabela 22. Os desvios devem-se a diferenças de aproximação quando se trabalhou com as médias.

De uma maneira geral os resultados colocados na Tabela 25 mostram que as estimativas foram baixas para todos os parâmetros considerados. Com relação à $\hat{\sigma}_{A(12)}^{2}$, SOUZA JÚNIOR (1983), trabalhando com meios innãos interpopulacionais das mesmas populações, encontrou uma valor de 260,4979 (g/planta) ${ }^{2}$. Essa estimativa corresponde a 6,38 vezes a estimativa encontrada no presente trabalho, para o sistema de autofecundação $\left(\hat{\sigma}_{A(12)}^{2}=40,85\right)$, e 3,73 vezes a estimativa encontrada para o sistema de 
cruzamentos fraternais $\left(\hat{\sigma}_{A(12)}^{2}=72,27\right)$, sem o ajuste. Mesmo levando em consideração a interação genótipo $\mathrm{x}$ ambiente e genótipo $\mathrm{x}$ anos e uma possível alteração nas freqüências alélicas das populações durante os dez anos de intervalo entre os experimentos, é evidente que o dialélico parcial circulante com $s=3$ não foi eficiente para estimar a variância aditiva interpopulacional. Neste ponto também deve ser considerado o problema de deriva genética, que será discutido no item seguinte.

Em comparação com estimativas referentes a outros grupos de germoplasmas, verifica-se que a variância aditiva interpopulacional aqui obtida é muito baixa. OBILANA et alii (1979) aplicaram os esquemas I e II de COMSTOCK \& ROBINSON (1948) nas populações BS10 e BS11 e encontraram uma variância aditiva interpopulacional de 178,7 (g/planta) ${ }^{2}$, utilizando uma densidade de $38,734 \mathrm{pl} / \mathrm{ha}$, enquanto MIRANDA FILHO \& PATERNIANI (1983) encontraram valor de 158,02 (g/planta) $)^{2}$ para as populações Piramex e Cateto utilizando-se de meios irmãos interpopulacionais numa densidade de $50.000 \mathrm{pl} / \mathrm{ha}$. Valores de 231,84, 414,26 e 231,14 $(\mathrm{g} / \mathrm{pl})^{2}$ também foram encontrados, respectivamente por PATERNIANI \& VENCOVSKY (1978), MIRANDA FILHO (1979) e SOUZA Jr et alii (1980).

Com relação à variância dominante interpopulacional existem poucos dados na literatura para possíveis comparações. As estimativas de 96,00 (g/planta) ${ }^{2}$ para o sistema de autofecundação, e 69,30 (g/planta) ${ }^{2}$ para o sistema de cruzamentos fraternais, sem ajuste, foram superiores em relação aos valores estimados por OBILANA et alii (1979), quando expressados na mesma unidade. No entanto STUBER (1965) encontrou pouca diferença entre as variâncias aditiva e dominante interpopulacionais envolvendo as populações Jarvis e Indiana Chief.

A inconsistência das estimativas entre os sistemas de multiplicação das progênies, deve ser creditada aos problemas de interação SISTEMAS $x$ EXPERIMENTOS e SISTEMAS $x$ HÍBRIDOS/E, amplamente discutidos no item 4.4., $\mathrm{e}$ não à ineficiência do processo utilizado que é perfeitamente viável do ponto de vista teórico. A variância dominante interpopulacional foi 2,35 vezes a variância aditiva no sistema de autofecundação e 0,96 vezes no sistema de cruzamentos fraternais. No sistema 
de autofecundação o intervalo de confiança para a variância aditiva interpopulacional foi $22,81 \leq \widehat{\sigma}_{A(12)}^{2} \leq 58,89$ e para a variância dominante foi $66,45 \leq \widehat{\sigma}_{D(12)}^{2} \leq 125,55$. Portanto, claramente a variância dominante foi superior. No sistema de cruzamentos fraternais isso não ocorreu e os intervalos de confiança foram praticamente coincidentes, ou seja, $55,24 \leq \hat{\sigma}_{A(12)}^{2} \leq 89,3$ e $46,03 \leq \hat{\sigma}_{D(12)}^{2} \leq 92,57$. Isso mostra que a decomposição da variância da variância de híbridos foi diferente quando se mudou o sistema de multiplicação das progênies, devido aos problemas de interação acima citados.

Considerações semelhantes podem ser feitas para as estimativas $\hat{\sigma}_{g l}^{2}, \hat{\sigma}_{g I l}^{2}$, e $\hat{\sigma}_{s}^{2}$. Houve também uma tendência das estimativas dos parâmetros mais influenciados por efeitos não aditivos $\left(\hat{\sigma}_{s}^{2}\right.$ e $\left.\hat{\sigma}_{D(12)}^{2}\right)$, serem menores no sistema de cruzamentos fratemais sem ajuste. $O$ aumento de $s$ no dialélico parcial circulante deve estar diretamente relacionado com o aumento na precisão das estimativas dos parâmetros interpopulacionais.

\subsection{Comparação dos sistemas de multiplicação das progênies}

Como um dos objetivos deste trabalho foi comparar os sistemas de multiplicação dos parentais dos hibridos intermediários, optou-se por um sistema multiplicativo de ajuste das médias das parcelas dos experimentos do sistema de cruzamentos fratemais, como já foi colocado e justificado no item 3.2.5. O fator de ajuste foi obtido pela divisão da média da testemunha de cada experimento do sistema de autofecundação pela média da testemunha do experimento correspondente no sistema de cruzamentos fratemais. Os valores desses índices, para cada par de experimentos, estão colocados na Tabela 19. Como se observa nesta tabela, houve diferença de até $29 \%$ (experimento 05) entre as médias de PE e PG da testemunha, quando se mudou da área experimental do sistema de autofecundação para a área experimental do sistema de cruzamentos fraternais. 
Na Tabela 26 encontram-se os quadrados médios da análise de variância que considera os 18 experimentos em conjunto. A discussão será centrada apenas nas fontes de variação sistemas, interação sistemas com experimentos ( $\mathrm{S} \times \mathrm{E})$ e interação sistemas com híbridos dentro de experimentos ( $\mathrm{S} \times \mathrm{H} / \mathrm{E})$, pois as demais já foram consideradas no item 4.2 .

A diferença entre sistemas foi significativa apenas para FF, enquanto que as interações de sistemas com experimentos e sistemas com híbridos dentro de experimentos mostraram-se altamente significativas para todas as variáveis. Tais resultados indicam que na média um sistema não difere do outro (exceto para FF), mas os diferentes sistemas não se comportam da mesma maneira à medida que se considera cada experimento como uma amostra. $\mathrm{Na}$ realidade cada experimento representa uma amostra de apenas dez progênies de cada população mas isso não pode ser considerado como uma possivel explicação para esses tipos de interação, uma vez que as dez progênies são as mesmas nos dois sistemas de multiplicação. $\mathrm{O}$ que pode ter ocorrido é uma deriva genética a partir do ponto onde cada progênie foi amostrada para se fazer os dois tipos de multiplicação, passando pela multiplicação propriamente dita e pela amostragem dos gametas masculinos e femininos no momento do cruzamento entre as progênies.

A heterose de um cruzamento, que contribui decisivamente para o valor final do híbrido, é dependente da diferença da freqüência alélica entre os parentais. Portanto, desde que a freqüência alélica dos parentais seja mantida constante, não importando a maneira como eles sejam multiplicados, espera-se que o valor do cruzamento seja o mesmo. Quando se trata de parentais variáveis geneticamente, como progênies de meios irmãos e irmãos germanos, a diferença no tipo de cruzamento dentro de cada parental altera apenas a freqüência genotípica dos mesmos, desde que não haja problemas de amostragem que provoquem deriva genética. No presente estudo os parentais foram multiplicados por dois sistemas diferentes de cruzamento, sendo o primeiro com autofecundação de cerca de cinco plantas e o segundo com cerca de cinco cruzamentos dentro de cada parental (cruzamentos fraternais). Nesta tarefa de realizar a multiplicação dos parentais surgiu a primeira possibilidade de ocorrência da deriva genética, alterando a freqüência alélica. Isto pode ocorrer em dois sentidos opostos 
quando se considera o mesmo parental multiplicado por autofecundação e por cruzamentos fratemais. Em termos de representatividade de uma população ou subpopulação, sabe-se que cada autofecundação contribui com uma unidade para o tamanho efetivo da população ou subpopulação da geração seguinte, enquanto que um cruzamento (irmãos germanos) contribui com duas unidades. Como foram feitas cinco autofecundações em cada progênie no primeiro sistema e cinco cruzamentos no segundo, o tamanho efetivo foi de 5 e 10 , respectivamente. Certamente o problema de deriva genética foi muito mais sério no sistema de autofecundação. Neste sistema ainda ocorreu eliminação de indivíduos que por ventura se tomaram homozigotos para determinados alelos deletérios e/ou letais, pois tais indivíduos não conseguiram contribuir com gametas para o cruzamento que se seguiu. No sistema de cruzamentos fraternais esses alelos ficaram, com maior freqüência, "escondidos" nos heterozigotos e participaram dos híbridos. A maior freqüência desses alelos nos progenitores do sistema de cruzamentos fraternais deve ter contribuído para uma maior freqüência de locos homozigotos para alelos deletérios e/ou letais nos respectivos híbridos. Também neste sistema os híbridos carregam um maior número de locos heterozigotos portadores de alelos deletérios e/ou letais. Em caso de interação alélica codominante em alguns desses locos a contribuição dos mesmos para a média do híbrido deve ter sido negativa.

Neste ponto não se está considerando o problema de variação no coeficiente de endogamia de cada parental devido às diferenças no tamanho efetivo de cada um, pelo fato dos cruzamentos terem sido controlados, ocorrendo só autofecundações no primeiro sistema e só cruzamentos entre irmãos completos no segundo sistema. De acordo com HALLAUER \& MIRANDA FILHO (1988) os coeficientes de endogamia na segunda geração de autofecundação e de acasalamentos entre irmãos germanos, são $1 / 2$ e $1 / 4$, respectivamente. Como não foi realizada mais nenhuma multiplicação das progênies parentais, não há porque considerar um aumento no coeficiente $F$, devido ao tamanho efetivo reduzido. $O$ que se realizou em seguida foi uma amostragem dos gametas de cada parental para a realização dos cruzamentos e se o tamanho efetivo foi pequeno e variável, ele afetou única e exclusivamente a freqüência alélica no ato do cruzamento. 
Da teoria de amostragem de populações ou subpopulações (LI, 1976; FALCONER, 1987), pode ser deduzido que a probabilidade de perda de um alelo dominante com freqüência $p$ é $q^{2 n}$, sendo $q$ a freqüência do alelo recessivo e $n$ o tamanho da amostra. Portanto essa probabilidade é pequena a não ser que a freqüência $p$ do alelo seja muito baixa. Sendo $\mathrm{p}=0,5$ e uma amostra de quatro indivíduos, a probabilidade de perda é $0,39 \%$. Com a mesma amostra e $p=0,2$, essa probabilidade sobe para $16,77 \%$. No caso de $\mathrm{p}=0,1$ a probabilidade sobe para $43,05 \%$. Estudo nesse sentido foi realizado por MORI (1993) que trabalhou com marcadores isoenzimáticos em uma população de Eucaliptus grandis submetida a diferentes intensidades de seleção. Foi verificado que os alelos menos freqüentes são facilmente perdidos quando o tamanho efetivo é reduzido. Em um pomar de sementes com 35 matrizes, os oito locos estudados possuíam 26 alelos. Na subpopulação formada por 14 matrizes selecionadas houve perda de sete alelos, e na subpopulação formada por seis matrizes selecionadas houve perda de dez alelos. Embora tenha havido seleção, a probabilidade de deriva genética é muito maior pois os locos estudados são neutros. Este exemplo, embora não seja com milho, ilustra bem o que pode acontecer quando o tamanho efetivo é drasticamente reduzido.

Segundo LI (1976) a frequêencia do alelo a na descendência de uma população com $\mathrm{N}$ indivíduos diplóides, varia ao acaso de acordo com a expansão do binômio $(p+q)^{2 N}$, onde $p$ é a freqüência do alelo $\mathbf{A}$ e q a freqüência do alelo a. $O$ s $2 \mathrm{~N}+1$ possíveis valores de $q$ na população descendente são: $0,1 / 2 \mathrm{~N}, 2 / 2 \mathrm{~N}, \ldots, \mathrm{j} / 2 \mathrm{~N}, \ldots,(2 \mathrm{~N}-$ 2)/2N, (2N-1)/2N e 1. Portanto, de uma geração para outra a oscilação não é contínua, mas da "saltos" de $1 / 2 \mathrm{~N}$, que é a chamada taxa de fixação, onde $\mathrm{N}$ é o tamanho efetivo da população. Também, de acordo com LI (1976), a maior probabilidade de mudança é de $q$ para $q+1 / 2 \mathrm{~N}$ ou para $\mathrm{q}-1 / 2 \mathrm{~N}$. Como consequiência disso as pequenas populações isoladas, e com freqüência alélica inicial idêntica, poderão divergir cada vez mais com o passar do tempo. Essa variação na freqüência alélica de uma geração para outra é apreciável e pode levar até à fixação ao acaso de locos onde um dos alelos possui freqüência muito baixa.

Neste trabalho considera-se que a deriva genética ocorreu com certa intensidade, sendo a principal responsável pelas interações significativas que apareceram. 
Mesmo que se conseguisse manter o tamanho efetivo constante, o problema poderia ter ocorrido da mesma maneira se ele fosse pequeno. Um estudo onde se introduzisse a fonte "diferentes tamanhos efetivos" ou um estudo de amostragem com genes marcadores seria útil para esclarecer esse tipo de colocação.

\subsection{Análise da capacidade de combinação}

\subsubsection{Análise da variância para capacidade de combinação}

O quadrado médio de híbridos, de cada experimento, dentro de cada sistema de multiplicação das progênies, foi desdobrado em quadrado médio da capacidade geral de combinação (CGC/Grupos) e quadrado médio da capacidade específica de combinação (CEC). A fonte de variação CGC/Grupos ainda foi desdobrada em quadrado médio da capacidade geral de combinação das progênies da população SUWAN $\left(\mathrm{CGC}_{1}\right)$ e das progênies da população ESALQ-PB1 $\left(\mathrm{CGC}_{2}\right)$. Este último desdobramento não é ortogonal pelo fato de haver híbridos com parentais comuns. Todas essas fontes de variação foram agrupadas dentro de cada sistema, para cada variável, e os valores dos quadrados médios resultantes estão colocados na Tabela 27. A única fonte de variação com teste $F$ não significativo foi aquela da capacidade específica de combinação da variável $\mathrm{FF}$, no sistema de autofecundação. Neste mesmo sistema, o teste $\mathrm{F}$ para capacidade específica de combinação das variáveis PE e PG foi significativo ao nível de $5 \%$ de probabilidade. As demais fontes de variação foram significativas ao nível de $1 \%$ de probabilidade para todas as variáveis em ambos os sistemas.

Os resultados obtidos indicam que existem diferenças nos valores genéticos das progênies em cruzamentos, sejam elas multiplicadas por autofecundação ou cruzamentos fraternais. Mesmo quando se considerou cada população separadamente $\left(\mathrm{CGC}_{1}\right.$ e $\mathrm{CGC}_{2}$ ) essas diferenças foram detectadas. Pela magnitude dos quadrados médios verifica-se que as duas populações em estudo possuem variação da mesma ordem de magnitude para as variáveis AP, AE, PE e PG. DANTAS (1988) e SOUZA JÚNIOR (1983) detectaram uma menor variabilidade, para PG, na população SUWAN, a qual 
sofreu uma alta intensidade de seleção durante sua obtenção, segundo MÔRO (1981). Variações da mesma ordem foram verificadas por DANTAS (1992) para as populações ESALQ-PB4 e ESALQ-PB5.

As estimativas obtidas para a variância genética de híbridos, herdabilidade e coeficiente de variação genética, aliadas às análises para capacidade geral de combinação, mostraram que as populações SUWAN e ESALQ-PB1 possuem alta potencialidade para desenvolvimento de híbridos intermediários e/ou de linhagens. Isto fica melhor fundamentado quando se considera os resultados de TOLEDO \& MIRANDA FILHO (1986) que constataram uma baixa depressão por endogamia para ambas as populações.

A significância para CEC (efeitos não aditivos), praticamente em todas as variáveis nos dois sistemas, indicou que certos cruzamentos tem desvios significativos daquilo que se espera dos mesmos com base na CGC, contrariando dados obtidos por DANTAS (1988) para as mesmas populações, porém utilizando linhagens. DANTAS (1992) também encontrou significância para CEC. Isto interferiria de maneira desastrosa no processo de predição com base nos efeitos aditivos (g's), que será considerado adiante, não fosse pela magnitude dos quadrados médios da CEC. De fato, tanto no presente trabalho como no trabalho de DANTAS (1992), os quadrados médios da CGC foram de magnitudes sempre maiores que aqueles da CEC. Os valores que mais se aproximaram foram de $\mathrm{AE}$ no sistema de autofecundação, mas mesmo assim o quadrado médio da CGC foi $39 \%$ superior àquele da CEC. Para PG, que é a variável que mais interessa no processo de predição, o quadrado médio da CGC foi $65 \%$ e $93 \%$ superior ao quadrado médio da $\mathrm{CEC}$, respectivamente para os sistemas de autofecundação e cruzamentos fraternais. Neste último sistema a superioridade ainda é maior (104\%) quando se considera o ajuste dos dados pelo índice multiplicativo. Portanto, o processo de predição, que se discutirá posteriormente, não se torna inválido, por este motivo, e considera-se que os efeitos não aditivos são menos importantes nas populações em estudo.

A maior importância dos efeitos não aditivos em relação aos aditivos raramente tem sido detectada para PG em milho. Alguns desses exemplos são os 
resultados relatados por MATZINGER et alii (1950), ROJAS \& SPRAGUE (1952) e LIMA (1977). O inverso é rotineiro, com as mais diferentes populações e métodos, como citado por DANTAS (1988). As exceções ocorrem geralmente quando se trabalha com material previamente selecionado com base na CGC. SPRAGUE \& TATUM (1942) afirmaram que, em germoplasma heterogêneo, a variação é principalmente de natureza aditiva. O resultado é uma superioridade da variância da CGC sobre a variância da CEC, como foi confirmado, na prática, por CRUZ et alii (1984).

\subsubsection{Efeitos da capacidade geral de combinação}

SPRAGUE \& TATUM (1942) definiram a capacidade geral de combinação como o comportamento médio de uma linhagem em combinações hibridas. Os cruzamentos que possuem um progenitor comum são correlacionados devido à capacidade geral de combinação desse progenitor. Isso fica evidente no modelo apresentado por KEMPTHORNE \& CURNOW (1961) e apresentado no item 3.2.6 deste trabalho. $\mathrm{O}$ mesmo modelo pode ser estendido para casos onde os progenitores tenham um grau intermediário de endogamia.

No presente estudo, como também nos trabalhos de DANTAS (1988) e DANTAS (1992), a capacidade geral de combinação foi calculada de duas maneiras diferentes. A determinação dos g's foi feita com base no esquema de análise para dados não balanceados. Tais parâmetros (Tabelas 28 a 37) foram obtidos pelo processo dos quadrados mínimos, assumindo-se que $g_{i}$ e $g_{j}$ são variáveis independentes, normalmente distribuidas, com média zero e variâncias $\sigma_{g 1}^{2}$ e $\sigma_{g 2}^{2}$, respectivamente. A determinação dos k's foi feita por meio de contrastes e as estimativas (Tabelas 38 a 47) não são de quadrados mínimos. Os valores dos g's e k's para o sistema de cruzamentos fratemais ajustado pelo índice multiplicativo não são apresentados pois a discussão será concentrada nas correlações, que não são alteradas pelo ajuste dos dados. Havendo interesse em valores de g's e k's ajustados, basta efetuar a multiplicação pelo índice correspondente da Tabela 19. 
Sendo estimados por processos diferentes, os dois tipos de parâmetros (g's e k's) estão associados a erros diferentes. Este fato, conforme salientado por DANTAS (1992), explica, em parte, as discrepâncias entre as estimativas de g e $\mathrm{k}$ para uma mesma progênie. Os resultados aqui obtidos mostram uma boa concordância com aqueles obtidos por DANTAS (1988) e DANTAS (1992). Os coeficientes de correlação entre g's e k's (Tabelas 48 e 49) foram superiores a 0,6 na maioria dos experimentos, para todas as variáveis consideradas nos dois sistemas. Coeficientes de correlação extremamente baixos, embora raros, foram encontrados para determinadas variáveis em alguns experimentos. A população SUWAN mostrou $r^{\prime}=0,16$ para PE e $r=0,25$ para $P$ em um experimento do sistema de autofecundação. Em um outro experimento do mesmo sistema a população ESALQ-PB1 mostrou $r=0,18$ para FF. No sistema de cruzamentos fraternais (Tabela 49) os coeficientes de correlação foram ligeiramente inferiores ao sistema de autofecundação, aparecendo também alguns valores extremamente baixos como $r=0,25$ para AE na população SUWAN, $r=0,05$ para $F F$ e $r=0,22$ para PG, na população ESALQ-PB1.

Como cada experimento representa uma sub-amostra da população, uma variação nas estimativas é esperada Agrupando-se os experimentos do sistema de autofecundação, os valores dos coeficientes de correlação foram: FF: 0,81; AP: 0,85; AE: 0,85; PE: 0,68; e PG: 0,70 na populaçāo SUWAN. Na população ESALQ-PB1 os valores foram: FF: 0,67; AP: 0,79; AE: 0,81; PE: 0,83; e PG: 0,82. Fazendo-se o mesmo agrupamento para o sistema de cruzamentos fratemais, os valores dos coeficientes de correlação foram: FF: 0,80; AP: 0,82; AE: 0,86; PE: 0,77; e PG: 0,78 na população SUWAN. Na população ESALQ-PB1 os valores foram: FF: 0,84; AP: 0,78; AE: 0,70; PE: 0,79; e PG: 0,77.

Do ponto de vista genético os parâmetros g's e k's são diferentes estimadores da capacidade de combinação. Obviamente os erros de estimação associados a cada estimador também devem ser diferentes. Embora as correlações entre g's e k's sejam relativamente altas, do ponto de vista estatístico os g's são melhores estimadores da capacidade geral de combinação. Portanto, baseando-se nos resultados da literatura 
pertinente e nos resultados deste trabalho, recomenda-se que essa metodologia deve ser preferida sempre que os recursos estatísticos e computacionais estejam disponíveis.

Considerando-se a seleção das duas progênies com melhor capacidade geral de combinação de cada experimento, tomando-se como base os g's e posteriormente os $\mathrm{k}$ 's, a coincidência entre os grupos é relativamente baixa. Para a variável PG, no sistema de autofecundação, essa coincidência foi de $50 \%$ para a população SUWAN e 44\% para a população ESALQ-PB1. No sistema de cruzamentos fratemais a coincidência foi de $61 \%$ para ambas as populações. Para as demais variáveis os valores de coincidência foram ainda menores.

A baixa coincidência entre os grupos selecionados com base nos diferentes estimadores da capacidade de combinação, ocorre pelo fato da seleção ser truncada. Assim, progenitores com a mesma potencialidade são preteridos quando se utilizam os g's e selecionados quando se utilizam os k's ou vice-versa. Mesmo assim, com base nos coeficientes de correlação observados, pode-se dizer que o comportamento dos dois grupos de progênies será muito parecido nos híbridos.

Outro tipo de comparação proposto neste trabalho foi aquele entre os sistemas de multiplicação dos progenitores. Verificou-se que a correlação entre os g's do sistema de autofecundação e do sistema de cruzamentos fraternais foi muito baixa (Tabela 50). Os valores dos coeficientes de correlação, em média para nove experimentos, foram: FF: 0,19; AP: 0,00, AE: 0,13; PE: 0,02 e PG: 0,03. Em relação aos k's, os valores de foram : FF: 0,14; AP: 0,19; AE: 0,09; PE: 0,08 e PG: 0,08. Ao se mudar o sistema de multiplicação das progênies, tanto os g's como os k's foram alterados, como era esperado após a verificação da alta interação de sistemas com experimentos e com híbridos, discutidos no item 4.4.

A análise das estimativas de $g_{i}, g_{j}, k_{i}$ e $k_{j}$ pode ser feita conjuntamente para todos os experimentos de cada sistema, pelo fato do modelo ser aleatório e as progênies representarem amostras das populações consideradas. Desta maneira, os intervalos observados para os valores dos g's, na população ESALQ-PB1, considerando as 90 progênies do sistema de autofecundação, foram de 4,2 dias para FF, 0,32 m/planta para AP, 0,34 m/planta para AE, 0,88 kg/parcela para $P E$ e $0,79 \mathrm{~kg} /$ parcela para $P G$. 
Estes valores representaram, respectivamente, 7,77\%, 13,58\%, 24,92\%, 33,92\% e $36,88 \%$ da média geral dos híbridos entre as populações estudadas. Para essa mesma população, no sistema de cruzamentos fraternais, as amplitudes dos g's foram de 5,1 dias para $\mathrm{FF}, 0,33 \mathrm{~m} /$ planta para $\mathrm{AP}, 0,44 \mathrm{~m} /$ planta para $\mathrm{AE}, 0,83 \mathrm{~kg} /$ parcela para $\mathrm{PE}$ e 0,79 kg/parcela para PG. Tais valores corresponderam à 9,52\%, 14,14\%, 32,7\%, 40,26\% e $46,14 \%$ da média geral dos híbridos entre as populações.

Na população SUWAN as amplitudes dos g's foram de 4,75 dias para FF, $0,28 \mathrm{~m} /$ planta para $\mathrm{AP}, 0,30 \mathrm{~m} /$ planta para $\mathrm{AE}, 1,20 \mathrm{~kg} /$ parcela para $\mathrm{PE} \mathrm{e} \mathrm{0,96} \mathrm{kg/parcela}$ para PG, no sistema de autofecundação, envolvendo 100 progênies. Esses valores representaram, respectivamente, 8,87\%, 12,01\%, 22,28\%, 46,41\% e 44,95\% da média geral dos híbridos entre progênies das duas-populações. No sistema de cruzamentos fratemais as amplitudes foram de 6,53 dias para $\mathrm{FF}, 0,41 \mathrm{~m} /$ planta para $\mathbf{A P}, 0,30$ $\mathrm{m} /$ planta para $\mathrm{AE}, 1,12 \mathrm{~kg} /$ parcela para PE e 0,95 kg/parcela para PG. Tais valores representaram $12,15 \%, 17,64 \%, 22,49 \%, 54,34 \%$ e $55,87 \%$ das médias dos híbridos entre progênies das duas populações.

As amplitudes dos g's para as variáveis relacionadas à produtividade (PE e PG) foram parecidas nos dois sistemas, para ambas as populações. No sistema de cruzamentos fratemais sem ajuste, devido à média ser menor, as amplitudes representaram uma maior porcentagem da mesma. Dentro de um mesmo sistema, a população SUWAN mostrou maiores amplitudes dos g's em relação à média, para as variáveis PE e PG.

\subsubsection{Efeitos da capacidade específica de combinação}

Determinados cruzamentos comportam-se de maneira diferente daquilo que se espera deles com base na capacidade geral de combinação. Essa diferença, para melhor ou para pior, é a capacidade específica de combinação de cada cruzamento, conforme definido por SPRAGUE \& TATUM (1942). Esse parâmetro depende fundamentalmente de efeitos não aditivos dos genes envolvidos no controle da variável em estudo. Portanto, quando se trabalha com dialélicos, a importância da capacidade 
específica em relação à capacidade geral de combinação deve ser quantificada. Como já foi discutido no item 4.5.1., se a importância da capacidade específica for maior do que a capacidade geral, um processo de predição como o proposto no presente estudo ficaria totalmente inviabilizado.

Na Tabela 51 são mostradas os intervalos de variação dos valores da capacidade específica de combinação para cada variável, em unidades e porcentagem da média do respectivo híbrido, considerando-se todos os híbridos avaliados em cada sistema de multiplicação dos parentais e na Figura 2 é apresentada uma distribuição de freqüência dos valores da capacidade específica de combinação para a variável PG. Verifica-se que a maioria dos valores extremos tem uma pequena importância para a média do híbrido. Em algumas variáveis essa importância aumenta, como PE nos dois sistemas (-21,1\% da média) e AP e PG no sistema de cruzamentos fratemais (20,3\% e $20,7 \%$ da média respectivamente). Estes valores também foram maiores que aqueles obtidos por DANTAS (1988) e DANTAS (1992), enquanto os demais foram parecidos. Considerando os maiores valores de $s_{i j}$ para PG, verifica-se uma contribuição de $11,9 \%$ e 15,1\% na média do híbrido, respectivamente nos sistemas de autofecundação e cruzamentos fraternais. No entanto é necessário levar em conta que esses valores são extremos e por isso pouco freqüentes. Outro fato importante é que não pertencem aos melhores híbridos avaliados em cada sistema.

Nas Tabelas 52 e 53 estão colocadas as médias observadas de PG e os componentes dessas médias ( $\mathrm{m}, \mathrm{g}_{\mathrm{i}}, \mathrm{g}_{\mathrm{j}}$ e $\mathrm{s}_{\mathrm{ij}}$ ) dos 20 híbridos mais produtivos avaliados nos sistemas de autofecundação e cruzamentos fraternais, respectivamente. $\mathrm{Na}$ maioria dos casos a contribuição de pelo menos um dos g's foi sempre mais importante que a contribuição de s. No sistema de autofecundação essa tendência foi contrariada apenas em quatro híbridos $\left(\mathrm{H}_{37.39^{\prime}}, \mathrm{H}_{73.74^{\prime}}, \mathrm{H}_{80.80^{\prime}}\right.$ e $\mathrm{H}_{81.83}$ ) e no sistema de cruzamentos fraternais em três híbridos ( $\mathrm{H}_{47.49}, \mathrm{H}_{96.96}, \mathrm{e} \mathrm{H}_{100.91}$ ).

De uma maneira geral, a análise das estimativas da capacidade específica de combinação confirmou a maior importância da capacidade geral de combinação, já evidenciada quando da discussão da análise de variância para a capacidade de combinação (item 4.5.1.). Porém o fato da maioria dos 20 melhores híbridos 
apresentarem valores positivos para a capacidade específica de combinação, tanto para o sistema de autofecundação como de cruzamentos fratemais, leva a crer que os efeitos desse componente podem representar uma importante contribuição para a média dos híbridos. Por isso, e pela significância dos efeitos da capacidade específica de combinação, a seleção de cruzamentos per se também é eficiente, mas não invalida a utilização da capacidade geral de combinação para seleção das progênies e predição de híbridos potenciais (não avaliados).

Uma comparação entre os melhores híbridos observados no sistema de autofecundação (Tabela 52) e os melhores híbridos do sistema de cruzamentos fraternais (Tabela 53) mostra apenas dois híbridos coincidentes. A explicação para esse resultado e as baixas correlações entre as estimativas de $s_{i j}$ dos dois sistemas (Tabela 50), passa necessariamente pelos mesmos problemas de deriva genética, amplamente discutidos no item 4.4..O confundimento do erro experimental com os efeitos da cec também pode explicar tais resultados.

\subsection{Predição de médias}

O processo de predição proposto neste trabalho, baseia-se na teoria de KEMPTHORNE \& CURNOW (1961), segundo a qual a produtividade de todos os cruzamentos realizados em um dialélico parcial, e também aqueles não realizados, pode ser prevista em função da capacidade geral de combinação de cada parental, ignorando-se os efeitos da capacidade específica de combinação. Essa teoria foi estendida para híbridos triplos e duplos, adaptando-se as fórmulas de predição propostas por JENKINS (1934), para serem usadas com base nos g's e k's, estimados no dialélico parcial circulante. Esta metodologia foi sugerida e utilizada por DANTAS (1988). Esse tipo de predição não é válido quando os efeitos da capacidade específica de combinação forem mais importantes que os efeitos da capacidade geral de combinação. Foi citado e discutido no item 4.5.1., a maior magnitude dos quadrados médios da capacidade geral de combinação em relação aos quadrados médios da capacidade específica de combinação. Isso eqüivale a dizer que a relação $\sigma_{s}^{2} / \sigma_{e}^{2}$ é baixa. Essa condição foi colocada por KEMPTHORNE \& CURNOW 
(1961) para que a previsão dos hibridos, com base apenas na capacidade geral de combinação, seja válida. Portanto o processo de predição em questão é perfeitamente possível.

Os coeficientes de correlação linear ( $r$ ) entre as médias observadas dos híbridos intermediários $\left(\mathrm{HS}_{\mathrm{o}}\right)$ e as médias dos híbridos simples preditas com base nos g's $\left(\mathrm{HS}_{\mathrm{g}}\right)$ e nos k's $\left(\mathrm{HS}_{\mathrm{k}}\right.$ ), encontram-se nas Tabelas 54 (sistema de autofecundação) e 55 (sistema de cruzamentos fraternais). De uma maneira geral, para os dois sistemas e para todas as variáveis, a correlação foi alta, com poucos experimentos mostrando valores abaixo de 0,8, concordando com resultados' de trabalhos anteriores que também utilizaram modelos reduzidos para obtenção de estimativas semelhantes (MARTINS, 1986; GONÇALVES, 1987; DANTAS, 1988; DANTAS, 1992). Embora todas as correlações tenham sido altas, notou-se uma pequena tendência de valores menores quando se considerou os k's como estimadores da capacidade geral de combinação, em ambos os sistemas de multiplicação das progênies parentais.

A mudança do sistema de multiplicação das progênies, de autofecundação para cruzamentos fraternais, também foi acompanhada por uma ligeira tendência de aumento nos coeficientes de correlação, como pode ser verificado nas Tabelas 54 e 55.

Embora, em alguns experimentos, os parâmetros g's e k's não tenham mostrado uma alta correlação (discussão do item 4.5.2.), a correspondência entre as médias preditas dos híbridos simples com base nos mesmos foi alta nos dois sistemas, para todas as variáveis em todos os experimentos. Os valores dos coeficientes de correlação colocaram-se no intervalo $0,82<r<0,96$. Essa forte associação, também foi verificada por DANTAS (1992). Isto se deve ao fato de que os erros associados às estimativas dos dois tipos de parâmetros, são diluídos quando estes participam da fórmula de predição. Isso diminui o problema dos diferentes erros associados às estimativas dos g's e k's, colocado anteriormente como causa da baixa correlação entre eles em alguns experimentos. Em outras palavras, pode-se considerar a hipótese de que os g's e os respectivos k's sejam semelhantes quanto à informação genética que contêm, e que a divergência entre eles esteja associada a erros de estimativas. Essa maior correlação entre 
os híbridos preditos com base nos dois parâmetros reforça a idéia de que ambos podem ser utilizados com igual eficiência no caso de seleção de progênies.

Utilizando-se as médias dos híbridos avaliados e o método B de JENKINS (1934), foi possível se fazer a predição de 60 híbridos triplos e 10 híbridos duplos em cada experimento. Esse método, de ampla aceitação, foi utilizado como padrão para comparações com os modelos reduzidos que utilizaram g's e k's. As correlações entre as previsões feitas pelos três métodos foram altas para todas as variáveis, nos dois sistemas e para os dois tipos de híbridos, como pode ser verificado nas Tabelas 56 a 59 . 0 menor valor de $\mathrm{r}$ foi 0,7 para FF no experimento 6, quando se correlacionou híbridos duplos previstos através do método $B$ de JENKINS (1934) $\left(\mathrm{HD}_{\mathrm{j}}\right)$ e através dos $\mathrm{g}$ 's $\left(\mathrm{HD}_{\mathrm{g}}\right)$. A grande maioria dos coeficientes $r$ foi superior a 0,8 , mostrando uma perfeita concordância entre os três métodos utilizados tanto para predição de híbridos triplos como duplos. DANTAS (1988), aplicando os mesmos métodos nas mesmas populações, porém utilizando linhagens, encontrou o mesmo tipo de resultado, indicando que a metodologia pode ser estendida para todos os híbridos potenciais entre os parentais envolvidos no dialélico.

Deve ficar claro neste ponto que a utilização direta dos k's não permite, a princípio, nenhuma informação sobre a importância da capacidade específica de combinação, pois não é possível uma análise de variância como aquela colocada na Tabela 27. No entanto, como salientado por DANTAS (1992) os coeficientes de correlação entre os valores observados dos híbridos simples $\left(\mathrm{HS}_{\mathrm{o}}\right)$ e estimados com base nos k's $\left(\mathrm{HS}_{\mathrm{k}}\right)$ podem fornecer uma informação indireta da capacidade específica de combinação. Valores altos de $r$ indicam a menor importância da capacidade específica de combinação e a validade do modelo reduzido para qualquer tipo de híbrido. Caso se trabalhe com populações que sofreram alta intensidade de seleção anteriormente, é possível uma menor correlação, devido ao aumento de importância dos efeitos não aditivos.

Pelos resultados observados, à medida que se avança de híbridos simples para híbridos duplos, a validade do método é mais evidente. Uma comparação entre coeficientes $\mathrm{r}$ dos híbridos simples (Tabelas 54 e 55) e dos híbridos triplos e duplos 
(Tabelas 56 a 59), mostra uma tendência de valores maiores nos dois últimos. Isto confinma o efeito de diluição dos erros associados aos estimadores dos parâmetros, considerado anteriormente para híbridos simples. Como os híbridos triplos e duplos envolvem mais progênies parentais, o efeito compensatório na soma dos erros também é maior. Estes resultados mostram que a utilização dos k's para seleção das progênies com maior capacidade geral de combinação é mais eficiente quando se usa como base o grupo dos melhores híbridos previstos. As linhagens com maior freqüência de participações nesses híbridos são as melhores.

Neste momento é interessante salientar que o problema da deriva genética, discutido no item 4.4. não interfere na manutenção das qualidade de um híbrido identificado por este sistema de predição. Considerando que haja deriva genética, os parentais de um determinado híbrido não representam as progênies retiradas das populações originais e portanto, as capacidades de combinação estimadas não são as mesmas das progênies originais. No entanto essas "novas" progênies manterão suas qualidades desde que deste ponto em diante sejam amostradas de maneira representativa. Portanto o problema da deriva vai afetar apenas as estimativas dos parâmetros referentes às populações originais.

Outro ponto a ser considerado neste momento é a conveniência de se trabalhar com híbridos triplos e duplos intermediários. No caso de linhagens (DANTAS, 1988) isso se justifica pois a produção de sementes fica menos complicada com a recuperação do vigor dos parentais através dos hibridos simples. Quando se trabalha com progênies de endogamia intermediária, o problema de vigor dos parentais não ocorre. Os problemas que podem aparecer referem-se à dificuldade na manutenção dos parentais variáveis geneticamente e ao despendoamento das linhas masculinas, provavelmente mais desuniformes que as linhagens. Por outro lado, os híbridos envolvendo dois parentais necessitam de uma geração a menos. Além disso, comparando-se as produtividades médias preditas dos melhores híbridos simples, triplos e duplos, com base nos g's e nos k's (Tabelas 60 a 63), verifica-se que as potencialidades são equivalentes. Nas Tabelas 60 a 63 também é possível verificar a potencialidade dos híbridos intermediários. Dentre os 20 melhores híbridos simples, triplos ou duplos previstos, a maioria mostrou 
potencialidade igual ou superior à testemunha comercial, nos dois sistemas de multiplicação estudados.

Nas Figuras 3 a 5 estão apresentadas as distribuições de freqüência dos híbridos simples observados, híbridos simples previstos com base nos g's e k's, híbridos triplos e duplos previstos com base no método de JENKINS (1934) e híbridos triplos e duplos previstos com base nos g's e k's. Nota-se que a amplitude de variação dos híbridos previstos não excede a mesma amplitude dos híbridos simples observados e dos híbridos triplos e duplos previstos pelo método de JENKINS (1934). Porém novos híbridos com a mesma potencialidade dos melhores híbridos simples observados ou híbridos triplos e duplos previstos pelo método JENKINS (1934) puderam ser identificados. Nestas figuras as médias dos híbridos observados e previstos no sistema de cnuzamentos fraternais estão ajustadas pelo índice multiplicativo. $\mathbf{O}$ ajuste refletiu em uma amplitude de variação ligeiramente superior para os híbridos observados e previstos neste sistema. Isso pode ser creditado ao fator de ajuste que possivelmente não foi muito preciso na correção das médias. 


\section{CONCLUSÕES}

\subsection{Predição e comportamento dos híbridos intermediários}

A avaliação do dialélico parcial circulante e do processo de predição aplicado, começa a partir das estimativas obtidas, -sejam elas representativas ou não, das progênies originais. Levando isso em consideração foi possível concluir que:

1) Os efeitos da capacidade geral de combinação foram mais importantes que os efeitos da capacidade específica de combinação, nas progênies das populações SUWAN e ESALQ-PB1, mostrando que os efeitos aditivos predominaram;

2) A seleção de híbridos simples promissores pode ser efetuada com eficiência, utilizando-se o esquema dialélico parcial circulante e o método de predição de híbridos pelo modelo reduzido. Para a obtenção de híbridos representativos daqueles obtidos com as progênies originais, apenas uma melhor amostragem das mesmas se faz necessário;

3) A utilização dos parâmetros k's, em substituição aos g's, para seleção das melhores progênies, é perfeitamente possivel desde que a seleção seja feita com base nos híbridos previstos. Recomenda-se a previsão dos híbridos simples pelo modelo reduzido, seleção dos melhores híbridos potenciais e seleção das progênies com maior número de participações nesses híbridos;

4) A potencialidade dos híbridos intermediários para utilização comercial é evidente quando se faz a comparação com a testemunha. Mesmo as estimativas dos g's e k's não sendo confiáveis, uma boa média predita indica, no mínimo, que através da seleção nos parentais é possível se chegar a um bom híbrido; 
5) A utilização de híbridos triplos e duplos intermediários, para finalidade comercial, não se justifica pois, com endogamia intermediária, o problema de baixo vigor dos parentais na obtenção híbrido simples é menos preocupante.

\subsection{Parâmetros genéticos e sistemas de multiplicação dos parentais}

Os resultados da análise agrupada para os dois sistemas de multiplicação das progênies parentais, as estimativas obtidas para os parâmetros genéticos interpopulacionais e as considerações sobre amostragem das progênies parentais, permitiram concluir que:

1) O dialélico parcial circulante pode ser usado para obtenção das estimativas de parâmetros genéticos interpopulacionais desde que a amostragem das progênies parentais, tanto na fase de multiplicação como de cruzamento, conserve as características originais das mesmas;

2) Os sistemas de multiplicação dos parentais são equivalentes. A presença da interação híbridos $\mathrm{x}$ sistemas de multiplicação foi creditada ao problema de deriva genética. 


\section{REFERÊNCIAS BIBLIOGRÁFICAS}

ANAND, I.J. \& MURTY, B.R. Serial analysis of combining ability on diallel and fractional diallel cross in linseed. Theoretical and Applied Genetics, Berlin, v. 39, n. 2, p. 88-94, 1969.

ANDERSON, D.C. The relation between singles and double cross yields in corn. Journal of American Society of Agronomy, Madison, v. 30, p. 209-11, 1938.

BARRIGA, P. \& VENCOVSKY, R. Heterose da produção de grãos e de outros caracteres agronômicos em cruzamentos intervarietais de milho. Ciência e Cultura, São Paulo, v. 25, p. 880-5, 1973.

BRAY, R.A. Quantitative evaluation of the circulant partial diallel cross. Heredity, London, v. 27, n. 2, p. 189-202, 1971.

CARVAlHO, H. W. L. de. Predição de médias de compostos de milho (Zea mays L.) para a microrregião homogênea 131 do Estado da Bahia. Piracicaba: USP, 1980. 112p. Dissertação (Mestrado em Genética e Melhoramento de Plantas) - Escola Superior de Agricultura "Luiz de Queiróz", Universidade de São Paulo, 1980.

COCKERHAM, C.C. Prediction of double crosses from single crosses. Der Zuchter, Berlin, v. 37 p. 160-69, 1967.

COMSTOCK, R.E. \& ROBINSON, H.F. The components of genetic variance in populations of biparental progenies and their use in estimating the average degree of dominance. Biometrics, Raleigh, v. 4, p. 254-66, 1948. 
CRUZ, C.D., SILVA, J.C., SEDIYAMA, C.S. Efeito da seleção prévia e de irregularidades no "stand" sobre as estimativas dos componentes de variância genotípica em um dialelo entre linhagens de milho. Revista Ceres, Viçosa, v. 31, p. 238-47, 1984.

CURNOW, R.N. Sampling the diallel cross. Biometrics, Raleigh, v. 19, p. 287-306, 1963.

DANTAS, A. C. V. L. Cruzamento dialélico parcial circulante para avaliação de linhagens de milho (Zea mays L.) e predição de híbridos. Piracicaba: USP, 1988. 152p. Tese (Doutorado em Genética e Melhoramento de Plantas) - Escola Superior de Agricultura "Luiz de Queiróz", Universidade de São Paulo, 1988.

DANTAS, J. L. L. Cruzamentos dialélicos parciais para avaliação de híbridos intermediários entre duas populaçōes de milho (Zea mayss L.). Piracicaba: USP, 1992. 216p. Tese (Doutorado em Genética e Melhoramento de Plantas) - Escola Superior de Agricultura "Luiz de Queiróz", Universidade de São Paulo, 1992.

DHILLON, B.S. \& SINGH, J. Evaluation of circulant partial diallel crosses in maize. Theoretical and Applied Genetics, Berlin, v. 52, n. 1, p. 29-37, 1978.

DOXTATOR, C.W. \& JOHNSON, I.J. Prediction of double-cross yields in com. Joumal of American Society of Agronomy, Madison, v. 28, p. 460-2, 1936.

EAST, E.M. The distinction between development and heredity in inbreeding. American Naturalist, Chicago, v. 43, p. 173-81, 1909.

EBERHART, S.A. Theoretical relations among single, th,ree-way and double-cross hybrids. Biometrics, Raleigh, v. 20, p. 522-39, 1964.

EBERHART, S.A. \& GARDNER, C.O. A general model for genetic effects. Biometrics, Raleigh, v. 22, n. 4, p. 864-81, dez. 1966.

FALCONER, D.S. Introdução à genética quantitativa. Viçosa: Impressora Universitária da UFV, 1987. 279p. 
FEDERER, W.J. Diallel cross design and their relation to fractional replication. Der Zuchter, Berlin, v. 37, p. 174-8, 1967.

FYFE, J.L. \& GLBERT, N. Partial diallel crosses. Biometrics, Raleigh, v. 19, n. 2, p. 278-86, jun. 1963.

GARDNER, C.O. Teoria de genética estatística aplicada a las medias de variedades, sus cruces y poblaciones afines. Fitotecnia Latinoamericana, San José, v. 2, p. 11-22, 1965.

GARDNER, C.O. Simplified methods for estimating constants and computing sums of squares for a diallel cross analysis. Fitotecnia Latinoamericana, San José, v. 4, p. $1-12,1967$.

GARDNER, C.O. \& EBERHART, S.A. Analysis and interpretation of the variety cross diallel and related populations. Biometrics, Raleigh, v. 22 , n. 3, p. 439-52, set. 1966.

GERALDI, I.O. \& MIRANDA FILHO, J.B. de. Adapted models for the analysis of combining ability of varieties in partial diallel crosses. Revista Brasileira de Genética, Ribeirão Preto, v. 11, n. 2, p. 419-30, 1988.

GONÇALVES, P. de S.. Esquema circulante de cruzamentos para avaliação de linhagens de milho (Zea mays L.) ao nível interpopulacional. Piracicaba, 1987. 140p. Tese (Doutorado em Genética e Melhoramento de Plantas) - Escola Superior de Agricultura "Luiz de Queiróz", Universidade de São Paulo, 1987.

GRIFFING, J.B. A generalized treatment of the use of diallel crosses in quantitative inheritance. Heredity, London, v. 10, p. 31-50, 1956a.

GRIFFING, J.B. Concept of general and specific combining ability in realtion to diallel systems. Australian Journal of Biological Science, Melbourne, v. 9, p. 463-93. 1956b.

HALLAUER, S.R. \& MIRANDA FILHO, J.B. de. Quantitative genetics in maize breeding. 2.ed. Ames: Iowa State University Press, 1988. 468p. 
HAYES, H.K., MURPHY, R.P., RINKE, E.H. A comparison of the actual yield of double crosses of maize with their predicted yield from single crosses. Journal of American Society of Agronomy, Madison, v. 35, p. 60-5, 1943.

HAYES, H.K., RINKE, E.H., TSIANG, Y.S. The relationship between predicted perfomance of double crosses of corn in one year with predicted and actual performance of double crosses in later years. Agronomy Journal, Madison, v. 38, p. 60-7, 1946.

HAYMAN, B.I. The analysis of variance of diallel tables. Biometrics, Raleigh, v. 10, p. 235-44, jun. 1954a.

HAYMAN, B.I. The theory and analysis of diallel crosses. Genetics, Princeton, v. 39, p. 784-809, nov. $1954 \mathrm{~b}$.

JENKINS, M.T. Methods of estimating the performance of double crosses in corn. Journal of American Society of Agronomy, Madison, v. 26, p. 199-204, 1934.

JENKINS, M.T. \& BRUNSON, A.M. Methods of testing inbred lines of maize in crossbred combinations. Journal of American Scoeity of Agronomy, Madison, v. 24, p. 523-30, 1932.

JINKS, J.L. \& HAYMAN, B.I. The analysis of diallel crosses. Maize Genetics Cooperation News Letter, Urbana, v. 27; p. 48-54, 1953.

JONES, D.F. The effects of inbreeding and cross breeding upon development. Bulletin "Connecticut Agricultural Experiment Station", New Haven, v. 207, p. 5-100, 1918.

JONES, D.F. The productiveness of single and double-cross first generation hybrid. Journal of American Society of Agronomy, Madison, v. 14, p. 241-52, 1922.

KEMPTHORNE, O, \& CURNOW, R.N. The partial diallel crosses. Biometrics, Rleigh, v.17, n. 2, p. 229-50, jun. 1961.

LI, C.C. Population Genetics. 2.ed. Pacific Grove: Boxwood Press, 1976. 631p. 
LIMA, T. de S. de O. Avaliação das capacidades geral e específica de combinação e correlação entre caracteres em oito populações de milho (Zea mays L.) Opaco 2. Vioçsa: UFV, 1977. 71p. Dissertação (Mestrado em Genética e Melhoramento de Plantas) - Universidade Federal de Viçosa, 1977.

LORDÊLO, J. A. C.. Parâmetros genéticos das populações de milho Piranão VD-2 e Piranão VF-1. Piracicaba: USP, 1982. 63p. Dissertação (Mestrado em Genética e Melhoramento de Plantas) - Escola Superior de Agricultura "Luiz de Queiróz", Universidade de São Paulo, 1982.

MARTINS, C. da S. Potencial genético de linhagens e híbridos de duas populações de milho (Zea mays L.) braquítico. Piracicaba: USP, 1986. 143p. Dissertação (Mestrado em Genética e Melhoramento de Plantas) - Escola Superior de Agricultura "Luiz de Queiróz", Universidade de São Paulo, 1986.

MATZINGER, D.F., SPRAGUE, G.F., COCKERHAM, C.C. Diallel cross of maize in expeniment repeated over locations and years. Agronomy Journal, Madison, v. 51, p. $346-50,1950$.

MIRANDA FILHO, J.B. de. Avaliação de famílias de meios-irmãos na população ESALQ-PB1. Relatório Científico do Instituto de Genética, Piracicaba, v. 11, p. 90-4, 1977.

MIRANDA FILHO, J.B. de. Avaliação de híbridos "crípticos" $S_{0} \times S_{0}$ entre duas populaçōes de milho braquitico. Relatório Científico do Instituto de Genética, Piracicaba, v.13, p. 159-71, 1979.

MIRANDA FILHO, J.B. de. Avaliação de híbridos intervarietais de milho no esquema de cruzamento dialélico parcial. In: CONGRESSO NACIOANL DE MIlLHO E SORGO, 5, Maceió, 1984. Anais, Brasília: EMBRAPA-DDT, 1986. p.195-201.

MIRANDA FILHO, J.B. de. Breeding methodologies for tropical maize. In: BRANDOLINL, A. \& SALAMINL, F. de. (ed.). Breeding strategies for maize production improvement in the tropics. Florence: FAO, 1985. p. 177-206. 
MIRANDA FILHO, J. B. de. Cruzamentos dialélicos e síntese de compostos de milho (Zea mays L.) com ênfase na produtividade e no porte da planta. Piracicaba: USP, 1974. 115p. Tese (Doutorado em Genética e Melhoramento de Plantas) Escola Superior de Agricultura "Luiz de Queiróz", Universidade de São Paulo, 1974.

MIRANDA FILHO, J.B. de. Aspectos teóricos e aplicados ao cruzamento dialélico parcial circulante. Relatório FAPESP (não publicado), 1993.

MIRANDA FILHO, J.B. de. \& GERALDI, I.O. An adapted model for the analysis of partial dialel crosses. Revista Brasileira de Genética, Ribeirão Preto, v. 7, n. 4, p. 677-88, 1984.

MIRANDA FILHO, J.B. de \& PATERNIANL, E. Intra and interpopulation genetic parameter estimates and implications in selection. Revista Brasileira de Genética, Ribeirão Preto, v. 6, n. 1, p. 15-27, 1983.

MIRANDA FILHO, J.B.de \& VENCOVSKY, R. The partial circulant diallel cross at interpopulation level. Theoretical and Applied Genetics, (no prelo), 1995.

MORI, E. S. Variabilidade genética isoenzimática em uma população de Eucalyptus grandis Hill ex Maiden submetida a diferentes intensidades de selecão. Piracicaba: USP, 1993. 119p. Tese (Doutorado em Genética e Melhoramento de Plantas) - Escola Superior de Agricultura "Luiz de Queiróz", Universidade de São Paulo, 1993.

MÔRO, J.R., NASPOLINI FILHO, V., GAMA, E.E.G., VIANNA, R.T. Introdução de novos germosplasmas de milho no Brasil. Pesquisa Agropecuária Brasileira, Brasília, v. 16 p. 867-82, 1981.

MOTA, M. G. da C. Potencialidade de um novo sistema de cruzamento a nível interpopulacional com progênies de meios irmãos de milho (Zea mayss L.). Piracicaba: USP, 1984. 156p. Tese (Doutorado em Genética e Melhoramento de 
Plantas) - Escola Superior de Agricultura "Luiz de Queiróz", Universidade de São Paulo, 1984.

MURTY, B.R., ARUNACHALAM, V., ANAND, I.J. Diallel and partial diallel analysis of some yield factores in Limus usitatissimum. Heredity, London, v. 22, p. 35-41, 1967.

OBILANA, A. T.; HALLAUER, AR; SMITH, O.S. Estimated genetic variability in a maize interpopulation. Journal of Heredity, Washington, v. 70, p. 127-32, 1979.

OTSUKA, V., EBERHART, S.A., RUSSEL, W.A. Comparisons of prediction formulas for maize hybrids. Crop Science, Madison, v. 12, n. 3, p. 325-31, mai.jun. 1972.

PATERNIANI, E., VENCOVSKY, R. Reciprocal recurrent selection based on half-sib progenies and prolific plants in maize (Zea mays L.). Maydica, Bergamo, v. 23, p. 209-19, 1978.

ROBINSON, P. Heritability: a second look. In: HANSON, W.D. \& ROBINSON, H.F. (ed.). Statistical genetics and plant breeding. Washington: National Academy of Science, 1963. p. 609-12.

ROBINSON, H.F.; COMSTOCK, R.E.; HARVEY, P.H. Estimates of heritability and the degree of dominance in corn. Agronomy Journal, Madison, v. 41, n. 8, p. 353-9, 1949.

ROJAS, B.A \& SPRAGUE, G.F. A comparison of variance components in corn yield trials; III. General and specific combining ability and their interaction with locations and years. Agronomy Journal, Madison, v. 44, p. 462-6, 1952

SAMPAIO, N. F. Potencial genético de progênies de meios-irmãos de milho (Zea mays L.) na obtenção de híbridos intermediários. Piracicaba: USP, 1989. 170p. Tese (Doutorado em Genética e Melhoramento de Plantas) - Escola Superior de Agricultura "Luiz de Queiróz", Universidade de São Paulo, 1989.

SHULL, G.H. The composition of a field of maize. Report "American Breeders Association", Washington, v. 4, p. 296-301, 1908. 
SHULL, G.H. A pure line method of corn breeding. Report "American Breeders Association", Washington, v. 5, p. 51-9, 1909.

SINGH, J., DHILLON, B.S., JOSHI, G.S.S. A comparative study of three sampling schemes of partial diallel crosses. Crop Improvement, v. 11, p. 10-4, 1984.

SOARES FILHO, W. dos S.. Características fenotípicas e genéticas das populações de milho (Zea mays L.) braquíttico Piranão-VD2B e Piranão-VF1B. Piracicaba: USP, 1987. 185p. Tese (Doutrorado em Genética e Melhoramento de Plantas) Escola Superior de Agricultura "Luiz de Queiróz", Universidade de São Paulo, 1987.

SOUZA JÚNIOR, C. L. de. Análise de -cruzamentos dialélicos e predição de compostos de milho (Zea mays L.) braquítico. Piracicaba: USP, 1981. 102p. Dissertação (Mestrado em Genética e Melhoramento de Plantas) - Escola Superior de Agricultura Luiz de Queiróz", Universidade de São Paulo, 1981.

SOUZA JÚNIOR, C. L. de. Variabilidade genética em milho (Zea mays L.) e relações com a seleção recorrente intra e inter- populacional. Piracicaba: USP, 1983. 151p. Tese (Doutorado em Genética e Melhoramento de Plantas) - Escola Superior de Agricultura "Luiz de Queiróz", Universidade de São Paulo, 1983.

SOUZA JÚNIOR, C.L. de, MIRANDA FILHO, J.B. de, ZINSLY, J.R. Potencial genético de dois compostos de milho (Zea mays L.) para a obtenção de híbridos. Relatório Científico do Instituto de Genética, Piracicaba, v.14, p. 153-62, 1980.

SPRAGUE, G.F. Corn breeding. In: SPRAGUE, G.F., ed. Corn and corn improvement. New York, Academic Press In. Publishers, 1955. p. 221-92.

SPRAGUE, G.F. \& TATUM, L.A General vs. specific combining ability in single crosses of corn. Journal of Amercian Society of Agronomy, Madison, v. 34, $\mathbf{n}$. 10, p. 923-32, 1942.

STEEL, .R.G.D. \& TORRIE, J.H. Principles and procedures of statistics. $2^{2}$. ed. New York, McGrall-Hill, 1960. 481 p. 
STUBER, C.W. Chatacterization and estimation of genetics parameters in the interpopulation formed by crossing two populations of maize. Raleigh: North Carolina State University, 1965. 105p. Ph. D. Thesis, North Carolina State University, 1965.

TOLEDO, C.V.F. \& MIRANDA FILHO, J.B. de. Progênies autofecundadas de duas populações de milho e de progênies de irmãos germanos interpopulacionais. In: CONGRESSO NACIONAL DE MILHO E SORGO, 15, 1984, Maceió. Anais. Brasilia: EMBRAPA/DDT, 1986. p. 133-9.

TRIFUNOVIC, V. Maize production and maize breeding in Europe. In: WALDEN, D.B. (ed.) Maize breeding and genetics. New York, John Wiley \& Sons, 1978. cap. 4, p.41-58.

VASAL, S.K. Aproaches and methodology in the development of QPM hybrids. In: CONGRESSO NACIONAL DE MILHO E SORGO, 15, Maceió, 1984. Anais. Brasilia, EMBRAPA/DDT, 1986. p.419-30.

VENCOVSKY, R. Alguns aspectos teóricos e aplicados relativos a cruzamentos dialélicos de variedades. Piracicaba: USP, 1970. 110p. Tese (Livre-Docência em Genética e Melhoramento de Plantas) - Escola Superior de Agricultura "Luiz de Queiróz", Universidade de São Paulo, 1970.

VENCOVSKY, R. Herança Quantitativa. In: PATERNIANL, E., ed. Melhoramento e produção do milho no Brasil. Campinas, Fundação Cargill, 1978. Cap. 5, p.12295.

VENCOVSKY, R., BARRIGA, P. Genética biométrica no fitomelhoramento. Ribeirão Preto: Sociedade Brasileira de Genética, 1992. 496 p. 


\section{TA B E L A S}


Tabela 9 - Médias do número de dias para o florescimento feminino referentes a 269 híbridos observados e um hibrido obtido a partir das estimativas de $\mathrm{m}, \mathrm{g}_{\mathrm{i}} \mathbf{e} \mathrm{g}_{\mathrm{j}}$, resultantes de um dialélico parcial circulante entre progênies de irmãos germanos, multiplicadas por autofecundação, das populações ESALQ PB-1 e SUWAN, avaliados em nove experimentos. Média de três repetições. Tha Solteira-SP, 1992/93.

\begin{tabular}{|c|c|c|c|c|c|c|c|c|c|}
\hline & \multicolumn{9}{|c|}{ Experimentos } \\
\hline Híbridos & 01 & 02 & 03 & 04 & 05 & 06 & 07 & 08 & 09 \\
\hline $\begin{array}{l}\text { H01.01 } \\
\text { H01.02 }\end{array}$ & $\begin{array}{l}55,00 \\
54,67\end{array}$ & $\begin{array}{l}53,00 \\
53,67\end{array}$ & $\begin{array}{l}53.33 \\
55,00\end{array}$ & $\begin{array}{l}53,00 \\
52,33\end{array}$ & $\begin{array}{l}52,33 \\
52,00\end{array}$ & $\begin{array}{l}54,67 \\
54,00\end{array}$ & $\begin{array}{l}53,00 \\
53,67\end{array}$ & $\begin{array}{l}53,33 \\
52,67\end{array}$ & $\begin{array}{l}56.00 \\
54,00\end{array}$ \\
\hline H01.03 & 53,67 & 55,00 & 53,33 & 53,33 & 52,33 & 54,67 & 54,00 & 53,67 & 53,67 \\
\hline H02.02 & 52,33 & 52,67 & 53,33 & 55,33 & 53,33 & 54,67 & 54,33 & 54,33 & 54,33 \\
\hline H02.03 & 51,33 & 52,67 & 53,67 & 54,00 & 53,00 & 54,33 & 54,33 & 53,33 & 54,67 \\
\hline H02.04 & 53,00 & 53,33 & 52,67 & 53,33 & 52,67 & 54,33 & 54,67 & 53,67 & 54,00 \\
\hline H03.03 & 52,33 & 52,33 & 55,33 & 53,67 & 53,00 & 53,00 & 54,33 & 52,67 & 53,67 \\
\hline H03.04 & 52,67 & 52,67 & 57,00 & 52,67 & 53,00 & 54,00 & 54,67 & 52,67 & 53,67 \\
\hline H03.05 & 53,67 & 53,33 & 55,00 & 54,00 & 54,33 & 54,33 & 52,67 & 54,00 & 54,00 \\
\hline H04.04 & 53,00 & 52,33 & 52,67 & 53,67 & 53,67 & 54,33 & 53,33 & 56,00 & 55,00 \\
\hline H04.05 & 53,33 & 53,00 & 53,33 & 53,00 & 53,67 & 54,33 & 52,00 & 54,00 & 53,00 \\
\hline H04.06 & 53,33 & 52,33 & 53,67 & 54,67 & 54,67 & 55,33 & 53,33 & 53,00 & 52,00 \\
\hline H05.05 & 53,33 & 54,33 & 53,00 & 51,67 & 53,67 & 54,67 & 54,33 & 51,00 & 57,00 \\
\hline H05.06 & 53,33 & 55,00 & 53,33 & 51,67 & 53,00 & 54,33 & 54,00 & 52,00 & 53,33 \\
\hline H05.07 & 54,67 & 53,00 & 53,67 & 54,00 & 53,67 & 53,67 & 53,33 & 51,33 & 55,33 \\
\hline H06.06 & 51,67 & 53,67 & 54,33 & 52,67 & 53,00 & 54,00 & 52,33 & 52,67 & 52,67 \\
\hline H06.07 & 51,00 & 53,00 & 54,33 & 53,33 & 53,33 & 54,00 & 51,67 & 52,33 & 56,67 \\
\hline H06.08 & 52,33 & 52,67 & 54,67 & 54,00 & 53,67 & 54,33 & 54,67 & 54,00 & 55,00 \\
\hline H07.07 & 54,00 & 54,00 & 54,00 & 53,33 & 54,33 & 54,67 & 54,00 & 51,67 & 54,67 \\
\hline H07.08 & 56,00 & 53,67 & 53,33 & 53,67 & 53,67 & 53,67 & 53,67 & 52,67 & 55,67 \\
\hline H07.09 & 55,00 & 53,67 & 54,00 & 51,00 & 53,67 & 52,67 & 54,33 & 54,00 & 53,00 \\
\hline H08.08 & 54,33 & 53,33 & 54,00 & 51,00 & 53,67 & 56,00 & 54,00 & 53,33 & 52,00 \\
\hline H08.09 & 52,67 & 52,00 & 53,67 & 51,00 & 54,00 & 55,33 & 55,00 & 55,33 & 53,67 \\
\hline H08.10 & 53,33 & 53,33 & 53,67 & 52,00 & 55,00 & 53,00 & 53,67 & 54,00 & 54,67 \\
\hline H09.09 & 56,00 & 52,67 & 53,00 & 52,67 & 54,33 & 54,00 & 54,00 & 55,67 & 53,67 \\
\hline H09.10 & 54,33 & 51,67 & 52,67 & 51,67 & 54,00 & 54,00 & 52,00 & 53,67 & 55,33 \\
\hline H09.01 & 54,67 & 52,33 & 51,67 & 52,67 & 53,67 & 55,33 & 52,67 & 53,00 & 55,33 \\
\hline H10.10 & 53,67 & 51,67 & 54,00 & 52,33 & 52,67 & 54,67 & 54,00 & 54,00 & 55,00 \\
\hline H10.01 & $54,10^{\mathrm{A}}$ & 52,67 & 52,33 & 53,33 & 52,67 & 53,67 & 54,67 & 54,33 & 54,33 \\
\hline H10.02 & 54,33 & 51,67 & 54,67 & 53,00 & 51,67 & 53,67 & 54,00 & 53,00 & 54,00 \\
\hline $\bar{H}$ & 53,57 & 53,02 & 53,75 & 52,93 & 53,39 & 54,25 & 53,69 & 53,38 & 54,31 \\
\hline $\mathbf{T}$ & 54,33 & 54,33 & 54,33 & 52,67 & 54,00 & 55,00 & 53,67 & 53,00 & 55,33 \\
\hline $\bar{H} \%$ & 98,57 & 97,59 & 98,94 & 100,51 & 98,87 & 98,65 & 100,04 & 100,71 & 98,15 \\
\hline
\end{tabular}


Tabela 10 - Médias de altura de plantas (m) referentes a 269 hibridos observados e um híbrido obtido a partir das estimativas de $\mathrm{m}, \mathrm{g}_{\mathrm{i}} \mathbf{e} \mathrm{g}_{\mathrm{j}}$, resultantes de um dialélico parcial circulante entre progênies de irmãos germanos, multiplicadas por autofecundação, das populações ESALQ PB-1 e SUWAN, avaliados em nove experimentos. Média de três repetições. Ilha Solteira-SP, 1992/93.

\begin{tabular}{|c|c|c|c|c|c|c|c|c|c|}
\hline & & & & & sperimen & tos & & & \\
\hline Hibridos & 01 & 02 & 03 & 04 & 05 & 06 & 07 & 08 & 09 \\
\hline $\begin{array}{l}\text { H01.01 } \\
\text { H01.02 }\end{array}$ & $\begin{array}{l}2,09 \\
2,24\end{array}$ & $\begin{array}{l}2,37 \\
2,28\end{array}$ & $\begin{array}{l}2.25 \\
2,15\end{array}$ & $\begin{array}{l}2,25 \\
2,22\end{array}$ & $\begin{array}{l}2,32 \\
2,35\end{array}$ & $\begin{array}{l}2,55 \\
2,56\end{array}$ & $\begin{array}{l}2,44 \\
2,57\end{array}$ & $\begin{array}{l}2,50 \\
2,63\end{array}$ & $\begin{array}{l}2,44 \\
2,46\end{array}$ \\
\hline H01.03 & 2,15 & 2,31 & 2,33 & 2,33 & 2,47 & 2,60 & 2,47 & 2,51 & 2,50 \\
\hline H02.02 & 2,37 & 2,29 & 2,28 & 2,32 & 2,24 & 2,41 & 2,31 & 2,44 & 2,50 \\
\hline $\mathrm{H} 02.03$ & 2,43 & 2,20 & 2,34 & 2,56 & 2,26 & 2,51 & 2,57 & 2,51 & 2,40 \\
\hline $\mathrm{H} 02.04$ & 2,42 & 2,40 & 2,15 & 2,29 & 2,31 & 2,46 & 2,31 & 2,35 & 2,34 \\
\hline H03.03 & 2,44 & 2,27 & 2,21 & 2,29 & 2,13 & 2,32 & 2,47 & 2,35 & 2,28 \\
\hline H03.04 & 2,34 & 2,35 & 2,34 & 2,33 & 2,25 & 2,34 & 2,49 & 2,67 & 2,30 \\
\hline H03.05 & 2,43 & 2,37 & 2,10 & 2,27 & 2,17 & 2,44 & 2,36 & 2,47 & 2,15 \\
\hline H04.04 & 2,40 & 2,21 & 2,21 & 2,42 & 2,39 & 2,56 & 2,48 & 2,42 & 2,34 \\
\hline H04.05 & 2,28 & 2,42 & 2,24 & 2,31 & 2,60 & 2,37 & 2,20 & 2,44 & 2,30 \\
\hline H04.06 & 2,19 & 2,35 & 2,29 & 2,38 & 2,43 & 2,45 & 2,21 & 2,50 & 2,18 \\
\hline H05.05 & 2,20 & 2,37 & 2,37 & 2,27 & 2,30 & 2,31 & 2,34 & 2,38 & 2,36 \\
\hline H05.06 & 2,33 & 2,21 & 2,22 & 2,19 & 2,47 & 2,48 & 2,41 & 2,59 & 2,31 \\
\hline H05.07 & 2,33 & 2,22 & 2,22 & 2,23 & 2,51 & 2,37 & 2,26 & 2,30 & 2,31 \\
\hline H06.06 & 2,28 & 2,11 & 2,29 & 2,34 & 2,28 & 2,62 & 2,28 & 2,63 & 2,28 \\
\hline H06.07 & 2,53 & 2,41 & 2,27 & 2,41 & 2,36 & 2,48 & 2,26 & 2,52 & 2,30 \\
\hline H06.08 & 2,33 & 2,09 & 2,39 & 2,29 & 2,41 & 2,72 & 2,31 & 2,49 & 2,38 \\
\hline H07.07 & 2,43 & 2,35 & 2,29 & 2,29 & 2,46 & 2,18 & 2,40 & 2,33 & 2,42 \\
\hline H07.08 & 2,32 & 2,07 & 2,19 & 2,36 & 2,41 & 2,38 & 2,49 & 2,31 & 2,35 \\
\hline H07.09 & 2,33 & 2,26 & 2,30 & 2,28 & 2,55 & 2,31 & 2,40 & 2,60 & 2,33 \\
\hline H08.08 & 2,58 & 2,50 & 2,22 & 2,15 & 2,32 & 2,55 & 2,52 & 2,55 & 2,18 \\
\hline H08.09 & 2,40 & 2,14 & 2,15 & 2,08 & 2,43 & 2,45 & 2,61 & 2,68 & 2,38 \\
\hline H08.10 & 2,44 & 2,31 & 2,41 & 2,17 & 2,54 & 2,43 & 2,29 & 2,61 & 2,37 \\
\hline H09.09 & 2,44 & 2,13 & 2,28 & 2,38 & 2,30 & 2,31 & 2,24 & 2,61 & 2,35 \\
\hline H09.10 & 2,38 & 2,26 & 2,24 & 2,31 & 2,35 & 2,56 & 2,29 & 2,61 & 2,31 \\
\hline H09.01 & 2,28 & 2,13 & 2,07 & 2,34 & 2,42 & 2,32 & 2,32 & 2,47 & 2,37 \\
\hline H10.10 & 2,47 & 2,17 & 2,30 & 2,29 & 2,45 & 2,29 & 2,36 & 2,51 & 2,27 \\
\hline H10.01 & $2,31^{A}$ & 2,17 & 2,20 & 2,42 & 2,44 & 2,38 & 2,55 & 2,63 & 2,37 \\
\hline H10.02 & 2,38 & 2,18 & 2,06 & 2,36 & 2,31 & 2,32 & 2,48 & 2,54 & 2,28 \\
\hline $\bar{H}$ & 2,35 & 2,26 & 2,24 & 2,30 & 2,37 & 2,43 & 2,39 & 2,50 & 2,34 \\
\hline$T$ & 2,06 & 1,98 & 2,20 & 2,21 & 2,28 & 2,13 & 2,30 & 2,37 & 2,30 \\
\hline $\bar{H} \%$ & 114,14 & 114,31 & 102,06 & 104,27 & 104,14 & 114,29 & 103,90 & 105,70 & 101,61 \\
\hline
\end{tabular}


Tabela 11 - Médias de altura de espigas (m) referentes a 269 híbridos ; observados e um híbrido obtido a partir das estimativas de $\mathrm{m}, \mathrm{g}, \mathrm{e} \mathrm{g}$, resultantes de um dialélico parcial circulante entre progênies de irmãos germanos, multiplicadas por autofecundação, das populações ESALQ PB-1 e SUWAN, avaliados em nove experimentos. Média de três repetições. Ilha Solteira-SP, 1992/93.

\begin{tabular}{|c|c|c|c|c|c|c|c|c|c|}
\hline & & & & & periment & & & & \\
\hline Híbridos & 01 & 02 & 03 & 04 & 05 & 06 & 07 & 08 & 09 \\
\hline $\begin{array}{l}\text { H01.01 } \\
\text { H01.02 }\end{array}$ & $\begin{array}{l}1,09 \\
1,27\end{array}$ & $\begin{array}{l}1,33 \\
1,33\end{array}$ & $\begin{array}{l}1,22 \\
1,22\end{array}$ & $\begin{array}{l}1,35 \\
1,28\end{array}$ & $\begin{array}{l}1,41 \\
1,34\end{array}$ & $\begin{array}{l}1.40 \\
1,47\end{array}$ & $\begin{array}{l}1.40 \\
1,54\end{array}$ & $\begin{array}{l}1,66 \\
1,61\end{array}$ & $\begin{array}{l}1,39 \\
1,47\end{array}$ \\
\hline H01.03 & 1,23 & 1,37 & 1,39 & 1,35 & 1,40 & 1,54 & 1,44 & 1,48 & 1,31 \\
\hline H02.02 & 1,39 & 1,27 & 1,35 & 1,45 & 1,16 & 1,29 & 1,42 & 1,49 & 1,55 \\
\hline H02.03 & 1,36 & 1,07 & 1,43 & 1,63 & 1,24 & 1,38 & 1,53 & 1,46 & 1,40 \\
\hline H02.03 & 1,43 & 1,33 & 1,13 & 1,35 & 1,25 & 1,35 & 1,44 & 1,36 & 1,41 \\
\hline H03.03 & 1,41 & 1,24 & 1,31 & 1,51 & 1,19 & 1,23 & 1,63 & 1,35 & 1,37 \\
\hline H03.04 & 1,31 & 1,18 & 1,39 & 1,27 & 1,29 & 1,29 & 1,72 & 1,58 & 1,28 \\
\hline H03.05 & 1,36 & 1,29 & 1,21 & 1,37 & 1,16 & 1,37 & 1,48 & 1,48 & 1,22 \\
\hline H04.04 & 1,41 & 1,16 & 1,27 & 1,38 & 1,34 & 1,47 & 1,49 & 1,35 & 1,36 \\
\hline H04.05 & 1,37 & 1,33 & 1,36 & 1,27 & 1,44 & 1,36 & 1,24 & 1,40 & 1,45 \\
\hline H04.06 & 1,31 & 1,38 & 1,35 & 1,35 & 1,41 & 1,40 & 1,15 & 1,50 & 1,24 \\
\hline H05.05 & 1,22 & 1,45 & 1,44 & 1,33 & 1,29 & 1,25 & 1,39 & 1,34 & 1,47 \\
\hline H05.06 & 1,26 & 1,18 & 1,25 & 1,10 & 1,45 & 1,36 & 1,50 & 1,45 & 1,30 \\
\hline H05.07 & 1,43 & 1,26 & 1,29 & 1,28 & 1,40 & 1,33 & 1,31 & 1,31 & 1,31 \\
\hline H06.06 & 1,33 & 1,07 & 1,37 & 1,33 & 1,33 & 1,45 & 1,38 & 1,57 & 1,45 \\
\hline H06.07 & 1,55 & 1,39 & 1,23 & 1,47 & 1,35 & 1,36 & 1,37 & 1,49 & 1,58 \\
\hline H06.08 & 1,23 & 1,13 & 1,43 & 1,34 & 1,41 & 1,53 & 1,32 & 1,49 & 1,42 \\
\hline H07.07 & 1,42 & 1,31 & 1,37 & 1,29 & 1,46 & 1,20 & 1,56 & 1,38 & 1,43 \\
\hline H07.08 & 1,47 & 1,09 & 1,26 & 1,29 & 1,28 & 1,28 & 1,47 & 1,42 & 1,40 \\
\hline H07.09 & 1,41 & 1,32 & 1,31 & 1,30 & 1,51 & 1,15 & 1,46 & 1,57 & 1,49 \\
\hline H08.08 & 1,45 & 1,47 & 1,27 & 1,29 & 1,27 & 1,49 & 1,45 & 1,61 & 1,32 \\
\hline H08.08 & 1,39 & 1,15 & 1,24 & 1,28 & 1,31 & 1,38 & 1,57 & 1,68 & 1,35 \\
\hline H08.10 & 1,45 & 1,28 & 1,33 & 1,37 & 1,40 & 1,40 & 1,30 & 1,62 & 1,39 \\
\hline H09.09 & 1,55 & 1,25 & 1,32 & 1,49 & 1,26 & 1,27 & 1,47 & 1,49 & 1,44 \\
\hline H09.10 & 1,40 & 1,27 & 1,13 & 1,37 & 1,19 & 1,55 & 1,32 & 1,58 & 1,34 \\
\hline H09.01 & 1,31 & 1,25 & 1,19 & 1,41 & 1,42 & 1,22 & 1,26 & 1,50 & 1,34 \\
\hline H10.10 & 1,43 & 1,14 & 1,34 & 1,32 & 1,44 & 1,27 & 1,48 & 1,49 & 1,39 \\
\hline H10.01 & $1,28^{\mathrm{A}}$ & 1,17 & 1,31 & 1,49 & 1,44 & 1,34 & 1,48 & 1,59 & 1,45 \\
\hline $\mathrm{H} 10.02$ & 1,44 & 1,14 & 1,15 & 1,45 & 1,22 & 1,32 & 1,34 & 1,50 & 1,45 \\
\hline $\bar{H}$ & 1,36 & 1,25 & 1,29 & 1,36 & 1,33 & 1,36 & 1,43 & 1,49 & 1,39 \\
\hline $\mathbf{T}$ & 1,14 & 1,01 & 1,12 & 1,14 & 1,18 & 1,06 & 1,19 & 1,27 & 1,24 \\
\hline $\bar{H} \%$ & 119,77 & 124,09 & 115,65 & 119,18 & 113,16 & 127,99 & 120,20 & 117,58 & 112,28 \\
\hline
\end{tabular}


Tabela 12 - Médias de peso de espigas $\left(\mathrm{kg} / 3,6 \mathrm{~m}^{2}\right)$ referentes a 269 híbridos observados e um híbrido obtido a partir das estimativas de $m, g_{i}$ e $g_{j}$, resultantes de um dialélico parcial circulante entre progênies de irmãos germanos, multiplicadas por autofecundação, das populações ESALQ PB-1 e SUWAN, avaliados em nove experimentos. Média de três repetições. Iltha Solteira-SP, 1992/93.

\begin{tabular}{|c|c|c|c|c|c|c|c|c|c|}
\hline & \multicolumn{9}{|c|}{ Experimentos } \\
\hline Híbridos & 01 & 02 & 03 & 04 & 05 & 06 & 07 & 08 & 09 \\
\hline $\begin{array}{l}\text { H01.01 } \\
\text { H01.02 }\end{array}$ & $\begin{array}{l}1.788 \\
2,228\end{array}$ & $\begin{array}{l}2,596 \\
2,176\end{array}$ & $\begin{array}{l}2.511 \\
2,210\end{array}$ & $\begin{array}{l}2,677 \\
2,251\end{array}$ & $\begin{array}{l}2,626 \\
2,510\end{array}$ & $\begin{array}{l}2.524 \\
2,801\end{array}$ & $\begin{array}{l}2.577 \\
3,075\end{array}$ & $\begin{array}{l}2,534 \\
3,281\end{array}$ & $\begin{array}{l}2,287 \\
3,004\end{array}$ \\
\hline H01.03 & 2,408 & 2,301 & 2,288 & 2,806 & 2,506 & 2,658 & 2,895 & 2,902 & 3,253 \\
\hline H02.02 & 2,227 & 2,640 & 2,993 & 1,829 & 2,471 & 2,600 & 2,902 & 2,842 & 3,063 \\
\hline H02.03 & 2,717 & 1,840 & 2,796 & 2,274 & 2,450 & 2,617 & 2,740 & 2,386 & 2,525 \\
\hline H02.04 & 2,510 & 2,544 & 2,500 & 2,603 & 2,780 & 2,668 & 2,945 & 3,040 & 2,656 \\
\hline H03.03 & 2,143 & 2,526 & 2,576 & 2,486 & 2,271 & 2,623 & 2,827 & 2,819 & 3,098 \\
\hline H03.04 & 2,639 & 2,295 & 2,695 & 3,075 & 2,572 & 2,495 & 2,901 & 3,054 & 3,058 \\
\hline H03.05 & 2,369 & 2,648 & 2,624 & 2,414 & 2,694 & 2,485 & 2,306 & 2,420 & 2,424 \\
\hline H04.04 & 2,494 & 2,327 & 2,377 & 2,912 & 2,421 & 2,870 & 2,175 & 2,358 & 2,951 \\
\hline H04.05 & 2,781 & 2,501 & 2,266 & 2,529 & 2,440 & 3,002 & 2,715 & 2,705 & 2,449 \\
\hline H04.06 & 2,387 & 2,669 & 2,421 & 2,661 & 2,221 & 2,723 & 2,443 & 3,510 & 2,664 \\
\hline H05.05 & 2,324 & 2,663 & 2,401 & 2,979 & 2,844 & 2,801 & 2,565 & 2,802 & 2,499 \\
\hline H05.06 & 2,115 & 2,330 & 2,020 & 2,857 & 2,920 & 2,772 & 2,431 & 3,011 & 2,770 \\
\hline H05.07 & 2,565 & 2,377 & 2,307 & 2,598 & 2,886 & 2,611 & 2,831 & 2,656 & 2,639 \\
\hline H06.06 & 2,397 & 2,560 & 2,019 & 2,862 & 2,300 & 3,088 & 2,309 & 3,271 & 2,341 \\
\hline H06.07 & 2,702 & 2,885 & 2,399 & 2,654 & 2,924 & 2,555 & 2,633 & 2,604 & 2,812 \\
\hline H06.08 & 2,531 & 2,562 & 2,408 & 2,886 & 2,608 & 2,949 & 2,449 & 2,532 & 2,669 \\
\hline H07.07 & 2,144 & 2,666 & 2,800 & 2,518 & 2,668 & 2,328 & 2,667 & 2,798 & 2,544 \\
\hline H07.08 & 2,048 & 2,579 & 2,575 & 2,550 & 3,137 & 2,334 & 2,502 & 2,775 & 2,293 \\
\hline H07.09 & 2,330 & 2,039 & 2,520 & 2,960 & 2,870 & 2,290 & 2,626 & 2,788 & 3,122 \\
\hline H08.08 & 2,812 & 2,681 & 2,771 & 2,773 & 2,577 & 2,799 & 2,851 & 2,801 & 2,322 \\
\hline H08.09 & 2,638 & 1,392 & 2,717 & 2,727 & 2,744 & 2,390 & 2,462 & 2,679 & 2,635 \\
\hline H08.10 & 1,947 & 2,480 & 2,749 & 2,417 & 2,259 & 2,978 & 2,714 & 2,879 & 2,755 \\
\hline H09.09 & 2,505 & 2,006 & 2,484 & 2,697 & 2,884 & 2,618 & 2,085 & 2,715 & 2,469 \\
\hline H09.10 & 1,914 & 2,846 & 2,627 & 2,622 & 2,086 & 2,995 & 3,237 & 2,795 & 2,643 \\
\hline H09.01 & 2,157 & 2,353 & 1,646 & 2,441 & 3,009 & 2,695 & 2,485 & 2,731 & 2,519 \\
\hline H10.10 & 2,412 & 2,573 & 2,607 & 2,154 & 3,117 & 2,447 & 3,277 & 3,104 & 2,969 \\
\hline H10.01 & $2,370^{A}$ & 2,918 & 2,159 & 2,500 & 2,752 & 2,647 & 3,091 & 2,492 & 2,276 \\
\hline $\mathrm{H} 10.02$ & 2,422 & 2,303 & 2,640 & 2,326 & 2,660 & 2,980 & 2,751 & 2,679 & 2,298 \\
\hline$\overline{\bar{H}}$ & 2,367 & 2,443 & 2,470 & 2,601 & 2,640 & 2,678 & 2,682 & 2,799 & $2_{2} 667$ \\
\hline $\mathbf{T}$ & 2,327 & 2,414 & 2,665 & 2,499 & 2,894 & 2,603 & 2,849 & 2,540 & 2,661 \\
\hline $\bar{H} \%$ & 101,73 & 101,17 & 92,69 & 104,10 & 91,21 & 102,90 & 94,13 & 110,17 & 100,23 \\
\hline
\end{tabular}


Tabela 13 - Médias de peso de grãos $\left(\mathrm{kg} / 3,6 \mathrm{~m}^{2}\right)$ referentes 269 hibridos observados e um híbrido obtido a partir da estimativas de $m, g_{i}$ e $g_{j}$, resultantes de um dialélico parcial circulante entre progênies de irmãos germanos, multiplicadas por autofecundação, das populações ESALQ PB-1 e SUWAN, avaliados em nove experimentos. Média de três repetições. Itha Solteira-SP, 1992/93.

\begin{tabular}{|c|c|c|c|c|c|c|c|c|c|}
\hline & \multicolumn{9}{|c|}{ Experimentos } \\
\hline Híbridos & 01 & 02 & 03 & 04 & 05 & 06 & 07 & 08 & 09 \\
\hline $\begin{array}{l}\mathrm{H} 01.01 \\
\mathrm{H} 01.02\end{array}$ & $\begin{array}{l}1,394 \\
1,798\end{array}$ & $\begin{array}{l}2,105 \\
1,898\end{array}$ & $\begin{array}{l}2,044 \\
1,812\end{array}$ & $\begin{array}{l}2,297 \\
1,865\end{array}$ & $\begin{array}{l}2,200 \\
2,082\end{array}$ & $\begin{array}{l}2,097 \\
2,323\end{array}$ & $\begin{array}{l}2,167 \\
2,562\end{array}$ & $\begin{array}{l}2,086 \\
2,709\end{array}$ & $\begin{array}{l}1,793 \\
2,490\end{array}$ \\
\hline H01.03 & 1,928 & 1,899 & 1,907 & 2,445 & 2,066 & 2,230 & 2,429 & 2,368 & 2,589 \\
\hline H02.02 & 1,868 & 2,208 & 2,447 & 1,489 & 2,011 & 2,132 & 2,448 & 2,301 & 2,537 \\
\hline H02.03 & 2,238 & 1,500 & 2,284 & 1,927 & 2,010 & 2,212 & 2,284 & 1,977 & 2,047 \\
\hline H02.04 & 2,111 & 2,096 & 2,040 & 2,145 & 2,330 & 2,169 & 2,472 & 2,518 & 2,165 \\
\hline H03.03 & 1,700 & 2,121 & 2,126 & 2,103 & 1,867 & 2,166 & 2,351 & 2,330 & 2,581 \\
\hline H03.04 & 2,180 & 2,020 & 2,235 & 2,562 & 2,155 & 2,028 & 2,352 & 2,629 & 2,472 \\
\hline H03.05 & 1,910 & 2,193 & 2,156 & 1,995 & 2,242 & 2,023 & 1,865 & 1,982 & 1,901 \\
\hline H04.04 & 2,135 & 1,940 & 1,916 & 2,417 & 2,008 & 2,293 & 1,804 & 1,904 & 2,403 \\
\hline H04.05 & 2,254 & 2,110 & 1,804 & 2,138 & 1,990 & 2,538 & 2,152 & 2,202 & 2,021 \\
\hline H04.06 & 1,941 & 2,231 & 1,988 & 2,171 & 1,738 & 2,171 & 2,006 & 2,856 & 2,172 \\
\hline H05.05 & 1,908 & 2,179 & 1,993 & 2,524 & 2,359 & 2,316 & 2,086 & 2,329 & 1,957 \\
\hline H05.06 & 1,749 & 1,884 & 1,686 & 2,401 & 2,470 & 2,264 & 1,961 & 2,433 & 2,272 \\
\hline H05.07 & 2,174 & 2,023 & 1,896 & 2,139 & 2,415 & 2,114 & 2,323 & 2,252 & 2,167 \\
\hline H06.06 & 1,977 & 2,128 & 1,603 & 2,392 & 1,834 & 2,601 & 1,891 & 2,699 & 1,887 \\
\hline H06.07 & 2,276 & 2,440 & 1,965 & 2,188 & 2,401 & 2,037 & 2,188 & 2,189 & 2,285 \\
\hline H06.08 & 2,123 & 2,124 & 2,015 & 2,442 & 2,158 & 2,462 & 1,951 & 2,167 & 2,218 \\
\hline H07.07 & 1,757 & 2,282 & 2,344 & 2,066 & 2,230 & 1,852 & 2,172 & 2,379 & 2,064 \\
\hline H07.08 & 1,685 & 2,173 & 2,104 & 2,117 & 2,615 & 1,901 & 2,027 & 2,334 & 1,805 \\
\hline H07.09 & 1,930 & 1,694 & 2,078 & 2,514 & 2,410 & 1,852 & 2,184 & 2,335 & 2,464 \\
\hline H08.08 & 2,296 & 2,208 & 2,272 & 2,333 & 2,136 & 2,284 & 2,381 & 2,275 & 1,979 \\
\hline H08.09 & 2,190 & 1,122 & 2,235 & 2,304 & 2,278 & 2,022 & 2,029 & 2,179 & 2,102 \\
\hline H08.10 & 1,560 & 2,056 & 2,274 & 2,113 & 1,880 & 2,486 & 2,245 & 2,342 & 2,306 \\
\hline H09.09 & 2,027 & 1,706 & 2,040 & 2,267 & 2,403 & 2,217 & 1,724 & 2,213 & 1,988 \\
\hline H09.10 & 1,571 & 2,344 & 2,142 & 2,304 & 1,734 & 2,471 & 2,578 & 2,353 & 2,154 \\
\hline H09.01 & 1,715 & 1,949 & 1,389 & 2,035 & 2,490 & 2,282 & 2,009 & 2,234 & 2,024 \\
\hline H10.10 & 2,082 & 2,098 & 2,171 & 1,790 & 2,589 & 1,995 & 2,735 & 2,547 & 2,427 \\
\hline H10.01 & 1,955 & 2,476 & 1,771 & 2,056 & 2,261 & 2,195 & 2,562 & 2,030 & 1,891 \\
\hline $\mathrm{H} 10.02$ & 1,986 & 1,901 & 2,178 & 1,940 & 2,200 & 2,492 & 2,303 & 2,188 & 1,922 \\
\hline $\bar{H}$ & 1,947 & 2,307 & 2,030 & 2,183 & 2,185 & 2,207 & 2,208 & 2,311 & 2,169 \\
\hline $\mathbf{T}$ & 1,962 & 2,067 & 2,262 & 2,168 & 2,490 & 2,210 & 2,419 & 2,130 & 2,293 \\
\hline $\bar{H} \%$ & 99,26 & 98,55 & 89,74 & 100,67 & 87,75 & 99,90 & 91,27 & 108,49 & $\overline{94,62}$ \\
\hline
\end{tabular}

A - Média estimada a partir de $\mathrm{m}, \mathrm{g}_{\mathrm{i}}$ e $\mathrm{g}_{\mathrm{j}} ; \bar{H}$ - Média dos hibridos; $\mathrm{T}$ - Média da testemunha; $\bar{H} \%$ Porcentagem em relação à testemunha. 
Tabela 14 - Médias do número de dias para o florescimento feminino referentes a 269 híbridos observados e um híbrido obtido a partir das estimativas de $\mathrm{m}, \mathrm{g}_{\mathrm{i}}$ e $\mathrm{g}_{\text {; }}$ resultantes de um dialélico parcial circulante entre progênies de irmãos germanos, multiplicadas por cruzamentos fratemais, das populações ESALQ PB-1 e SUWAN, avaliados em dez experimentos. Média de três repetições. Ilha Solteira-SP, 1992/93.

\begin{tabular}{|c|c|c|c|c|c|c|c|c|c|c|}
\hline & \multicolumn{10}{|c|}{ Experimentos } \\
\hline Hibridos & 01 & 02 & 03 & 04 & 05 & 06 & 07 & 08 & 09 & 10 \\
\hline H01.01 & 52.67 & 55,33 & 53,33 & 53,00 & 50.67 & 51.00 & 55.67 & 55.00 & 51.67 & 55,00 \\
\hline $\mathrm{H} 01.02$ & 54,00 & 52,67 & 52,00 & 53,00 & 53,67 & 51,00 & 53,67 & 55,33 & 53,00 & 57,67 \\
\hline H01.03 & 52,67 & 51,00 & 54,33 & 51,00 & 53,00 & 55,00 & 54,00 & 56,00 & 54,33 & 55,00 \\
\hline H02.02 & 54,33 & 54,00 & 52,00 & 51,33 & 50,67 & 50,33 & 55,00 & 53,00 & 54,33 & 55,67 \\
\hline H02.03 & 54,33 & 52,33 & 55,33 & 51,00 & 52,67 & 55,00 & 54,33 & 56,33 & 55,33 & 52,33 \\
\hline H02.04 & $56,01^{A}$ & 52,67 & 53,00 & 51,67 & 50,00 & 53,33 & 54,00 & 54,00 & 54,33 & 51,33 \\
\hline H03.03 & 56,33 & 53,00 & 55,00 & 51,00 & $51 ; 67$ & 58,33 & 54,00 & 51,33 & 55,00 & 52,33 \\
\hline H03.04 & 57,67 & 54,67 & 53,67 & 51,00 & 55,00 & 54,67 & 53,00 & 55,33 & 55,00 & 51,00 \\
\hline H03.05 & 55,33 & 54,00 & 52,33 & 50,00 & 53,67 & 55,33 & 51,67 & 55,33 & 53,00 & 53,33 \\
\hline H04.04 & 52,67 & 52,33 & 52,67 & 54,33 & 52,33 & 52,67 & 55,00 & 54,67 & 55,67 & 55,67 \\
\hline H04.05 & 54,00 & 55,33 & 55,33 & 54,00 & 52,33 & 55,00 & 52,00 & 57,33 & 53,33 & 58,33 \\
\hline H04.06 & 51,67 & 53,67 & 53,33 & 50,67 & 51,33 & 53,67 & 53,67 & 55,00 & 56,00 & 55,00 \\
\hline H05.05 & 56,67 & 55,00 & 52,33 & 53,00 & 52,67 & 56,33 & 53,33 & 56,33 & 51,33 & 56,00 \\
\hline H05.06 & 51,33 & 53,33 & 52,33 & 52,00 & 52,33 & 54,00 & 54,00 & 51,67 & 55,00 & 57,00 \\
\hline H05.07 & 51,33 & 52,33 & 55,67 & 53,00 & 52,33 & 54,00 & 55,00 & 55,00 & 55,00 & 55,33 \\
\hline H06.06 & 57,33 & 55,00 & 54,00 & 50,67 & 55,00 & 55,00 & 56,00 & 51,00 & 55,00 & 55,33 \\
\hline H06.07 & 52,67 & 53,67 & 54,33 & 50,67 & 52,33 & 53,67 & 54,00 & 51,67 & 00 & 54,33 \\
\hline H06.08 & 50,67 & 55,00 & 51,33 & 52,67 & 53,33 & 53,67 & 55,00 & 52,67 & 55,67 & 57,67 \\
\hline H07.07 & 52,00 & 51,33 & 54,67 & 52,00 & 53,67 & 54,33 & 54,00 & 57,33 & 54,67 & 54,67 \\
\hline H07.08 & 51,33 & 54,00 & 51,67 & 53,67 & 54,67 & 52,67 & 51,33 & 55,67 & 55,33 & 57,00 \\
\hline H07.09 & 54,00 & 53,33 & 53,33 & 51,00 & 54,00 & 52,33 & 52,33 & 55,00 & 54,00 & 56,67 \\
\hline H08.08 & 51,00 & 53,00 & 54,67 & 55,00 & 52,00 & 53,33 & 54,00 & 54,00 & 54,00 & 55,00 \\
\hline H08.09 & 54,00 & 56,00 & 55,67 & 51,33 & 54,00 & 55,00 & 54,00 & 53,67 & 54,00 & 53,00 \\
\hline H08.10 & 54,33 & 54,00 & 56,00 & 53,67 & 55,33 & 52,67 & 53,67 & 55,67 & 53,67 & 51,67 \\
\hline H09.09 & 56,67 & 55,67 & 52,00 & 50,00 & 52,67 & 51,33 & 54,33 & 51,33 & 55,00 & 54,00 \\
\hline H09.10 & 53,00 & 55,00 & 57,00 & 56,33 & 55,00 & 51,67 & 56,00 & 56,00 & 54,00 & 52,33 \\
\hline H09.01 & 52,67 & 56,33 & 55,00 & 54,33 & 52,67 & 52,67 & 55,00 & 52,67 & 51,00 & 55,33 \\
\hline H10.10 & 54,67 & 53,00 & 55,00 & 54,00 & 51,67 & 54,00 & 57,00 & 57,00 & 55,00 & 53,33 \\
\hline H10.01 & 53,00 & 53,67 & 51,67 & 53,00 & 51,33 & 50,67 & 57,00 & 57,00 & 51,33 & 52,00 \\
\hline $\mathrm{H} 10.02$ & 55,00 & 54,00 & 54,00 & 52,67 & 50,67 & 50,67 & 55,00 & 53,00 & 55,00 & 55,33 \\
\hline $\bar{H}$ & 53,78 & 53,82 & 53,77 & 52,37 & 52,76 & 53,44 & 54,23 & 54,51 & 54,17 & 54,62 \\
\hline $\mathbf{T}$ & 55,17 & 54,67 & 55,00 & 53,00 & 54,67 & 55,00 & 55,33 & 55,33 & 54,33 & 56,00 \\
\hline $\bar{H} \%$ & 97,48 & 98,46 & 97,76 & 98,81 & 96,50 & 97,17 & 98,01 & 98,51 & 99,69 & 97,54 \\
\hline
\end{tabular}


Tabela 15 - Médias de altura de plantas (m) referentes a 269 híbridos observados e um híbrido obtido a partir das estimativas de $\mathrm{m}, \mathrm{g}_{\mathrm{i}} \mathbf{e} \mathrm{g}_{\mathrm{j}}$, resultantes de um dialélico parcial circulante entre progênies de irmãos germanos, multiplicadas por cruzamentos fratemais, das populações ESALQ PB-1 e SUWAN, avaliados em dez experimentos. Média de três repetições. Tha Solteira-SP, 1992/93.

\begin{tabular}{|c|c|c|c|c|c|c|c|c|c|c|}
\hline & \multicolumn{10}{|c|}{ Experimentos } \\
\hline Hibridos & 01 & 02 & 03 & 04 & 05 & 06 & 07 & 08 & 09 & 10 \\
\hline $\begin{array}{l}\text { H01.01 } \\
\text { H01.02 }\end{array}$ & $\begin{array}{l}2,10 \\
2,41\end{array}$ & $\begin{array}{l}2.41 \\
2,57\end{array}$ & $\begin{array}{l}2,33 \\
2,15\end{array}$ & $\begin{array}{l}2,46 \\
2,34\end{array}$ & $\begin{array}{l}2.47 \\
2,37\end{array}$ & $\begin{array}{l}2,29 \\
2,31\end{array}$ & $\begin{array}{l}2,39 \\
2,33\end{array}$ & $\begin{array}{l}2,20 \\
2,20\end{array}$ & $\begin{array}{l}2,19 \\
2,45\end{array}$ & $\begin{array}{l}2,29 \\
2,54\end{array}$ \\
\hline H01.03 & 2,30 & 2,55 & 2,16 & 2,37 & 2,40 & 2,27 & 2,41 & 2,20 & 2,33 & 2,35 \\
\hline H02.02 & 2,51 & 2,35 & 2,34 & 2,44 & 2,31 & 2,22 & 2,45 & 2,30 & 2,23 & 2,38 \\
\hline H02.03 & 2,33 & 2,45 & 2,30 & 2,28 & $2,25^{\circ}$ & 2,28 & 2,25 & 2,44 & 2,43 & 2,29 \\
\hline H02.04 & $2,31^{\mathrm{A}}$ & 2,28 & 2,25 & 2,34 & 2,29 & 2,31 & 2,38 & 2,23 & 2,39 & 2,24 \\
\hline H03.03 & 2,36 & 2,41 & 2,21 & 2,24 & 2,24 & 2,26 & 2,30 & 2,20 & 2,27 & 2,25 \\
\hline H03.04 & 2,35 & 2,28 & 2,15 & 2,24 & 2,29 & 2,26 & 2,35 & 2,16 & 2,26 & 2,14 \\
\hline H03.05 & 2,21 & 2,44 & 2,34 & 2,26 & 2,21 & 2,25 & 2,30 & 2,27 & 2,33 & 2,25 \\
\hline H04.04 & 2,02 & 2,37 & 2,27 & 2,49 & 2,22 & 2,28 & 2,26 & 2,29 & 2,48 & 2,53 \\
\hline H04.05 & 2,20 & 2,64 & 2,29 & 2,41 & 2,20 & 2,24 & 2,15 & 2,35 & 2,45 & 2,42 \\
\hline H04.06 & 2,29 & 2,43 & 2,31 & 2,34 & 2,34 & 2,29 & 2,28 & 2,32 & 2,30 & 2,55 \\
\hline H05.05 & 2,15 & 2,47 & 2,23 & 2,34 & 2,20 & 2,29 & 2,25 & 2,30 & 2,11 & 2,56 \\
\hline H05.06 & 2,26 & 2,32 & 2,37 & 2,41 & 2,34 & 2,30 & 2,41 & 2,24 & 2,26 & 2,38 \\
\hline H05.07 & 2,26 & 2,44 & 2,44 & 2,31 & 2,35 & 2,26 & 2,32 & 2,25 & 2,29 & 2,50 \\
\hline H06.06 & 2,33 & 2,48 & 2,24 & 2,36 & 2,32 & 2,28 & 2,44 & 2,17 & 2,30 & 2,47 \\
\hline H06.07 & 2,29 & 2,52 & 2,32 & 2,26 & 2,40 & 2,28 & 2,46 & 2,10 & 2,27 & 2,52 \\
\hline H06.08 & 2,14 & 2,51 & 2,14 & 2,35 & 2,41 & 2,23 & 2,16 & 2,16 & 2,29 & 2,66 \\
\hline H07.07 & 2,24 & 2,29 & 2,40 & 2,31 & 2,28 & 2,24 & 2,39 & 2,33 & 2,34 & 2,32 \\
\hline H07.08 & 2,12 & 2,40 & 2,35 & 2,30 & 2,12 & 2,20 & 2,26 & 2,31 & 2,35 & 2,56 \\
\hline H07.09 & 2,39 & 2,40 & 2,29 & 2,22 & 2,39 & 2,30 & 2,23 & 2,24 & 2,37 & 2,31 \\
\hline H08.08 & 2,30 & 2,30 & 2,20 & 2,32 & 2,48 & 2,28 & 2,30 & 2,16 & 2,35 & 2,46 \\
\hline H08.09 & 2,42 & 2,43 & 2,31 & 2,07 & 2,38 & 2,27 & 2,32 & 2,24 & 2,45 & 2,21 \\
\hline H08.10 & 2,45 & 2,38 & 2,32 & 2,26 & 2,40 & 2,12 & 2,39 & 2,26 & 2,36 & 2,26 \\
\hline H09.09 & 2,47 & 2,34 & 2,31 & 2,32 & 2,38 & 2,39 & 2,35 & 2,25 & 2,63 & 2,40 \\
\hline H09.10 & 2,38 & 2,46 & 2,37 & 2,32 & 2,40 & 2,25 & 2,33 & 2,38 & 2,42 & 2,41 \\
\hline H09.01 & 2,19 & 2,36 & 2,33 & 2,26 & 2,15 & 2,18 & 2,18 & 2,29 & 2,30 & 2,40 \\
\hline H10.10 & 2,49 & 2,45 & 2,39 & 2,49 & 2,39 & 2,19 & 2,31 & 2,15 & 2,29 & 2,30 \\
\hline H10.01 & 2,11 & 2,34 & 2,32 & 2,49 & 2,28 & 2,27 & 2,44 & 2,23 & 2,02 & 2,33 \\
\hline H10.02 & 2,22 & 2,32 & 2,29 & 2,36 & 2,28 & 2,30 & 2,39 & 2,12 & 2,32 & 2,33 \\
\hline $\bar{H}$ & 2,29 & 2,41 & 2,29 & 2,33 & 2,32 & 2,26 & 2,33 & 2,25 & 2,33 & 2,39 \\
\hline $\mathbf{T}$ & 2,13 & 2,19 & 2,15 & 2,19 & 2,16 & 2,17 & 2,13 & 2,17 & 2,28 & 2,31 \\
\hline $\bar{H} \%$ & 107,4 & 110,3 & 106,3 & 106,4 & 107,1 & 104,1 & 109,2 & 103,6 & 102,2 & 103,1 \\
\hline
\end{tabular}


Tabela 16 - Médias de altura de espigas (m) referentes a 269 híbridos observados e um híbrido obtido a partir das estimativas de $\mathrm{m}, \mathrm{g}_{\mathrm{i}}$ e $\mathrm{g}_{\mathrm{j}}$, resultantes de um dialélico parcial circulante entre progênies de irmãos germanos, multiplicadas por cruzamentos fraternais, das populações ESALQ PB-1 e SUWAN, avaliados em dez experimentos. Média de três repetições. Ilha Solteira-SP, 1992/93.

\begin{tabular}{|c|c|c|c|c|c|c|c|c|c|c|}
\hline & \multicolumn{10}{|c|}{ Experimentos } \\
\hline Híbridos & 01 & 02 & 03 & 04 & 05 & 06 & 07 & 08 & 09 & 10 \\
\hline $\begin{array}{l}\text { H01.01 } \\
\text { H01.02 }\end{array}$ & $\begin{array}{l}1,14 \\
1,37\end{array}$ & $\begin{array}{l}1,41 \\
1,49\end{array}$ & $\begin{array}{l}1,35 \\
1,24\end{array}$ & $\begin{array}{l}1,42 \\
1,34\end{array}$ & $\begin{array}{l}1,40 \\
1,36\end{array}$ & $\begin{array}{l}1,31 \\
1,33\end{array}$ & $\begin{array}{l}1,42 \\
1,36\end{array}$ & $\begin{array}{l}1,32 \\
1,25\end{array}$ & $\begin{array}{l}1,30 \\
1,55\end{array}$ & $\begin{array}{l}1,30 \\
1,51\end{array}$ \\
\hline H01.03 & 1,25 & 1,44 & 1,22 & 1,38 & 1,31 & 1,24 & 1,44 & 1,27 & 1,40 & 1,22 \\
\hline H02.02 & 1,55 & 1,37 & 1,36 & 1,52 & 1,29 & 1,28 & 1,38 & 1,29 & 1,33 & 1,43 \\
\hline H02.03 & 1,29 & 1,45 & 1,34 & 1,33 & 1,33 & 1,31 & 1,28 & 1,54 & 1,43 & 1,38 \\
\hline H02.04 & $1,39^{\mathrm{A}}$ & 1,26 & 1,28 & 1,34 & 1,23 & 1,26 & 1,40 & 1,28 & 1,36 & 1,34 \\
\hline H03.03 & 1,30 & 1,41 & 1,39 & 1,32 & 1,38 & 1,23 & 1,32 & 1,23 & 1,49 & 1,26 \\
\hline H03.04 & 1,38 & 1,32 & 1,29 & 1,34 & 1,31 & 1,29 & 1,36 & 1,32 & 1,37 & 1,17 \\
\hline H03.05 & 1,20 & 1,49 & 1,36 & 1,28 & 1,30 & 1,25 & 1,36 & 1,35 & 1,44 & 1,32 \\
\hline H04.04 & 1,14 & 1,30 & 1,43 & 1,50 & 1,29 & 1,25 & 1,30 & 1,35 & 1,46 & 1,64 \\
\hline H04.05 & 1,21 & 1,61 & 1,34 & 1,42 & 1,36 & 1,27 & 1,20 & 1,37 & 1,51 & 1,37 \\
\hline H04.06 & 1,26 & 1,41 & 1,36 & 1,25 & 1,37 & 1,25 & 1,24 & 1,32 & 1,36 & 1,53 \\
\hline H05.05 & 1,22 & 1,55 & 1,30 & 1,38 & 1,26 & 1,33 & 1,24 & 1,36 & 1,15 & 1,59 \\
\hline H05.06 & 1,26 & 1,29 & 1,44 & 1,41 & 1,28 & 1,32 & 1,47 & 1,28 & 1,30 & 1,44 \\
\hline H05.07 & 1,25 & 1,40 & 1,45 & 1,35 & 1,35 & 1,22 & 1,35 & 1,27 & 1,37 & 1,35 \\
\hline H06.06 & 1,35 & 1,41 & 1,35 & 1,38 & 1,38 & 1,26 & 1,58 & 1,24 & 1,37 & 1,53 \\
\hline H06.07 & 1,29 & 1,53 & 1,33 & 1,35 & 1,45 & 1,24 & 1,45 & 1,18 & 1,34 & 1,54 \\
\hline H06.08 & 1,23 & 1,53 & 1,22 & 1,35 & 1,45 & 1,31 & 1,18 & 1,21 & 1,42 & 1,67 \\
\hline H07.07 & 1,31 & 1,37 & 1,44 & 1,34 & 1,34 & 1,27 & 1,41 & 1,31 & 1,42 & 1,27 \\
\hline H07.08 & 1,20 & 1,42 & 1,42 & 1,35 & 1,28 & 1,25 & 1,30 & 1,30 & 1,47 & 1,52 \\
\hline H07.09 & 1,38 & 1,44 & 1,44 & 1,30 & 1,42 & 1,28 & 1,29 & 1,24 & 1,39 & 1,40 \\
\hline H08.08 & 1,26 & 1,29 & 1,32 & 1,34 & 1,37 & 1,28 & 1,36 & 1,18 & 1,32 & 1,37 \\
\hline H08.09 & 1,44 & 1,50 & 1,41 & 1,18 & 1,49 & 1,24 & 1,33 & 1,30 & 1,35 & 1,26 \\
\hline H08.10 & 1,43 & 1,37 & 1,49 & 1,35 & 1,38 & 1,16 & 1,38 & 1,34 & 1,42 & 1,26 \\
\hline H09.09 & 1,37 & 1,39 & 1,46 & 1,28 & 1,43 & 1,48 & 1,36 & 1,23 & 1,54 & 1,44 \\
\hline H09.10 & 1,30 & 1,40 & 1,41 & 1,27 & 1,50 & 1,27 & 1,42 & 1,41 & 1,61 & 1,44 \\
\hline H09.01 & 1,23 & 1,45 & 1,42 & 1,27 & 1,23 & 1,24 & 1,20 & 1,26 & 1,42 & 1,42 \\
\hline H10.10 & 1,45 & 1,43 & 1,47 & 1,43 & 1,36 & 1,21 & 1,60 & 1,17 & 1,40 & 1,29 \\
\hline H10.01 & 1,19 & 1,35 & 1,39 & 1,48 & 1,27 & 1,25 & 1,57 & 1,30 & 1,27 & 1,32 \\
\hline H10.02 & 1,28 & 1,34 & 1,42 & 1,39 & 1,32 & 1,32 & 1,51 & 1,12 & 1,46 & 1,41 \\
\hline $\bar{H}$ & 1,30 & 1,41 & 1,37 & 1,35 & 1,35 & 1,27 & 1,37 & 1,29 & 1,40 & 1,40 \\
\hline$T$ & 1,16 & 1,15 & 1,18 & 1,14 & 1,18 & 1,19 & 1,20 & 1,21 & 1,24 & 1,24 \\
\hline $\bar{H} \%$ & 112,2 & 122,5 & 116,5 & 118,4 & 114,7 & 107,2 & 114,0 & 106,2 & 113,0 & 112,5 \\
\hline
\end{tabular}


Tabela 17 - Médias de peso de espigas $\left(\mathrm{kg} / 3,6 \mathrm{~m}^{2}\right)$ referentes a 269 híbridos observados e um híbrido obtido a partir das estimativas de $m, g_{i} e g_{j}$, resultantes de um dialélico parcial circulante entre progênies de irmãos germanos, multiplicadas por cruzamentos fraternais, das populações ESALQ PB-1 e SUWAN, avaliados em dez experimentos. Média de três repetições. Tha Solteira-SP, 1992/93.

\begin{tabular}{|c|c|c|c|c|c|c|c|c|c|c|}
\hline \multirow[b]{2}{*}{ Híbridos } & \multicolumn{10}{|c|}{ Experimentos } \\
\hline & 01 & 02 & 03 & 04 & 05 & 06 & 07 & 08 & 09 & 10 \\
\hline $\begin{array}{l}\text { H01.01 } \\
\text { H01.02 }\end{array}$ & $\begin{array}{l}1.693 \\
1,611\end{array}$ & $\begin{array}{l}1,693 \\
2,179\end{array}$ & $\begin{array}{l}1.845 \\
1,774\end{array}$ & $\begin{array}{l}2,558 \\
2,440\end{array}$ & $\begin{array}{l}2,347 \\
2,099\end{array}$ & $\begin{array}{l}2,376 \\
2,501\end{array}$ & $\begin{array}{l}2.039 \\
1,984\end{array}$ & $\begin{array}{l}2.056 \\
2,440\end{array}$ & $\begin{array}{l}2,441 \\
2,562\end{array}$ & $\begin{array}{l}2,361 \\
2,856\end{array}$ \\
\hline H01.03 & 1,938 & 2,239 & 1,448 & 2,011 & 2,157 & 2,327 & 2,112 & 1,534 & 2,608 & 2,465 \\
\hline H02.02 & 1,845 & 1,793 & 1,894 & 1,975 & 2,352 & 2,294 & 1,538 & 2,025 & 2,078 & 2,870 \\
\hline H02.03 & 2,117 & 2,052 & 1,718 & 1,893 & 2,254 & 2,206 & 1,845 & 1,540 & 2,132 & 2,255 \\
\hline H02.04 & $2,438^{A}$ & 1,670 & 1,940 & 1,790 & 2,463 & 1,723 & 2,136 & 1,866 & 2,019 & 2,866 \\
\hline H03.03 & 1,579 & 1,842 & 1,678 & 2,498 & 2,333 & 1,519 & 1,972 & 2,085 & 1,934 & 2,322 \\
\hline H03.04 & 1,871 & 1,842 & 1,918 & 2,104 & 2,129 & 1,735 & 2,234 & 2,028 & 2,148 & 2,345 \\
\hline H03.05 & 1,821 & 1,761 & 2,251 & 2,169 & 1,989 & 1,937 & 2,056 & 1,783 & 2,321 & 1,962 \\
\hline H04.04 & 2,161 & 1,555 & 2,138 & 2,121 & 2,223 & 2,216 & 1,964 & 2,023 & 2,456 & 2,493 \\
\hline H04.05 & 2,359 & 1,767 & 1,957 & 2,141 & 1,983 & 2,412 & 1,902 & 1,956 & 2,658 & 1,421 \\
\hline H04.06 & 1,938 & 2,048 & 1,907 & 2,428 & 2,362 & 2,082 & 2,213 & 2,156 & 1,964 & 2,465 \\
\hline H05.05 & 2,037 & 2,028 & 2,239 & 2,552 & 2,086 & 2,058 & 1,773 & 2,020 & 2,451 & 2,330 \\
\hline H05.06 & 1,757 & 1,777 & 2,278 & 2,270 & 2,210 & 2,204 & 2,205 & 2,033 & 2,390 & 1,994 \\
\hline H05.07 & 1,730 & 1,954 & 1,845 & 2,170 & 2,202 & 2,829 & 2,026 & 2,054 & 2,313 & 2,614 \\
\hline H06.06 & 1,704 & 1,878 & 1,652 & 2,265 & 2,148 & 1,734 & 1,951 & 1,852 & 2,597 & 2,632 \\
\hline H06.07 & 1,709 & 2,225 & 1,984 & 2,027 & 2,616 & 2,255 & 2,416 & 1,724 & 2,130 & 2,540 \\
\hline H06.08 & 1,822 & 1,832 & 1,898 & 2,266 & 2,318 & 2,060 & 1,516 & 1,523 & 2,066 & 2,683 \\
\hline H07.07 & 1,755 & 1,827 & 1,824 & 2,010 & 2,558 & 1,898 & 1,904 & 1,324 & 2,249 & 2,031 \\
\hline H07.08 & 1,779 & 2,231 & 1,920 & 1,918 & 1,881 & 1,970 & 1,704 & 1,410 & 2,290 & 2,409 \\
\hline H07.09 & 2,013 & 2,023 & 1,994 & 2,142 & 2,698 & 2,460 & 1,813 & 1,769 & 2,264 & 2,142 \\
\hline H08.08 & 2,178 & 2,005 & 1,521 & 1,976 & 2,538 & 1,936 & 1,471 & 1,383 & 2,869 & 2,470 \\
\hline H08.09 & 2,117 & 1,790 & 1,993 & 1,686 & 2,242 & 1,758 & 1,836 & 1,568 & 2,619 & 2,432 \\
\hline H08.10 & 1,702 & 2,214 & 2,042 & 2,138 & 2,396 & 2,014 & 2,119 & 1,632 & 2,432 & 2,344 \\
\hline H09.09 & 2,095 & 1,657 & 1,747 & 2,439 & 2,175 & 2,299 & 1,625 & 2,284 & 2,340 & 2,477 \\
\hline H09.10 & 1,914 & 2,044 & 2,010 & 1,941 & 1,790 & 1,922 & 1,371 & 1,803 & 2,269 & 2,659 \\
\hline H09.01 & 1,711 & 1,829 & 1,674 & 2,110 & 2,094 & 2,118 & 1,719 & 2,201 & 2,204 & 2,273 \\
\hline H10.10 & 1,785 & 2,085 & 2,133 & 2,424 & 2,273 & 1,980 & 1,733 & 1,021 & 2,029 & 2,892 \\
\hline H10.01 & 1,810 & 1,975 & 1,693 & 2,347 & 2,416 & 2,341 & 1,968 & 1,713 & 1,890 & 2,568 \\
\hline $\mathrm{H} 10.02$ & 1,420 & 2,114 & 1,701 & 2,091 & 2,093 & 2,826 & 1,549 & 2,218 & 1,840 & 2,235 \\
\hline$\overline{\bar{H}}$ & 1,880 & 1,931 & 1,887 & 2,163 & 2,248 & 2,133 & 1,890 & 1,834 & 2,285 & 2,414 \\
\hline$T$ & 2,094 & 1,933 & 1,727 & 2,362 & 2,306 & 2,169 & 1,817 & 1,852 & 2,361 & 2,348 \\
\hline $\bar{H} \%$ & 89,78 & 99,91 & 109,2 & 91,61 & 97,46 & 98,34 & 104,0 & 99,05 & 96,79 & 102,7 \\
\hline
\end{tabular}


Tabela 18 - Médias de peso de grãos $\left(\mathrm{kg} / 3,6 \mathrm{~m}^{2}\right)$ referentes a 269 híbridos observados e um híbrido obtido a partir das estimativas de $\mathrm{m}, \mathrm{g}_{\mathrm{i}}$ e $\mathrm{g}_{\mathrm{j}}$, resultantes de um dialélico parcial circulante entre progênies de irmãos germanos, multiplicadas por cruzamentos fraternais, das populações ESALQ PB-1 e SUWAN, avaliados em dez experimentos. Média de três repetições. Tha Solteira-SP, 1992/93.

\begin{tabular}{|c|c|c|c|c|c|c|c|c|c|c|}
\hline & \multicolumn{10}{|c|}{ Experimentos } \\
\hline Híbridos & 01 & 02 & 03 & 04 & 05 & 06 & 07 & 08 & 09 & 10 \\
\hline $\begin{array}{l}\text { H01.01 } \\
\text { H01.02 }\end{array}$ & $\begin{array}{l}1,395 \\
1,265\end{array}$ & $\begin{array}{l}1,408 \\
1,763\end{array}$ & $\begin{array}{l}1,558 \\
1,469\end{array}$ & $\begin{array}{l}2,138 \\
1,988\end{array}$ & $\begin{array}{l}1,949 \\
1,732\end{array}$ & $\begin{array}{l}2.012 \\
2,101\end{array}$ & $\begin{array}{l}1,656 \\
1,631\end{array}$ & $\begin{array}{l}1,741 \\
2,092\end{array}$ & $\begin{array}{l}2,010 \\
2,151\end{array}$ & $\begin{array}{l}1,964 \\
2,440\end{array}$ \\
\hline H01.03 & 1,647 & 1,847 & 1,187 & 1,662 & 1,804 & 1,943 & 1,704 & 1,282 & 2,216 & 2,011 \\
\hline H02.02 & 1,575 & 1,480 & 1,585 & 1,576 & 1, & 1 , & 1,273 & 1,714 & 1,669 & 2,333 \\
\hline HO & 1,814 & 1,731 & 1,398 & 1,548 & 1,857 & 1,799 & 1,505 & 1,246 & 1,706 & 070 \\
\hline 4 & $2,120^{A}$ & 1,436 & 1,592 & 1,497 & 2,038 & 1,434 & 1,841 & 1,600 & 1,024 & 356 \\
\hline $\mathrm{HO}$ & 1,263 & 1,568 & 1,389 & 2,140 & 1,953 & 1,183 & 1,655 & 1,724 & 1,598 & 1,939 \\
\hline H & 1,552 & 1,489 & 1,622 & 1,777 & 1,759 & 1,412 & 1,830 & 1,746 & 1,755 & 1,937 \\
\hline H03.05 & 1,483 & 1,437 & 1,851 & 1,755 & 1,627 & 1,571 & 1,683 & 1,407 & 1,939 & 1,633 \\
\hline 04 & 1,797 & 1,277 & 1,764 & 1,793 & 1,751 & 1,849 & 1,683 & 1,695 & 1,919 & 1,956 \\
\hline $\mathrm{H}$ & 1,943 & 1,446 & 1,542 & 1,753 & 1, & 51 & 1,597 & 1,648 & 08 & 46 \\
\hline H( & 1,602 & 1,672 & 1,615 & 2,044 & 1,947 & 1,711 & 1,848 & 1,752 & 1,543 & 1,972 \\
\hline HC & 1,719 & 1,677 & 1,855 & 2,131 & 1,705 & 1,708 & 1,475 & 1,625 & 2,081 & 1,916 \\
\hline $\mathrm{H}$ & 1,424 & 1,456 & 1,890 & 1,916 & 1,842 & 1,815 & 1,817 & 1,680 & 1,933 & 1,634 \\
\hline HU & 1,424 & 1,705 & 1,493 & 1,800 & 1,854 & 2,394 & 1,688 & 1,724 & 1,950 & 2,118 \\
\hline 06 & 1,358 & 1,529 & 1,294 & 1,859 & 1,750 & 1,413 & 1,526 & 1 & 2 , & 148 \\
\hline & 1,411 & 1,856 & 1,593 & 1,695 & 2,1 & 1,854 & 2,021 & 1,419 & 1 , & 2,073 \\
\hline & 32 & 1,503 & 1,560 & 1,879 & 1,936 & 686 & 207 & 1,227 & & 195 \\
\hline HO & 1,480 & 1,514 & 1,483 & 1,645 & 2,116 & 1,563 & 1,595 & 1,049 & 55 & 1,669 \\
\hline H07.08 & 1,476 & 1,805 & 1,571 & 1,612 & 1,546 & 1,671 & 1,376 & 1,139 & 1,866 & 1,963 \\
\hline H07.09 & 1,702 & 1,669 & 1,611 & 1,853 & 2,169 & 2,054 & 1,519 & 1,455 & 1,849 & 1,717 \\
\hline H08.08 & 1,810 & 1,630 & 1,275 & 1,583 & 2,092 & 1,620 & 1,173 & 1,152 & 2,426 & 2,076 \\
\hline $\mathbf{H}$ & 1,722 & 1,466 & 1,626 & 1,403 & 1,843 & 1,449 & 1,473 & 1,301 & 2,219 & 2,016 \\
\hline & 1, & 1 , & 1, & 1,739 & & 32 & 11 & & 53 & 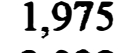 \\
\hline H09.09 & 1,706 & 1,373 & 1,431 & 2,018 & 1,800 & 1,940 & 1,353 & 1,913 & 1,879 & 2,038 \\
\hline H09.10 & 1,452 & 1,694 & 1,622 & 1,527 & 1,483 & 1,634 & 1,124 & 1,512 & 1,825 & 2,216 \\
\hline H09.01 & 1,415 & 1,495 & 1,411 & 1,736 & 1,776 & 1,776 & 1,364 & 1,811 & 1,747 & 1,802 \\
\hline H10.10 & 1,472 & 1,757 & 1,688 & 1,989 & 1,895 & 1,689 & 1,424 & 0,801 & 1,642 & 2,468 \\
\hline 10.01 & 1,540 & 1,653 & 1,365 & 1,906 & 2,048 & 1,950 & 1,576 & 1,416 & 1,548 & 2,194 \\
\hline H10.02 & 1,165 & 1,750 & 1,436 & 1,716 & 1,759 & 2,357 & 1,239 & 1,867 & 1,498 & 1,82 \\
\hline $\bar{H}$ & 1,555 & 1,598 & 1,549 & 1,789 & 1,860 & 1,771 & 1,552 & 1,521 & 1,877 & 1,986 \\
\hline$T$ & 1,745 & 1,636 & 1,448 & 2,019 & 1,933 & 1,825 & 1,538 & 1,552 & 2,004 & 1,995 \\
\hline $\bar{H} \%$ & 89,11 & 97,66 & 106,9 & 88,62 & 96,24 & 97,00 & 100,9 & 98,02 & 93,65 & 99,55 \\
\hline
\end{tabular}

A-Média estimada a partir de $\mathrm{m}, \mathrm{g}_{\mathrm{i}}$ e $\mathrm{g}_{j} ; \bar{H}$ - Média dos híbridos; $\mathrm{T}$ - média da testemunha; $\bar{H} \%$ Porcentagem em relação à testemunha. 
Tabela 19 - Relação entre as médias da testemunha (FT 9043), para cinco variáveis, em experimentos correspondentes aos sistemas de multiplicação por autofecundação e cruzamentos fraternais das progênies participantes de um dialélico parcial circulante entre as populações SUWAN e ESALQ PB-1. Tha Solteira-SP, 1992/93.

\begin{tabular}{cccccc}
\hline \multicolumn{7}{c}{ Relação autofecundação/cruzamentos fraternais } \\
\hline Experimentos & FF & AP & AE & PE & PG \\
\hline 01 & 0,98 & 0,97 & 0,99 & 1,11 & 1,12 \\
02 & 0,99 & 0,91 & 0,87 & 1,25 & 1,26 \\
03 & 0,99 & 1,02 & 0,95 & 1,54 & 1,56 \\
04 & 0,99 & 1,01 & 1,00 & 1,06 & 1,07 \\
05 & 0,99 & 1,05 & 1,01 & 1,26 & 1,29 \\
06 & 1,00 & 0,98 & 0,89 & 1,20 & 1,21 \\
07 & 0,97 & 1,08 & 0,99 & 1,57 & 1,57 \\
08 & 0,96 & 1,10 & 1,05 & 1,37 & 1,37 \\
09 & 1,02 & 1,01 & 1,00 & 1,13 & 1,14 \\
\hline
\end{tabular}

Tabela 20 - Quadrados médios da análise agrupada da variância para as variáveis florescimento feminino (FF), altura de plantas (AP) altura de espigas (AE), peso de espigas (PE) e peso de grãos (PG), no sistema de autofecundação de multiplicação das progênies participantes de um dialélico parcial circulante. Illha Solteira, 1992/93.

\begin{tabular}{lccllll}
\hline \multicolumn{1}{c}{ F. V. } & G.L $^{\prime \prime}$ & FF & AP & AE & PE & PG \\
\hline Blocos & 18 & $5,1840^{* *}$ & $0,0475^{* *}$ & $0,0256^{* *}$ & $0,4508^{* *}$ & $0,3305^{* *}$ \\
Tratamentos & 269 & $3,0422^{* *}$ & $0,0366^{* *}$ & $0,0344^{* *}$ & $0,2234^{* *}$ & $0,1676^{* *}$ \\
Híbridos & 260 & $3,0869^{* *}$ & $0,0335^{* *}$ & $0,0303^{* *}$ & $0,2287^{* *}$ & $0,1707^{* *}$ \\
$\quad$ Diagonais & 18 & 0,8660 & $0,0298^{* *}$ & $0,0329^{* *}$ & 0,0756 & 0,0395 \\
$\quad$ Diagonal 1 & 81 & $3,5749^{* *}$ & $0,0347^{* *}$ & $0,0303^{* *}$ & $0,2496^{* *}$ & $0,1945^{* *}$ \\
$\quad$ Diagonal 2 & 80 & $3,5236^{* *}$ & $0,0338^{* *}$ & $0,0333^{* *}$ & $0,2864^{* *}$ & $0,2104^{* *}$ \\
$\quad$ Diagonal 3 & 81 & $2,6613^{* *}$ & $0,0336^{* *}$ & $0,0267^{* *}$ & $0,1848^{* *}$ & $0,1369^{* *}$ \\
H vs Test. & 9 & 1,7487 & $0,1250^{* *}$ & $0,1541^{* *}$ & 0,0702 & 0,0777 \\
Resíduo Médio & $541(532$ & 1,5835 & $0,0128^{* *}$ & $0,0109^{* *}$ & 0,1089 & 0,0791 \\
\hline C.V. (\%) & & 2,3475 & 4,8235 & 7,6956 & 12,7191 & 13,1152 \\
Médias & & 53,6057 & 2,3502 & 1,3570 & 2,5945 & 2,1447 \\
\hline
\end{tabular}

" - G.L. para PE e PG, entre parêntesis; ${ }^{*}$ - Teste F significativo ao nível de $5 \%$ de probabilidade; ${ }^{* *}$

- Teste F significativo ao nível de $1 \%$ de probabilidade. 
Tabela 21 - Quadrados médios da análise agrupada da variância para as variáveis florescimento feminino (FF), altura de plantas (AP) altura de espigas (AE), peso de espigas (PE) e peso de grãos (PG), no sistema de cruzamentos fraternais de multiplicação das progênies participantes de un dialélico parcial circulante, considerando os dados originais e corrigidos pelos índices da Tabela 19 Illha Solteira, 1992/93.

\begin{tabular}{|c|c|c|c|c|c|c|}
\hline F. V. & G.L. $L^{/ 1}$ & FF & AP & $\mathrm{AE}$ & PE & PG \\
\hline & \multicolumn{6}{|c|}{ COM OS DADOS ORIGINAIS } \\
\hline Blocos & 20 & $4,0054^{*}$ & $0,0428 * *$ & $0,0210^{* *}$ & $0,1434^{*}$ & $0,1090^{*}$ \\
\hline Tratamentos & 299 & $8,0776^{* *}$ & $0,0287^{* *}$ & $0,0256 * *$ & $0,1884^{* *}$ & $0,1446 * *$ \\
\hline Híbridos & 289 & $8,1896^{* *}$ & $0,0274^{* *}$ & $0,0233^{* *}$ & $0,1930^{* *}$ & $0,1478 * *$ \\
\hline Diagonais & 20 & $4,2561^{*}$ & 0,0108 & $0,0156^{*}$ & $0,1714^{* *}$ & $0,1060 * *$ \\
\hline Diagonal 1 & 90 & $9,0196 * *$ & $0,0306 * *$ & $0,0267^{* *}$ & $0,1945^{* *}$ & $0,1541^{* *}$ \\
\hline Diagonal 2 & 90 & $9,6452 * *$ & $0,0341 * *$ & $0,0255^{* *}$ & $0,2108 * *$ & $0,1638 * *$ \\
\hline Diagonal 3 & 89 & $6,7624 * *$ & $0,0212 * *$ & $0,0194^{* *}$ & $0,1784 * *$ & $0,1340 * *$ \\
\hline H vs Test. & 10 & $4,8402^{*}$ & $0,0649 * *$ & $0,0898^{* *}$ & 0,0553 & 0,0508 \\
\hline Residuo Médio & $601(591$ & 2,2574 & 0,0086 & 0,0082 & 0,0860 & 0,0649 \\
\hline \multirow[t]{2}{*}{ Médias } & & 53,7796 & 2,3140 & 1,3454 & 2,06647 & 1,7066 \\
\hline & \multicolumn{6}{|c|}{ COM OS DADOS AJUSTADOS } \\
\hline Blocos & 20 & $3,8734^{*}$ & $0,0427 * *$ & $0,0189 * *$ & $0,2147^{*}$ & $0,1697^{*}$ \\
\hline Tratamentos & 299 & $7,9630 * *$ & $0,0282 * *$ & $0,0242 * *$ & $0,2869 * *$ & $0,2215^{* *}$ \\
\hline Híbridos & 289 & $8,0739 * *$ & $0,0270^{* *}$ & $0,0222 * *$ & $0,2941^{* *}$ & $0,2268 * *$ \\
\hline Diagonais & 20 & $4,0902^{*}$ & 0,0109 & $0,0153^{*}$ & $0,2494 * *$ & $0,1552^{* *}$ \\
\hline Diagonal 1 & 90 & $8,8154^{* *}$ & $0,0303 * *$ & $0,0253 * *$ & $0,3049 * *$ & $0,2422 * *$ \\
\hline Diagonal 2 & 90 & $9,5569 * *$ & $0,0337 * *$ & $0,0244^{* *}$ & $0,3067^{* *}$ & $0,2395^{* *}$ \\
\hline Diagonal 3 & 89 & $6,7194^{* *}$ & $0,0205^{* *}$ & $0,0182^{* *}$ & $0,2805^{* *}$ & $0,2138 * *$ \\
\hline H vs Test. & 10 & $4,7586^{*}$ & $0,0643 * *$ & $0,0828 * *$ & 0,0772 & 0,0673 \\
\hline Resíduo Médio & $601(591$ & 2,2233 & 0,0088 & 0,0078 & 0,1357 & 0,1046 \\
\hline Médias & & 53,3647 & 2,3180 & 1,3050 & 2,5140 & 2,0924 \\
\hline C.V.(\%) & & 2,7938 & 4,0103 & 6,7334 & 14,1939 & 14,9320 \\
\hline
\end{tabular}


Tabela 22 - Estimativas de parâmetros genéticos para as variáveis florescimento feminino (FF), altura de plantas (AP), altura de espigas (AE), peso de espigas (PE) e peso de grãos (PG), em dois sistemas de multiplicação das progênies, em um dialélico parcial circulante Ilha Solteira-SP, 1992/93.

\begin{tabular}{|c|c|c|c|c|c|}
\hline Parâmetros ${ }^{11}$ & FF & $\mathbf{A P}$ & $\mathrm{AE}$ & PE & PG \\
\hline & \multicolumn{5}{|c|}{ MULTIPLICAÇĀO POR AUTOFECUNDAÇĀo } \\
\hline$\hat{\sigma}_{h}^{2}$ & 0,5011 & 68,8304 & 64,6419 & 99,8238 & 76,3368 \\
\hline$\hat{\sigma}_{h^{*}}^{2}$ & 0,5562 & 70,7000 & 64,0000 & 109,3125 & 84,4675 \\
\hline$\hat{\sigma}_{F}^{2}$ & 1,0290 & 111,6600 & 100,9900 & 190,5725 & 142,2725 \\
\hline$\hat{\sigma}_{F^{*}}^{2}$ & 1,0840 & 113,5300 & 100,3500 & 200,0600 & 150,4050 \\
\hline$\hat{h}_{H}^{2}$ & 0,4870 & 0,6164 & 0,6401 & 0,5238 & 0,5365 \\
\hline$\hat{h}_{H^{*}}^{2}$ & 0,5131 & 0,6227 & 0,6378 & 0,5464 & 0,5616 \\
\hline $\mathbf{C V}_{\mathrm{g}}$ & 1,3205 & 3,5300 & 5,9250 & 7,7018 & 8,1475 \\
\hline $\mathrm{CV}_{\mathrm{g}^{*}}$ & 1,3912 & 3,5776 & 5,8957 & 8,0596 & 8,5704 \\
\hline$\theta$ & 0,5625 & 0,7318 & 0,7699 & 0,6055 & 0,6212 \\
\hline \multirow[t]{2}{*}{$\theta$. } & 0,5927 & 0,7417 & 0,7661 & 0,6336 & 0,6535 \\
\hline & \multicolumn{5}{|c|}{ MULTIPLICAÇÃO POR CRUZAMENTOS FRATENAIS } \\
\hline$\hat{\sigma}_{h}^{2}$ & 1,9774 & 62,7744 & 50,4264 & 89,1611 & 69,0657 \\
\hline$\hat{\sigma}_{h}^{2}(c)$ & 1,9502 & 60,5933 & 47,8518 & 132,0422 & 101,8975 \\
\hline$\hat{\sigma}_{h^{*}}^{2}$ & 2,0749 & 66,8800 & 52,3300 & 90,4975 & 71,4650 \\
\hline$\hat{\sigma}_{h^{*}}^{2}(\mathrm{c})$ & 2,0489 & 64,5908 & 49,5517 & 134,8138 & 106,0961 \\
\hline$\tilde{\sigma}_{F}^{2}$ & 2,7299 & 91,4700 & 77,7800 & 160,84753 & 123,1775 \\
\hline$\hat{\sigma}_{F}^{2}(\mathrm{c})$ & 2,6913 & 90,0012 & 73,8991 & 245,1024 & 189,0322 \\
\hline$\hat{\sigma}_{F^{*}}^{2}$ & 2,8274 & 95,5900 & 79,6900 & 162,1850 & 125,5800 \\
\hline $\bar{\sigma}_{F^{*}}^{2}(\mathrm{c})$ & 2,8900 & 93,9987 & 75,5990 & 247,8739 & 193,2308 \\
\hline$\hat{h}_{H}^{2}$ & 0,7243 & 0,6862 & 0,6483 & 0,5543 & 0,5607 \\
\hline$\hat{h}_{H^{*}}^{2}$ & 0,7338 & 0,6997 & 0,6567 & 0,5580 & 0,5691 \\
\hline $\mathrm{CV}_{\mathrm{g}}$ & 2,6147 & 3,4240 & 5,2780 & 9,1391 & 9,7395 \\
\hline $\mathrm{CV}_{\mathrm{g}^{*}}$ & 2,6784 & 3,5345 & 5,3772 & 9,2074 & 9,9074 \\
\hline$\theta$ & 0,9359 & 0,8538 & 0,7839 & 0,6439 & 0,6522 \\
\hline$\theta$ & 0,9587 & 0,8814 & 0,7986 & 0,6487 & 0,6635 \\
\hline
\end{tabular}

/1 - 0 asterisco indica parâmetros calculados com base no Q.M. conjunto das três diagonais [ $\left(S_{\mathrm{DQ}_{1}}+\right.$ $\mathrm{SQ}_{\mathrm{b} 2}+\mathrm{SQ}_{\mathrm{b}_{3}}$ )/269]; (c) indica parâmetros calculados com os dados corrigidos pelos índices da Tabela 19; vanâncias em (dias) ${ }^{2}$ para FF, (cm/planta) $)^{2}$ para AP e AE e em (g/planta) $)^{2}$ para PE e PG. 


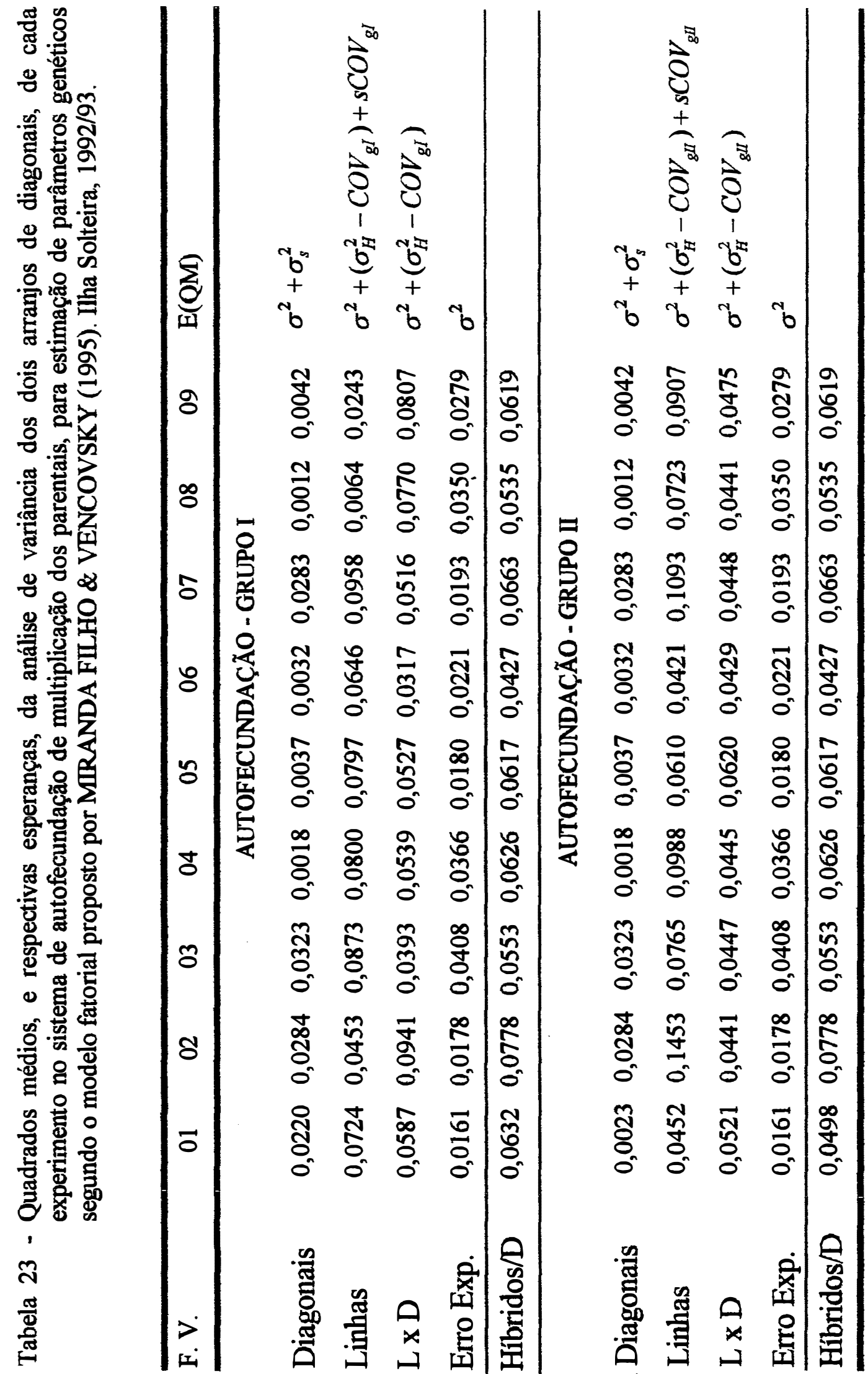


悉

원

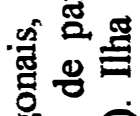

용응

햏잉

․․ㄹ

os

沓语

영

임

옹욱

도요

敋

s

.

월 2

염

of

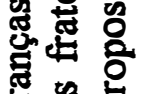

ㅎ⿺ㅇ

항 현

a

릉

옹웜

울

o ह

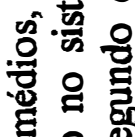

음

s:

⿶

彭器

त
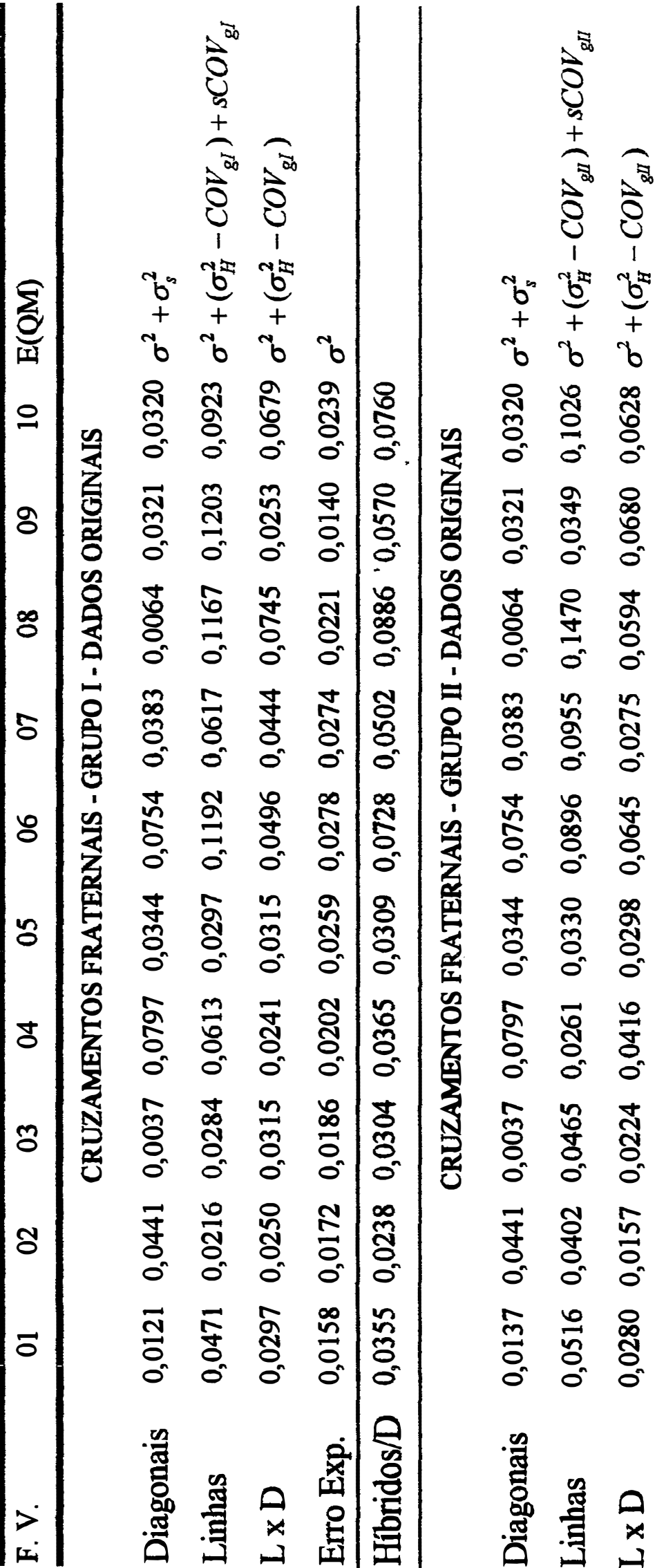

|

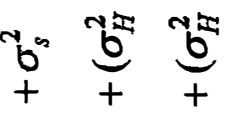

ib

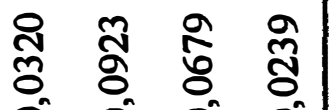

\begin{tabular}{llll|l}
0 & 0 & 0 & $0^{n}$ & $0^{n}$. \\
0 & $m$ & $m$ & 0 & 0
\end{tabular}

तิ

$\begin{array}{llllll}0^{n} & 0^{n} & 0^{n} & 0^{n} & 0^{n}\end{array}$

オัర

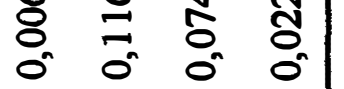

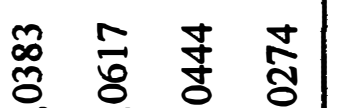

$\begin{array}{llll}0 & 0 & 0 & 0 \\ 0 & 0 & 0 & 0^{n}\end{array}$

華

on on on

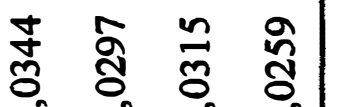

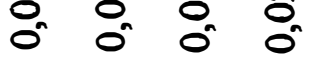

กิ $\frac{m}{0}$ 웡

$\begin{array}{lllll}0 & 0^{n} & 0^{n} & 0^{n} & 0^{n} \\ 0 & 0 & 0 & 0\end{array}$

ஸे ั⿱艹

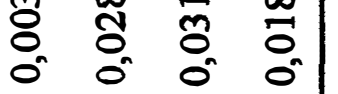

ষ

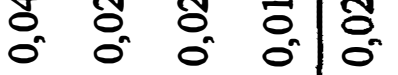

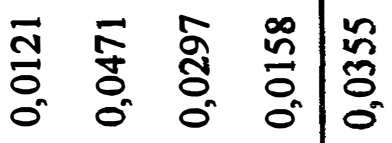

瓷 $b_{+}^{n} \underbrace{t^{2 x}}_{+}$

ib ${ }^{+}{ }^{+}$)

유 ญั

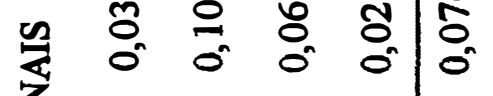

구 웅 웡요

\begin{tabular}{llll|l} 
on & กิ & 0 & 0 & 0 \\
0 & 0 & 0 & 0 & 0 \\
0
\end{tabular}

ปัర

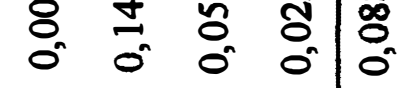

๗ૂׁ

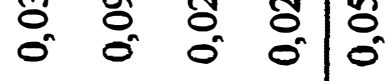

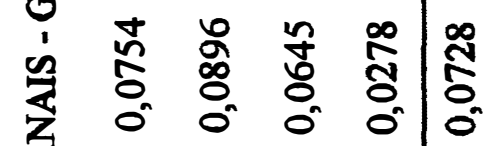

サ

娄

ป

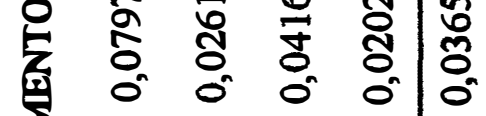

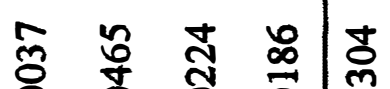

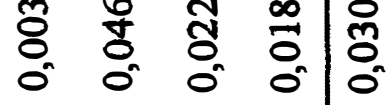

‡

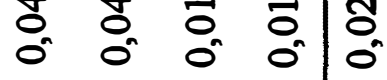

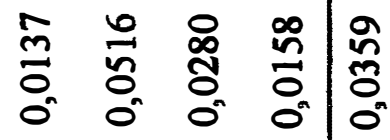

骂 


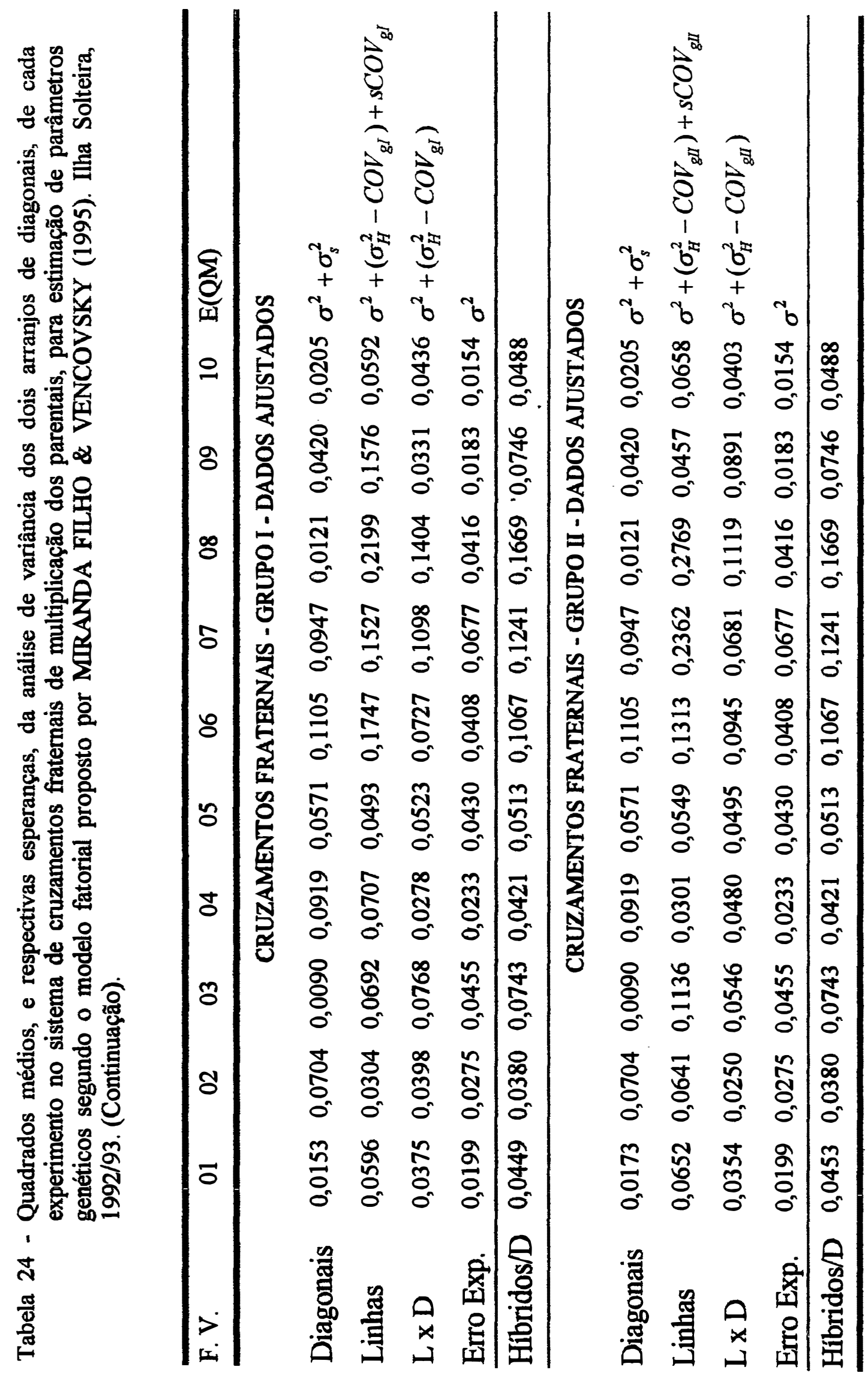


Tabela 25 - Estimativas das variâncias interpopulacionais, em (g/planta) ${ }^{2}$, para a variável produção de grãos, com dois sistemas de multiplicação dos parentais, em um dialélico parcial circulante entre progênies de irmãos germanos das populações SUWAN e ESALQ-PB1. Iha Solteira, 1992/93.

\begin{tabular}{|c|c|c|c|c|c|c|}
\hline Exp. & $\bar{\sigma}_{H}^{2}$ & $\bar{\sigma}_{g I}^{2}$ & $\hat{\sigma}_{g I}^{2}$ & $\overline{\sigma_{s}^{2}}$ & $\overline{\hat{\sigma}_{A(12)}^{2}}$ & $\hat{\sigma}_{D(12)}^{2}$ \\
\hline \multicolumn{7}{|c|}{ MULTIPLICAÇÃO POR AUTOFECUNDAÇÃO } \\
\hline 01 & 117,89 & 11,42 & $-5,72$ & 95,41 & 7,61 & 169,62 \\
\hline 02 & 150,09 & $-40,59$ & 84,41 & 106,28 & 58,42 & 188,94 \\
\hline 03 & 36,31 & 40,02 & 26,54 & $-30,25$ & 88,75 & $-53,77$ \\
\hline 04 & 65,10 & 21,73 & 45,31 & $-1,94$ & 89,39 & $-3,44$ \\
\hline 05 & 109,04 & 22,51 & $-0,87$ & 87,40 & 28,85 & 155,38 \\
\hline 06 & 51,48 & 27,43 & $-0,66$ & 24,72 & 35,69 & 43,94 \\
\hline 07 & 117,48 & 36,81 & 53,73 & 26,93 & 120,73 & 47,88 \\
\hline 08 & 46,12 & $-58,84$ & 23,57 & 81,38 & $-47,02$ & 144,68 \\
\hline 09 & 85,01 & $-47,00$ & $35,93^{\circ}$ & 96,08 & $-14,76$ & 170,81 \\
\hline Média & $86,50 \pm 13,09$ & $1,50 \pm 12,97$ & $29,14 \pm 9,87$ & $54,00 \pm 16,62$ & $40_{2} 85 \pm 18_{2} 04$ & $96,00 \pm 29_{2} 55$ \\
\hline \multicolumn{7}{|c|}{ MULTIPLICAÇÃO POR CRUZAMENTOS FRATERNAIS SEM CORREÇÃO } \\
\hline 01 & 49,28 & 14,56 & 19,64 & 15,52 & 54,72 & 39,74 \\
\hline 02 & 16,45 & $-2,83$ & 20,41 & $-1,13$ & 28,13 & $-2,90$ \\
\hline 03 & 29,49 & $-2,59$ & 20,13 & 11,95 & 28,07 & 30,59 \\
\hline 04 & 40,77 & 31,00 & $-12,92$ & 22,69 & 28,93 & 58,08 \\
\hline 05 & 12,44 & $-1,50$ & 2,70 & 11,24 & 1,92 & 28,78 \\
\hline 06 & 112,57 & 58,01 & 20,92 & 33,65 & 126,28 & 86,14 \\
\hline 07 & 57,01 & 14,44 & 56,63 & $-14,07$ & 113,72 & $-36,02$ \\
\hline 08 & 166,27 & 35,16 & 72,98 & 58,13 & 173,02 & 148,82 \\
\hline 09 & 107,44 & 79,20 & $-27,65$ & 55,89 & 82,48 & 143,08 \\
\hline 10 & 130,25 & 20,27 & 33,14 & 76,85 & 85,45 & 196,73 \\
\hline Média & $72,20 \pm 16,78$ & $24,57 \pm 8,59$ & $20,60 \pm 9_{2} 41$ & $27,07 \pm 9,09$ & $72,27 \pm 17,03$ & $69,30 \pm 23,27$ \\
\hline \multicolumn{7}{|c|}{ MULTIPLICAÇÃO POR CRUZAMENTOS FRATERNAIS COM CORREÇÃO } \\
\hline 01 & 62,85 & 18,41 & 24,82 & 19,62 & 69,16 & 50,23 \\
\hline 02 & 26,25 & $-4,51$ & 32,57 & $-1,81$ & 44,90 & $-4,63$ \\
\hline 03 & 71,99 & $-6,32$ & 49,14 & 29,17 & 68,52 & 74,67 \\
\hline 04 & 47,01 & 35,75 & $-14,90$ & 26,16 & 33,36 & 66,98 \\
\hline 05 & 20,65 & $-2,50$ & 4,49 & 18,67 & 3,18 & 47,78 \\
\hline 06 & 164,97 & 85,00 & 30,65 & 49,31 & 185,05 & 126,23 \\
\hline 07 & 141,00 & 35,72 & 140,08 & $-34,80$ & 281,28 & $-89,09$ \\
\hline 08 & 313,30 & 66,24 & 137,51 & 109,54 & 236,01 & 280,42 \\
\hline 09 & 140,66 & 103,69 & $-36,19$ & 73,17 & 107,09 & 187,32 \\
\hline 10 & 83,61 & 83,61 & 21,27 & 49,33 & 54,85 & 126,28 \\
\hline Média & $107,23 \pm 27,8$ & $34,45 \pm 12,30$ & $38,94 \pm 18,38$ & $33,83 \pm 12,58$ & $117,43 \pm 34,8$ & $86,62 \pm 32,21$ \\
\hline
\end{tabular}


Tabela 26 - Quadrados médios da análise de variância conjunta para dois sistemas de multiplicação das progênies (autofecundação e cruzamentos fraternais -nove experimentos cada um), para cinco variáveis, em um dialélico parcial circulante entre as populações SUWAN e ESALQ PB-1. Tha Solteira-SP, 1992/93.

\begin{tabular}{lcccccc}
\hline F.V. & G.L & FF & AP & AE & PE & PG \\
\hline Híbridos/E & 259 & $4,8381^{* *}$ & $0,0314^{* * *}$ & $0,0266^{* *}$ & $0,2908^{* *}$ & $0,2240^{* *}$ \\
Experimentos & 8 & $87,3021^{* *}$ & $1,2312^{* *}$ & $0,7553^{* *}$ & $6,0739^{* *}$ & $4,0321^{* *}$ \\
Sistemas & 1 & $145,6033^{*}$ & 0,0513 & 1,2593 & 0,1799 & 0,0002 \\
S x E & 8 & $23,8725^{* *}$ & $0,5445^{* *}$ & $0,4911^{* *}$ & $3,2850^{* *}$ & $2,3725^{* *}$ \\
S x H/E & 259 & $5,8280^{* *}$ & $0,0276^{* *}$ & $0,3139^{* *}$ & $0,2444^{* *}$ & $0,1836^{* *}$ \\
Erro Médio & $(1142) 1123$ & 1,9381 & 0,0106 & 0,0095 & 0,0968 & 0,0716 \\
\hline
\end{tabular}

7 - Graus de Liberdade para PE e PG entre parêntesis; * - significativo pelo teste F ao nível de 5\% de probabilidade; ${ }^{* *}$ - significativo pelo teste $F$ ao nível de $1 \%$ de probabilidade. 
Tabela 27 - Quadrados médios da análise agnupada de variância da capacidade geral de combinação para as variáveis florescimento feminino (FF), altura de plantas (AP), altura de espigas (AE), peso de espigas (PE) e peso de grãos (PG), em dois sistemas de multiplicação das progênies participantes de um dialélico parcial circulante entre as populações ESALQ PB-1 e SUWAN. Três repetições. Ilha Solteira, 1992/93.

\begin{tabular}{|c|c|c|c|c|c|c|}
\hline F.V. & G.L. & $\mathbf{F F}$ & $\mathbf{A P}$ & $\overline{\mathrm{AE}}$ & $\mathbf{P E}$ & PG \\
\hline & \multicolumn{6}{|c|}{ MULTIPLICAÇÃO POR AUTOFECUNDAÇÃO } \\
\hline Híbridos & 260 & $1,0290 * *$ & $0,0112^{* *}$ & $0,0101^{* *}$ & $0,0762^{* *}$ & $0,0569 * *$ \\
\hline CGC/Grupos & 162 & $1,3259 * *$ & $0,0129 * *$ & $0,0113^{* *}$ & $0,0888 * *$ & $0,0669 * *$ \\
\hline $\mathrm{CGC}_{1}$ & 81 & $1,4049 * *$ & $0,0138^{* *}$ & $0,0115^{* *}$ & $0,0590^{* *}$ & $0,0479 * *$ \\
\hline $\mathrm{CGC}_{2}$ & 81 & $0,8890^{* *}$ & $0,0079 * *$ & $0,0077^{* *}$ & $0,1014^{* *}$ & $0,0727^{* *}$ \\
\hline CEC & 98 & 0,5381 & $0,0083 * *$ & $0,0081^{* *}$ & $0,0554^{*}$ & $0,0404^{*}$ \\
\hline \multirow[t]{2}{*}{ Resíduo Médio } & $541(532)$ & 0,5278 & 0,0043 & 0,0036 & 0,0363 & 0,0264 \\
\hline & \multicolumn{6}{|c|}{ MULTIPLICAÇÃO POR CF SEM CORREÇÃO } \\
\hline Híbridos & 289 & $2,7299 * *$ & $0,0091^{* *}$ & $0,0078^{* *}$ & $0,0643^{* *}$ & $0,0493 * *$ \\
\hline CGC/Grupos & 180 & $3,6055^{* *}$ & $0,0120^{* *}$ & $0,0097^{* *}$ & $0,0775^{* *}$ & $0,0602^{* *}$ \\
\hline $\mathrm{CGC}_{1}$ & 90 & $2,5523^{* *}$ & $0,0109^{* *}$ & $0,0096^{* *}$ & $0,0675^{* *}$ & $0,0539 * *$ \\
\hline $\mathrm{CGC}_{2}$ & 90 & $3,5084^{* *}$ & $0,0106^{* *}$ & $0,0082^{* *}$ & $0,0668 * *$ & $0,0506^{* *}$ \\
\hline CEC & 109 & $1,2839 * *$ & $0,0044^{* *}$ & $0,0046^{* *}$ & $0,0426^{* *}$ & $0,0312^{* *}$ \\
\hline \multirow[t]{2}{*}{ Resíduo Médio } & $01(591)$ & 0,7525 & 0,0029 & 0,0027 & 0,0287 & 0,0216 \\
\hline & \multicolumn{6}{|c|}{ MULTIPLICAÇÃO POR CF COM CORREÇÃO } \\
\hline Hibridos & 289 & $2,6913^{* *}$ & $0,0090^{* *}$ & $0,0074^{* *}$ & $0,0980^{* *}$ & $0,0756^{* *}$ \\
\hline CGC/Grupos & 180 & $3,5634^{* *}$ & $0,0117^{* *}$ & $0,0092^{* *}$ & $0,1202^{* *}$ & $0,0936^{* *}$ \\
\hline $\mathrm{CGC}_{1}$ & 90 & $2,5054^{* *}$ & $0,0108 * *$ & $0,0091^{* *}$ & $0,0997^{* *}$ & $0,0790^{* *}$ \\
\hline $\mathrm{CGC}_{2}$ & 90 & $3,4690^{* *}$ & $0,0104^{* *}$ & $0,0077^{* *}$ & $0,1083^{* *}$ & $0,0824^{* *}$ \\
\hline CEC & 109 & $1,2510^{* *}$ & $0,0045^{* *}$ & $0,0044^{* *}$ & $0,0614^{* *}$ & $0,0459 * *$ \\
\hline Resíduo Médio & $601(591)$ & 0,7411 & 0,0029 & 0,0026 & 0,0452 & 0,0349 \\
\hline
\end{tabular}

7 - Graus de Liberdade para PE e PG entre parêntesis. * - significativo pelo teste F ao nível de $5 \%$ de probabilidade; ** - significativo pelo teste $\mathrm{F}$ ao nível de $1 \%$ de probabilidade. 
Tabela 28 - Estimativas dos parâmetros $g_{i}$ e $g_{j}$ das progênies de irmãos germanos das populações SUWAN e ESALQ PB-1, multiplicadas por autofecundação, para a variável dias para o florescimento feminino, referentes a nove experimentos. Ilha Solteira-SP, 1992/93.

\begin{tabular}{|c|c|c|c|c|c|c|c|c|c|}
\hline \multirow{2}{*}{$\begin{array}{c}\text { Progê- } \\
\text { nies }\end{array}$} & \multicolumn{9}{|c|}{ Experimentos } \\
\hline & 01 & 02 & 03 & 04 & 05 & 06 & 07 & 08 & 09 \\
\hline & \multicolumn{9}{|c|}{ População SUWAN (gi) } \\
\hline 01 & 1,4749 & 1,0719 & 0,3833 & $-0,1985$ & $-0,8614$ & 0,7619 & $-0,2573$ & 0,0835 & $-0,3763$ \\
\hline 02 & $-0,6980$ & $-0,3341$ & $-0,6096$ & 1,6829 & 0,1937 & 0,6433 & 0,4345 & 0,6470 & $-0,2086$ \\
\hline 03 & $-0,1088$ & $-0,9964$ & 2,3187 & 1,2489 & 0,4392 & $-0,5067$ & 0,1709 & $-0,0006$ & $-0,6788$ \\
\hline 04 & $-0,2607$ & $-1,4133$ & $-0,4026$ & 1,5914 & 0,8071 & $-0,1231$ & $-0,5695$ & 1,3965 & $-0,1987$ \\
\hline 05 & 0,1097 & 0,4447 & $-0,4367$ & $-0,5366$ & $-0,1550$ & $-0,8425$ & 0,8727 & $-1,1844$ & 1,7780 \\
\hline 06 & $-2,5179$ & $-0,0326$ & 0,4198 & $-0,2290$ & $-0,2695$ & $-1,0035$ & $-0,5887$ & 0,1122 & 1,4883 \\
\hline 07 & 0,6642 & 1,2267 & $-0,3129$ & $-0,8734$ & 0,2054 & $-0,9750$ & 0,0617 & $-1,1132$ & 0,4573 \\
\hline 08 & $-0,7346$ & 0,5249 & $-0,2396$ & $-1,8053$ & 0,4854 & 0,7469 & 0,1584 & $-0,1283$ & $-1,0221$ \\
\hline 09 & 1,3805 & $-0,0794$ & $-1,1212$ & $-0,6354$ & 0,2856 & 0,8160 & $-0,9718$ & $-0,1527$ & $-0,3064$ \\
\hline \multirow[t]{2}{*}{10} & 0,6907 & $-0,4124$ & 0,0008 & $-0,2450$ & $-1,1304$ & 0,4827 & 0,6891 & 0,3401 & $-0,9327$ \\
\hline & \multicolumn{9}{|c|}{ População ESALQ PB-1 ( $\left.\mathrm{g}_{j}\right)$} \\
\hline 01 & $-0,1623$ & $-0,5494$ & $-1,0667$ & 0,4260 & 0,0691 & $-0,3858$ & $-0,0624$ & 0,0851 & 1,4468 \\
\hline 02 & $-0,2821$ & $-0,4611$ & 0,6528 & 0,2065 & $-0,4569$ & $-0,7716$ & 0,0222 & $-0,4015$ & 0,3042 \\
\hline 03 & $-1,3490$ & 0,3969 & $-0,3431$ & $-0,1781$ & $-0,5368$ & $-0,5552$ & 0,4150 & $-0,3980$ & 0,1129 \\
\hline 04 & $-0,3238$ & 0,6686 & $-0,0778$ & $-1,2181$ & $-0,7563$ & $-0,0402$ & 0,5224 & 0,0544 & 0,2737 \\
\hline 05 & $-0,0397$ & 1,1857 & $-0,4721$ & $-0,8116$ & 0,1366 & 0,6784 & $-0,8470$ & $-0,4485$ & 0,0548 \\
\hline 06 & 0,0967 & 0,9777 & 0,1608 & $-0,2056$ & 0,0395 & 0,9540 & $-0,3738$ & $-0,9294$ & $-2,6675$ \\
\hline 07 & 0,2351 & $-0,2356$ & 0,3543 & 1,1660 & 0,4600 & 0,7980 & $-0,8042$ & $-0,8728$ & 0,0038 \\
\hline 08 & 1,5132 & $-0,3723$ & 0,2886 & 0,9256 & 0,1399 & 0,8215 & 0,5472 & 0,3318 & $-0,3962$ \\
\hline 09 & 0,5504 & $-0,8001$ & 0,3589 & $-0,2723$ & 0,2849 & $-0,4516$ & 1,0049 & 2,0867 & $-0,5746$ \\
\hline 10 & $-0,2385$ & $-0,8104$ & 0,1443 & $-0,0384$ & 0,6201 & $-1,0475$ & $-0,4243$ & 0,4923 & 1,4421 \\
\hline $\bar{H}$ & 53,5696 & 53,0227 & 53,7557 & 52,9337 & 53,3897 & 54,2557 & 53,6890 & 53,3780 & 54,3117 \\
\hline
\end{tabular}

$\bar{H}$ - Média estimada dos híbridos. 
Tabela 29 - Estimativas dos parâmetros $\mathrm{g}_{\mathrm{i}} \mathbf{e} \mathrm{g}_{\mathrm{j}}$ das progênies de irmãos germanos das populações SUWAN e ESALQ PB-1, multiplicadas por autofecundação, para a variável altura de plantas, referentes a nove experimentos. Tha Solteira-SP, 1992/93.

\begin{tabular}{|c|c|c|c|c|c|c|c|c|c|}
\hline \multirow{2}{*}{$\begin{array}{l}\text { Progê- } \\
\text { nies }\end{array}$} & \multicolumn{9}{|c|}{ Experimentos } \\
\hline & 01 & 02 & 03 & 04 & 05 & 06 & 07 & 08 & 09 \\
\hline & \multicolumn{9}{|c|}{ População SUWAN ( $\left.\mathrm{g}_{\mathrm{i}}\right)$} \\
\hline 01 & $-0,1419$ & 0,1296 & 0,0089 & $-0,0742$ & 0,0129 & 0,1532 & 0,0279 & 0,0508 & 0,0478 \\
\hline 02 & 0,0580 & 0,0794 & 0,0290 & 0,0448 & $-0,0790$ & 0,0287 & $-0,0925$ & $-0,0744$ & 0,0124 \\
\hline 03 & 0,0526 & 0,0394 & $-0,0198$ & $-0,0540$ & $-0,1745$ & $-0,0600$ & $-0,0113$ & 0,0057 & $-0,1131$ \\
\hline 04 & $-0,0517$ & $-0,0054$ & 0,0413 & 0,0643 & 0,1285 & 0,0253 & $-0,0950$ & $-0,0834$ & $-0,0186$ \\
\hline 05 & $-0,0951$ & $-0,1113$ & 0,0716 & $-0,0681^{\circ}$ & 0,0712 & $-0,0112$ & 0,0096 & $-0,0710$ & 0,0659 \\
\hline 06 & $-0,0234$ & $-0,1179$ & 0,1055 & 0,0550 & $-0,0036$ & 0,1553 & $-0,0638$ & 0,0743 & 0,0703 \\
\hline 07 & $-0,0530$ & $-0,0505$ & 0,0156 & 0,0272 & 0,0917 & $-0,1481$ & 0,0760 & $-0,0631$ & 0,0752 \\
\hline 08 & 0,1077 & 0,1014 & $-0,0527$ & $-0,1327$ & 0,0243 & $-0,0047$ & 0,1313 & 0,0970 & $-0,0116$ \\
\hline 09 & 0,0587 & $-0,0284$ & $-0,1137$ & 0,0666 & $-0,0725$ & $-0,0389$ & $-0,0685$ & 0,0200 & $-0,0321$ \\
\hline \multirow[t]{2}{*}{10} & 0,0881 & $-0,0362$ & $-0,0856$ & 0,0712 & 0,0010 & $-0,0996$ & 0,0863 . & 0,0440 & $-0,0963$ \\
\hline & \multicolumn{9}{|c|}{ População ESALQ PB-1 ( $\left.\mathrm{g}_{\mathrm{j}}\right)$} \\
\hline 01 & $-0,1249$ & $-0,0617$ & $-0,0086$ & 0,0112 & 0,0385 & $-0,0226$ & 0,0318 & $-0,0100$ & 0,0832 \\
\hline 02 & $-0,0229$ & $-0,0709$ & $-0,0661$ & $-0,0182$ & $-0,0526$ & $-0,0318$ & 0,0564 & 0,0248 & 0,0883 \\
\hline 03 & $-0,0010$ & $-0,0861$ & 0,0420 & 0,1168 & $-0,0075$ & 0,0017 & 0,1390 & $-0,0424$ & 0,0739 \\
\hline 04 & 0,0156 & 0,0189 & $-0,0288$ & 0,0240 & $-0,0160$ & 0,0210 & 0,1033 & 0,0257 & 0,0294 \\
\hline 05 & $-0,0167$ & 0,1491 & $-0,0397$ & $-0,0017$ & $-0,0260$ & $-0,0457$ & $-0,0575$ & $-0,0254$ & $-0,0451$ \\
\hline 06 & $-0,0281$ & 0,0382 & $-0,0514$ & $-0,0181$ & $-0,0463$ & 0,0258 & $-0,0399$ & 0,0950 & $-0,1196$ \\
\hline 07 & 0,1356 & 0,1566 & $-0,0495$ & 0,0010 & 0,0159 & $-0,0897$ & $-0,0903$ & $-0,1017$ & $-0,0642$ \\
\hline 08 & 0,0480 & $-0,0210$ & $-0,0014$ & $-0,0208$ & $-0,0318$ & 0,1149 & 0,0025 & $-0,0911$ & $-0,0783$ \\
\hline 09 & 0,0007 & $-0,0941$ & 0,0483 & $-0,0447$ & 0,0378 & $-0,0137$ & $-0,0193$ & 0,1070 & 0,0059 \\
\hline 10 & $-0,0063$ & $-0,0289$ & 0,1553 & $-0,0494$ & 0,0880 & 0,0401 & $-0,1260$ & 0,0180 & 0,0264 \\
\hline $\bar{H}$ & 2,3515 & 2,2633 & 2,2453 & 2,3043 & 2,3743 & 2,4343 & 2,3897 & 2,5050 & 2,3370 \\
\hline
\end{tabular}

$\bar{H}$ - Média estimada dos híbridos. 
Tabela 30 - Estimativas dos parâmetros $\mathrm{g}_{\mathrm{i}} \mathrm{e} \mathrm{g}_{\mathrm{j}}$ das progênies de irmãos germanos das populações SUWAN e ESALQ PB-1, multiplicadas por autofecundação, para a variável altura de espigas, referentes a nove experimentos. Itha Solteira-SP, 1992/93.

\begin{tabular}{|c|c|c|c|c|c|c|c|c|c|}
\hline \multirow{2}{*}{$\begin{array}{l}\text { Progê- } \\
\text { nies }\end{array}$} & \multicolumn{9}{|c|}{ Experimentos } \\
\hline & 01 & 02 & 03 & 04 & 05 & 06 & 07 & 08 & 09 \\
\hline & \multicolumn{9}{|c|}{ População SUWAN (gi) } \\
\hline 01 & $-0,1222$ & 0,1409 & $-0,0396$ & $-0,1172$ & 0,0447 & 0,1594 & 0,0384 & 0,0950 & $-0,0683$ \\
\hline 02 & 0,0195 & 0,0151 & 0,0036 & 0,0786 & $-0,0820$ & $-0,0157$ & $-0,0249$ & $-0,0092$ & 0,0133 \\
\hline 03 & $-0,0039$ & $-0,0262$ & $-0,0100$ & 0,0054 & $-0,0952$ & $-0,0752$ & 0,1317 & 0,0429 & $-0,1163$ \\
\hline 04 & 0,0081 & 0,0025 & 0,0573 & 0,0415 & 0,0835 & 0,0249 & $-0,1623$ & $-0,0673$ & $-0,0064$ \\
\hline 05 & $-0,0967$ & $-0,0430$ & 0,0577 & $-0,0808$ & 0,0608 & $-0,0590$ & $-0,0038$ & $-0,1147$ & 0,0165 \\
\hline 06 & $-0,0394$ & $-0,1015$ & 0,0749 & 0,0711 & 0,0417 & 0,0437 & $-0,0549$ & 0,0290 & 0,1779 \\
\hline 07 & 0,0063 & $-0,0442$ & 0,0218 & $-0,0550$ & 0,0800 & $-0,1563$ & 0,0600 & $-0,0342$ & 0,0824 \\
\hline 08 & 0,0561 & 0,0731 & $-0,0371$ & $-0,0237$ & $-0,0251$ & 0,0481 & 0,0205 & 0,1089 & $-0,0238$ \\
\hline 09 & 0,1012 & 0,0449 & $-0,1024$ & 0,0463 & $-0,1140$ & 0,0374 & $-0,0575$ & $-0,0365$ & $-0,0505$ \\
\hline \multirow[t]{2}{*}{10} & 0,0711 & $-0,0617$ & $-0,0262$ & 0,0338 & 0,0057 & $-0,0073$ & 0,0529 & $-0,0139$ & $-0,0247$ \\
\hline & \multicolumn{9}{|c|}{ População ESALQ PB-1 ( $\left.g_{j}\right)$} \\
\hline 01 & $-0,1549$ & $-0,0447$ & 0,0008 & 0,0703 & 0,1092 & $-0,0998$ & $-0,0616$ & 0,0751 & 0,0488 \\
\hline 02 & 0,0118 & $-0,0381$ & $-0,0346$ & 0,0363 & $-0,0848$ & $-0,0421$ & $-0,0191$ & 0,0160 & 0,1242 \\
\hline 03 & 0,0035 & $-0,0699$ & 0,0966 & 0,1491 & $-0,0145$ & 0,0038 & 0,0546 & $-0,1062$ & 0,0248 \\
\hline 04 & 0,0101 & $-0,0272$ & $-0,0490$ & $-0,0671$ & $-0,0107$ & 0,0353 & 0,1382 & $-0,0521$ & $-0,0058$ \\
\hline 05 & $-0,0179$ & 0,1255 & 0,0063 & $-0,0240$ & $-0,0550$ & 0,0064 & $-0,0488$ & $-0,0403$ & 0,0231 \\
\hline 06 & $-0,0227$ & 0,0040 & $-0,0353$ & $-0,1093$ & $-0,0007$ & 0,0435 & $-0,0133$ & 0,0643 & $-0,1250$ \\
\hline 07 & 0,1446 & 0,1295 & $-0,0501$ & 0,0096 & 0,0072 & $-0,0028$ & $-0,0174$ & $-0,0600$ & $-0,0446$ \\
\hline 08 & 0,0103 & 0,0008 & 0,0048 & $-0,0495$ & $-0,0475$ & 0,0982 & $-0,0255$ & $-0,0212$ & $-0,0911$ \\
\hline 09 & 0,0301 & $-0,0379$ & 0,0339 & 0,0088 & 0,0444 & $-0,0664$ & 0,0620 & 0,0739 & 0,0317 \\
\hline 10 & $-0,0148$ & $-0,0421$ & 0,0266 & $-0,0242$ & 0,0525 & 0,0239 & $-0,0690$ & 0,0505 & 0,0140 \\
\hline$H$ & 1,3654 & 1,2533 & 1,2953 & 1,3587 & 1,3353 & 1,3567 & 1,4303 & 1,4933 & 1,3923 \\
\hline
\end{tabular}

H - Média estimada dos híbridos. 
Tabela 31 - Estimativas dos parâmetros $g_{i}$ e $g_{j}$ das progênies de irmãos germanos das populações SUWAN e ESALQ PB-1, multiplicadas por autofecundação, para a variável peso de espigas, referentes a nove experimentos. Iha Solteira-SP, $1992 / 93$.

\begin{tabular}{|c|c|c|c|c|c|c|c|c|c|}
\hline \multirow{2}{*}{$\begin{array}{l}\text { Progê- } \\
\text { nies }\end{array}$} & \multicolumn{9}{|c|}{ Experimentos } \\
\hline & 01 & 02 & 03 & 04 & 05 & 06 & 07 & 08 & 09 \\
\hline & \multicolumn{9}{|c|}{ População SUWAN $\left(\mathrm{g}_{\mathrm{i}}\right)$} \\
\hline 01 & $-0,0407$ & 0,0007 & 0,0096 & 0,0684 & 0,0737 & $-0,1534$ & 0,1847 & 0,2730 & 0,0518 \\
\hline 02 & 0,1200 & 0,0738 & 0,4085 & $-0,4688$ & 0,0801 & $-0,2581$ & 0,1898 & $-0,0099$ & $-0,1163$ \\
\hline 03 & $-0,1252$ & 0,1257 & 0,3047 & $-0,1641$ & $-0,0909$ & $-0,3034$ & 0,0511 & 0,0328 & 0,2361 \\
\hline 04 & 0,0828 & 0,0006 & 0,0290 & $-0,1054$ & $-0,3001$ & 0,0844 & $-0,1310$ & $-0,1472$ & 0,2448 \\
\hline 05 & $-0,1844$ & $-0,1579$ & $-0,2173$ & 0,2471 & 0,1889 & 0,0915 & $-0,0288$ & $-0,1549$ & 0,2815 \\
\hline 06 & 0,0273 & 0,0414 & $-0,2779$ & 0,2572 & $-0,1327$ & 0,3064 & $-0,2306$ & $-0,1766$ & 0,1734 \\
\hline 07 & $-0,4284$ & 0,0322 & $-0,0389$ & 0,1142 & 0,0385 & $-0,1179$ & $-0,0826$ & 0,0569 & 0,0326 \\
\hline 08 & 0,1155 & $-0,2122$ & 0,0575 & 0,0783 & $-0,2082$ & 0,1918 & $-0,0838$ & 0,0209 & $-0,2456$ \\
\hline 09 & 0,0369 & 0,0267 & $-0,2767$ & 0,0461 & $-0,0017$ & 0,2210 & $-0,1169$ & 0,0732 & $-0,3134$ \\
\hline \multirow[t]{2}{*}{10} & 0,3960 & 0,0690 & 0,0014 & $-0,0729$ & 0,3524 & $-0,0624$ & 0,2482 & 0,0317 & $-0,3450$ \\
\hline & \multicolumn{9}{|c|}{ População ESALQ PB-1 $\left(\mathrm{g}_{\mathrm{j}}\right)$} \\
\hline 01 & $-0,3932$ & 0,1473 & $-0,2762$ & $-0,0757$ & 0,0142 & $-0,0580$ & $-0,0700$ & $-0,3386$ & $-0,1042$ \\
\hline 02 & $-0,2338$ & $-0,1175$ & 0,0041 & $-0,3080$ & $-0,2621$ & 0,2738 & 0,0194 & 0,0367 & 0,2579 \\
\hline 03 & 0,0705 & $-0,2867$ & $-0,1578$ & 0,1089 & $-0,2524$ & 0,1929 & $-0,0034$ & $-0,1951$ & 0,2346 \\
\hline 04 & 0,1542 & $-0,1208$ & $-0,1935$ & 0,5081 & 0,0543 & 0,1587 & $-0,0452$ & 0,0600 & 0,0999 \\
\hline 05 & 0,1992 & 0,1721 & $-0,0788$ & 0,0469 & 0,0867 & 0,1267 & $-0,1172$ & $-0,0667$ & $-0,4639$ \\
\hline 06 & $-0,0431$ & 0,1157 & $-0,1613$ & 0,0591 & $-0,0788$ & 0,0219 & $-0,1576$ & 0,6247 & $-0,3087$ \\
\hline 07 & 0,2980 & 0,2285 & 0,2098 & $-0,2174$ & 0,1542 & $-0,2732$ & 0,1420 & $-0,0213$ & $-0,1642$ \\
\hline 08 & 0,1914 & 0,2109 & 0,2011 & $-0,0146$ & 0,2345 & $-0,1111$ & 0,0508 & $-0,0631$ & $-0,2257$ \\
\hline 09 & 0,2157 & $-0,5790$ & 0,1893 & 0,1134 & 0,2498 & $-0,3437$ & $-0,1969$ & $-0,1218$ & 0,2506 \\
\hline 10 & $-0,4590$ & 0,2293 & 0,2632 & $-0,2208$ & $-0,2005$ & 0,0119 & 0,3782 & 0,0852 & 0,4236 \\
\hline $\bar{H}$ & 2,3676 & 2,4426 & 2,4702 & 2,6014 & 2,6402 & 2,6782 & 2,6823 & 2,7989 & 2,6671 \\
\hline
\end{tabular}

$\bar{H}$ - Média estimada dos híbridos. 
Tabela 32 - Estimativas dos parâmetros $g_{i}$ e $g_{j}$ das progênies de irmãos germanos das populações SUWAN e ESALQ PB-1, multiplicadas por autofecundação, para a variável peso de grãos, referentes a nove experimentos. Ilha Solteira-SP, 1992/93.

\begin{tabular}{|c|c|c|c|c|c|c|c|c|c|}
\hline \multirow{2}{*}{$\begin{array}{l}\text { Progê- } \\
\text { nies }\end{array}$} & \multicolumn{9}{|c|}{ Experimentos } \\
\hline & 01 & 02 & 03 & 04 & 05 & 06 & 07 & 08 & 09 \\
\hline & \multicolumn{9}{|c|}{ População SUWAN ( $\left.\mathrm{g}_{\mathrm{i}}\right)$} \\
\hline 01 & $-0,0645$ & $-0,0015$ & 0,0051 & 0,0769 & 0,0793 & $-0,1349$ & 0,1861 & 0,2239 & $-0,0074$ \\
\hline 02 & 0,1335 & 0,0314 & 0,3181 & $-0,4354$ & 0,0569 & $-0,2298$ & 0,1937 & $-0,0200$ & $-0,0975$ \\
\hline 03 & $-0,1177$ & 0,1475 & 0,2613 & $-0,1746$ & $-0,0707$ & $-0,2962$ & 0,0335 & 0,0613 & 0,2074 \\
\hline 04 & 0,0929 & 0,0180 & $-0,0028$ & $-0,1053$ & $-0,2896$ & 0,0358 & $-0,1227$ & $-0,1477$ & 0,2428 \\
\hline 05 & $-0,1097$ & $-0,1549$ & $-0,1591$ & 0,2348 & 0,1986 & 0,0702 & $-0,0420$ & $-0,1085$ & 0,2341 \\
\hline 06 & 0,0532 & 0,0295 & $-0,2401$ & 0,2506 & $-0,1319$ & 0,2944 & $-0,2071$ & $-0,1098$ & 0,1367 \\
\hline 07 & $-0,3776$ & 0,0385 & $-0,0222$ & 0,1149 & 0,0490 & $-0,1093$ & $-0,0884$ & 0,0802 & $-0,0253$ \\
\hline 08 & 0,0488 & $-0,1905$ & 0,0494 & 0,0908 & $-0,1784$ & 0,1937 & $-0,0522$ & $-0,0336$ & $-0,1635$ \\
\hline 09 & $-0,0185$ & 0,0334 & $-0,2208$ & 0,0507 & $-0,0025$ & 0,2236 & $-0,1386$ & 0,0535 & $-0,2583$ \\
\hline \multirow[t]{2}{*}{10} & 0,3596 & 0,0486 & 0,0111 & $-0,1034$ & 0,2894 & $-0,0476$ & 0,2377 & 0,0009 & $-0,2691$ \\
\hline & \multicolumn{9}{|c|}{ População ESALQ PB-1 ( $\left.\mathrm{g}_{\mathrm{j}}\right)$} \\
\hline 01 & $-0,3512$ & 0,1128 & $-0,2278$ & $-0,0612$ & 0,0093 & $-0,0298$ & $-0,0571$ & $-0,2873$ & $-0,0885$ \\
\hline 02 & $-0,2062$ & $-0,0607$ & 0,0035 & $-0,2640$ & $-0,2295$ & 0,2456 & 0,0235 & 0,0201 & 0,2713 \\
\hline 03 & 0,0223 & $-0,2560$ & $-0,1196$ & 0,1533 & $-0,2262$ & 0,2152 & 0,0086 & $-0,1745$ & 0,2022 \\
\hline 04 & 0,1587 & $-0,0839$ & $-0,1590$ & 0,4306 & 0,0803 & 0,1192 & $-0,0338$ & 0,0730 & 0,0595 \\
\hline 05 & 0,1217 & 0,1202 & $-0,0791$ & 0,0516 & 0,0653 & 0,1483 & $-0,1289$ & $-0,0752$ & $-0,4380$ \\
\hline 06 & $-0,0703$ & 0,0800 & $-0,1372$ & 0,0120 & $-0,0971$ & 0,0046 & $-0,1316$ & 0,4734 & $-0,2636$ \\
\hline 07 & 0,2665 & 0,2402 & 0,1783 & $-0,2518$ & 0,1246 & $-0,2915$ & 0,1322 & 0,0083 & $-0,1124$ \\
\hline 08 & 0,1798 & 0,1720 & 0,1706 & $-0,0372$ & 0,2049 & $-0,1184$ & 0,0276 & $-0,0316$ & $-0,1511$ \\
\hline 09 & 0,2178 & $-0,4901$ & 0,1518 & 0,0935 & 0,2224 & $-0,2799$ & $-0,1359$ & $-0,1020$ & 0,1643 \\
\hline 10 & $-0,3392$ & 0,1653 & 0,2187 & $-0,1267$ & $-0,1540$ & $-0,0133$ & 0,2955 & 0,0959 & 0,3564 \\
\hline$H$ & 471 & 2,0370 & 05 & 827 & 54 & 2,2075 & 2,2082 & 112 & 2,1695 \\
\hline
\end{tabular}

$\bar{H}$ - Média estimada dos híbridos. 
Tabela 33 - Estimativas dos parâmetros $g_{i}$ e $g_{j}$ das progênies de irmãos germanos das populações SUWAN e ESALQ PB-1, multiplicadas por cruzamentos fraternais, para a variável dias para o florescimento feminino, referentes a 10 experimentos. Itha Solteira-SP, 1992/93.

\begin{tabular}{|c|c|c|c|c|c|c|c|c|c|c|}
\hline \multirow{2}{*}{$\begin{array}{c}\text { Progê- } \\
\text { nies }\end{array}$} & \multicolumn{10}{|c|}{ Experimentos } \\
\hline & 01 & 02 & 03 & 04 & 05 & 06 & 07 & 08 & 09 & 10 \\
\hline & \multicolumn{10}{|c|}{ População SUWAN (gi) } \\
\hline 01 & $-0,703$ & $-1,154$ & $-0,892$ & $-0,691$ & $-0,412$ & $-0,987$ & $-0,128$ & 1,834 & $-0,288$ & 0,512 \\
\hline 02 & $-0,127$ & $-0,311$ & $-0,672$ & $-1,571$ & $-2,259$ & $-0,978$ & 0,271 & 0,750 & 0,439 & $-1,756$ \\
\hline 03 & 0,816 & 0,570 & $-0,564$ & $-1,874$ & 0,021 & 0,982 & $-0,765$ & $-1,112$ & 0,741 & $-1,943$ \\
\hline 04 & $-2,754$ & 0,135 & 0,258 & 1,113 & $-1,258$ & $-0,522$ & $-0,047$ & 0,755 & 1,252 & 2,309 \\
\hline 05 & $-0,944$ & 0,245 & $-0,671$ & 1,365 & $-0,108$ & 0,550 & 0,409 & $-0,835$ & $-0,325$ & 2,067 \\
\hline 06 & 1,520 & 1,501 & $-0,313$ & $-0,397$ & 1,575 & 0,764 & 0,820 & $-2,669$ & $-0,098$ & 1,350 \\
\hline 07 & 0,325 & $-0,692$ & $-0,020$ & 0,644 & 2,365 & 0,175 & $-1,648$ & 1,594 & $-0,660$ & 1,358 \\
\hline 08 & 0,433 & 0,086 & 2,264 & 0,806 & 1,204 & 0,974 & $-0,552$ & $-0,301$ & $-1,212$ & $-1,718$ \\
\hline 09 & 0,671 & 0,779 & 0,979 & 1,012 & $0 ; 723$ & $-0,639$ & 0,174 & $-1,318$ & $-0,343$ & $-0,534$ \\
\hline 10 & 0,764 & $-1,161$ & $-0,370$ & $-0,407$ & $-1,851$ & $-0,319$ & 1,467 & 1,302 & 0,493 & $-1,645$ \\
\hline
\end{tabular}

População ESALQ PB-1 $\left(\mathrm{g}_{\mathrm{j}}\right)$

\begin{tabular}{lrlllllllll}
01 & $-1,242$ & 1,800 & $-0,339$ & 1,105 & $-0,686$ & $-1,350$ & 1,152 & $-0,227$ & $-2,787$ & 0,044 \\
02 & 0,687 & 0,610 & $-0,455$ & 0,856 & 0,421 & $-2,017$ & $-0,213$ & $-2,030$ & $-0,271$ & 2,565 \\
03 & 0,669 & $-1,414$ & 1,829 & 0,012 & 0,574 & 2,993 & 0,084 & $-0,448$ & 0,423 & $-0,339$ \\
04 & 2,360 & $-0,730$ & $-0,327$ & 0,744 & 0,853 & 0,285 & $-0,053$ & 0,025 & 0,023 & $-1,492$ \\
05 & 2,516 & 0,638 & $-0,111$ & $-0,235$ & 0,583 & 1,772 & $-1,766$ & 2,216 & $-2,169$ & 0,454 \\
06 & 0,391 & $-0,449$ & $-0,304$ & $-1,947$ & 0,061 & 0,515 & $-0,071$ & $-1,038$ & 0,891 & $-0,754$ \\
07 & $-2,079$ & $-1,730$ & 1,458 & $-1,015$ & $-1,257$ & 0,059 & 0,240 & 0,792 & 1,085 & $-1,437$ \\
08 & $-3,538$ & $-0,120$ & $-1,853$ & 1,062 & $-1,137$ & $-0,859$ & $-0,330$ & 0,061 & 1,490 & 1,605 \\
09 & 0,635 & 1,120 & $-1,174$ & $-2,411$ & $-0,630$ & $-0,728$ & $-0,005$ & $-1,169$ & 0,905 & 0,233 \\
10 & $-0,401$ & 0,277 & 1,276 & 1,829 & 1,219 & $-0,670$ & 0,960 & 1,818 & 0,411 & $-0,879$ \\
\hline $\bar{H}$ & 53,778 & 53,822 & 53,766 & 52,367 & 52,756 & 53,445 & 54,233 & 54,511 & 54,166 & 54,622 \\
\hline
\end{tabular}

$\bar{H}$ - Média estimada dos híbridos. 
Tabela 34 - Estimativas dos parâmetros $g_{i}$ e $g_{j}$ das progênies de irmãos germanos das populações SUWAN e ESALQ PB-1, multiplicadas por cruzamentos fratemais, para a variável altura de plantas, referentes a 10 experimentos. Iha Solteira-SP, 1992/93.

\begin{tabular}{|c|c|c|c|c|c|c|c|c|c|c|}
\hline \multirow{2}{*}{$\begin{array}{c}\text { Progê- } \\
\text { nies }\end{array}$} & \multicolumn{10}{|c|}{ Experimentos } \\
\hline & 01 & 02 & 03 & 04 & 05 & 06 & 07 & 08 & 09 & 10 \\
\hline & \multicolumn{10}{|c|}{ População SUWAN (gi) } \\
\hline 01 & 0,041 & 0,091 & $-0,045$ & 0,074 & 0,174 & 0,065 & 0,078 & $-0,065$ & 0,072 & $-0,010$ \\
\hline 02 & 0,138 & $-0,034$ & 0,093 & 0,045 & 0,049 & 0,012 & 0,034 & 0,089 & 0,004 & $-0,090$ \\
\hline 03 & 0,103 & $-0,044$ & 0,021 & $-0,067$ & 0,024 & $-0,017$ & $-0,002$ & $-0,044$ & $-0,068$ & $-0,142$ \\
\hline 04 & $-0,076$ & 0,104 & 0,036 & 0,079 & $-0,013$ & $-0,024$ & $-0,145$ & 0,081 & 0,057 & 0,162 \\
\hline 05 & $-0,077$ & 0,004 & 0,013 & 0,028 & $-0,021$ & $-0,010$ & $-0,067$ & 0,011 & $-0,133$ & 0,127 \\
\hline 06 & $-0,055$ & 0,128 & $-0,104$ & $-0,026$ & $-0,002$ & $-0,030$ & $-0,016$ & $-0,085$ & $-0,071$ & 0,129 \\
\hline 07 & $-0,086$ & $-0,053$ & 0,013 & $-0,051$ & $-0,152$ & $-0,056$ & $-0,020$ & 0,076 & $-0,035$ & $-0,028$ \\
\hline 08 & 0,021 & $-0,082$ & $-0,043$ & $-0,136$ & $-0,001$ & $-0,037$ & 0,066 & $-0,017$ & 0,026 & $-0,115$ \\
\hline 09 & 0,012 & $-0,056$ & $-0,003$ & $-0,041$ & $-0,068$ & 0,041 & $-0,003$ & 0,050 & 0,176 & 0,048 \\
\hline 10 & $-0,022$ & $-0,059$ & 0,019 & 0,096 & 0,010 & 0,056 & 0,076 & $-0,098$ & $-0,028$ & $-0,081$ \\
\hline
\end{tabular}

População ESALQ PB-1 ( $\left.g_{j}\right)$

\begin{tabular}{lllllllllll}
01 & $-0,164$ & $-0,035$ & 0,046 & 0,029 & $-0,057$ & $-0,070$ & $-0,040$ & 0,033 & $-0,231$ & $-0,033$ \\
02 & 0,041 & 0,001 & $-0,053$ & $-0,023$ & $-0,076$ & $-0,031$ & 0,002 & $-0,014$ & $-0,011$ & 0,090 \\
03 & $-0,051$ & 0,053 & $-0,091$ & $-0,052$ & $-0,104$ & $-0,013$ & $-0,042$ & 0,042 & 0,013 & $-0,010$ \\
04 & $-0,115$ & $-0,112$ & $-0,117$ & 0,006 & $-0,071$ & 0,030 & 0,042 & $-0,060$ & 0,051 & $-0,060$ \\
05 & $-0,083$ & 0,082 & $-0,027$ & $-0,009$ & $-0,111$ & 0,014 & $-0,021$ & 0,046 & 0,017 & $-0,026$ \\
06 & 0,076 & $-0,082$ & 0,034 & 0,011 & 0,027 & 0,048 & 0,127 & $-0,004$ & 0,008 & $-0,060$ \\
07 & 0,049 & $-0,023$ & 0,122 & $-0,023$ & 0,084 & 0,029 & 0,098 & $-0,019$ & 0,052 & $-0,016$ \\
08 & $-0,060$ & $-0,007$ & $-0,016$ & 0,062 & 0,070 & 0,015 & $-0,096$ & $-0,026$ & 0,029 & 0,178 \\
09 & 0,158 & 0,041 & 0,024 & $-0,053$ & 0,139 & 0,074 & $-0,040$ & $-0,038$ & 0,100 & $-0,049$ \\
10 & 0,150 & 0,082 & 0,078 & 0,052 & 0,098 & $-0,096$ & $-0,029$ & 0,040 & $-0,029$ & $-0,014$ \\
\hline $\bar{H}$ & 2,286 & 2,413 & 2,291 & 2,332 & 2,318 & 2,263 & 2,326 & 2,245 & 2,328 & 2,387 \\
\hline
\end{tabular}


Tabela 35 - Estimativas dos parâmetros $g_{i}$ e $g_{j}$ das progênies de irmãos germanos das populações SUWAN e ESALQ PB-1, multiplicadas por cruzamentos fratemais, para a variável altura de espigas, referentes a 10 experimentos. Ilha Solteira-SP, 1992/93.

\begin{tabular}{|c|c|c|c|c|c|c|c|c|c|c|}
\hline \multirow{2}{*}{$\begin{array}{c}\text { Progê- } \\
\text { nies }\end{array}$} & \multicolumn{10}{|c|}{ Experimentos } \\
\hline & 01 & 02 & 03 & 04 & 05 & 06 & 07 & 08 & 09 & 10 \\
\hline & \multicolumn{10}{|c|}{ População SUWAN (gi) } \\
\hline 01 & $-0,023$ & 0,014 & $-0,119$ & $-0,018$ & 0,037 & 0,047 & 0,106 & $-0,021$ & 0,020 & $-0,100$ \\
\hline 02 & 0,114 & $-0,021$ & $-0,028$ & 0,009 & $-0,013$ & 0,016 & 0,004 & 0,091 & $-0,054$ & $-0,061$ \\
\hline 03 & 0,047 & $-0,009$ & 0,022 & $-0,049$ & 0,051 & $-0,017$ & $-0,029$ & $-0,015$ & 0,041 & $-0,143$ \\
\hline 04 & $-0,073$ & 0,069 & 0,048 & 0,052 & 0,062 & $-0,034$ & $-0,202$ & 0,051 & 0,075 & 0,137 \\
\hline 05 & $-0,041$ & 0,004 & 0,044 & 0,071 & $-0,030$ & 0,004 & $-0,103$ & 0,017 & $-0,109$ & 0,130 \\
\hline 06 & 0,011 & 0,125 & $-0,059$ & 0,048 & 0,067 & $-0,023$ & $-0,022$ & $-0,039$ & $-0,028$ & 0,217 \\
\hline 07 & $-0,007$ & $-0,014$ & 0,062 & 0,015 & $-0,072$ & $-0,042$ & $-0,021$ & 0,042 & 0,010 & 0,016 \\
\hline 08 & 0,037 & $-0,058$ & 0,017 & $-0,055$ & $-0,024$ & $-0,060$ & 0,027 & $-0,002$ & $-0,067$ & $-0,127$ \\
\hline 09 & $-0,040$ & $-0,044$ & 0,004 & $-0,097$ & $-0,030$ & 0,079 & $-0,002$ & $-0,013$ & 0,142 & 0,037 \\
\hline \multirow[t]{2}{*}{10} & $-0,026$ & $-0,065$ & 0,008 & 0,026 & $-0,047$ & 0,030 & 0,240 & $-0,112$ & $-0,028$ & $-0,106$ \\
\hline & \multicolumn{10}{|c|}{ População ESALQ PB-1 ( $\left.\mathrm{g}_{\mathrm{j}}\right)$} \\
\hline 01 & $-0,081$ & 0,021 & 0,051 & 0,065 & $-0,036$ & $-0,059$ & $-0,087$ & 0,056 & $-0,115$ & 0,003 \\
\hline 02 & 0,081 & 0,010 & 0,015 & 0,057 & $-0,018$ & 0,006 & $-0,069$ & $-0,052$ & 0,067 & 0,139 \\
\hline 03 & $-0,063$ & 0,025 & $-0,013$ & 0,008 & $-0,034$ & $-0,029$ & $-0,049$ & 0,042 & 0,037 & $-0,012$ \\
\hline 04 & $-0,024$ & $-0,133$ & $-0,052$ & 0,035 & $-0,106$ & 0,005 & 0,060 & $-0,012$ & $-0,025$ & 0,006 \\
\hline 05 & $-0,065$ & 0,115 & $-0,076$ & $-0,019$ & $-0,071$ & 0,026 & 0,009 & 0,056 & $-0,036$ & $-0,014$ \\
\hline 06 & 0,027 & $-0,110$ & 0,001 & $-0,065$ & $-0,039$ & 0,021 & 0,170 & $-0,016$ & $-0,036$ & $-0,061$ \\
\hline 07 & $-0,002$ & $-0,019$ & 0,020 & $-0,053$ & 0,042 & $-0,010$ & 0,083 & $-0,040$ & 0,019 & $-0,134$ \\
\hline 08 & $-0,081$ & $-0,018$ & $-0,058$ & $-0,011$ & 0,027 & 0,048 & $-0,084$ & $-0,057$ & 0,031 & 0,085 \\
\hline 09 & 0,103 & 0,068 & 0,038 & $-0,056$ & 0,139 & 0,068 & $-0,044$ & $-0,039$ & $-0,002$ & $-0,008$ \\
\hline 10 & 0,105 & 0,042 & 0,076 & 0,038 & 0,097 & $-0,076$ & 0,009 & 0,062 & 0,061 & $-0,004$ \\
\hline $\bar{H}$ & 1,297 & 1,414 & 1,371 & 1,355 & 1,350 & 1,273 & 1,369 & 1,286 & 1,401 & 1,400 \\
\hline
\end{tabular}

$\bar{H}$ - Média estimada dos híbridos. 
Tabela 36 - Estimativas dos parâmetros $\mathrm{g}_{\mathrm{i}}$ e $\mathrm{g}_{\mathrm{j}}$ das progênies de irmãos germanos das populações SUWAN e ESALQ PB-1, multiplicadas por cruzamentos fraternais, para a variável peso de espigas, referentes a 10 experimentos. Itha Solteira-SP, 1992/93.

\begin{tabular}{|c|c|c|c|c|c|c|c|c|c|c|}
\hline \multirow{2}{*}{$\begin{array}{c}\text { Progê- } \\
\text { nies }\end{array}$} & \multicolumn{10}{|c|}{ Experimentos } \\
\hline & 01 & 02 & 03 & 04 & 05 & 06 & 07 & 08 & 09 & 10 \\
\hline & \multicolumn{10}{|c|}{ População SUWAN $\left(\mathrm{g}_{\mathrm{i}}\right)$} \\
\hline 01 & 0,097 & 0,055 & $-0,086$ & 0,135 & $-0,054$ & 0,146 & 0,229 & $-0,089$ & 0,343 & 0,253 \\
\hline 02 & 0,336 & $-0,158$ & 0,085 & $-0,170$ & 0,178 & $-0,072$ & $-0,008$ & $-0,232$ & $-0,230$ & 0,289 \\
\hline 03 & $-0,278$ & $-0,154$ & 0,142 & 0,242 & 0,012 & $-0,259$ & 0,164 & 0,191 & $-0,319$ & 0,011 \\
\hline 04 & 0,105 & $-0,111$ & 0,118 & 0,185 & 0,046 & 0,338 & 0,011 & 0,257 & $-0,122$ & $-0,132$ \\
\hline 05 & $-0,133$ & $-0,018$ & 0,279 & 0,253 & $-0,060$ & 0,329 & $-0,041$ & 0,333 & $-0,033$ & 0,073 \\
\hline 06 & $-0,176$ & 0,049 & 0,055 & 0,060 & 0,085 & $-0,073$ & 0,023 & 0,036 & $-0,028$ & 0,123 \\
\hline 07 & $-0,141$ & 0,159 & 0,037 & $-0,158$ & 0,028 & $-0 ; 161$ & $-0,042$ & $-0,198$ & 0,033 & $-0,382$ \\
\hline 08 & 0,057 & 0,096 & $-0,194$ & $-0,359$ & 0,111 & $-0,288$ & 0,053 & $-0,151$ & 0,444 & $-0,244$ \\
\hline 09 & 0,082 & $-0,019$ & $-0,268$ & $-0,179$ & $-0,344$ & $-0,095$ & $-0,320$ & 0,242 & 0,130 & $-0,065$ \\
\hline 10 & 0,051 & 0,101 & $-0,167$ & $-0,009$ & $-0,003$ & 0,135 & $-0,068$ & $-0,388$ & $-0,218$ & 0,074 \\
\hline
\end{tabular}

População ESALQ PB-1 ( $\left.g_{j}\right)$

\begin{tabular}{lllllllllll}
01 & $-0,219$ & $-0,144$ & 0,024 & 0,193 & 0,172 & 0,083 & 0,072 & 0,234 & $-0,192$ & $-0,100$ \\
02 & $-0,416$ & 0,099 & $-0,042$ & 0,020 & $-0,107$ & 0,338 & $-0,250$ & 0,630 & $-0,090$ & 0,035 \\
03 & $-0,054$ & 0,199 & $-0,320$ & $-0,098$ & $-0,045$ & $-0,054$ & $-0,042$ & $-0,071$ & 0,008 & $-0,251$ \\
04 & 0,222 & $-0,101$ & $-0,004$ & $-0,244$ & $-0,054$ & $-0,244$ & 0,166 & 0,066 & 0,146 & 0,098 \\
05 & 0,294 & 0,015 & 0,083 & $-0,103$ & $-0,228$ & $-0,134$ & $-0,024$ & $-0,175$ & 0,349 & $-0,493$ \\
06 & $-0,013$ & $-0,003$ & $-0,092$ & $-0,008$ & $-0,031$ & $-0,324$ & 0,236 & $-0,029$ & 0,093 & $-0,071$ \\
07 & 0,001 & 0,008 & $-0,126$ & $-0,146$ & 0,194 & 0,162 & 0,246 & $-0,190$ & $-0,045$ & 0,044 \\
08 & 0,132 & $-0,010$ & $-0,073$ & 0,042 & $-0,077$ & 0,030 & $-0,337$ & $-0,291$ & $-0,027$ & 0,275 \\
09 & 0,195 & $-0,187$ & 0,166 & 0,157 & 0,192 & 0,221 & $-0,029$ & 0,075 & $-0,080$ & 0,167 \\
10 & $-0,143$ & 0,124 & 0,384 & 0,186 & $-0,016$ & $-0,078$ & $-0,037$ & $-0,249$ & $-0,161$ & 0,297 \\
\hline $\bar{H}$ & 1,880 & 1,931 & 1,887 & 2,163 & 2,248 & 2,133 & 1,890 & 1,834 & 2,285 & 2,414 \\
\hline
\end{tabular}


Tabela 37 - Estimativas dos parâmetros $\mathrm{g}_{\mathrm{i}} \mathrm{e} \cdot \mathrm{g}_{\mathrm{j}}$ das progênies de irmãos germanos das populações SUWAN e ESALQ PB-1, multiplicadas por cruzamentos fratemais, para a variável peso de grãos, referentes a 10 experimentos. Itha Solteira-SP, 1992/93.

\begin{tabular}{|c|c|c|c|c|c|c|c|c|c|c|}
\hline \multirow{2}{*}{$\begin{array}{c}\text { Progê- } \\
\text { nies }\end{array}$} & \multicolumn{10}{|c|}{ Experimentos } \\
\hline & 01 & 02 & 03 & 04 & 05 & 06 & 07 & 08 & 09 & 10 \\
\hline & \multicolumn{10}{|c|}{ População SUWAN ( $\left.\mathrm{g}_{\mathrm{i}}\right)$} \\
\hline 01 & 0,070 & 0,034 & $-0,072$ & 0,093 & $-0,044$ & 0,164 & 0,190 & $-0,042$ & 0,333 & 0,267 \\
\hline 02 & 0,344 & $-0,094$ & 0,062 & $-0,174$ & 0,170 & $-0,059$ & 0,026 & $-0,198$ & $-0,224$ & 0,256 \\
\hline 03 & $-0,276$ & $-0,122$ & 0,148 & 0,224 & 0,031 & $-0,247$ & 0,146 & 0,154 & $-0,269$ & 0,044 \\
\hline 04 & 0,072 & $-0,084$ & 0,101 & 0,187 & 0,018 & 0,267 & 0,060 & 0,214 & $-0,157$ & $-0,167$ \\
\hline 05 & $-0,114$ & 0,017 & 0,248 & 0,264 & $-0,049$ & 0,289 & $-0,017$ & 0,280 & $-0,017$ & 0,032 \\
\hline 06 & $-0,159$ & 0,034 & 0,011 & 0,075 & 0,055 & $-0,093$ & $-0,009$ & 0,029 & $-0,024$ & 0,068 \\
\hline 07 & $-0,091$ & 0,101 & 0,021 & $-0,102$ & $-0,017$ & $-0,139$ & $-0,043$ & $-0,190$ & 0,021 & $-0,351$ \\
\hline 08 & 0,060 & 0,058 & $-0,141$ & $-0,332$ & 0,081 & $-0,255$ & $-0,002$ & $-0,119$ & 0,436 & $-0,189$ \\
\hline 09 & 0,024 & $-0,040$ & $-0,212$ & $-0,201$ & $-0,268$ & $-0,060$ & $-0,279$ & 0,211 & 0,076 & $-0,075$ \\
\hline 10 & 0,072 & 0,097 & $-0,166$ & $-0,034$ & 0,023 & 0,131 & $-0,073$ & $-0,338$ & $-0,175$ & 0,116 \\
\hline
\end{tabular}

População ESALQ PB-1 ( $\mathrm{g}_{\mathrm{j}}$ )

\begin{tabular}{lllllllllll}
01 & $-0,160$ & $-0,109$ & 0,046 & 0,185 & 0,160 & 0,063 & 0,034 & 0,191 & $-0,186$ & $-0,102$ \\
02 & $-0,382$ & 0,054 & 0,007 & 0,009 & $-0,084$ & 0,269 & $-0,219$ & 0,563 & $-0,082$ & 0,001 \\
03 & $-0,026$ & 0,178 & $-0,270$ & $-0,054$ & $-0,041$ & $-0,082$ & $-0,052$ & $-0,075$ & 0,017 & $-0,242$ \\
04 & 0,221 & $-0,097$ & 0,007 & $-0,179$ & $-0,084$ & $-0,193$ & 0,155 & 0,102 & 0,106 & 0,053 \\
05 & 0,267 & $-0,015$ & 0,035 & $-0,135$ & $-0,208$ & $-0,130$ & $-0,030$ & $-0,177$ & 0,347 & $-0,390$ \\
06 & $-0,026$ & $-0,035$ & $-0,069$ & $-0,025$ & $-0,021$ & $-0,279$ & 0,167 & $-0,034$ & 0,058 & $-0,046$ \\
07 & 0,005 & 0,043 & $-0,119$ & $-0,155$ & 0,198 & 0,147 & 0,239 & $-0,164$ & $-0,020$ & 0,051 \\
08 & 0,105 & $-0,016$ & $-0,044$ & 0,022 & $-0,041$ & 0,051 & $-0,283$ & $-0,255$ & $-0,020$ & 0,249 \\
09 & 0,158 & $-0,135$ & 0,118 & 0,181 & 0,145 & 0,195 & 0,004 & 0,068 & $-0,072$ & 0,143 \\
10 & $-0,161$ & 0,132 & 0,290 & 0,151 & $-0,024$ & $-0,041$ & $-0,014$ & $-0,219$ & $-0,149$ & 0,283 \\
\hline $\bar{H}$ & 1,555 & 1,598 & 1,549 & 1,789 & 1,860 & 1,771 & 1,552 & 1,521 & 1,877 & 1,986 \\
\hline
\end{tabular}


Tabela 38 - Estimativas dos parâmetros $k_{\mathbf{i}}$ e $k_{\mathbf{j}}$ das progênies de imãos germanos das populações SUWAN e ESALQ PB-1, multiplicadas por autofecundação, para a variável dias para o florescimento feminino, referentes a nove experimentos. Ilha Solteira-SP, 1992/93.

\begin{tabular}{cccccccccc}
\hline Progê- & \multicolumn{10}{c}{ Experimentos } \\
\cline { 2 - 10 } nies & 01 & 02 & 03 & 04 & 05 & 06 & 07 & 08 & 09 \\
\hline & \multicolumn{10}{c}{ População SUWAN $\left(k_{i}\right)$} \\
01 & 0,8927 & 0,8667 & 0,1333 & $-0,0444$ & $-1,1667$ & 0,1889 & $-0,1333$ & $-0,1556$ & 0,2444 \\
02 & $-1,3295$ & $-0,1333$ & $-0,5333$ & 1,2889 & $-0,3889$ & 0,1889 & 0,7556 & 0,4000 & 0,0222 \\
03 & $-0,6628$ & $-0,2444$ & 2,0222 & 0,5111 & 0,0556 & $-0,4778$ & 0,2000 & $-0,2667$ & $-0,5333$ \\
04 & $-0,3295$ & $-0,4667$ & $-0,5333$ & 0,8444 & 0,6111 & 0,4111 & $-0,8000$ & 0,9556 & $-0,9778$ \\
05 & 0,2261 & 1,0889 & $-0,4222$ & $-0,4889$ & 0,0556 & $-0,0333$ & 0,2000 & $-1,9333$ & 0,9111 \\
06 & $-1,8851$ & 0,0889 & 0,6889 & 0,4000 & $-0,0556$ & $-0,1444$ & $-0,8000$ & $-0,3778$ & 0,4667 \\
07 & 1,4483 & 0,7556 & 0,0222 & $-0,2667$ & 0,5000 & $-0,5889$ & 0,3111 & $-0,6000$ & 0,1333 \\
08 & $-0,1073$ & $-0,1333$ & 0,0222 & $-1,6000$ & 0,8333 & 0,5222 & 0,5333 & 0,8444 & $-0,8667$ \\
09 & 1,4483 & $-0,8000$ & $-1,3111$ & $-0,6000$ & 0,6111 & 0,1889 & $-0,8000$ & 0,7333 & 0,4667 \\
10 & 0,4483 & $-1,0222$ & $-0,0889$ & $-0,0444$ & $-1,0556$ & $-0,2556$ & 0,5333 & 0,4000 & 0,1333
\end{tabular}

População ESALQ PB-1 ( $\left.\mathbf{k}_{\mathbf{j}}\right)$

\begin{tabular}{cccccccccc}
01 & 1,2816 & $-0,3556$ & $-1,3111$ & 0,0667 & $-0,5000$ & 0,3000 & $-0,2444$ & 0,1778 & 0,9111 \\
02 & 0,2261 & $-0,3556$ & 0,5778 & 0,6222 & $-1,0556$ & $-0,1444$ & 0,3111 & $-0,0444$ & $-0,2000$ \\
03 & $-1,1073$ & 0,3111 & 0,3556 & 0,7333 & $-0,6111$ & $-0,2556$ & 0,5333 & $-0,1556$ & $-0,3111$ \\
04 & $-0,6628$ & $-0,2444$ & 0,3556 & 0,2889 & $-0,2778$ & $-0,0333$ & 0,5333 & 0,7333 & $-0,0889$ \\
05 & $-0,1073$ & 0,5333 & 0,0222 & $-0,0444$ & 0,5000 & 0,1889 & $-0,6889$ & $-0,3778$ & 0,3556 \\
06 & $-0,7739$ & 0,6444 & 0,0222 & 0,0667 & 0,1667 & 0,3000 & $-0,4667$ & $-0,8222$ & $-1,6444$ \\
07 & $-0,3295$ & 0,3111 & 0,2444 & 0,6222 & 0,3889 & $-0,1444$ & $-0,6889$ & $-1,6000$ & 1,2444 \\
08 & 0,6705 & 0,2000 & 0,2444 & $-0,0444$ & 0,2778 & 0,4111 & 0,4222 & $-0,0444$ & $-0,0889$ \\
09 & 1,0038 & $-0,2444$ & $-0,2000$ & $-1,3778$ & 0,6111 & $-0,2556$ & 0,7556 & 1,6222 & $-0,8667$ \\
10 & 0,2261 & $-0,8000$ & $-0,3111$ & $-0,9333$ & 0,5000 & $-0,3667$ & $-0,4667$ & 0,5111 & 0,6889 \\
\hline $\bar{H}$ & 53,5517 & 53,0222 & 53,7556 & 52,9333 & 53,3889 & 54,2556 & 53,6889 & 53,3778 & 54,3111 \\
\hline- Média dos híbridos.
\end{tabular}


Tabela 39 - Estimativas dos parâmetros $\mathbf{k}_{\mathbf{i}} \mathbf{e} \mathbf{k}_{\mathbf{j}}$ das progênies de irmãos germanos das populações SUWAN e ESALQ PB-1, multiplicadas por autofecundação, para a variável altura de plantas, referentes a nove experimentos. Itha Solteira-SP, 1992/93.

\begin{tabular}{|c|c|c|c|c|c|c|c|c|c|}
\hline \multirow{2}{*}{$\begin{array}{c}\text { Progê- } \\
\text { nies }\end{array}$} & \multicolumn{9}{|c|}{ Experimentos } \\
\hline & 01 & 02 & 03 & 04 & 05 & 06 & 07 & 08 & 09 \\
\hline & \multicolumn{9}{|c|}{ População SUWAN $\left(k_{i}\right)$} \\
\hline 01 & $-0,1925$ & $-0,0009$ & 0,0586 & $-0,0388$ & 0,0036 & 0,1352 & 0,1012 & 0,0420 & 0,1311 \\
\hline 02 & 0,0519 & 0,0102 & 0,0330 & 0,0868 & $-0,1042$ & 0,0263 & 0,0090 & $-0,0702$ & 0,0744 \\
\hline 03 & 0,0508 & $-0,0298$ & 0,0674 & $-0,0077$ & $-0,1909$ & $-0,0659$ & 0,0512 & $-0,0102$ & $-0,0956$ \\
\hline 04 & $-0,0636$ & 0,0013 & 0,0630 & 0,0646 & 0,1002 & 0,0274 & $-0,0954$ & $-0,0536$ & $-0,0633$ \\
\hline 05 & $-0,0636$ & 0,0247 & 0,0030 & $-0,0721$ & 0,0513 & $-0,0492$ & $-0,0543$ & $-0,0813$ & $-0,0100$ \\
\hline 06 & 0,0286 & 0,0702 & $-0,0614$ & 0,0423 & $-0,0253$ & 0,1719 & $-0,1043$ & 0,0431 & $-0,0144$ \\
\hline 07 & 0,0041 & 0,0169 & $-0,0392$ & 0,0046 & 0,0991 & $-0,1426$ & 0,0379 & $-0,0913$ & 0,0278 \\
\hline 08 & 0,1208 & 0,0158 & 0,0541 & $-0,1677$ & 0,0558 & 0,0419 & 0,0834 & 0,1098 & $-0,0267$ \\
\hline 09 & 0,0141 & $-0,0498$ & $-0,0881$ & 0,0368 & $-0,0164$ & $-0,0403$ & $-0,1032$ & 0,0576 & 0,0056 \\
\hline \multirow[t]{2}{*}{10} & 0,0741 & $-0,0587$ & $-0,0903$ & 0,0512 & 0,0269 & $-0,1048$ & 0,0746 & 0,0542 & $-0,0289$ \\
\hline & \multicolumn{9}{|c|}{ População ESALQ PB-1 $\left(k_{j}\right)$} \\
\hline 01 & $-0,1692$ & $-0,0742$ & $-0,0370$ & 0,0334 & 0,0191 & $-0,0181$ & 0,0457 & 0,0276 & 0,0589 \\
\hline 02 & $-0,0236$ & $-0,0809$ & $-0,0137$ & $-0,0054$ & $-0,0742$ & $-0,0048$ & 0,0646 & 0,0309 & 0,0767 \\
\hline 03 & $-0,0136$ & 0,0480 & $-0,0037$ & 0,0868 & $-0,0864$ & 0,0430 & 0,1146 & $-0,0480$ & 0,0578 \\
\hline 04 & 0,0341 & $-0,0120$ & 0,0563 & 0,0446 & $-0,0576$ & 0,0208 & 0,0357 & $-0,0258$ & $-0,0133$ \\
\hline 05 & $-0,0481$ & $-0,0098$ & 0,1230 & $-0,0221$ & $-0,0187$ & $-0,0603$ & $-0,0910$ & $-0,0769$ & $-0,0678$ \\
\hline 06 & $-0,0848$ & 0,0213 & $-0,0392$ & 0,0001 & 0,0180 & 0,0830 & $-0,0877$ & 0,0676 & $-0,0778$ \\
\hline 07 & 0,0786 & 0,0158 & 0,0630 & 0,0068 & 0,0691 & $-0,0914$ & $-0,0854$ & $-0,1202$ & 0,0067 \\
\hline 08 & 0,0552 & 0,0213 & $-0,0459$ & $-0,0377$ & 0,0047 & 0,1141 & 0,0501 & $-0,0536$ & $-0,0333$ \\
\hline 09 & 0,0352 & $-0,0009$ & $-0,0859$ & $-0,0577$ & 0,0536 & $-0,0759$ & 0,0279 & 0,1287 & 0,0144 \\
\hline 10 & 0,0797 & 0,0713 & $-0,0170$ & $-0,0488$ & 0,0724 & $-0,0103$ & $-0,0743$ & 0,0698 & $-0,0222$ \\
\hline$H$ & 2,3525 & 2,2453 & 2,2637 & 2,3043 & 2,3742 & 2,4348 & 2,3899 & 2,5047 & 2,3367 \\
\hline
\end{tabular}

$\bar{H}$-Média dos híbridos. 
Tabela 40 - Estimativas dos parâmetros $\mathbf{k}_{\mathbf{i}}$ e $\mathbf{k}_{\mathbf{j}}$ das progênies de irmãos germanos das populações SUWAN e ESALQ PB-1, multiplicadas por autofecundação, para a variável altura de espigas, referentes a nove experimentos. Ilha Solteira-SP, 1992/93.

\begin{tabular}{|c|c|c|c|c|c|c|c|c|c|}
\hline \multirow{2}{*}{$\begin{array}{l}\text { Progê- } \\
\text { nies }\end{array}$} & \multicolumn{9}{|c|}{ Experimentos } \\
\hline & 01 & 02 & 03 & 04 & 05 & 06 & 07 & 08 & 09 \\
\hline & \multicolumn{9}{|c|}{ População SUWAN ( $\left.\mathbf{k}_{\mathbf{i}}\right)$} \\
\hline 01 & $-0,1733$ & 0,0916 & $-0,0194$ & $-0,0316$ & 0,0494 & 0,1115 & 0,0274 & 0,0902 & $-0,0019$ \\
\hline 02 & 0,0267 & $-0,0284$ & 0,0050 & 0,1173 & $-0,1194$ & $-0,0176$ & 0,0319 & $-0,0553$ & 0,0612 \\
\hline 03 & $-0,0089$ & $-0,0173$ & 0,0050 & 0,0262 & $-0,1217$ & $-0,0565$ & 0,1797 & $-0,0264$ & $-0,1021$ \\
\hline 04 & $-0,0066$ & 0,0360 & 0,0317 & $-0,0249$. & 0,0594 & 0,0558 & $-0,1348$ & $-0,0776$ & $-0,0432$ \\
\hline 05 & $-0,0633$ & 0,0427 & 0,0317 & $-0,1227$ & 0,0439 & $-0,0442$ & $-0,0303$ & $-0,1242$ & $-0,0332$ \\
\hline 06 & 0,0000 & $-0,0573$ & 0,0494 & 0,0207 & 0,0272 & 0,0891 & $-0,0714$ & 0,0224 & 0,0934 \\
\hline 07 & 0,0667 & $-0,0151$ & 0,0206 & $-0,0660$ & 0,0817 & $-0,1465$ & 0,0641 & $-0,0364$ & 0,0468 \\
\hline 08 & 0,0600 & 0,0449 & $-0,0172$ & $-0,0471$ & $-0,0072$ & 0,0647 & 0,0074 & 0,1424 & $-0,0388$ \\
\hline 09 & 0,0534 & 0,0049 & $-0,0794$ & 0,0629 & $-0,0450$ & $-0,0109$ & $-0,0781$ & 0,0291 & $-0,0188$ \\
\hline \multirow[t]{2}{*}{10} & 0,0678 & $-0,1018$ & $-0,0272$ & 0,0651 & 0,0317 & $-0,0453$ & 0,0041 & 0,0358 & 0,0368 \\
\hline & \multicolumn{9}{|c|}{ População ESALQ PB-1 ( $\left.\mathbf{k}_{\mathbf{j}}\right)$} \\
\hline 01 & $-0,1689$ & $-0,0018$ & $-0,0550$ & 0,0596 & 0,0883 & $-0,0353$ & $-0,0492$ & 0,0924 & $-0,0010$ \\
\hline 02 & $-0,0022$ & $-0,0062$ & $-0,0550$ & 0,0351 & $-0,0950$ & 0,0026 & $-0,0003$ & 0,0402 & 0,0990 \\
\hline 03 & $-0,0333$ & $-0,0240$ & 0,0783 & 0,1396 & $-0,0594$ & 0,0280 & 0,1052 & $-0,0642$ & $-0,0319$ \\
\hline 04 & 0,0134 & $-0,0307$ & $-0,0328$ & $-0,0271$ & $-0,0428$ & 0,0158 & 0,1197 & $-0,0631$ & $-0,0421$ \\
\hline 05 & $-0,0511$ & 0,1004 & 0,0406 & $-0,0338$ & $-0,0372$ & $-0,0298$ & $-0,0603$ & $-0,0876$ & $-0,0132$ \\
\hline 06 & $-0,0700$ & $-0,0440$ & 0,0272 & $-0,1004$ & 0,0594 & 0,0458 & $-0,0870$ & 0,0124 & $-0,0621$ \\
\hline 07 & 0,1000 & 0,0649 & 0,0050 & $-0,0093$ & 0,0683 & $-0,0598$ & $-0,0159$ & $-0,0987$ & 0,0456 \\
\hline 08 & 0,0134 & $-0,0240$ & 0,0228 & $-0,0549$ & $-0,0139$ & 0,0780 & $-0,0170$ & 0,0113 & $-0,0110$ \\
\hline 09 & 0,0845 & $-0,0129$ & $-0,0039$ & $-0,0027$ & 0,0228 & $-0,0931$ & 0,0674 & 0,0880 & 0,0334 \\
\hline 10 & 0,0578 & $-0,0218$ & $-0,0272$ & $-0,0060$ & 0,0094 & 0,0480 & $-0,0626$ & 0,0691 & $-0,0166$ \\
\hline$H$ & 1,3689 & 1,2529 & 1,2950 & 1,3582 & 1,3350 & 1,3565 & 1,4303 & 1,4931 & 1,3921 \\
\hline
\end{tabular}

$\overline{H-M e ́ d i a ~ d o s ~ h i ́ b r i d o s . ~}$ 
Tabela 41 - Estimativas dos parâmetros $\mathbf{k}_{\mathbf{i}} \mathbf{e} \mathbf{k}_{\mathbf{j}}$ das progênies de irmãos germanos das populações SUWAN e ESALQ PB-1, multiplicadas por autofecundação, para a variável peso de espigas, referentes a nove experimentos. Tha Solteira-SP, 1992/93.

\begin{tabular}{cccccccccc}
\hline Progê- & \multicolumn{10}{c}{ Experimentos } \\
\cline { 2 - 10 } nies & 01 & 02 & 03 & 04 & 05 & 06 & 07 & 08 & 09 \\
\hline \multicolumn{10}{c}{ População SUWAN $\left(\mathbf{k}_{\mathbf{i}}\right)$} \\
01 & $-0,2261$ & $-0,0849$ & $-0,1337$ & $-0,0233$ & $-0,0930$ & $-0,0171$ & 0,1667 & 0,1073 & 0,1813 \\
02 & 0,1171 & $-0,1012$ & 0,2928 & $-0,3658$ & $-0,0733$ & $-0,0496$ & 0,1800 & $-0,0427$ & 0,0812 \\
03 & 0,0162 & 0,0472 & 0,1614 & 0,0573 & $-0,1280$ & $-0,1439$ & $-0,0042$ & $-0,0344$ & 0,1930 \\
04 & 0,1864 & 0,0563 & $-0,1155$ & 0,0993 & $-0,2794$ & 0,1869 & $-0,2377$ & 0,0588 & 0,0206 \\
05 & $-0,0329$ & 0,0142 & $-0,2274$ & 0,2100 & 0,2430 & 0,0500 & $-0,0731$ & 0,0240 & $-0,0307$ \\
06 & 0,1762 & 0,2265 & $-0,1947$ & 0,1995 & $-0,0294$ & 0,1857 & $-0,2189$ & 0,0035 & $-0,0595$ \\
07 & $-0,1933$ & $-0,0144$ & 0,1612 & 0,0747 & 0,2513 & $-0,3606$ & $-0,0840$ & $-0,0119$ & $-0,0138$ \\
08 & 0,0983 & $-0,2585$ & 0,2754 & 0,0376 & $-0,1136$ & 0,0442 & $-0,0064$ & $-0,0123$ & $-0,0961$ \\
09 & $-0,1751$ & $-0,0407$ & $-0,2180$ & $-0,0149$ & 0,0194 & 0,0911 & $-0,0798$ & $-0,0518$ & $-0,1234$ \\
10 & 0,0497 & 0,1554 & $-0,0015$ & $-0,2744$ & 0,2030 & 0,0135 & 0,3574 & $-0,0405$ & $-0,1525$
\end{tabular}

População ESALQ PB-1 ( $\left.\mathbf{k}_{\mathbf{j}}\right)$

\begin{tabular}{rrrrrrrrrr}
01 & $-0,3950$ & 0,1795 & $-0,3648$ & $-0,0619$ & 0,1557 & $-0,0562$ & 0,0354 & $-0,2126$ & $-0,3064$ \\
02 & $-0,0752$ & $-0,0697$ & 0,1440 & $-0,4657$ & $-0,0933$ & 0,1159 & 0,2269 & 0,1350 & 0,1214 \\
03 & 0,0553 & $-0,2200$ & 0,0832 & $-0,0793$ & $-0,2314$ & $-0,0454$ & 0,1384 & $-0,0965$ & 0,2918 \\
04 & 0,1802 & $-0,0540$ & 0,0539 & 0,2621 & $-0,0494$ & $-0,0003$ & $-0,0086$ & 0,0186 & 0,2214 \\
05 & 0,1238 & 0,1616 & $-0,0400$ & 0,0395 & 0,0194 & 0,0842 & $-0,1535$ & $-0,1564$ & $-0,2097$ \\
06 & $-0,0677$ & 0,0771 & $-0,3167$ & 0,1921 & $-0,1601$ & 0,1827 & $-0,2878$ & 0,4651 & $-0,0755$ \\
07 & 0,1029 & 0,2004 & 0,0318 & $-0,0113$ & 0,1858 & $-0,1799$ & 0,0280 & $-0,1129$ & $-0,0017$ \\
08 & 0,0963 & 0,1647 & 0,1147 & 0,1353 & 0,1337 & 0,0157 & $-0,0816$ & $-0,0960$ & $-0,2389$ \\
09 & 0,1238 & $-0,6301$ & 0,1033 & 0,1930 & 0,1926 & $-0,2454$ & $-0,2913$ & $-0,0715$ & 0,0751 \\
10 & $-0,2761$ & 0,1905 & 0,1906 & $-0,2037$ & $-0,1530$ & 0,1287 & 0,3940 & 0,1272 & 0,1223 \\
\hline $\bar{H}$ & 2,3675 & 2,4426 & 2,4702 & 2,6014 & 2,6402 & 2,6782 & 2,6823 & 2,7989 & 2,6671 \\
\hline
\end{tabular}


Tabela 42 - Estimativas dos parâmetros $\mathbf{k}_{\mathbf{i}}$ e $\mathbf{k}_{\mathbf{j}}$ das progênies de irmãos germanos das populações SUWAN e ESALQ PB-1, multiplicadas por autofecundação, para a variável peso de grãos, referentes a nove experimentos. Iha Solteira-SP, 1992/93.

\begin{tabular}{|c|c|c|c|c|c|c|c|c|c|}
\hline \multirow{2}{*}{$\begin{array}{l}\text { Progê- } \\
\text { nies }\end{array}$} & \multicolumn{9}{|c|}{ Experimentos } \\
\hline & 01 & 02 & 03 & 04 & 05 & 06 & 07 & 08 & 09 \\
\hline & \multicolumn{9}{|c|}{ População SUWAN ( $\left.\mathrm{k}_{\mathrm{i}}\right)$} \\
\hline 01 & $-0,2426$ & $-0,0695$ & $-0,1096$ & 0,0196 & $-0,0696$ & 0,0088 & 0,1778 & 0,0767 & 0,1209 \\
\hline 02 & 0,1254 & $-0,1022$ & 0,2264 & $-0,3288$ & $-0,0683$ & $-0,0365$ & 0,1931 & $-0,0471$ & 0,0802 \\
\hline 03 & $-0,0165$ & 0,0743 & 0,1421 & 0,0372 & $-0,0975$ & $-0,1353$ & $-0,0178$ & 0,0024 & 0,1487 \\
\hline 04 & 0,1632 & 0,0568 & $-0,1279$ & 0,0594 & $-0,2735$ & 0,1265 & $-0,2208$ & 0,0093 & 0,0288 \\
\hline 05 & $-0,0034$ & $-0,0081$ & $-0,1718$ & 0,1721 & 0,2295 & 0,0240 & $-0,0848$ & 0,0270 & $-0,0373$ \\
\hline 06 & 0,1788 & 0,1936 & $-0,1695$ & 0,1582 & $-0,0545$ & 0,1593 & $-0,1977$ & 0,0402 & $-0,0390$ \\
\hline 07 & $-0,1559$ & 0,0126 & 0,1447 & 0,0497 & 0,2330 & $-0,3393$ & $-0,0804$ & 0,0384 & $-0,0584$ \\
\hline 08 & 0,0686 & $-0,2414$ & 0,2297 & 0,0673 & $-0,0873$ & 0,0565 & 0,0102 & $-0,0462$ & $-0,0403$ \\
\hline 09 & $-0,1757$ & $-0,0372$ & $-0,1733$ & 0,0192 & 0,0234 & 0,1160 & $-0,1045$ & $-0,0444$ & $-0,1142$ \\
\hline \multirow[t]{2}{*}{10} & 0,0872 & 0,1211 & 0,0092 & $-0,2541$ & 0,1646 & 0,0199 & 0,3249 & $-0,0563$ & $-0,0894$ \\
\hline & \multicolumn{9}{|c|}{ População ESALQ PB-1 ( $\left.\mathbf{k}_{\mathbf{j}}\right)$} \\
\hline 01 & $-0,3924$ & 0,1396 & $-0,2960$ & $-0,0531$ & 0,1314 & $-0,0160$ & 0,0379 & $-0,1946$ & $-0,2668$ \\
\hline 02 & $-0,0630$ & $-0,0345$ & 0,1149 & $-0,4180$ & $-0,0877$ & 0,1082 & 0,2293 & 0,0883 & 0,1467 \\
\hline 03 & 0,0064 & $-0,1969$ & 0,0752 & $-0,0244$ & $-0,2044$ & $-0,0051$ & 0,1464 & $-0,0861$ & 0,2363 \\
\hline 04 & 0,1952 & $-0,0183$ & 0,0332 & 0,1921 & $-0,0208$ & $-0,0442$ & 0,0010 & 0,0376 & 0,1771 \\
\hline 05 & 0,0771 & 0,1237 & $-0,0460$ & 0,0366 & 0,0114 & 0,0849 & $-0,1727$ & $-0,1402$ & $-0,2099$ \\
\hline 06 & $-0,0579$ & 0,0443 & $-0,2712$ & 0,1387 & $-0,1714$ & 0,1380 & $-0,2555$ & 0,3513 & $-0,0591$ \\
\hline 07 & 0,1221 & 0,2113 & 0,0378 & $-0,0517$ & 0,1632 & $-0,2065$ & 0,0197 & $-0,0378$ & 0,0028 \\
\hline 08 & 0,0882 & 0,1312 & 0,0996 & 0,1149 & 0,1178 & 0,0079 & $-0,0883$ & $-0,0527$ & $-0,1685$ \\
\hline 09 & 0,1023 & $-0,5296$ & 0,0873 & 0,1790 & 0,1784 & $-0,1772$ & $-0,2290$ & $-0,0687$ & 0,0153 \\
\hline 10 & $-0,2089$ & 0,1291 & 0,1652 & $-0,1140$ & $-0,1179$ & 0,1099 & 0,3111 & 0,1028 & 0,1261 \\
\hline$H$ & 1,9468 & 2,0370 & 2,0305 & 2,1827 & 2,1854 & 2,2075 & 2,2082 & 2,3112 & 2,1695 \\
\hline
\end{tabular}

H-Média dos híbridos. 
Tabela 43 - Estimativas dos parâmetros $\mathbf{k}_{\mathbf{i}}$ e $\mathbf{k}_{\mathbf{j}}$ das progênies de irmãos gemanos das populações SUWAN e ESALQ PB-1, multiplicadas por cruzamentos fraternais, para a variável dias para o florescimento feminino, referentes a 10 experimentos. Ilha Solteira-SP, 1992/93.

\begin{tabular}{|c|c|c|c|c|c|c|c|c|c|c|}
\hline \multirow{2}{*}{$\begin{array}{c}\text { Progê- } \\
\text { nies }\end{array}$} & \multicolumn{10}{|c|}{ Experimentos } \\
\hline & 01 & 02 & 03 & 04 & 05 & 06 & 07 & 08 & 09 & 10 \\
\hline & \multicolumn{10}{|c|}{ População SUWAN (k $\left.k_{i}\right)$} \\
\hline 01 & $-0,590$ & $-0,822$ & $-0,544$ & $-0,033$ & $-0,311$ & $-1,111$ & 0,211 & 0,933 & $-1,167$ & 1,267 \\
\hline 02 & 0,632 & $-0,822$ & $-0,322$ & $-1,033$ & $-1,644$ & $-0,556$ & 0,211 & $-0,067$ & 0,500 & $-1,511$ \\
\hline 03 & 2,743 & 0,067 & $-0,100$ & $-1,700$ & 0,689 & 2,667 & $-1,344$ & $-0,511$ & 0,167 & $-2,400$ \\
\hline 04 & $-0,923$ & $-0,044$ & 0,011 & 0,633 & $-0,756$ & 0,333 & $-0,678$ & 1,156 & 0,833 & 1,711 \\
\hline 05 & $-0,590$ & $-0,267$ & $-0,322$ & 0,300 & $-0,311$ & 1,333 & $-0,122$ & $-0,178$ & $-0,389$ & 1,489 \\
\hline 06 & $-0,146$ & 0,733 & $-0,544$ & $-1,033$ & 0,800 & 0,667 & 0,767 & $-2,733$ & 1,056 & 1,156 \\
\hline 07 & $-1,257$ & $-0,933$ & $-0,544$ & $-0,144$ & 1,356 & $-0,333$ & $-1,678$ & 1,489 & 0,500 & 1,489 \\
\hline 08 & $-0,590$ & 0,511 & 1,678 & 0,967 & 1,022 & 0,222 & $-0,344$ & $-0,067$ & $-0,278$ & $-1,400$ \\
\hline 09 & 0,410 & 1,844 & 0,900 & 1,189 & 0,689 & $-1,556$ & 0,878 & $-1,178$ & $-0,833$ & $-0,733$ \\
\hline \multirow[t]{2}{*}{10} & 0,521 & $-0,267$ & $-0,211$ & 0,856 & $-1,533$ & $-1,667$ & 2,100 & 1,156 & $-0,389$ & $-1,067$ \\
\hline & \multicolumn{10}{|c|}{ População ESALQ PB-1 $\left(\mathrm{k}_{\mathrm{j}}\right)$} \\
\hline 01 & $-0,923$ & 1,289 & $-0,433$ & 1,078 & $-1,200$ & $-2,000$ & 1,656 & 0,378 & $-2,833$ & $-0,511$ \\
\hline 02 & 0,743 & $-0,267$ & $-1,100$ & $-0,033$ & $-1,089$ & $-2,778$ & 0,322 & $-0,733$ & $-0,056$ & 1,600 \\
\hline 03 & 0,743 & $-1,711$ & 1,122 & $-1,367$ & $-0,311$ & 2,667 & $-0,122$ & 0,044 & 0,722 & $-1,400$ \\
\hline 04 & 1,466 & $-0,600$ & $-0,656$ & $-0,033$ & $-0,311$ & 0,111 & $-0,233$ & 0,156 & 0,833 & $-1,956$ \\
\hline 05 & 1,632 & 0,956 & $-0,433$ & $-0,033$ & 0,133 & 2,111 & $-1,900$ & 1,822 & $-1,611$ & 1,267 \\
\hline 06 & $-0,257$ & 0,178 & $-0,544$ & $-1,256$ & 0,133 & 0,778 & 0,322 & $-1,956$ & 1,167 & 1,156 \\
\hline 07 & $-1,701$ & $-1,378$ & 1,122 & $-0,478$ & 0,022 & 0,556 & 0,100 & 0,156 & 0,722 & 0,156 \\
\hline 08 & $-2,701$ & 0,178 & $-1,211$ & 1,411 & 0,578 & $-0,222$ & $-0,789$ & $-0,400$ & 0,833 & 1,933 \\
\hline 09 & 1,188 & 1,178 & $-0,100$ & $-1,589$ & 0,800 & $-0,556$ & $-0,678$ & $-1,178$ & 0,167 & $-0,067$ \\
\hline 10 & 0,299 & 0,178 & 2,233 & 2,300 & 1,244 & $-0,667$ & 1,322 & 1,711 & 0,056 & $-2,178$ \\
\hline $\bar{H}$ & 53,701 & 53,822 & 53,767 & 52,367 & 52,756 & 53,444 & 54,233 & 54,511 & 54,167 & 54,622 \\
\hline
\end{tabular}


Tabela 44 - Estimativas dos parâmetros $k_{i}$ e $k_{j}$ das progênies de irmãos germanos das populações SUWAN e ESALQ PB-1, multiplicadas por cruzamentos fratemais, para a variável altura de plantas, referentes a 10 experimentos. Iha Solteira-SP, 1992/93.

\begin{tabular}{|c|c|c|c|c|c|c|c|c|c|c|}
\hline \multirow{2}{*}{$\begin{array}{c}\text { Progê- } \\
\text { nies }\end{array}$} & \multicolumn{10}{|c|}{ Experimentos } \\
\hline & 01 & 02 & 03 & 04 & 05 & 06 & 07 & 08 & 09 & 10 \\
\hline & \multicolumn{10}{|c|}{ População SUWAN ( $\left.\mathbf{k}_{\mathbf{i}}\right)$} \\
\hline 01 & $-0,016$ & 0,100 & $-0,078$ & 0,059 & 0,095 & 0,029 & 0,050 & $-0,045$ & $-0,005$ & 0,006 \\
\hline 02 & 0,138 & $-0,052$ & 0,009 & 0,023 & $-0,036$ & 0,007 & 0,033 & 0,078 & 0,020 & $-0,083$ \\
\hline 03 & 0,023 & $-0,037$ & $-0,058$ & $-0,084$ & $-0,071$ & $-0,009$ & $-0,011$ & $-0,035$ & $-0,039$ & $-0,171$ \\
\hline 04 & $-0,116$ & 0,063 & 0,001 & 0,081 & $-0,065$ & 0,006 & $-0,096$ & 0,074 & 0,082 & 0,113 \\
\hline 05 & $-0,062$ & $-0,002$ & 0,057 & 0,021 & $-0,023$ & 0,021 & 0,003 & 0,020 & $-0,106$ & 0,091 \\
\hline 06 & $-0,033$ & 0,088 & $-0,059$ & $-0,006$ & 0,057 & 0,001 & 0,028 & $-0,101$ & $-0,043$ & 0,163 \\
\hline 07 & $-0,038$ & $-0,047$ & 0,054 & $-0,056$ & $-0,053$ & $-0,017$ & $-0,033$ & 0,049 & 0,024 & 0,009 \\
\hline 08 & 0,105 & $-0,047$ & $-0,016$ & $-0,117$ & 0,104 & $-0,040$ & 0,009 & $-0,026$ & 0,062 & $-0,074$ \\
\hline 09 & 0,060 & $-0,025$ & 0,047 & $-0,033$ & $-0,006$ & 0,012 & $-0,040$ & 0,063 & 0,122 & 0,016 \\
\hline \multirow[t]{2}{*}{10} & $-0,015$ & $-0,042$ & 0,044 & 0,113 & $-0,001$ & $-0,009$ & 0,056 & $-0,077$ & $-0,117$ & $-0,069$ \\
\hline & \multicolumn{10}{|c|}{ População ESALQ PB-1 ( $\left.\mathbf{k}_{\mathbf{j}}\right)$} \\
\hline 01 & $-0,154$ & $-0,040$ & 0,036 & 0,074 & $-0,019$ & $-0,017$ & 0,012 & $-0,002$ & $-0,159$ & $-0,049$ \\
\hline 02 & 0,095 & 0,000 & $-0,029$ & 0,046 & 0,001 & 0,014 & 0,065 & $-0,038$ & 0,006 & 0,031 \\
\hline 03 & 0,046 & 0,059 & $-0,066$ & $-0,034$ & $-0,022$ & 0,007 & $-0,008$ & 0,035 & 0,015 & $-0,091$ \\
\hline 04 & $-0,098$ & $-0,103$ & $-0,065$ & 0,027 & $-0,054$ & 0,020 & 0,000 & $-0,018$ & 0,049 & $-0,083$ \\
\hline 05 & $-0,097$ & 0,102 & $-0,005$ & 0,005 & $-0,115$ & $-0,004$ & $-0,092$ & 0,059 & $-0,030$ & 0,023 \\
\hline 06 & 0,006 & $-0,004$ & 0,016 & 0,039 & 0,018 & 0,029 & 0,053 & $-0,001$ & $-0,041$ & 0,080 \\
\hline 07 & $-0,023$ & 0,005 & 0,095 & $-0,040$ & 0,023 & $-0,004$ & 0,066 & $-0,017$ & $-0,027$ & 0,059 \\
\hline 08 & $-0,100$ & $-0,011$ & $-0,063$ & $-0,009$ & 0,018 & $-0,025$ & $-0,084$ & $-0,035$ & 0,002 & 0,172 \\
\hline 09 & 0,139 & $-0,023$ & 0,012 & $-0,131$ & 0,068 & 0,055 & $-0,030$ & 0,002 & 0,155 & $-0,079$ \\
\hline 10 & 0,153 & 0,016 & 0,069 & 0,023 & 0,081 & $-0,076$ & 0,018 & 0,016 & 0,031 & $-0,063$ \\
\hline$\vec{H}$ & 2,285 & 2,413 & 2,291 & 2,332 & 2,319 & 2,263 & 2,326 & 2,245 & 2,327 & 2,387 \\
\hline
\end{tabular}

$\bar{H}$-Média dos híbridos. 
Tabela 45 - Estimativas dos parâmetros $k_{\mathbf{i}}$ e $k_{\mathbf{j}}$ das progênies de irmãos germanos das populações SUWAN e ESALQ PB-1, multiplicadas por cruzamentos fraternais, para a variável altura de espigas, referentes a 10 experimentos. Iha Solteira-SP, 1992/93.

\begin{tabular}{|c|c|c|c|c|c|c|c|c|c|c|}
\hline \multirow{2}{*}{$\begin{array}{c}\text { Progê- } \\
\text { nies }\end{array}$} & \multicolumn{10}{|c|}{ Experimentos } \\
\hline & 01 & 02 & 03 & 04 & 05 & 06 & 07 & 08 & 09 & 10 \\
\hline & \multicolumn{10}{|c|}{ População SUWAN $\left(k_{i}\right)$} \\
\hline 01 & $-0,039$ & 0,032 & $-0,101$ & 0,025 & 0,008 & 0,021 & 0,039 & $-0,007$ & 0,015 & $-0,058$ \\
\hline 02 & 0,128 & $-0,052$ & $-0,046$ & 0,045 & $-0,069$ & 0,010 & $-0,015$ & 0,083 & $-0,027$ & $-0,018$ \\
\hline 03 & $-0,003$ & $-0,008$ & $-0,024$ & $-0,042$ & $-0,022$ & $-0,017$ & $-0,021$ & 0,014 & 0,033 & $-0,152$ \\
\hline 04 & $-0,092$ & 0,025 & 0,005 & 0,035 & $-0,010$ & $-0,019$ & $-0,122$ & 0,061 & 0,042 & 0,114 \\
\hline 05 & $-0,050$ & $-0,002$ & 0,026 & 0,025 & $-0,052$ & 0,017 & $-0,014$ & 0,017 & $-0,128$ & 0,061 \\
\hline 06 & $-0,002$ & 0,076 & $-0,072$ & 0,006 & 0,076 & $-0,002$ & 0,032 & $-0,076$ & $-0,024$ & 0,182 \\
\hline 07 & 0,002 & $-0,002$ & 0,062 & $-0,025$ & $-0,004$ & $-0,008$ & $-0,034$ & $-0,003$ & 0,026 & $-0,002$ \\
\hline 08 & 0,083 & $-0,026$ & 0,038 & $-0,065$ & 0,065 & $-0,047$ & $-0,012$ & $-0,010$ & $-0,036$ & $-0,103$ \\
\hline 09 & 0,003 & $-0,002$ & 0,059 & $-0,082$ & 0,039 & 0,056 & $-0,042$ & 0,012 & 0,125 & 0,035 \\
\hline \multirow[t]{2}{*}{10} & 0,013 & $-0,040$ & 0,053 & 0,080 & $-0,032$ & $-0,012$ & 0,190 & $-0,091$ & $-0,026$ & $-0,059$ \\
\hline & \multicolumn{10}{|c|}{ População ESALQ PB-1 $\left(\mathbf{k}_{\mathbf{j}}\right)$} \\
\hline 01 & $-0,108$ & $-0,008$ & 0,015 & 0,034 & $-0,051$ & $-0,004$ & 0,027 & 0,005 & $-0,073$ & $-0,052$ \\
\hline 02 & 0,107 & $-0,016$ & $-0,034$ & 0,061 & $-0,024$ & 0,036 & 0,048 & $-0,066$ & 0,046 & 0,047 \\
\hline 03 & $-0,013$ & 0,021 & $-0,056$ & $-0,010$ & $-0,012$ & $-0,014$ & $-0,022$ & 0,059 & 0,039 & $-0,113$ \\
\hline 04 & $-0,032$ & $-0,119$ & $-0,037$ & 0,039 & $-0,074$ & $-0,005$ & $-0,014$ & 0,032 & $-0,006$ & $-0,019$ \\
\hline 05 & $-0,087$ & 0,133 & $-0,036$ & 0,007 & $-0,046$ & $0 ; 009$ & $-0,104$ & 0,073 & $-0,033$ & 0,027 \\
\hline 06 & $-0,003$ & $-0,044$ & 0,010 & $-0,009$ & $-0,004$ & 0,001 & 0,062 & $-0,007$ & $-0,056$ & 0,101 \\
\hline 07 & $-0,012$ & 0,019 & 0,036 & $-0,008$ & 0,029 & $-0,027$ & 0,037 & $-0,035$ & $-0,026$ & $-0,010$ \\
\hline 08 & $-0,062$ & 0,000 & $-0,049$ & $-0,008$ & 0,018 & 0,006 & $-0,091$ & $-0,053$ & 0,003 & 0,120 \\
\hline 09 & 0,102 & 0,029 & 0,065 & $-0,103$ & 0,097 & 0,058 & $-0,039$ & $-0,030$ & 0,028 & $-0,033$ \\
\hline 10 & 0,096 & $-0,015$ & 0,084 & $-0,004$ & 0,067 & $-0,059$ & 0,097 & 0,021 & 0,077 & $-0,068$ \\
\hline $\bar{H}$ & 1,294 & 1,414 & 1,371 & 1,354 & 1,350 & 1,273 & 1,369 & 1,286 & 1,402 & 1,399 \\
\hline
\end{tabular}

$\bar{H}$ - Média dos híbridos. 
Tabela 46 - Estimativas dos parâmetros $k_{i}$ e $k_{j}$ das progênies de inmãos germanos das populações SUWAN e ESALQ PB-1, multiplicadas por cruzamentos fraternais, para a variável peso de espigas, referentes a 10 experimentos. Itha Solteira-SP, 1992/93.

\begin{tabular}{|c|c|c|c|c|c|c|c|c|c|c|}
\hline \multirow{2}{*}{$\begin{array}{c}\text { Progê- } \\
\text { nies }\end{array}$} & \multicolumn{10}{|c|}{ Experimentos } \\
\hline & 01 & 02 & 03 & 04 & 05 & 06 & 07 & 08 & 09 & 10 \\
\hline & \multicolumn{10}{|c|}{ População SUWAN ( $\left.\mathbf{k}_{\mathbf{i}}\right)$} \\
\hline 01 & $-0,114$ & 0,106 & $-0,198$ & 0,173 & $-0,047$ & 0,268 & 0,155 & 0,176 & 0,252 & 0,147 \\
\hline 02 & 0,120 & $-0,093$ & $-0,036$ & $-0,278$ & 0,109 & $-0,059$ & $-0,050$ & $-0,024$ & $-0,209$ & 0,250 \\
\hline 03 & $-0,104$ & $-0,116$ & 0,062 & 0,094 & $-0,097$ & $-0,403$ & 0,198 & 0,131 & $-0,151$ & $-0,204$ \\
\hline 04 & 0,292 & $-0,141$ & 0,113 & 0,067 & $-0,058$ & 0,104 & 0,136 & 0,211 & 0,074 & $-0,287$ \\
\hline 05 & $-0,020$ & $-0,011$ & 0,233 & 0,167 & $-0,081$ & 0,231 & 0,112 & 0,202 & 0,099 & $-0,101$ \\
\hline 06 & $-0,116$ & 0,047 & $-0,042$ & 0,022 & 0,113 & $-0,117$ & 0,071 & $-0,135$ & $-0,021$ & 0,205 \\
\hline 07 & $-0,012$ & 0,096 & 0,026 & $-0,140$ & 0,131 & $-0,024$ & $-0,083$ & $-0,333$ & $-0,018$ & $-0,220$ \\
\hline 08 & 0,138 & 0,072 & $-0,035$ & $-0,230$ & 0,144 & $-0,230$ & $-0,081$ & $-0,306$ & 0,355 & 0,002 \\
\hline 09 & 0,046 & $-0,088$ & $-0,077$ & 0,000 & $-0,228$ & $-0,020$ & $-0,318$ & 0,262 & $-0,014$ & 0,056 \\
\hline 10 & $-0,189$ & 0,127 & $-0,045$ & 0,124 & 0,013 & 0,249 & $-0,140$ & $-0,183$ & $-0,366$ & 0,151 \\
\hline
\end{tabular}

População ESALQ PB-1 ( $\left.\mathbf{k}_{\mathbf{j}}\right)$

$\begin{array}{lllllllllll}01 & -0,123 & -0,099 & -0,150 & 0,175 & 0,038 & 0,145 & 0,019 & 0,156 & -0,107 & -0,013\end{array}$

$\begin{array}{lllllllllll}02 & -0,236 & 0,098 & -0,098 & 0,005 & -0,066 & 0,407 & -0,200 & 0,394 & -0,125 & 0,240\end{array}$

$\begin{array}{lllllllllll}03 & 0,017 & 0,114 & -0,272 & -0,029 & 0,000 & -0,116 & 0,087 & -0,114 & -0,061 & -0,066\end{array}$

$\begin{array}{lllllllllll}04 & 0,155 & -0,242 & 0,111 & -0,158 & 0,024 & -0,242 & 0,221 & 0,138 & -0,078 & 0,154\end{array}$

$\begin{array}{lllllllllll}05 & 0,211 & -0,079 & 0,262 & 0,124 & -0,228 & 0,002 & 0,021 & 0,085 & 0,191 & -0,509\end{array}$

$\begin{array}{lllllllllll}06 & -0,062 & -0,030 & 0,058 & 0,158 & -0,007 & -0,126 & 0,233 & 0,180 & 0,032 & -0,050\end{array}$

$\begin{array}{lllllllllll}07 & -0,130 & 0,071 & -0,003 & -0,094 & 0,211 & 0,194 & 0,226 & -0,133 & -0,055 & -0,019\end{array}$

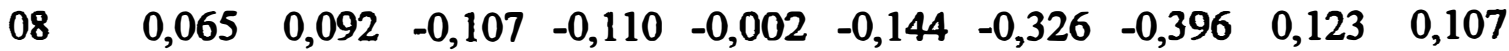

$\begin{array}{lllllllllll}09 & 0,214 & -0,108 & 0,024 & -0,074 & 0,124 & 0,040 & -0,132 & 0,039 & 0,122 & -0,063\end{array}$

$\begin{array}{lllllllllll}10 & -0,061 & 0,183 & 0,174 & 0,004 & -0,094 & -0,161 & -0,149 & -0,348 & -0,042 & 0,218\end{array}$

$\begin{array}{llllllllllll}H & 1,861 & 1,931 & 1,887 & 2,163 & 2,248 & 2,133 & 1,890 & 1,834 & 2,285 & 2,414\end{array}$

H-Média dos híbridos. 
Tabela 47 - Estimativas dos parâmetros $k_{\mathbf{i}}$ e $\mathbf{k}_{\mathbf{j}}$ das progênies de irmãos germanos das populações SUWAN e ESALQ PB-1, multiplicadas por cruzamentos fratemais, para a variável peso de grãos, referentes a 10 experimentos. Ilha Solteira-SP, 1992/93.

\begin{tabular}{|c|c|c|c|c|c|c|c|c|c|c|}
\hline \multirow{2}{*}{$\begin{array}{c}\text { Progê- } \\
\text { nies }\end{array}$} & \multicolumn{10}{|c|}{ Experimentos } \\
\hline & 01 & 02 & 03 & 04 & 05 & 06 & 07 & 08 & 09 & 10 \\
\hline & \multicolumn{10}{|c|}{ População SUWAN (k $\left.\mathbf{k}_{\mathbf{i}}\right)$} \\
\hline 01 & $-0,100$ & 0,075 & $-0,144$ & 0,140 & $-0,032$ & 0,248 & 0,111 & 0,184 & 0,249 & 0,152 \\
\hline 02 & 0,159 & $-0,049$ & $-0,024$ & $-0,249$ & 0,100 & $-0,061$ & $-0,013$ & $-0,001$ & $-0,210$ & 0,193 \\
\hline 03 & $-0,103$ & $-0,100$ & 0,072 & 0,101 & $-0,080$ & $-0,382$ & 0,170 & 0,104 & $-0,113$ & $-0,149$ \\
\hline 04 & 0,245 & $-0,133$ & 0,092 & 0,074 & $-0,087$ & 0,066 & 0,157 & 0,177 & 0,013 & $-0,294$ \\
\hline 05 & $-0,013$ & 0,015 & 0,197 & 0,159 & $-0,060$ & 0,202 & 0,108 & 0,155 & 0,112 & $-0,097$ \\
\hline 06 & $-0,112$ & 0,032 & $-0,066$ & 0,022 & 0,100 & $-0,120$ & 0,032 & $-0,122$ & $-0,018$ & 0,153 \\
\hline 07 & 0,017 & 0,065 & 0,006 & $-0,086$ & 0,084 & $-0,008$ & $-0,056$ & $-0,307$ & $-0,016$ & $-0,203$ \\
\hline 08 & 0,113 & 0,051 & $-0,020$ & $-0,214$ & 0,108 & $-0,187$ & $-0,100$ & $-0,255$ & 0,356 & 0,036 \\
\hline 09 & $-0,011$ & $-0,077$ & $-0,061$ & $-0,029$ & $-0,174$ & 0,013 & $-0,271$ & 0,224 & $-0,060$ & 0,033 \\
\hline \multirow[t]{2}{*}{010} & $-0,143$ & 0,122 & $-0,052$ & 0,081 & 0,041 & 0,228 & $-0,139$ & $-0,160$ & $-0,314$ & 0,176 \\
\hline & \multicolumn{10}{|c|}{ População ESALQ PB-1 $\left(\mathbf{k}_{\mathbf{j}}\right)$} \\
\hline 01 & $-0,086$ & $-0,079$ & $-0,104$ & 0,138 & 0,064 & 0,142 & $-0,020$ & 0,135 & $-0,108$ & 0,001 \\
\hline 02 & $-0,200$ & 0,066 & $-0,052$ & $-0,029$ & $-0,034$ & 0,348 & $-0,171$ & 0,370 & $-0,104$ & 0,213 \\
\hline 03 & 0,039 & 0,117 & $-0,224$ & $-0,006$ & 0,011 & $-0,129$ & 0,069 & $-0,104$ & $-0,036$ & $-0,053$ \\
\hline 04 & 0,139 & $-0,197$ & 0,111 & $-0,100$ & $-0,011$ & $-0,206$ & 0,232 & 0,159 & $-0,110$ & 0,097 \\
\hline 05 & 0,180 & $-0,078$ & 0,201 & 0,090 & $-0,209$ & $-0,027$ & 0,033 & 0,039 & 0,200 & $-0,421$ \\
\hline 06 & $-0,074$ & $-0,046$ & 0,051 & 0,150 & $-0,014$ & $-0,124$ & 0,178 & 0,140 & $-0,008$ & $-0,068$ \\
\hline 07 & $-0,097$ & 0,094 & $-0,026$ & $-0,076$ & 0,194 & 0,166 & 0,216 & $-0,124$ & $-0,027$ & $-0,032$ \\
\hline 08 & 0,061 & 0,048 & $-0,080$ & $-0,098$ & $-0,002$ & $-0,112$ & $-0,301$ & $-0,349$ & 0,125 & 0,092 \\
\hline 09 & 0,174 & $-0,095$ & 0,007 & $-0,031$ & 0,077 & 0,044 & $-0,104$ & 0,035 & 0,106 & $-0,062$ \\
\hline 10 & $-0,090$ & 0,170 & 0,117 & $-0,038$ & $-0,078$ & $-0,102$ & $-0,133$ & $-0,301$ & $-0,036$ & 0,234 \\
\hline $\bar{H}$ & 1,535 & 1,598 & 1,549 & 1,789 & 1,860 & 1,771 & 1,552 & 1,521 & 1,877 & 1,986 \\
\hline
\end{tabular}


Tabela 48 - Coeficientes de correlação entre as estimativas de $\mathbf{g}$ e de $\mathbf{k}$ das progênies participantes de um dialélico parcial circulante interpopulacional, multiplicadas por autofecundação, para as variáveis dias para florescimento feminino (FF), altura de plantas (AP), altura de espigas (AE), peso de espigas (PE) e peso de grãos (PG). Tha Solteira, 1992/93.

\begin{tabular}{|c|c|c|c|c|c|}
\hline \multirow{2}{*}{$\begin{array}{l}\text { Experi- } \\
\text { mento }\end{array}$} & \multicolumn{5}{|c|}{ Variáveis } \\
\hline & FF & AP & $\mathrm{AE}$ & PE & PG \\
\hline & \multicolumn{5}{|c|}{ População SUWAN } \\
\hline 01 & 0,8940 & 0,9130 & 0,8807 & 0,5139 & 0,6032 \\
\hline 02 & 0,6881 & 0,6597 & 0,7575 & 0,5398 & 0,6079 \\
\hline 03 & 0,9697 & 0,8601 & 0,9763 & 0,7997 & 0,7917 \\
\hline 04 & 0,9304 & 0,9186 & 0,7718 & 0,7857 & 0,8209 \\
\hline 05 & 0,8733 & 0,9491 & 0,9087 & 0,7697 & 0,7985 \\
\hline 06 & 0,6360 & 0,9759 & 0,9203 & 0,6770 & 0,6626 \\
\hline 07 & 0,8558 & 0,7433 & 0,9212 & 0,9432 & 0,9554 \\
\hline 08 & 0,7418 & 0,9451 & 0,8592 & 0,1563 & 0,2547 \\
\hline 09 & 0,6555 & 0,5665 & 0,7792 & 0,5629 & 0,4787 \\
\hline \multirow[t]{2}{*}{ GERAL } & 0,8125 & 0,8466 & 0,8536 & 0,6776 & 0,7013 \\
\hline & \multicolumn{5}{|c|}{ População ESALQ PB-1 } \\
\hline 01 & 0,5450 & 0,8230 & 0,8612 & 0,9344 & 0,9210 \\
\hline 02 & 0,7324 & 0,7964 & 0,8580 & 0,9841 & 0,9829 \\
\hline 03 & 0,6843 & 0,6172 & 0,5257 & 0,6746 & 0,7017 \\
\hline 04 & 0,1782 & 0,9165 & 0,9734 & 0,7719 & 0,7082 \\
\hline 05 & 0,7676 & 0,6551 & 0,7641 & 0,8580 & 0,8598 \\
\hline 06 & 0,6827 & 0,6482 & 0,7603 & 0,7046 & 0,7013 \\
\hline 07 & 0,9633 & 0,8659 & 0,9001 & 0,8310 & 0,7939 \\
\hline 08 & 0,8865 & 0,8774 & 0,8817 & 0,9366 & 0,9557 \\
\hline 09 & 0,8039 & 0,8448 & 0,6208 & 0,7463 & 0,7622 \\
\hline GERAL & 0,6770 & 0,7916 & 0,8081 & 0,8276 & 0,8164 \\
\hline
\end{tabular}


Tabela 49 - Coeficientes de correlação entre as estimativas de $\mathrm{g}$ e de $\mathrm{k}$ das progênies participantes de um dialélico parcial circulante interpopulacional, multiplicadas por cruzamentos fraternais, para as variáveis dias para florescimento ferninino (FF), altura de plantas (AP), altura de espigas (AE), peso de espigas (PE) e peso de grãos (PG). Tha Solteira, 1992/93.

\begin{tabular}{cccccc}
\hline \multirow{2}{*}{$\begin{array}{c}\text { Experi- } \\
\text { mento }\end{array}$} & FF & AP & AE & PE & PG \\
\cline { 2 - 6 } & \multicolumn{5}{c}{ População SUWAN } \\
01 & 0,4351 & 0,7836 & 0,8684 & 0,4860 & 0,5406 \\
02 & 0,7188 & 0,9595 & 0,8701 & 0,9099 & 0,9199 \\
03 & 0,9340 & 0,4911 & 0,8206 & 0,7398 & 0,7864 \\
04 & 0,7775 & 0,9791 & 0,7569 & 0,8285 & 0,8515 \\
05 & 0,9590 & 0,4746 & 0,2455 & 0,8356 & 0,7621 \\
06 & 0,7366 & 0,5545 & 0,8624 & 0,8391 & 0,8464 \\
07 & 0,9109 & 0,8218 & 0,9061 & 0,8307 & 0,8574 \\
08 & 0,9351 & 0,9763 & 0,8924 & 0,7545 & 0,7397 \\
09 & 0,3869 & 0,8057 & 0,9628 & 0,8576 & 0,8642 \\
10 & 0,9613 & 0,9531 & 0,9696 & 0,6932 & 0,7141 \\
\hline GERAL & 0,7995 & 0,8223 & 0,8601 & 0,7716 & 0,7788 \\
\hline
\end{tabular}

População ESALQ PB-1

\begin{tabular}{cccccc}
01 & 0,9608 & 0,8860 & 0,9447 & 0,9187 & 0,9209 \\
02 & 0,9126 & 0,7734 & 0,8651 & 0,7840 & 0,8732 \\
03 & 0,8413 & 0,9351 & 0,8091 & 0,6729 & 0,6120 \\
04 & 0,8452 & 0,5704 & 0,7082 & 0,3788 & 0,2259 \\
05 & 0,0553 & 0,8513 & 0,9715 & 0,8657 & 0,9005 \\
06 & 0,9613 & 0,8031 & 0,7760 & 0,8122 & 0,8127 \\
07 & 0,9247 & 0,6846 & 0,3530 & 0,9257 & 0,8966 \\
08 & 0,8657 & 0,7321 & 0,8271 & 0,8379 & 0,8635 \\
09 & 0,9306 & 0,8193 & 0,8630 & 0,5399 & 0,5531 \\
10 & 0,6856 & 0,6599 & 0,2708 & 0,8149 & 0,7610 \\
\hline GERAL & 0,8405 & 0,7807 & 0,6994 & 0,7868 & 0,7738 \\
\hline
\end{tabular}


Tabela 50 - Correlação dos valores da capacidade geral de combinação (medida pelos parâmetros g e k), e da capacidade específica de combinação (e), entre os sistemas de autofecundação e cruzamentos fraternais de multiplicação das progênies participantes de um dialélico parcial circulante entre as populações SUWAN e ESALQ-PB1, para as variáveis dias para florescimento feminino (FF), altura de plantas (AP), altura de espigas (AE), peso de espigas (PE) e peso de grãos (PG). Tha Solteira, 1992/93.

\begin{tabular}{|c|c|c|c|c|c|c|c|c|c|c|c|}
\hline \multirow[b]{2}{*}{ Variáveis } & & \multicolumn{9}{|c|}{ Experimentos } & \multirow[b]{2}{*}{ GERAL } \\
\hline & & 01 & 02 & 03 & 04 & 05 & 06 & 07 & 08 & 09 & \\
\hline \multirow{3}{*}{ FF } & g & 0,36 & 0,35 & 0,25 & 0,25 & 0,05 & 0,04 & 0,14 & 0,00 & 0,37 & 0,19 \\
\hline & $\mathbf{k}$ & 0,29 & 0,37 & 0,17 & 0,38 & 0,70 & 0,13 & 0,12 & 0,05 & 0,42 & 0,14 \\
\hline & e & 0,39 & 0,70 & 0,45 & 0,72 & 0,12 & 0,63 & 0,26 & 0,32 & 0,34 & 0,06 \\
\hline \multirow{3}{*}{$\mathbf{A P}$} & $\mathbf{g}$ & 0,35 & 0,29 & 0,05 & 0,23 & 0,00 & 0,08 & 0,15 & 0,54 & 0,31 & 0,00 \\
\hline & $\mathbf{k}$ & 0,47 & 0,25 & 0,06 & 0,46 & 0,33 & 0,06 & 0,19 & 0,39 & 0,02 & 0,19 \\
\hline & e & 0,04 & 0,39 & 0,02 & 0,10 & 0,03 & 0,23 & 0,23 & 0,29 & 0,00 & 0,04 \\
\hline \multirow{3}{*}{$\mathrm{AE}$} & g & 0,21 & 0,05 & 0,16 & 0,17 & 0,20 & 0,31 & 0,40 & 0,15 & 0,15 & 0,13 \\
\hline & $\mathbf{k}$ & 0,55 & 0,49 & 0,34 & 0,13 & 0,24 & 0,20 & 0,01 & 0,45 & 0,01 & 0,09 \\
\hline & e & 0,09 & 0,32 & 0,38 & 0,01 & 0,36 & 0,15 & 0,32 & 0,57 & 0,23 & 0,06 \\
\hline \multirow{3}{*}{ PE } & g & 0,67 & 0,06 & 0,30 & 0,14 & 0,07 & 0,08 & 0,04 & 0,18 & 0,40 & 0,02 \\
\hline & $\mathbf{k}$ & 0,50 & 0,18 & 0,01 & 0,10 & 0,28 & 0,03 & 0,23 & 0,23 & 0,12 & 0,08 \\
\hline & e & 0,51 & 0,04 & 0,22 & 0,05 & 0,06 & 0,44 & 0,14 & 0,11 & 0,01 & 0,06 \\
\hline \multirow{3}{*}{ PG } & $\mathbf{g}$ & 0,65 & 0,03 & 0,29 & 0,02 & 0,10 & 0,13 & 0,14 & 0,16 & 0,44 & 0,03 \\
\hline & $\mathbf{k}$ & 0,47 & 0,16 & 0,02 & 0,23 & 0,30 & 0,04 & 0,22 & 0,16 & 0,16 & 0,08 \\
\hline & e & 0,49 & 0,13 & 0,12 & 0,11 & 0,02 & 0,39 & 0,11 & 0,16 & 0,05 & 0,09 \\
\hline
\end{tabular}


Tabela 51 - Intervalo de variação dos valores da capacidade específica de combinação (e ), em unidades de cada variável e porcentagem da média do respectivo híbrido, para os híbridos avaliados em um dialélico parcial circulante com dois sistemas de multiplicação das progênies parentais. Ilha Solteira, 1992/93.

\begin{tabular}{|c|c|c|c|c|}
\hline \multirow[b]{2}{*}{ Variáveis $^{A}$} & \multicolumn{2}{|c|}{ Em unidades } & \multicolumn{2}{|c|}{$\mathrm{Em} \%$} \\
\hline & Limite inferior & Limite superior & Limite inferior & Limite superior \\
\hline & \multicolumn{4}{|c|}{ AUTOFECUNDAÇÃO } \\
\hline FF & $-1,194$ & 1,294 & $-2,25$ & 2,32 \\
\hline $\mathbf{A P}$ & $-0,130$ & 0,156 & $-6,07$ & 6,24 \\
\hline $\mathrm{AE}$ & $-0,142$ & 0,150 & $-12,35$ & 10,79 \\
\hline PE & $-0,390$ & 0,356 & $-21,19$ & 11,83 \\
\hline \multirow[t]{2}{*}{$\mathbf{P G}$} & $-0,332$ & 0,297 & $-17,44$ & 11,93 \\
\hline & \multicolumn{4}{|c|}{ CRUZAMENTOS FRATERNAIS } \\
\hline FF & $-1,892$ & 1,909 & $-3,68$ & 3,45 \\
\hline $\mathbf{A P}$ & $-0,350$ & 0,470 & $-13,31$ & 20,26 \\
\hline AE & $-0,149$ & 0,120 & $-10,87$ & 7,79 \\
\hline PE & $-0,421$ & 0,337 & $-21,11$ & 14,46 \\
\hline PG & $-0,338$ & 0,289 & $-20,68$ & 15,08 \\
\hline
\end{tabular}

A - FF - dias para florescimento feminino, em dias; AP - altura de plantas em m/planta: AE - altura de espigas em m/plante; PE - peso de espigas em kg/parcela; e PG - peso de grãos em kg/parcela. 
Tabela 52 - Componentes do peso médio de grãos dos 20 melhores híbridos ${ }^{\mathrm{A}}$ avaliados em um dialélico parcial circulante, com multiplicação dos parentais por autofecundação. Ilha Solteira, 1992/93.

\begin{tabular}{|c|c|c|c|c|c|c|c|c|c|}
\hline \multirow{2}{*}{$\begin{array}{l}\text { Híbri- } \\
\text { dos }\end{array}$} & \multicolumn{9}{|c|}{ Componentes em kg/parcela e $\%$ da média observada ${ }^{\mathrm{B}}$} \\
\hline & $\mathbf{m}$ & $\mu$ & $\mathrm{g}_{\mathrm{i}}$ & $\mathbf{g}_{\mathbf{j}}$ & $\mathbf{S}_{\mathbf{i j}}$ & $\mu \%$ & $\mathrm{~g}_{\mathrm{i}} \%$ & $\mathrm{~g}_{\mathrm{i}} \%$ & $\mathrm{~s}_{\mathrm{ij}} \%$ \\
\hline H74.76 & 2,856 & 2,311 & $-0,148$ & 0,473 & 0,219 & 80,92 & $-5,17$ & 16,58 & 7,67 \\
\hline $\mathrm{H} 70.70$ & 2,735 & 2,208 & 0,238 & 0,296 & $-0,007$ & 80,75 & 8,69 & 10,81 & $-0,26$ \\
\hline H71.72 & 2,710 & 2,311 & 0,224 & 0,020 & 0,154 & 85,30 & 8,26 & 0,74 & 5,68 \\
\hline H76.76 & 2,699 & 2,311 & $-0,110$ & 0,473 & 0,024 & 85,64 & $-4,07$ & 17,54 & 0,89 \\
\hline H73.74 & 2,629 & 2,311 & 0,061 & 0,073 & 0,183 & 87,92 & 2,33 & 2,78 & 6,96 \\
\hline H47.48 & 2,615 & 2,185 & 0,049 & 0,205 & 0,176 & 83,57 & 1,87 & 7,84 & 6,73 \\
\hline H56.56 & 2,601 & 2,208 & 0,294 & 0,005 & 0,095 & 84,86 & 11,32 & 0,18 & 3,65 \\
\hline H50.50 & 2,589 & 2,185 & 0,289 & $-0,154$ & 0,268 & 84,42 & 11,18 & $-5,95$ & 10,35 \\
\hline H81.83 & 2,589 & 2,170 & $-0,007$ & 0,202 & 0,224 & 83,81 & $-0,29$ & 7,81 & 8,65 \\
\hline H83.83 & 2,581 & 2,170 & 0,207 & 0,202 & 0,002 & 84,04 & 8,03 & 7,83 & 0,08 \\
\hline H69.70 & 2,578 & 2,208 & $-0,139$ & 0,296 & 0,213 & 85,66 & $-5,38$ & 11,46 & 8,26 \\
\hline H70.61 & 2,562 & 2,208 & 0,238 & $-0,057$ & 0,173 & 86,19 & 9,28 & $-2,23$ & 6,75 \\
\hline H33.34 & 2,562 & 2,183 & $-0,175$ & 0,431 & 0,123 & 85,20 & $-6,82$ & 16,81 & 4,80 \\
\hline H61.62 & 2,562 & 2,208 & 0,186 & 0,024 & 0,144 & 86,20 & 7,26 & 0,92 & 5,62 \\
\hline H80.80 & 2,547 & 2,311 & 0,001 & 0,096 & 0,139 & 90,73 & 0,04 & 3,76 & 5,46 \\
\hline H54.55 & 2,538 & 2,208 & 0,036 & 0,148 & 0,146 & 86,98 & 1,41 & 5,84 & 5,75 \\
\hline H82.82 & 2,537 & 2,170 & $-0,098$ & 0,271 & 0,193 & 85,53 & $-3,84$ & 10,70 & 7,61 \\
\hline H35.35 & 2,524 & 2,183 & 0,235 & 0,051 & 0,055 & 86,47 & 9,30 & 2,00 & 2,18 \\
\hline H37.39 & 2,515 & 2,183 & 0,115 & 0,094 & 0,123 & 86,80 & 4,57 & 3,72 & 4,89 \\
\hline H72.74 & 2,514 & 2,311 & $-0,020$ & 0,070 & 0,149 & 91,94 & $-0,80$ & 2,80 & 5,93 \\
\hline
\end{tabular}

A - $O$ primeiro número indica linhagem da população SUWAN e o segundo da população ESALQPB1. ${ }^{B}-m=$ média observada; $\mu=$ média estimada; $g_{i}=$ capacidade geral de combinação da progênie da população SUWAN; $g_{j}=$ capacidade geal de combinação da população ESAL - PB1; $s_{\mathrm{ij}}=$ capacidade específica de combinação do híbrido “ij". 
Tabela 53 - Componentes do peso médio de grãos dos 20 melhores híbridos ${ }^{\mathrm{A}}$ avaliados em um dialélico parcial circulante, com multiplicação dos parentais por cruzamentos fraternais. Ilha Solteira, 1992/93.

\begin{tabular}{|c|c|c|c|c|c|c|c|c|c|}
\hline \multirow{2}{*}{$\begin{array}{l}\text { Hibri- } \\
\text { dos }\end{array}$} & \multicolumn{9}{|c|}{ Componentes em kg/parcela e $\%$ da média observada ${ }^{B}$} \\
\hline & $\mathbf{m}$ & $\mu$ & $\mathrm{g}_{\mathrm{i}}$ & $\overline{g_{i}}$ & $s_{i j}$ & $\mu \%$ & $\mathrm{~g}_{\mathrm{i}} \%$ & $\mathrm{~g}_{\mathrm{j}} \%$ & $\mathrm{~s}_{\mathrm{ij}} \%$ \\
\hline H100.01 & 2,468 & 1,986 & 0,116 & 0,283 & 0,084 & 80,46 & 4,70 & 11,47 & 3,40 \\
\hline H 91.92 & 2,440 & 1,986 & 0,267 & 0,001 & 0,187 & 81,38 & 10,94 & 0,04 & 7,66 \\
\hline H 88.88 & 2,426 & 1,877 & 0,436 & $-0,020$ & 0,133 & 77,37 & 17,97 & $-0,82$ & 5,48 \\
\hline H 55.57 & 2,394 & 1,771 & 0,289 & 0,147 & 0,187 & 73,97 & 12,07 & 6,14 & 7,81 \\
\hline H 60.52 & 2,357 & 1,771 & 0,131 & 0,269 & 0,187 & 75,14 & 5,56 & 11,41 & 7,93 \\
\hline H 92.94 & 2,356 & 1,986 & 0,256 & 0,053 & 0,061 & 84,29 & 10,87 & 2,25 & 2,59 \\
\hline H 92.92 & 2,333 & 1,986 & 0,256 & 0,001 & 0,091 & 85,12 & 10,97 & 0,04 & 3,90 \\
\hline Н 88.89 & 2,219 & 1,877 & 0,436 & $-0,072$ & $-0,022$ & 84,60 & 19,65 & $-3,25$ & $-0,99$ \\
\hline H 81.83 & 2,216 & 1,877 & 0,333 & 0,017 & $-0,010$ & 84,69 & 15,03 & 0,77 & $-0,45$ \\
\hline Н 99.10 & 2,216 & 1,986 & $-0,075$ & 0,283 & 0,022 & 89,63 & $-3,38$ & 12,77 & 0,99 \\
\hline H 84.85 & 2,208 & 1,877 & $-0,157$ & 0,347 & 0,141 & 85,02 & $\cdot-7,11$ & 15,72 & 6,39 \\
\hline H 96.98 & 2,195 & 1,986 & 0,068 & 0,249 & $-0,108$ & 90,49 & 3,10 & 11,35 & $-4,92$ \\
\hline H100.91 & 2,194 & 1,986 & 0,116 & $-0,102$ & 0,194 & 90,54 & 5,29 & $-4,65$ & 8,84 \\
\hline H 46.47 & 2,193 & 1,860 & 0,055 & 0,198 & 0,080 & 84,81 & 2,51 & 9,03 & 3,65 \\
\hline H 47.49 & 2,169 & 1,860 & $-0,017$ & 0,145 & 0,181 & 85,77 & $-0,78$ & 6,69 & 8,35 \\
\hline H 81.82 & 2,151 & 1,877 & 0,333 & $-0,082$ & 0,024 & 87,25 & 15,48 & $-3,81$ & 1,12 \\
\hline H 96.96 & 2,148 & 1,986 & 0,068 & $-0,046$ & 0,140 & 92,47 & 3,17 & $-2,14$ & 6,52 \\
\hline H 33.33 & 2,140 & 1,789 & 0,224 & $-0,054$ & 0,180 & 83,61 & 10,47 & $-2,52$ & 8,41 \\
\hline H 31.31 & 2,138 & 1,789 & 0,093 & 0,185 & 0,071 & 83,67 & 4,35 & 8,65 & 3,32 \\
\hline .35 & 2,131 & 1,789 & 0,264 & $-0,135$ & 0,212 & 83,96 & 12,39 & $-6,34$ & 9,95 \\
\hline
\end{tabular}

A - O primeiro número indica linhagem da população SUWAN e o segundo da população ESALQPBI. ${ }^{B}-m=$ média observada; $\mu=$ média estimada; $g_{i}=$ capacidade geral de combinação da progênie da população SUWAN; $\mathrm{g}_{\mathrm{j}}=$ capacidade geal de combinação da população ESAL - PB1; $\mathrm{s}_{\mathrm{ij}}=$ capacidade especifica de combinação do híbrido “ij”". 
Tabela 54 - Coeficientes de correlação entre híbridos simples observados $\left(\mathrm{HS}_{\mathrm{o}}\right)$, híbridos simples previstos com base nos g's $\left(\mathrm{HS}_{\mathrm{g}}\right)$ e híbridos simples previstos com base nos $\mathrm{k}$ 's $\left(\mathrm{HS}_{\mathrm{k}}\right)$, para cinco variáveis em nove experimentos de um dialélico parcial circulante entre progênies das populações SUWAN e ESALQ PB-1, multiplicadas por autofecundação. Ilha Solteira-SP, 1992/93.

\begin{tabular}{|c|c|c|c|c|c|c|c|c|c|c|}
\hline \multirow{2}{*}{$\begin{array}{l}\text { Vari- } \\
\text { áveis }^{\mathrm{A}}\end{array}$} & \multirow{2}{*}{$\begin{array}{c}\text { Combina- } \\
\text { ção }\end{array}$} & \multicolumn{9}{|c|}{ Experimentos } \\
\hline & & 01 & 02 & 03 & 04 & 05 & 06 & 07 & 08 & 09 \\
\hline \multirow{3}{*}{ FF } & $\mathrm{HS}_{\mathbf{0}} \cdot \mathrm{HS}_{\mathrm{g}}$ & 0,95 & 0,90 & 0,93 & 0,88 & 0,93 & 0,76 & 0,87 & 0,90 & 0,86 \\
\hline & $\mathrm{HS}_{\mathbf{0}} \cdot \mathrm{HS}_{\mathbf{k}}$ & 0,88 & 0,80 & 0,87 & 0,77 & 0,87 & 0,62 & 0,81 & 0,84 & 0,79 \\
\hline & $\mathrm{HS}_{\mathrm{g}} \cdot \mathrm{HS}_{\mathrm{k}}$ & 0,92 & 0,88 & 0,94 & 0,88 & 0,94 & 0,82 & 0,93 & 0,94 & 0,91 \\
\hline \multirow{3}{*}{$\mathbf{A P}$} & $\mathrm{HS}_{\mathbf{0}} \cdot \mathrm{HS}_{\mathrm{g}}$ & 0,89 & 0,78 & 0,71 & 0,89 & 0,84 & 0,90 & 0,85 & 0,84 & 0,88 \\
\hline & $\mathrm{HS}_{\mathbf{o}} \cdot \mathrm{HS}_{\mathrm{k}}$ & 0,85 & 0,68 & 0,61 & 0,83 & 0,79 & 0,88 & 0,78 & 0,79 & 0,79 \\
\hline & $\mathrm{HS}_{\mathrm{g}} \cdot \mathrm{HS}_{\mathrm{k}}$ & 0,95 & 0,87 & 0,85 & 0,94 & 0,93 & 0,97 & 0,92 & 0,93 & 0,90 \\
\hline \multirow{3}{*}{$\mathbf{A E}$} & $\mathrm{HS}_{\mathrm{o}} \cdot \mathrm{HS}_{\mathrm{g}}$ & 0,89 & 0,68 & 0,62 & 0,89 & 0,85 & 0,87 & 0,84 & 0,92 & 0,88 \\
\hline & $\mathbf{H S}_{\mathbf{o}} \cdot \mathbf{H S}_{\mathbf{k}}$ & 0,84 & 0,64 & 0,55 & 0,81 & 0,79 & 0,84 & 0,79 & 0,85 & 0,78 \\
\hline & $\mathrm{HS}_{\mathrm{g}} \cdot \mathrm{HS}_{\mathrm{k}}$ & 0,94 & 0,93 & 0,88 & 0,90 & 0,93 & 0,96 & 0,95 & 0,92 & 0,88 \\
\hline \multirow{3}{*}{ PE } & $\mathbf{H S}_{\mathbf{0}} \cdot \mathbf{H S}_{\mathrm{g}}$ & 0,90 & 0,84 & 0,87 & 0,94 & 0,82 & 0,91 & 0,79 & 0,79 & 0,82 \\
\hline & $\mathrm{HS}_{\mathbf{0}} \cdot \mathrm{HS}_{\mathbf{k}}$ & 0,77 & 0,80 & 0,82 & 0,84 & 0,75 & 0,82 & 0,76 & 0,73 & 0,71 \\
\hline & $\mathbf{H S}_{\mathbf{g}} \cdot \mathbf{H S}_{\mathbf{k}}$ & 0,82 & 0,95 & 0,94 & 0,89 & 0,92 & 0,90 & 0,95 & 0,92 & 0,85 \\
\hline \multirow{3}{*}{ PG } & $\mathbf{H S}_{\mathbf{0}} \cdot \mathbf{H S}_{\mathbf{g}}$ & 0,91 & 0,84 & 0,87 & 0,93 & 0,84 & 0,90 & 0,83 & 0,77 & 0,82 \\
\hline & $\mathbf{H S}_{\mathbf{o}} \cdot \mathbf{H S}_{\mathbf{k}}$ & 0,79 & 0,80 & 0,82 & 0,82 & 0,77 & 0,81 & 0,79 & 0,70 & 0,70 \\
\hline & $\mathbf{H S}_{\mathbf{g}} \cdot \mathbf{H S}_{\mathbf{k}}$ & 0,84 & 0,95 & 0,94 & 0,88 & 0,92 & 0,90 & 0,96 & 0,91 & 0,85 \\
\hline
\end{tabular}

- FF = dias paraflorescimento feminino; $\mathrm{AP}=$ altura de plantas; $\mathrm{AE}=$ altura de espigas; $\mathrm{PE}$ = peso de espigas; $\mathbf{P G}=$ peso de grãos. 
Tabela 55 - Coeficientes de correlação entre híbridos simples observados $\left(\mathrm{HS}_{\mathrm{o}}\right)$, híbridos simples previstos com base nos g's $\left(\mathrm{HS}_{\mathrm{g}}\right)$ e híbridos simples previstos com base nos $\mathbf{k}$ 's $\left(\mathrm{HS}_{\mathrm{k}}\right)$, para cinco variáveis em 10 experimentos de um dialélico parcial circulante entre progênies das populações SUWAN e ESALQ PB-1, multiplicadas por cruzamentos fraternais Ilha Solteira-SP, 1992/93.

\begin{tabular}{|c|c|c|c|c|c|c|c|c|c|c|c|}
\hline \multirow{2}{*}{$\begin{array}{l}\text { Vari- } \\
\text { áveis }^{A}\end{array}$} & \multirow{2}{*}{$\begin{array}{c}\text { Combina- } \\
\text { ção }\end{array}$} & \multicolumn{10}{|c|}{ Experimentos } \\
\hline & & 01 & 02 & 03 & 04 & 05 & 06 & 07 & 08 & 09 & 10 \\
\hline \multirow{3}{*}{ FF } & $\mathrm{HS}_{\mathrm{o}} \cdot \mathrm{HS}_{\mathrm{g}}$ & 0,88 & 0,90 & 0,84 & 0,94 & 0,84 & 0,93 & 0,89 & 0,89 & 0,97 & 0,95 \\
\hline & $\mathbf{H S}_{\mathbf{0}} \cdot \mathbf{H S}_{\mathbf{k}}$ & 0,79 & 0,84 & 0,79 & 0,86 & 0,73 & 0,89 & 0,87 & 0,84 & 0,89 & 0,89 \\
\hline & $\mathbf{H S}_{\mathbf{g}} \cdot \mathbf{H S}_{\mathbf{k}}$ & 0,90 & 0,93 & 0,94 & 0,92 & 0,87 & 0,96 & 0,96 & 0,95 & 0,92 & 0,94 \\
\hline \multirow{3}{*}{$\mathbf{A P}$} & $\mathbf{H S}_{\mathbf{o}} \cdot \mathbf{H S}_{\mathrm{g}}$ & 0,92 & 0,92 & 0,90 & 0,87 & 0,89 & 0,87 & 0,83 & 0,91 & 0,89 & 0,94 \\
\hline & $\mathbf{H S}_{\mathbf{o}} \cdot \mathbf{H S}_{\mathbf{k}}$ & 0,87 & 0,86 & 0,82 & 0,82 & 0,77 & 0,75 & 0,74 & 0,86 & 0,83 & 0,87 \\
\hline & $\mathrm{HS}_{\mathrm{g}} \cdot \mathrm{HS}_{\mathrm{k}}$ & 0,94 & 0,93 & 0,91 & 0,94 & 0,86 & 0,87 & 0,89 & 0,94 & 0,93 & 0,92 \\
\hline \multirow{3}{*}{$\mathbf{A E}$} & $\mathbf{H S}_{\mathbf{0}} \cdot \mathbf{H S}_{\mathrm{g}}$ & 0,90 & 0,91 & 0,89 & 0,79 & 0,91 & 0,82 & 0,90 & 0,80 & 0,87 & 0,90 \\
\hline & $\mathbf{H S}_{\mathbf{o}} \cdot \mathbf{H S}_{\mathbf{k}}$ & 0,85 & 0,84 & 0,83 & 0,73 & 0,80 & 0,76 & 0,81 & 0,73 & 0,81 & 0,82 \\
\hline & $\mathbf{H S}_{\mathbf{g}} \cdot \mathbf{H S}_{\mathbf{k}}$ & 0,95 & 0,93 & 0,93 & 0,93 & 0,88 & 0,92 & 0,89 & 0,91 & 0,92 & 0,90 \\
\hline \multirow{3}{*}{$\mathbf{P E}$} & $\mathbf{H S}_{\mathbf{o}} \cdot \mathbf{H S}_{\mathrm{g}}$ & 0.96 & 0,77 & 0,88 & 0,79 & 0,78 & 0,85 & 0,89 & 0,94 & 0,89 & 0,82 \\
\hline & $\mathbf{H S}_{\mathbf{o}} \cdot \mathbf{H S}_{\mathbf{k}}$ & 0.87 & 0,73 & 0,77 & 0,72 & 0,71 & 0,80 & 0,81 & 0,85 & 0,82 & 0,75 \\
\hline & $\mathrm{HS}_{\mathrm{g}} \cdot \mathbf{H} \mathrm{S}_{\mathrm{k}}$ & 0.88 & 0,94 & 0,88 & 0,91 & 0,91 & 0,94 & 0,92 & 0,91 & 0,93 & 0,92 \\
\hline \multirow{3}{*}{ PG } & $\mathbf{H S}_{\mathbf{o}} \cdot \mathbf{H S}_{\mathrm{g}}$ & 0.96 & 0,78 & 0,85 & 0,80 & 0,79 & 0,87 & 0,89 & 0,93 & 0,91 & 0,83 \\
\hline & $\mathbf{H S}_{\mathbf{o}} \cdot \mathbf{H S}_{\mathbf{k}}$ & 0.86 & 0,75 & 0,75 & 0,71 & 0,71 & 0,81 & 0,80 & 0,85 & 0,85 & 0,75 \\
\hline & $\mathbf{H S}_{\mathbf{g}} \cdot \mathbf{H S}_{\mathbf{k}}$ & 0.88 & 0,95 & 0,88 & 0,89 & 0,91 & 0,94 & 0,92 & 0,91 & 0,93 & 0,91 \\
\hline
\end{tabular}

A - FF = dias paraflorescimento feminino; $\mathrm{AP}=$ altura de plantas; $\mathrm{AE}=$ altura de espigas; $\mathrm{PE}$ = peso de espigas; $\mathbf{P G}=$ peso de grãos. 
Tabela 56 - Coeficientes de correlação entre híbridos triplos previstos pelo método de JENKINS $\left(\mathrm{HT}_{\mathrm{j}}\right)$, híbridos triplos previstos com base nos g's $\left(\mathrm{HT}_{\mathrm{g}}\right)$ e híbridos triplos previstos com base nos $\mathrm{k}$ 's $\left(\mathrm{HT}_{\mathrm{k}}\right)$, para cinco variáveis em nove experimentos de um dialélico parcial circulante entre progênies das populações SUWAN e ESALQ PB-1, multiplicadas por autofecundação. Ilha Solteira-SP, 1992/93.

\begin{tabular}{|c|c|c|c|c|c|c|c|c|c|c|}
\hline \multirow{2}{*}{$\begin{array}{l}\text { Vari- } \\
\text { áveis }^{A}\end{array}$} & \multirow{2}{*}{$\begin{array}{l}\text { Combina- } \\
\text { ção }\end{array}$} & \multicolumn{9}{|c|}{ Experimentos } \\
\hline & & 01 & 02 & 03 & 04 & 05 & 06 & 07 & 08 & 09 \\
\hline \multirow{3}{*}{ FF } & $\mathrm{HT}_{\mathbf{j}} \cdot \mathrm{HT}_{\mathrm{g}}$ & 0,98 & 0,96 & 0,97 & 0,95 & 0,97 & 0,85 & 0,94 & 0,96 & 0,94 \\
\hline & $\mathrm{HT}_{\mathbf{j}} \cdot \mathrm{HT}_{\mathbf{k}}$ & 0,93 & 0,89 & 0,92 & 0,88 & 0,94 & 0,75 & 0,89 & 0,92 & 0,88 \\
\hline & $\mathrm{HT}_{\mathrm{g}} \cdot \mathrm{HT}_{\mathrm{k}}$ & 0,94 & 0,92 & 0,94 & 0,93 & 0,96 & 0,88 & 0,94 & 0,96 & 0,94 \\
\hline \multirow{3}{*}{$\mathbf{A P}$} & $\mathrm{HT}_{\mathbf{j}} \cdot \mathrm{HT}_{\mathrm{g}}$ & 0,96 & 0,89 & 0,84 & 0,95 & 0,94 & 0,96 & 0,94 & 0,93 & 0,95 \\
\hline & $\mathrm{HT}_{\mathbf{j}} \cdot \mathbf{H T}_{\mathbf{k}}$ & 0,92 & 0,81 & 0,75 & 0,90 & 0,88 & 0,94 & 0,88 & 0,88 & 0,90 \\
\hline & $\mathrm{HT}_{\mathrm{g}} \cdot \mathrm{HT}_{\mathrm{k}}$ & 0,96 & 0,90 & 0,89 & 0,94 & 0,94 & 0,98 & 0,94 & 0,94 & 0,94 \\
\hline \multirow{3}{*}{$\mathbf{A E}$} & $\mathrm{HT}_{\mathbf{j}} \cdot \mathrm{HT}_{\mathrm{g}}$ & 0,95 & 0,82 & 0,79 & 0,95 & 0,94 & 0,94 & 0,93 & 0,97 & 0,95 \\
\hline & $\mathrm{HT}_{\mathbf{j}} \cdot \mathbf{H T}_{\mathbf{k}}$ & 0,91 & 0,78 & 0,72 & 0,88 & 0,89 & 0,92 & 0,89 & 0,92 & 0,87 \\
\hline & $\mathrm{HT}_{\mathrm{g}} \cdot \mathrm{HT}_{\mathrm{k}}$ & 0,96 & 0,95 & 0,92 & 0,92 & 0,94 & 0,97 & 0,96 & 0,94 & 0,92 \\
\hline \multirow{3}{*}{ PE } & $\mathrm{HT}_{\mathbf{j}} \cdot \mathrm{HT}_{\mathrm{g}}$ & 0,95 & 0,93 & 0,95 & 0,98 & 0,92 & 0,96 & 0,92 & 0,89 & 0,92 \\
\hline & $\mathrm{HT}_{\mathbf{j}} \cdot \mathrm{HT}_{\mathrm{k}}$ & 0,85 & 0,89 & 0,92 & 0,90 & 0,86 & 0,91 & 0,88 & 0,83 & 0,82 \\
\hline & $\mathrm{HT}_{\mathrm{g}} \cdot \mathrm{HT}_{\mathrm{k}}$ & 0,86 & 0,96 & 0,97 & 0,93 & 0,93 & 0,95 & 0,96 & 0,93 & 0,90 \\
\hline \multirow{3}{*}{ PG } & $\mathrm{HT}_{\mathbf{j}} \cdot \mathbf{H} \mathbf{T}_{\mathrm{g}}$ & 0,96 & 0,93 & 0,95 & 0,97 & 0,93 & 0,96 & 0,93 & 0,87 & 0,91 \\
\hline & $\mathrm{HT}_{\mathbf{j}} \cdot \mathrm{HT}_{\mathrm{k}}$ & 0,86 & 0,89 & 0,92 & 0,89 & 0,86 & 0,90 & 0,90 & 0,80 & 0,82 \\
\hline & $\mathrm{HT}_{\mathrm{g}} \cdot \mathrm{HT}_{\mathrm{k}}$ & 0,87 & 0,96 & 0,97 & 0,92 & 0,93 & 0,94 & 0,97 & 0,92 & 0,90 \\
\hline
\end{tabular}

- FF = dias paraflorescimento feminino; $\mathrm{AP}=$ altura de plantas; $\mathrm{AE}=$ altura de espigas; $\mathrm{PE}=$ peso de espigas; $\mathbf{P G}=$ peso de grãos. 
Tabela 57- Coeficientes de correlação entre híbridos triplos previstos pelo método de JENKINS ( $\left(\mathrm{HT}_{\mathrm{j}}\right)$, híbridos triplos previstos com base nos g's $\left(\mathrm{HT}_{\mathrm{g}}\right)$ e híbridos triplos previstos com base nos $\mathrm{k}$ 's $\left(\mathrm{HT}_{\mathrm{k}}\right)$, para cinco variáveis em 10 experimentos de um dialélico parcial circulante entre progênies das populações SUWAN e ESALQ PB-1, multiplicadas por cruzamentos fratemais tha Solteira-SP, 1992/93.

\begin{tabular}{|c|c|c|c|c|c|c|c|c|c|c|c|}
\hline \multirow{2}{*}{$\begin{array}{l}\text { Vari- } \\
\text { áveis }^{\mathrm{A}}\end{array}$} & \multirow{2}{*}{$\begin{array}{c}\text { Combina- } \\
\text { ção }\end{array}$} & \multicolumn{10}{|c|}{ Experimentos } \\
\hline & & 01 & 02 & 03 & 04 & 05 & 06 & 07 & 08 & 09 & 10 \\
\hline \multirow{3}{*}{ FF } & $\overline{\mathrm{HT}_{\mathrm{j}} \cdot \mathrm{HT}_{\mathrm{g}}}$ & 0,95 & 0,96 & $\overline{0,93}$ & 0,97 & 0,93 & 0,97 & 0,96 & 0,95 & 0,99 & 0,98 \\
\hline & $\mathrm{HT}_{\mathrm{j}} \cdot \mathrm{HT}_{\mathrm{k}}$ & 0,87 & 0,91 & 0,88 & 0,91 & 0,85 & 0,95 & 0,94 & 0,90 & 0,93 & 0,94 \\
\hline & $\mathrm{HT}_{\mathrm{g}} \cdot \mathrm{HT}_{\mathrm{k}}$ & 0,93 & 0,95 & 0,94 & 0,93 & 0,92 & 0,97 & 0,97 & 0,95 & 0,94 & 0,95 \\
\hline \multirow{3}{*}{ AP } & $\mathrm{HT}_{\mathbf{j}} \cdot \mathrm{HT}_{\mathrm{g}}$ & 0,97 & 0,96 & 0,96 & 0,95 & 0,95 & 0,93 & 0,92 & 0,96 & 0,95 & 0,98 \\
\hline & $\mathrm{HT}_{\mathbf{j}} \cdot \mathrm{HT}_{\mathrm{k}}$ & 0,93 & 0,90 & 0,90 & 0,91 & 0,87 & 0,85 & 0,85 & 0,91 & 0,91 & 0,92 \\
\hline & $\mathrm{HT}_{\mathrm{g}} \cdot \mathrm{HT}_{\mathrm{k}}$ & 0,95 & 0,94 & 0,94 & 0,96 & 0,91 & 0,90 & 0,92 & 0,95 & 0,95 & 0,94 \\
\hline \multirow{3}{*}{$\mathrm{AE}$} & $\mathrm{HT}_{\mathbf{j}} \cdot \mathbf{H} \mathbf{T}_{\mathrm{g}}$ & 0.96 & 0,96 & 0,96 & 0,90 & 0,96 & 0,91 & 0,96 & 0,89 & 0,94 & 0,96 \\
\hline & $\mathrm{HT}_{\mathbf{j}} \cdot \mathrm{HT}_{\mathbf{k}}$ & 0.92 & 0,90 & 0,91 & 0,87 & 0,88 & 0,85 & 0,89 & 0,85 & 0,87 & 0,89 \\
\hline & $\mathrm{HT}_{\mathrm{g}} \cdot \mathrm{HT}_{\mathrm{k}}$ & 0.95 & 0,94 & 0,95 & 0,95 & 0,92 & 0,94 & 0,93 & 0,93 & 0,92 & 0,93 \\
\hline \multirow{3}{*}{ PE } & $\mathrm{HT}_{\mathrm{j}} \cdot \mathrm{HT}_{\mathrm{g}}$ & 0.98 & 0,89 & 0,95 & 0,91 & 0,89 & 0,94 & 0,95 & 0,97 & 0,95 & 0,92 \\
\hline & $\mathrm{HT}_{\mathrm{j}} \cdot \mathrm{HT}_{\mathrm{k}}$ & 0.92 & 0,86 & 0,88 & 0,87 & 0,83 & 0,90 & 0,89 & 0,91 & 0,90 & 0,87 \\
\hline & $\mathrm{HT}_{\mathrm{g}} \cdot \mathrm{HT}_{\mathrm{k}}$ & 0.90 & 0,96 & 0,93 & 0,95 & 0,93 & 0,96 & 0,93 & 0,93 & 0,95 & 0,95 \\
\hline \multirow{3}{*}{ PG } & $\mathrm{HT}_{\mathrm{j}} \cdot \mathrm{HT}_{\mathrm{g}}$ & 0.98 & 0,90 & 0,94 & 0,90 & 0,89 & 0,94 & 0,96 & 0,97 & 0,96 & 0,93 \\
\hline & $\mathrm{HT}_{\mathbf{j}} \cdot \mathrm{HT}_{\mathbf{k}}$ & 0.91 & 0,87 & 0,87 & 0,85 & 0,83 & 0,88 & 0,89 & 0,91 & 0,91 & 0,88 \\
\hline & $\mathrm{HT}_{\mathrm{g}} \cdot \mathrm{HT}_{\mathrm{k}}$ & 0.90 & 0,96 & 0,93 & 0,94 & 0,93 & 0,94 & 0,94 & 0,93 & 0,95 & 0,94 \\
\hline
\end{tabular}

- FF = dias paraflorescimento feminino; AP = altura de plantas; AE = altura de espigas; $\mathrm{PE}=$ peso de espigas; $P G=$ peso de grãos. 
Tabela 58 - Coeficientes de correlação entre híbridos duplos previstos pelo método de JENKINS $\left(\mathrm{HD}_{\mathrm{j}}\right)$, híbridos duplos previstos com base nos $\mathrm{g}^{\prime} \mathrm{s}\left(\mathrm{HD}_{\mathrm{g}}\right)$ e híbridos duplos previstos com base nos $\mathrm{k}$ 's $\left(\mathrm{HD}_{\mathrm{k}}\right)$, para cinco variáveis em nove experimentos de um dialélico parcial circulante entre progênies das populações SUWAN e ESALQ PB-1, multiplicadas por autofecundação. Tha Solteira-SP, 1992/93.

\begin{tabular}{|c|c|c|c|c|c|c|c|c|c|c|}
\hline \multirow{2}{*}{$\begin{array}{l}\text { Vari- } \\
\text { áveis }^{\mathbf{A}}\end{array}$} & \multirow{2}{*}{$\begin{array}{c}\text { Combina- } \\
\text { ção }\end{array}$} & \multicolumn{9}{|c|}{ Experimentos } \\
\hline & & 01 & 02 & 03 & 04 & 05 & 06 & 07 & 08 & 09 \\
\hline \multirow{3}{*}{ FF } & $\mathrm{HD}_{\mathrm{j}} \cdot \mathrm{HD}_{\mathrm{g}}$ & 0,99 & 0,98 & 0,98 & 0,96 & 0,98 & 0,70 & 0,92 & 0,96 & 0,95 \\
\hline & $\mathrm{HD}_{\mathrm{j}} \cdot \mathrm{HD}_{\mathbf{k}}$ & 0,98 & 0,97 & 0,97 & 0,94 & 0,96 & 0,65 & 0,94 & 0,94 & 0,93 \\
\hline & $\mathbf{H D}_{\mathrm{g}} \cdot \mathbf{H D}_{\mathbf{k}}$ & 0,97 & 0,98 & 0,96 & 0,98 & 0,99 & 0,98 & 0,96 & 0,99 & 0,97 \\
\hline \multirow{3}{*}{ AP } & $\mathrm{HD}_{\mathrm{j}} \cdot \mathrm{HD}_{\mathrm{g}}$ & 0,98 & 0,91 & 0,86 & 0,98 & 0,98 & 0,89 & 0,99 & 0,97 & 0,96 \\
\hline & $\mathrm{HD}_{\mathbf{j}} \cdot \mathrm{HD}_{\mathbf{k}}$ & 0,95 & 0,95 & 0,77 & 0,97 & 0,95 & 0,83 & 0,97 & 0,93 & 0,93 \\
\hline & $\mathbf{H D}_{\mathbf{g}} \cdot \mathbf{H D}_{\mathbf{k}}$ & 0,93 & 0,97 & 0,97 & 0,96 & 0,98 & 0,97 & 0,97 & 0,96 & 0,99 \\
\hline \multirow{3}{*}{$\mathrm{AE}$} & $\mathrm{HD}_{\mathrm{j}} \cdot \mathrm{HD}_{\mathrm{g}}$ & 0,96 & 0,75 & 0,85 & 0,97 & 0,95 & 0,89 & 0,99 & 0,99 & 0,97 \\
\hline & $\mathrm{HD}_{\mathrm{j}} \cdot \mathrm{HD}_{\mathrm{k}}$ & 0,96 & 0,82 & 0,80 & 0,97 & 0,93 & 0,79 & 0,99 & 0,97 & 0,97 \\
\hline & $\mathrm{HD}_{\mathrm{g}} \cdot \mathrm{HD}_{\mathrm{k}}$ & 0,90 & 0,96 & 0,98 & 0,97 & 0,99 & 0,94 & 0,98 & 0,98 & 0,98 \\
\hline \multirow{3}{*}{ PE } & $\mathbf{H D}_{\mathbf{j}} \cdot \mathrm{HD}_{\mathrm{g}}$ & 0,87 & 0,98 & 0,97 & 0,99 & 0,94 & 0,95 & 0,94 & 0,80 & 0,85 \\
\hline & $\mathbf{H D}_{\mathbf{j}} \cdot \mathbf{H} \mathrm{D}_{\mathbf{l}}$ & 0,86 & 0,97 & 0,96 & 0,97 & 0,92 & 0,95 & 0,94 & 0,80 & 0,87 \\
\hline & $H_{\mathrm{g}} \cdot \mathrm{HD}_{\mathrm{k}}$ & 0,98 & 0,98 & 1,00 & 0,98 & 0,96 & 0,98 & 0,99 & 0,98 & 0,97 \\
\hline \multirow{3}{*}{ PG } & $\mathrm{HD}_{\mathrm{j}} \cdot \mathrm{HD}_{\mathrm{g}}$ & 0,85 & 0,98 & 0,97 & 0,99 & 0,94 & 0,95 & 0,95 & 0,71 & 0,87 \\
\hline & $\mathbf{H D}_{\mathrm{j}} \cdot \mathrm{HD}_{\mathrm{k}}$ & 0,84 & 0,97 & 0,96 & 0,96 & 0,92 & 0,95 & 0,95 & 0,71 & 0,89 \\
\hline & $\mathrm{HD}_{\mathrm{g}} \cdot \mathrm{HD}_{\mathrm{k}}$ & 0,97 & 0,98 & 1,00 & 0,99 & 0,96 & 0,98 & 0,99 & 0,97 & 0,97 \\
\hline
\end{tabular}

\footnotetext{
${ }^{\mathrm{A}}-\mathrm{FF}=$ dias paraflorescimento feminino; $\mathrm{AP}=$ altura de plantas; $\mathrm{AE}=$ altura de espigas; $\mathrm{PE}=$ peso de espigas; $\mathbf{P G}=$ peso de grãos.
} 
Tabela 59 - Coeficientes de correlação entre híbridos duplos previstos pelo método de JENKINS $\left(\mathrm{HD}_{\mathrm{j}}\right)$, híbridos duplos previstos com base nos g's $\left(\mathrm{HD}_{\mathrm{g}}\right)$ e hibridos duplos previstos com base nos $\mathrm{k}$ 's $\left(\mathrm{HD}_{\mathrm{k}}\right)$, para cinco variáveis em 10 experimentos de um dialélico parcial circulante entre progênies das populações SUWAN e ESALQ PB-1, multiplicadas por cruzamentos fraternais tha Solteira-SP, 1992/93.

\begin{tabular}{|c|c|c|c|c|c|c|c|c|c|c|c|}
\hline \multirow{2}{*}{$\begin{array}{l}\text { Vari- } \\
\text { áveis }^{\mathrm{A}}\end{array}$} & \multirow{2}{*}{$\begin{array}{c}\text { Combina- } \\
\text { ção }\end{array}$} & \multicolumn{10}{|c|}{ Experimentos } \\
\hline & & 01 & 02 & 03 & 04 & 05 & 06 & 07 & 08 & 09 & 10 \\
\hline \multirow{3}{*}{ FF } & $\mathrm{HD}_{\mathrm{j}} \cdot \mathrm{HD}_{\mathrm{g}}$ & 0,98 & 0,97 & 0,93 & 0,97 & 0,95 & 0,98 & 0,99 & 0,98 & 0,99 & 0,99 \\
\hline & $\mathbf{H D}_{\mathbf{j}} \cdot \mathrm{HD}_{\mathbf{k}}$ & 0,95 & 0,97 & 0,93 & 0,97 & 0,90 & 0,97 & 0,99 & 0,96 & 0,98 & 0,97 \\
\hline & $\mathrm{HD}_{\mathrm{g}} \cdot \mathrm{HD}_{\mathrm{k}}$ & 0,98 & 0,99 & 0,97 & 0,97 & 0,99 & 0,99 & 0,98 & 0,96 & 0,98 & 0,97 \\
\hline \multirow{3}{*}{ AP } & $\mathrm{HD}_{\mathrm{j}} \cdot \mathrm{HD}_{\mathrm{g}}$ & 0,98 & 0,97 & 0,95 & 0,98 & 0,99 & 0,92 & 0,98 & 0,97 & 0,97 & 0,99 \\
\hline & $\mathrm{HD}_{\mathbf{j}} \cdot \mathrm{HD}_{\mathrm{k}}$ & 0,95 & 0,93 & 0,97 & 0,98 & 0,95 & 0,83 & 0,94 & 0,92 & 0,95 & 0,96 \\
\hline & $\mathrm{HD}_{\mathrm{g}} \cdot \mathrm{HD}_{\mathrm{k}}$ & 0,97 & 0,94 & 0,98 & 0,98 & 0,96 & 0,96 & 0,97 & 0,95 & 0,98 & 0,98 \\
\hline \multirow{3}{*}{$\mathrm{AE}$} & $\mathrm{HD}_{\mathrm{j}} \cdot \mathrm{HD}_{\mathrm{g}}$ & 0,96 & 0,95 & 0,96 & 0,95 & 0,97 & 0,73 & 0,97 & 0,95 & 0,95 & 0,98 \\
\hline & $\mathbf{H D}_{\mathbf{j}} \cdot \mathrm{HD}_{\mathbf{k}}$ & 0,94 & 0,89 & 0,97 & 0,95 & 0,97 & 0,71 & 0,93 & 0,94 & 0,92 & 0,95 \\
\hline & $\mathrm{HD}_{\mathrm{g}} \cdot \mathrm{HD}_{\mathrm{k}}$ & 0,96 & 0,94 & 0,99 & 0,98 & 0,96 & 0,96 & 0,98 & 0,97 & 0,95 & 0,98 \\
\hline \multirow{3}{*}{ PE } & $\mathrm{HD}_{\mathbf{j}} \cdot \mathrm{HD}_{\mathrm{g}}$ & 0,99 & 0,97 & 0,98 & 0,95 & 0,94 & 0,96 & 0,98 & 0,96 & 0,93 & 0,97 \\
\hline & $\mathrm{HD}_{\mathrm{j}} \cdot \mathrm{HD}_{\mathbf{k}}$ & 0,96 & 0,95 & 0,98 & 0,95 & 0,92 & 0,94 & 0,98 & 0,93 & 0,88 & 0,98 \\
\hline & $\mathrm{HD}_{\mathrm{g}} \cdot \mathrm{HD}_{\mathrm{k}}$ & 0,97 & 0,98 & 0,99 & 0,99 & 0,98 & 0,99 & 0,97 & 0,98 & 0,97 & 0,98 \\
\hline \multirow{3}{*}{ PG } & $\mathrm{HD}_{\mathrm{j}} \cdot \mathrm{HD}_{\mathrm{g}}$ & 0,99 & 0,97 & 0,96 & 0,93 & 0,93 & 0,96 & 0,98 & 0,96 & 0,94 & 0,97 \\
\hline & $\mathrm{HD}_{\mathrm{j}} \cdot \mathrm{HD}_{\mathrm{k}}$ & 0,96 & 0,96 & 0,97 & 0,93 & 0,92 & 0,94 & 0,98 & 0,93 & 0,89 & 0,98 \\
\hline & $\mathrm{HD}_{\mathrm{g}} \cdot \mathrm{HD}_{\mathrm{k}}$ & 0,97 & 0,98 & 0,99 & 0,99 & 0,98 & 0,99 & 0,98 & 0,97 & 0,96 & 0,98 \\
\hline
\end{tabular}

A - FF = dias paraflorescimento feminino; $\mathbf{A P}=$ altura de plantas; $\mathrm{AE}=$ altura de espigas; $\mathrm{PE}=$ peso de espigas; $\mathbf{P G}=$ peso de grãos. 


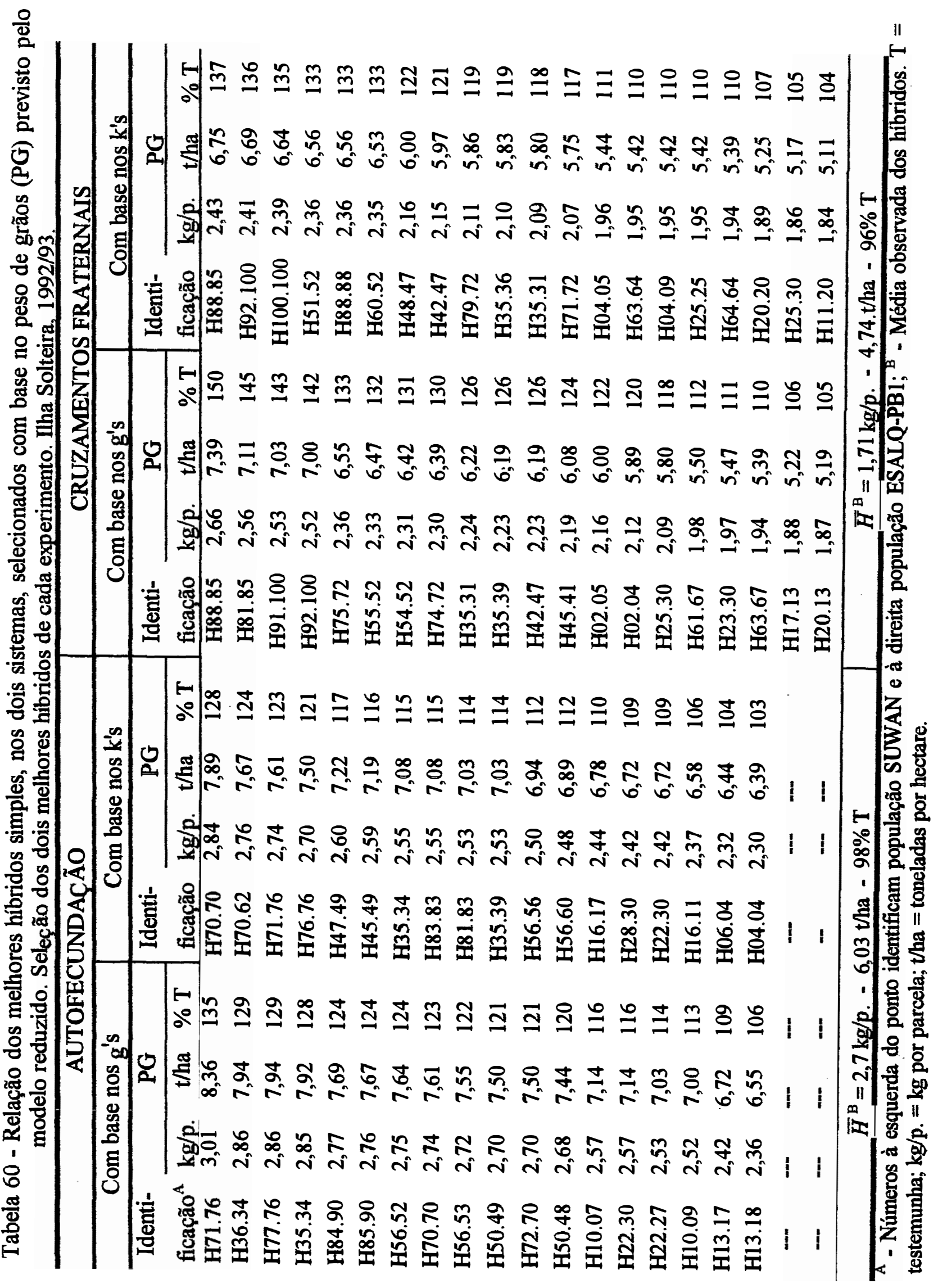




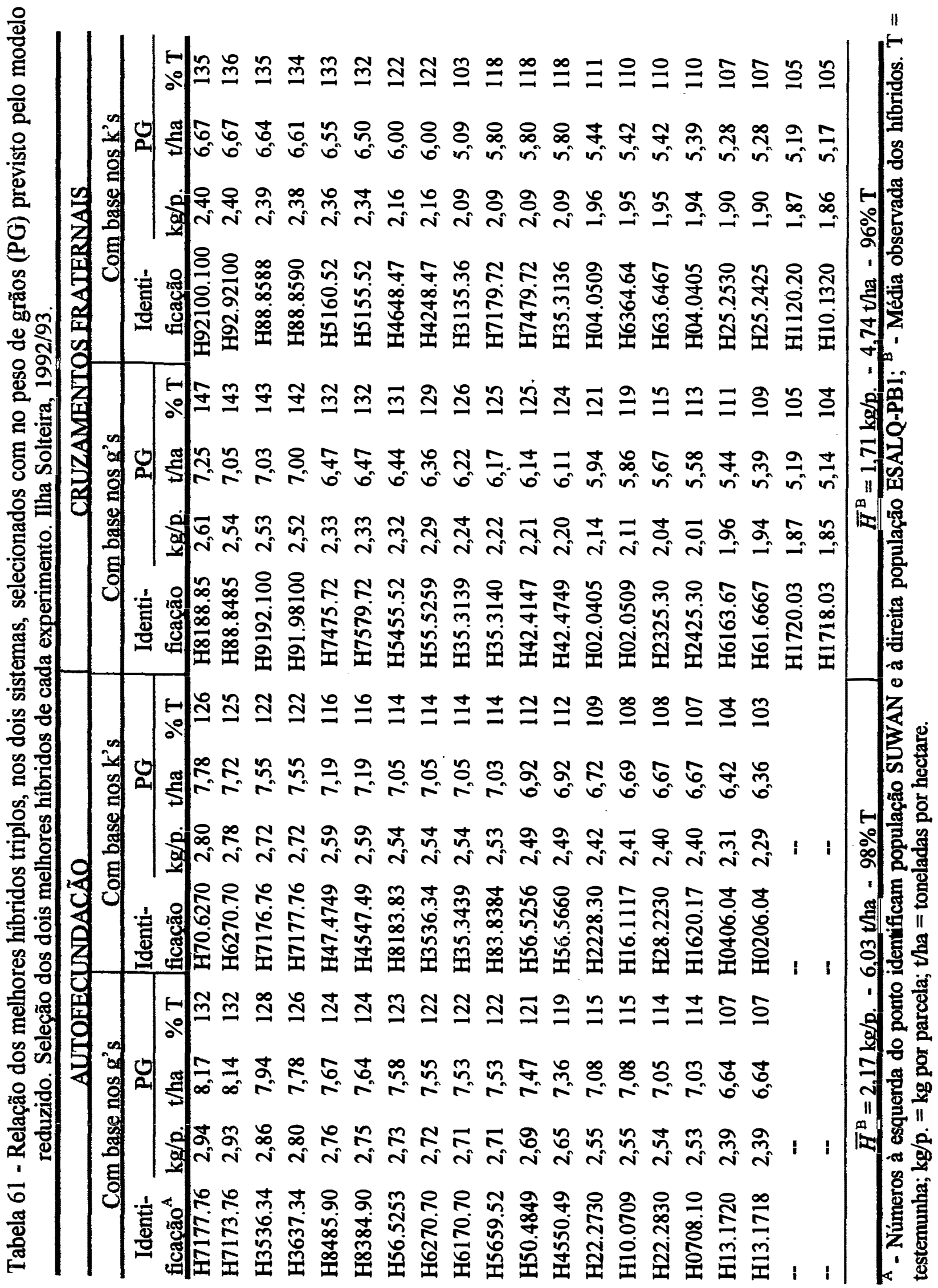




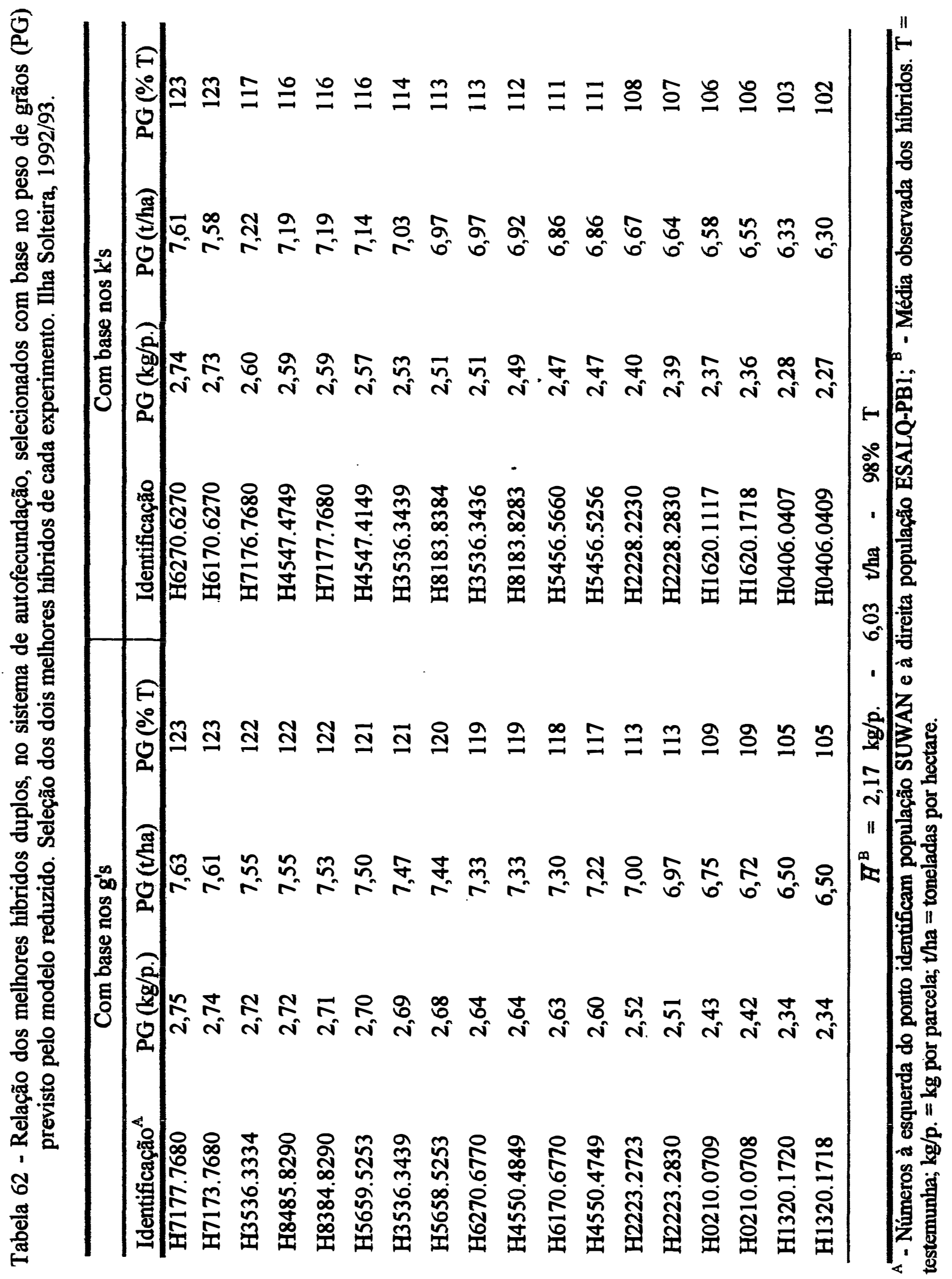




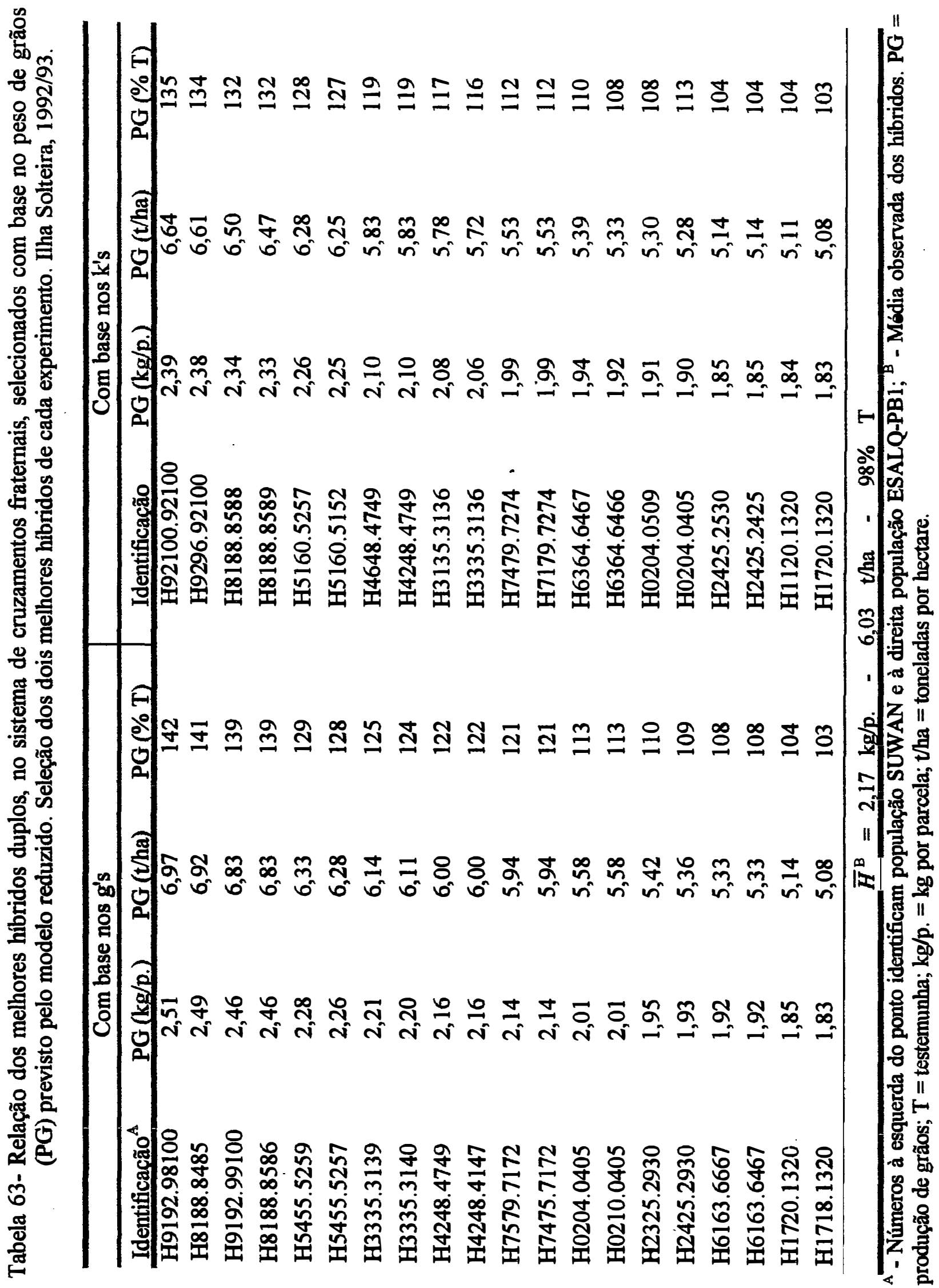




\section{F I G U RA S}




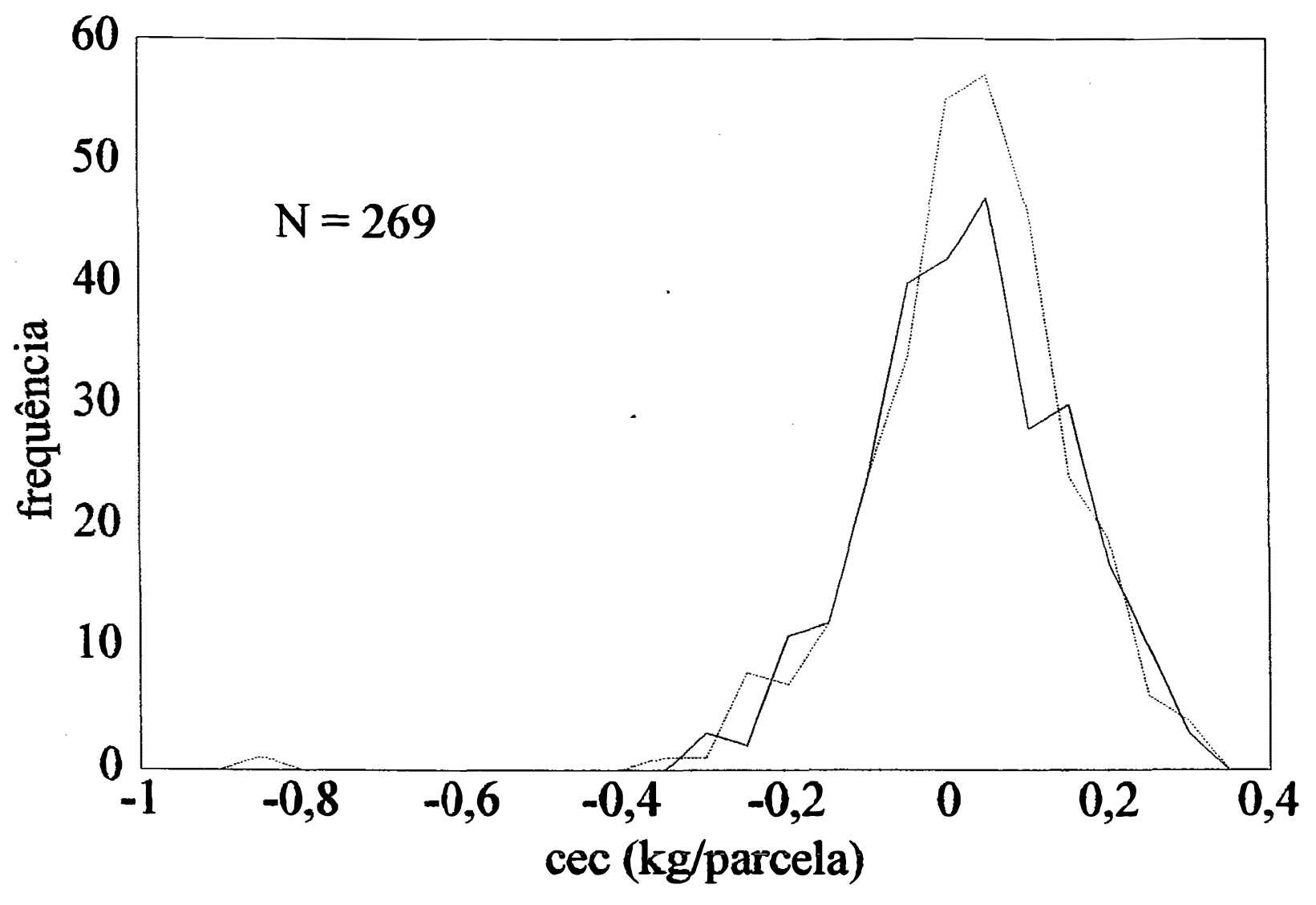

autofecundação ....cruzamentos fraternais

Figura 02 - Distribuição de frequência dos valores da capacidade específica de combinação dos híbridos simples avaliados em nove experimentos para cada sistema de multiplicação dos parentais (autofecundação e cruzamentos fraternais). 

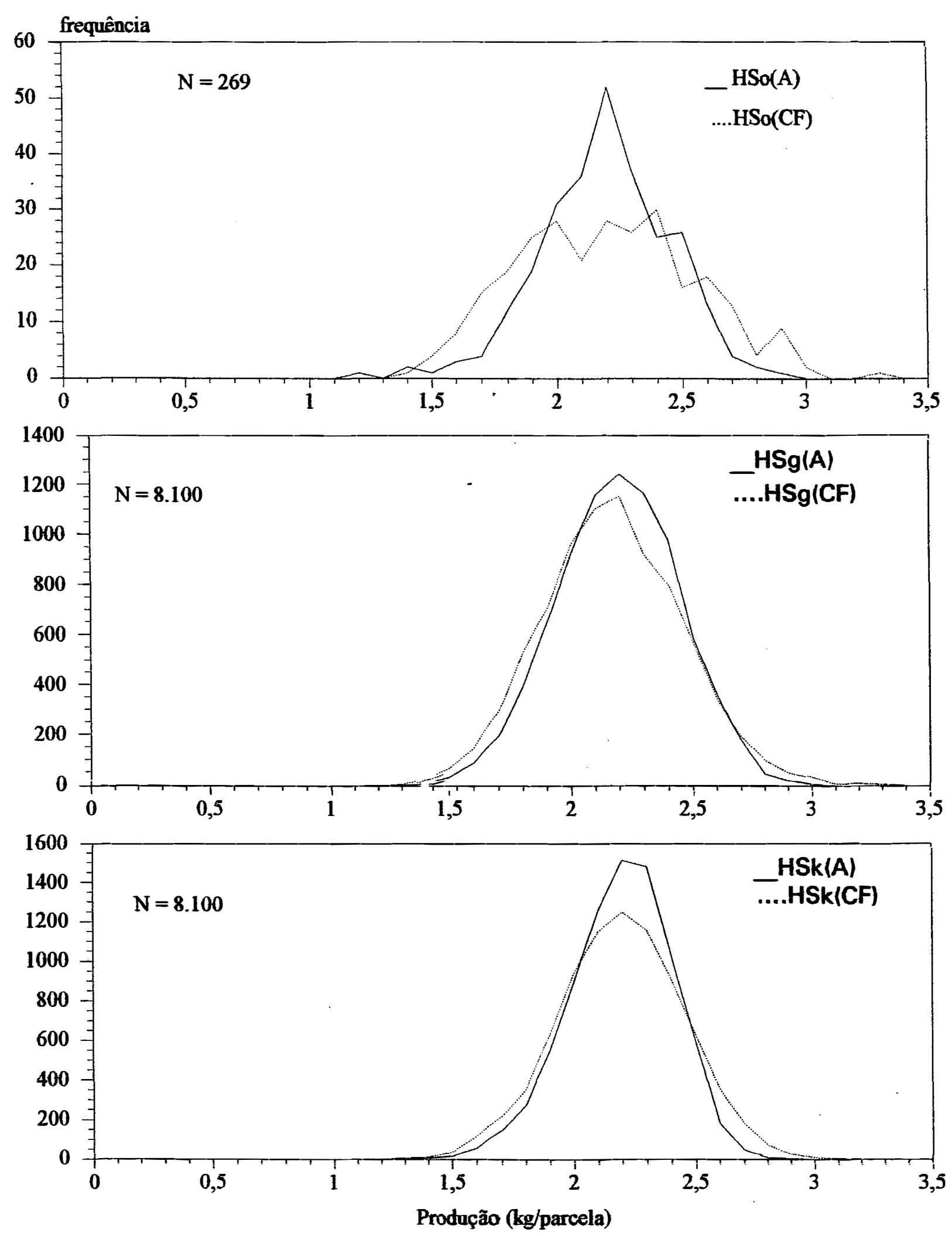

Figura 03 - Distribuição de frequênicia da produção de grãos dos híbridos simples observados (Hso) e previstos com base nos g's (HSg) e k's (HSk), nos sistemas de autofecundação (A) e cruzamentos fraternais (CF). 

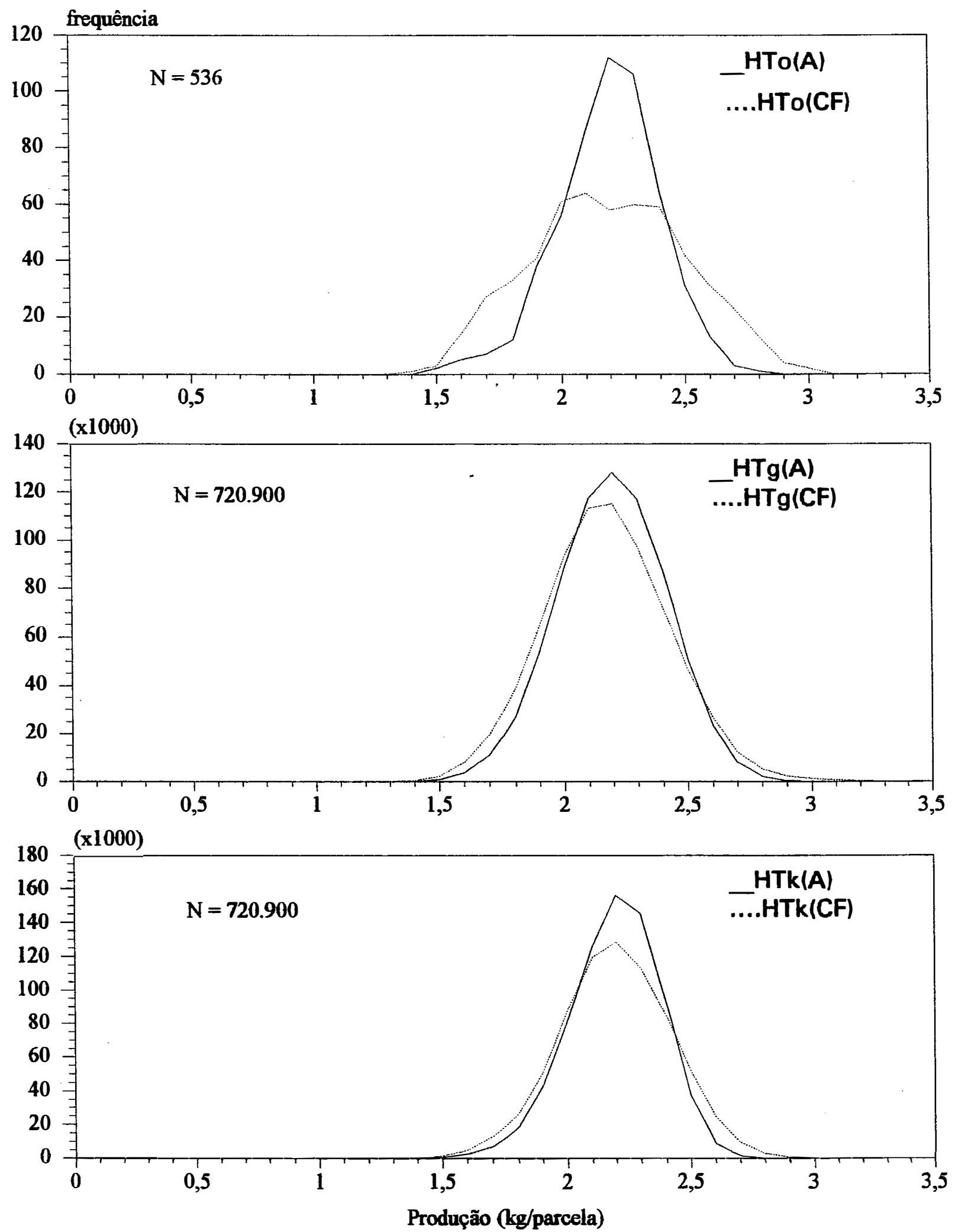

Figura 04 - Distribuição de frequênicia da produção de grãos dos híbridos triplos observados (Hto) e previstos com base nos g's (HTg) e k's (HTk), nos sistemas de autofecundação (A) e cruzamentos fraternais (CF). 

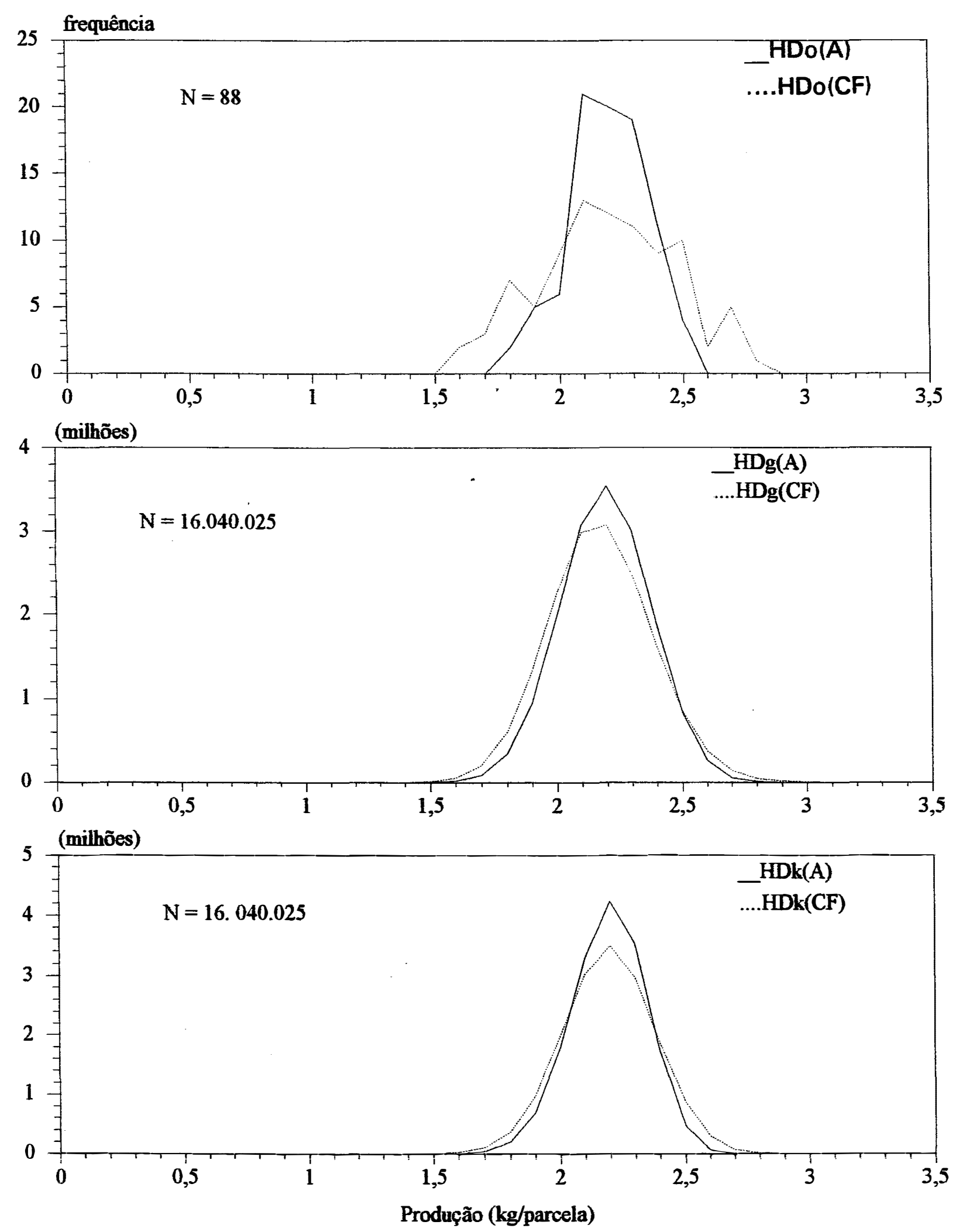

Figura 05 - Distribuição de frequênicia da produção de grãos dos híbridos duplos observados (Hdo) e previstos com base nos g's (HDg) e k's (HDk), nos sistemas de autofecundação (A) e cruzamentos fraternais (CF). 